\title{
Relevance and dynamics of nutritional status in patients on maintenance dialysis
}

Citation for published version (APA):

Marcelli, D. (2017). Relevance and dynamics of nutritional status in patients on maintenance dialysis. [Doctoral Thesis, Maastricht University]. Maastricht University. https://doi.org/10.26481/dis.20170406dm

Document status and date:

Published: 01/01/2017

DOI:

10.26481/dis.20170406dm

Document Version:

Publisher's PDF, also known as Version of record

\section{Please check the document version of this publication:}

- A submitted manuscript is the version of the article upon submission and before peer-review. There can be important differences between the submitted version and the official published version of record.

People interested in the research are advised to contact the author for the final version of the publication, or visit the DOI to the publisher's website.

- The final author version and the galley proof are versions of the publication after peer review.

- The final published version features the final layout of the paper including the volume, issue and page numbers.

Link to publication

\footnotetext{
General rights rights.

- You may freely distribute the URL identifying the publication in the public portal. please follow below link for the End User Agreement:

www.umlib.nl/taverne-license

Take down policy

If you believe that this document breaches copyright please contact us at:

repository@maastrichtuniversity.nl

providing details and we will investigate your claim.
}

Copyright and moral rights for the publications made accessible in the public portal are retained by the authors and/or other copyright owners and it is a condition of accessing publications that users recognise and abide by the legal requirements associated with these

- Users may download and print one copy of any publication from the public portal for the purpose of private study or research.

- You may not further distribute the material or use it for any profit-making activity or commercial gain

If the publication is distributed under the terms of Article $25 \mathrm{fa}$ of the Dutch Copyright Act, indicated by the "Taverne" license above, 


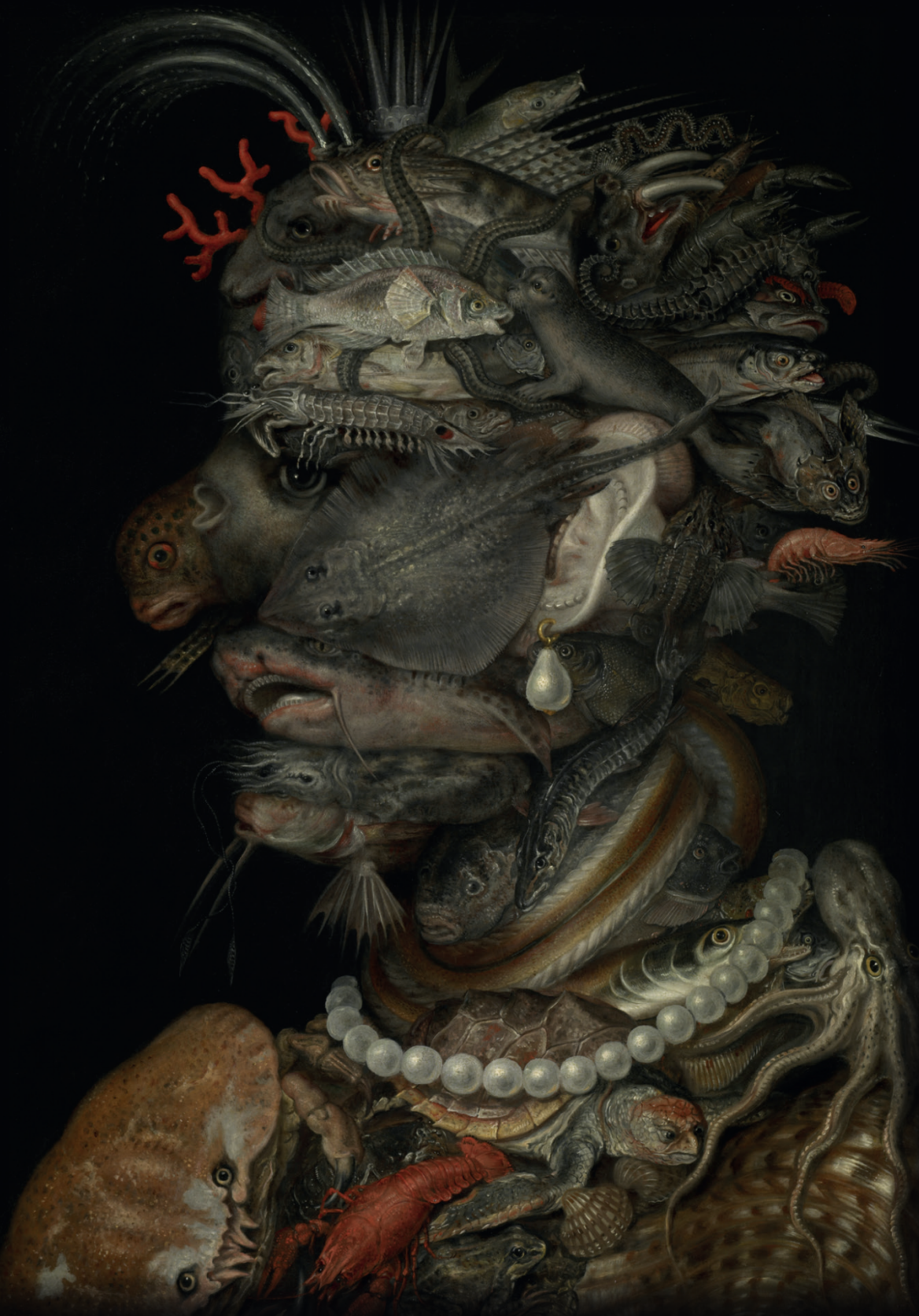

\section{Relevance and Dynamics of Nutritional status in patients on maintenance dialysis}

Daniele Marcelli 



\section{Relevance and Dynamics of Nutritional status in patients on maintenance dialysis}

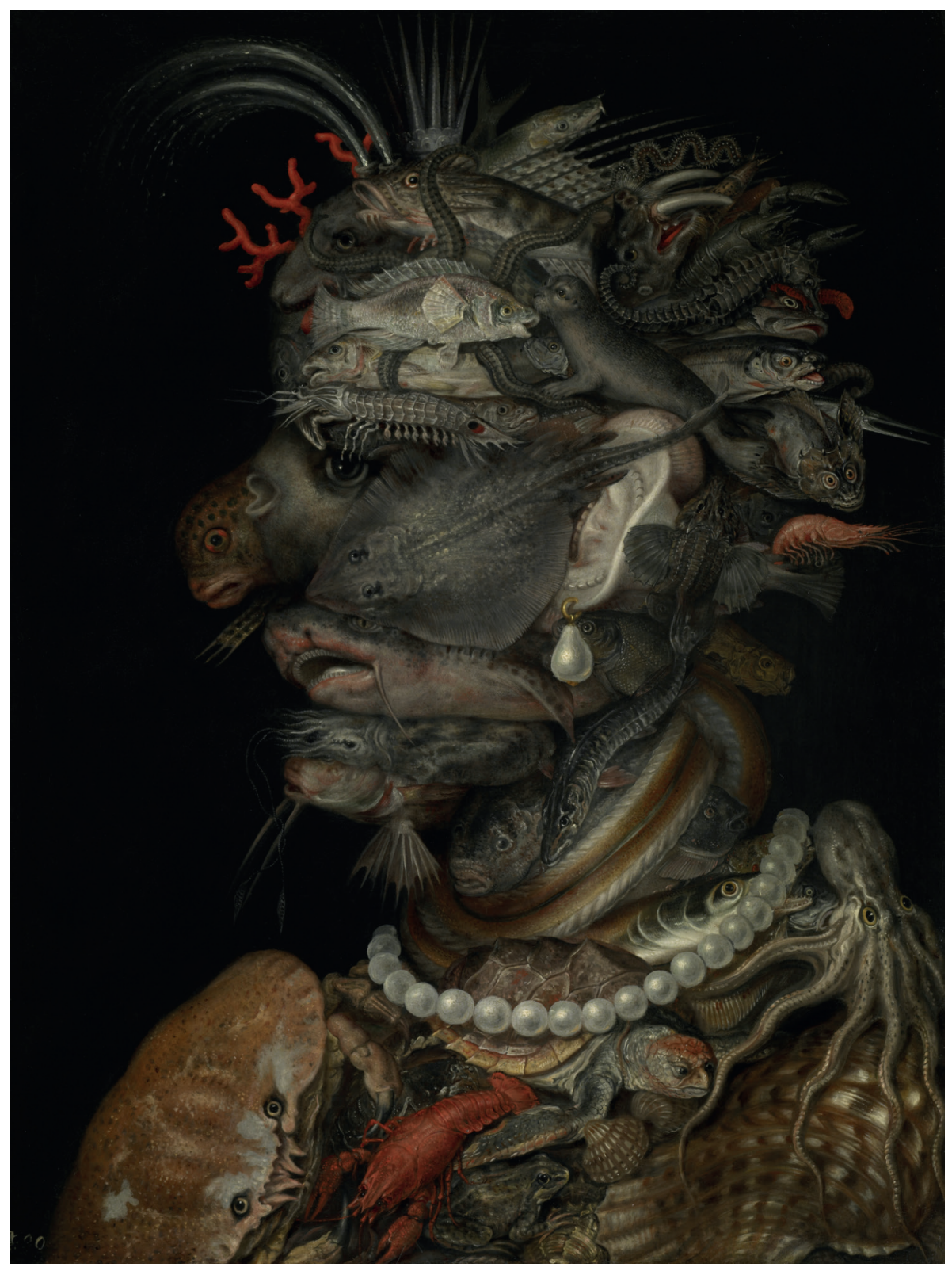

Daniele Marcelli 



\section{Relevance and Dynamics of Nutritional status in patients on maintenance dialysis}


(C) Daniele Marcelli, Maastricht 2017

ISBN:

Cover-drawing: 'Water' Giuseppe Arcinboldo (1566)

Kunsthistorisches Museum, Vienna, Austria

(Museumn of Art History, Vienna

Layout:

Production: ProefschrifMaken, Vianen 


\title{
Relevance and Dynamics of Nutritional status in patients on maintenance dialysis
}

\author{
Proefschrift \\ ter verkrijging van de graad van doctor aan de Universiteit Maastricht \\ op gezag van de Rector Magnificus, Prof. dr. Rianne M. Letschert \\ volgens het besluit van het College van Decanen,
} in het openbaar te verdedigen op donderdag 6 april 2017, om 12:00 uur.

door

Daniele Marcelli 


\section{Promotores:}

Prof. dr. J.P. Kooman

Prof. dr. B. Canaud, (Université de Montpellier)

\section{Co-Promotores:}

Dr. F.M. van der Sande

\section{Beoordelingscommissie:}

Prof. dr. ir. A.M.W.J Schols (Voorzitter)

Prof. dr. F.W. Dekker (Leids Universitair Medisch Centrum, Leiden)

Dr. M.P.C. Grooteman (Vrije Universiteit Medisch Centrum, Amsterdam)

Dr. D. Jonkers

Prof. dr. C.D.A. Stehouwer 


\section{CONTENTS}

Chapter

page

1 General introduction

From body mass index to Body composition

2 Is there any survival advantage of obesity in Southern European haemodialysis patients?

3 Physical methods for evaluating the nutrition status of hemodialysis patients

\section{Nutritional status and its dynamics as marker of outcome in} CKD patients

4 Longitudinal Changes in Body Composition in Patients After Initiation of Hemodialysis Therapy: Results From an International Cohort

5 Analysis of creatinine and albumin change dynamics during the first two years on extracorporeal dialysis therapy

6 Relationship of Neutrophil-to-Lymphocyte Ratio and Serum Albumin Levels with C-Reactive Protein in Hemodialysis Patients: Results from International Cohort Studies

7 Body Composition and Survival in Dialysis Patients: Results from an International Cohort Study

8 Unravelling the relationship between mortality, hyponatremia, inflammation and malnutrition in hemodialysis patients: results from the international MONDO initiative

\section{Discussion, conclusion and future perspective}

9 Discussion

$10 \quad$ Valorization

\section{Acknowledgement/Curriculum Vitae}

11 Acknowledgement 


\section{Introduction}

\section{Functional losses associated with ESRD}

The three main functions of the kidneys are i) removal of water-soluble waste substances from the blood, ii) production of various hormones regulating blood pressure and red blood cells generation and iii) homeostasis of body fluids, $\mathrm{pH}$, and electrolytes. Chronic kidney disease (CKD) is a syndrome due to the progressive loss of renal function. Several diseases cause CKD, the most common being related to hypertension, atherosclerotic disease, type 2 diabetes and chronic glomerulonephritis. CKD can be quantified in 5 levels according to renal function estimated on the bases of age, gender, ethnicity and creatinine level ${ }^{1}$. Symptoms associated to CKD may be even undetectable until the highest level of CKD, close to the time to start renal replacement therapy. The proportion of people affected by different levels of CKD is very high, up to $10 \%$ depending from the age structure of the population and socio-economic factors. However, because it is often paucisymptomatic, the clinical detection is difficult and some countries tested pilot projects aimed to improve the detection of CKD patients and their referral to the adequate therapy, with the main aim to prevent the development to end-stage renal failure ${ }^{2-4}$. 
Introduction

\section{Renal Replacement therapy (RRT)}

RRT can be delivered as peritoneal dialysis, obtained by infusion of buffered osmotic solution of electrolytes or by extra-corporeal treatment, including hemodialysis and convective modalities such as hemodiafiltration (HDF).

Hemodialysis is the most commonly used modality of renal replacement therapy (RRT) for patient with ESRD. The procedure is able to remove waste/toxic substances, balance electrolyte composition of the body fluids, normalize blood $\mathrm{pH}$ and remove the fluids accumulated between two hemodialysis sessions. Hemodialysis is usually performed 3 times a week for approximately 4 hours each session. The centre-piece of the process is a semipermeable dialysis membrane. On one side, inside capillaries, the blood of the patient flows at a rate between $250-400$ $\mathrm{mL} / \mathrm{min}$, on the other side, an ultra-pure solution of electrolytes buffered with bicarbonate and acetate at a slightly basic $\mathrm{pH}$ moves counter-flow at a rate of 500 $\mathrm{mL} / \mathrm{min}$. Blood is continuously drained and returned from a vascular access, which could be a native artero-venous fistula or graft, or a catheter.

The previously described renal replacement functions are realized through two mechanisms driven by difference in concentration of solutes and by differences in the hydraulic pressure on the two sides of the dialysis membrane. Small molecular weight substances such as urea are mainly removed with the first mechanism, namely diffusion, while those of medium molecular weight are removed mainly by convection. HDF combines the conventional diffusive mechanism of hemodialysis with the convective mechanism of hemofiltration. Accordingly, this method is able to couple optimal small molecular clearance with the clearance of larger molecules clearance, making it the dialysis treatment with the highest performance. With the 
development of techniques for on-line production of sterile infusate from dialysate ${ }^{5}$, HDF has become cheaper and potentially more widely applicable. Extra-corporeal RRT is increasingly safer and better tolerated. However, life expectancy is still significantly lower than in age-gender matched subjects from the general population.

\section{Protein energy wasting}

The unsatisfactory outcome of patients on dialysis is mainly due not only to the high prevalence of cardiovascular risk factors (hypertension, dyslipidemia, smoking, advanced age and diabetes mellitus) but also to the high prevalence of uremia related risk factors (fluid overload, hyperphosphatemia, high calcium-phosphate product, anaemia, left ventricular hypertrophy, inflammation, oxidative stress, endothelial dysfunction, insulin resistance, excess sympathetic tone, hyperhomocysteinemia, high level of lipoprotein (a) and increased asymmetrical dimethylarginine concentration $)^{6,7}$. In addition, the frequent use of catheters as vascular access, mainly at initiation of hemodialysis has been associated with an enhanced inflammatory state. In patients with advanced CKD multiple metabolic and nutritional derangements, generically defined as malnutrition, have been reported ${ }^{8}$. More recently, the term "malnutrition" has been replaced by "wasting" in recognition that the disorder cannot be corrected by simply increasing dietary nutritional intake. The International Society of Renal Nutrition and Metabolism defined protein energy wasting according to the presence of at least three out of the following four characteristics $^{9}$ : (1) abnormal levels of circulating biomarkers (low serum albumin, pre-albumin, or cholesterol concentrations); (2) decreased body mass (low or decreased body mass or fat mass, or weight loss with decreased protein and energy intake); (3) decreased muscle mass; and (4) abnormal nutritional score. 
Traditionally, an important component in the assessment of nutritional status in chronic patients is the evaluation of body weight or body mass index $(\mathrm{BMI})^{10}$. However, it is well known that BMI is not capable to differentiate between fat, muscle and bone, or body fat distribution (abdominal vs. peripheral). Recently, Rodrigues et $\mathrm{al}^{11}$ found that BMI thresholds do not accurately diagnose adiposity in elderly on hemodialysis. The conclusion is that considering only BMI as marker of nutritional status carries a high risk of misclassification, explained by the changes of body composition along the natural aging process (such as an increase in fat mass and decline in muscle mass), probably accelerated by the presence of a chronic disease such as CKD.

\section{Physical methods for evaluating the nutrition status of hemodialysis patients}

Nutrition status assessment is made on the basis of anamnesis, physical examination, evaluation of nutrient intake, and on a selection of various screening/diagnostic methodologies.

These methodologies can be subjective, e.g. the Subjective Global Assessment score $(\mathrm{SGA})^{12}$, or objective in nature (e.g. bioimpedance analysis $\left.(B I A)\right)^{13}$. In addition, certain biochemical tests may be employed (e.g. albumin, pre-albumin) ${ }^{14}$. There are several different types of bioimpedance methods available today, and the results may vary depending on which type is applied. This may vary from monofrequency BIA methods, using either vector plots or empirical equations used to convert measured impedances into clinically meaningful information, to Bioimpedance spectroscopy without a physiological model using multiple frequencies to estimate body fluid compartments. It is assumed that the latter provide a more precise assessment of the extracellular and total body water ${ }^{15}$. 
However, very large databases providing normal values for vectors in the general population and in dialysis patients have been published ${ }^{16}$ and both phase angle and vector length have been shown to be higly predictive of survival ${ }^{17}$.

Finally, a more recently validated physiological model ${ }^{18}$ facilitates separation of the body into three essential compartments, lean body mass, adipose tissue mass, and fluid overload (3 compartment [3C] model). The bioimpedance spectroscopy method with a physiological model is a promising practical method that may allow the diagnostic separation necessary for the diagnosis of protein energy wasting in CKD patients.

However, there are still limited data regarding the value of this model in the clinical assessment of ESRD patients. In chapter 2, an overview is given on different methods to assess body composition and protein energy wasting in dialysis patients.

\section{'Reverse epidemiology' paradox}

Several parameters related to inflammation, malnutrition and presence of various cardiovascular diseases have been established as major risk factors for mortality and morbidity in patients on renal replacement therapy. Nutritional problems, including loss of appetite and decrease of body weight can be present also in the phase before the need for initiating renal replacement therapy. Some of these risk factors, i.e. low albumin and high C-reactive protein (CRP) levels, have similar behavior in patients on dialysis as well as in the general population, but others show a different relationship with outcome. On the contrary than in the general population, higher blood pressure levels ${ }^{19}$ and obesity ${ }^{10}$ are associated with better survival in patients on chronic hemodialysis. This observation produced a list of publications under the umbrella of the term 'reverse epidemiology'. Specifically, obesity as 
defined by higher BMI in dialysis patients is associated with better outcome ${ }^{10}$. This paradoxical benefit of obesity has been shown to exist also for patients with a wide range of cardiovascular diseases as coronary artery disease, hypertension, peripheral vascular disease, atrial fibrillation and aortic stenosis, and for patients with coronary bypass cardiac implants and other acute coronary syndromes ${ }^{20-26}$. The obesity paradox has been specifically demonstrated in heart failure patients with a consistency of results seen among a wide range of clinical subpopulations across geographical locations, gender, age range, and the presence or absence of comorbidities $^{27}$, and across different measures of body fatness, but mainly BMI.

Most of the data concerning the obesity paradox in dialysis patients are derived from US populations ${ }^{28}$. However, European data are lacking so far, which is of importance given the fact that various risk factors may differ between populations. As an example, the cardiovascular risk profile is completely different between US, Northern and Southern European populations ${ }^{29}$. In chapter 3, the relation between BMI and survival was investigated in a larger cohort of Southern European dialysis patients. However, as mentioned previously, BMI does not differentiate between fat and lean body mass. Therefore, it is not possible to recognize which component of body composition is related to better survival, either fat or lean tissue mass or both. For this reason, in order to clarify the paradox, is fundamental to further distinguish between main body components, for which the novel 3-C bioimpedance model appears to be a promising clinical tool. However, the prognostic value of fat mass and lean tissue mass expressed by this method with regard to survival has not yet been validated. In chapter 4, the relation between body compartments expressed by the 3-C bioimpedance method with outcome was assessed in a larger international 
cohort of dialysis patients. In this chapter, also the relation between BMI with fat and lean tissue mass was assessed.

\section{The effects of starting dialysis on nutritional parameters}

As reported by Pupim et al, ${ }^{30}$ the progression of renal insufficiency is associated with the development of protein-caloric malnutrition. At the initiation of renal replacement therapy inflammation, metabolic acidosis, and impaired insulin/insulin-like growth factor functionality are often already present and all of them negatively affect protein anabolism even in presence of an adequate nutritional intake ${ }^{31}$. In patients with advanced kidney disease, metabolic and nutritional derangements induced by uremia interact and reinforce each other in a deleterious vicious circle. Based $^{30}$ on this evidence, some investigators have advocated the initiation of renal replacement therapy before the development of malnutrition ${ }^{32-34}$. Whereas the start of dialysis with the increased clearance of uremic toxins may lead to an improvement in nutritional state by an increase in appetite and wellbeing resulting from the improvement in the uremic state, the interference of dialysis with regular meals, the loss of proteins and amino acids in the dialysate, and the catabolism resulting from the dialysis treatment may negatively affect nutritional state ${ }^{30,35}$. Ikizler et $\mathrm{al}^{36}$ showed that a dialysis session is a catabolic event and leads to a net loss of protein stores. However, longitudinal survey of the nutritional effects of dialysis treatment showed that hemodialysis per se improves body protein metabolism, which may be due to the clearance of uremic toxins counterbalancing the catabolic effects of hemodialysis. Using a leucine kinetic study before and 8 to 10 weeks after initiation of dialysis treatment in incident patients maintained on an unchanged diet, Lim, Yarasheski, and Flanigan ${ }^{37}$ observed after initiation of dialysis treatment an increase in protein 
synthesis. Therefore, the benefit may be above and beyond the potential catabolic effect that dialysis has ${ }^{38}$. However, literature addressing the effect of dialysis initiation on changes in nutritional parameters and body composition is limited and contradictory and some other investigators ${ }^{30}$ support the alternative policy to delay the initiation of dialysis therapy until clear uremic symptoms are present, with the aim to postpone the catabolic process induced by dialysis and the high mortality rate detected in the first weeks/months of treatment ${ }^{36,39-43}$.

Finally, it has to be considered that Patients undergoing a chronic haemodialysis programme often need to be admitted to hospital mainly because of vascular access complications, infections and cardiovascular diseases ${ }^{44}$. When patients are admitted to hospital, a significant weight loss is often observed, which is probably a sign of progressive malnutrition ${ }^{45-47}$. According to Borrego et $\mathrm{al}^{47}$, body weight loss was already observed at discharge, and continued progressively for at least 4 weeks after the hospital stay. This weight loss was not sex- or age-dependent, but was related to the length of the hospital stay, and the presence of hypoalbuminemia, which is probably a sign of inflammation during hospital stay. Many factors are involved in this malnutrition ${ }^{47}$, and the decrease caloric and protein intake play an important role. The cause can be illness-related anorexia and the general low level of appreciation of the hospital food ${ }^{48,49}$. On the other hand, inflammation- and prolonged fasting related protein catabolism also cause mobilization of protein reserves, especially from muscles, as occurs in patients who have been in the intensive care unit for a long period of time or in difficult post-operative recoveries ${ }^{50}$.

Accordingly, following the start of dialysis treatment in chapter 5, changes in body composition and the effect of possible determinants on these changes, were 
investigated and in chapter 6 , the course of two nutritional biomarkers, serum albumin and creatinine was analyzed.

\section{Inflammation and malnutrition}

Loss of muscle mass, a common feature of many inflammatory disorders, is considered one of the most important markers of protein energy wasting in $C K D^{51}$. According to Roubenoff ${ }^{52}$, subclinical chronic inflammation is an important component of the pathophysiology of muscle wasting. Pro-inflammatory cytokines, such as IL-6 and tumor necrosis factor (TNF), stimulate the breakdown of muscle protein $^{53}$. The close association between muscle wasting IL-6 and CRP in previous studies performed in CKD patients ${ }^{54,55}$ suggests that systemic inflammation is involved in muscle wasting also in patients with advanced CKD. Various biomarkers have been proposed to measure systemic inflammation and, given the expenses associated with regular IL-6 or CRP monitoring, recently neutrophil to lymphocyte ratio has been proposed as easily available, cost-efficient indicator ${ }^{56-58}$. However, the relation between the neutrophil to lymphocyte ratio and other biomarkers of inflammation, such as CRP, as well as serum albumin have not been investigated yet. In chapter 7 , the relation between the neutrophil to lymphocyte ratio, CRP and serum albumin was investigated.

\section{Hyponatremia, inflammation and nutritional state}

Another marker which may be related to the nutritional state of the patient is the serum sodium level. 
Hyponatremia, defined as a concentration of serum sodium levels below 135 $\mathrm{mMol} / \mathrm{L}$, is a common electrolyte disorder associated with increased mortality in general population ${ }^{60-62}$. The worse prognosis associated with hyponatremia is more pronounced in certain populations: women, postsurgical patients, patients with cirrhotic and cardiac failure ${ }^{63-65}$, and remains even in people with hyponatremia at moderate levels, that is $130-134 \mathrm{mMol} / \mathrm{L}$.

Patients with chronic kidney disease also have a high prevalence of hyponatremia, estimated in the range of $13.5 \%{ }^{66}$. Whereas well-functioning kidneys can prevent hyponatremia in the general population, in patients with advanced CKD, the protection from this risk dissolves in connection with the loss of residual renal function. After HD initiation, the balance of sodium and water occurring during dialysis sessions appears as a new potential factor in the development and maintenance hyponatremia. Hyponatremia may also be associated with inflammation, likely for the so called sick cell syndrome ${ }^{67,68}$, a disorder of the cellular $\mathrm{Na}+/ \mathrm{K}+$ pump with several causes which include hypoxia, sepsis, hypovolaemia and malnourishment.

As in the general population, in patients on dialysis hyponatremia is also associated with increased risk of death ${ }^{69-73}$. These studies found that low pre-HD sodium is associated with diabetes, neurological and psychiatric diseases and greater interdialysis weight gain. In HD patients, it is unclear whether the relationship between hyponatremia and mortality is causal or explanatory of some associated cofactor.

However, the association between hyponatremia and impaired cerebral function is clearly demonstrated ${ }^{65,74}$. It has been suggested that hyponatremia is associated with a "frail phenotype", given its association with low body mass index (BMI) and 
biochemical markers of malnutrition ${ }^{69,70,75}$. In other patient populations, such as patients with cirrhosis or heart failure additional associations with malnutrition ${ }^{75,77,78}$, abnormalities in fluid status ${ }^{75,78,79}$ or with inflammation ${ }^{67}$ have been detected. However, these associations, have not yet been investigated systematically in dialysis patients. One of the reasons is the absence of a routine evaluation of the inflammatory status, i.e. by monitoring C-reactive proteins. As a consequence, the interpretation on the causative nature of the relationship between hyponatremia and outcome still remains unclear. For this reason, in chapter 8 , the relation between hyponatremia with body composition, fluid overload and inflammation was investigated, as well as the relation between hyponatremia and outcome after correction for these parameters.

In chapter 9, the main results of the thesis are outlined in a general discussion

\section{Aim of the thesis}

In summary, with the exception of the Asian patients, patients on maintenance hemodialysis the relationship between body mass index and mortality is often the reverse of the normal association. Accordingly, do we have to question the appropriateness of target levels for BMI as well as other main measures (i.e. blood pressure) used to assess patient on dialysis? We believe that the correct answer should deal with the causes for the observed reversed epidemiologic relations, and for this reason the major aims of this thesis are a) to clarify the paradoxical observation of the improved survival in obese patients on chronic hemodialysis, and to assess the relation between body composition with outcome in more detail b) to study the development of nutritional biomarkers as well as body composition after 
admission to RRT, c) to investigate the relationship between nutritional status, hyponatremia and inflammation.

\section{Outline of this thesis}

In chapter 2, in a Southern European HD population the relationship between survival and BMI at the start of HD treatment is examined, as is the influence of body weight variations during the first year of treatment. Chapter 3 provides an overview of the different nutritional markers and the available methodologies for the physical assessment of nutrition status in hemodialysis patients, with special emphasis on early detection of protein energy wasting.

Chapter 4 and chapter 5 focus on changes in nutritional parameters following the start of dialysis. In chapter 4 , changes in body composition, assessed by the 3compartment bioimpedance model are studied.

Serum albumin and creatinine levels are indicators of both nutritional status and of mortality risk in hemodialysis patients. In chapter $\mathbf{5}$ changes and determinants of these nutritional indicators in the 2 years following the first 3 months of hemodialysis are examined.

Inflammation likely plays an important role in the pathogenesis of muscle wasting in CKD. C-reactive protein, an acute-phase reactant, has emerged as the most widespread inflammatory biomarker for clinical use but it's use is limited by the costs of the methods. The neutrophil lymphocyte ratio has been proposed as an alternative and cost-effective marker for inflammation. The aim of the study reported in chapter 6 was to evaluate to which extent neutrophil lymphocyte ratio correlated with C reactive protein and serum albumin levels. Furthermore, it was aimed at determining 
whether the combination of inflammatory markers (neutrophil lymphocyte ratio and albumin levels) improves prediction of $\mathrm{C}$ reactive protein levels in chronic HD patients. The association between hyponatremia and mortality has also been observed in patients with acute and chronic diseases, such as ESRD, congestive heart failure, pulmonary embolism and myocardial infarction. It has been suggested that hyponatremia is associated with a "frail phenotype", given its association with low body mass index (BMI) and biochemical markers of malnutrition.

Concerning the problem of reverse epidemiology, In chapter 7 , body composition assessed by MF-BIS, using the 3-C physiological model, was used to explore the relationship between lean tissue, fat tissue, and survival.

Given the relation between hyponatremia with outcome in dialysis, the study reported in chapter 8 aimed to explore the relationship between hyponatremia, nutrition, inflammation and fluid status. The primary goal was to determine predictors of hyponatremia, including biomarkers of inflammation, fluid status and malnutrition. The secondary goal was to assess the association between hyponatremia and mortality with appropriate adjustments for malnutrition, fluid status and inflammation. The thesis ends with a summary and general discussion of the results in in chapter 9.

\section{Reference List}

1. National Kidney F. K/DOQI clinical practice guidelines for chronic kidney disease: evaluation, classification, and stratification. Am J Kidney Dis. 2002;39(2 Suppl 1):S1-266.

2. Richards $\mathrm{N}$, Harris $\mathrm{K}$, Whitfield $\mathrm{M}$, et al. The impact of population-based identification of chronic kidney disease using estimated glomerular filtration rate (eGFR) reporting. Nephrol Dial Transplant. 2008;23(2):556-561.

3. Richards N, Harris K, Whitfield M, et al. Primary care-based disease management of chronic kidney disease (CKD), based on estimated glomerular filtration rate (eGFR) reporting, improves patient outcomes. Nephrol Dial Transplant. 2008;23(2):549-555. 
4. Richards N, Hassan M, Saleh A, et al. Epidemiology and referral patterns of patients with chronic kidney disease in the Emirate of Abu Dhabi. Saudi J. Kidney Dis. Transpl. 2015;26(5):1028-1034.

5. Canaud B, N'Guyen QV, Lagarde C, Stec F, Polaschegg HD, Mion C. Clinical evaluation of a multipurpose dialysis system adequate for hemodialysis or for postdilution hemofiltration/hemodiafiltration with on-line preparation of substitution fluid from dialysate. Contrib Nephrol. 1985;46:184-186.

6. Di Benedetto A, Marcelli D, D'Andrea A, et al. Risk factors and underlying cardiovascular diseases in incident ESRD patients. J Nephrol. 2005;18(5):592-598.

7. Kendrick J, Chonchol MB. Nontraditional risk factors for cardiovascular disease in patients with chronic kidney disease. Nat. Clin. Pract. Nephrol. 2008;4(12):672-681.

8. Ikizler TA. Nutrition, inflammation and chronic kidney disease. Curr Opin Nephrol Hypertens. 2008;17(2):162-167.

9. Fouque D, Kalantar-Zadeh K, Kopple J, et al. A proposed nomenclature and diagnostic criteria for protein-energy wasting in acute and chronic kidney disease. Kidney Int. 2008;73(4):391398.

10. Chazot C, Gassia JP, Di Benedetto A, Cesare S, Ponce P, Marcelli D. Is there any survival advantage of obesity in Southern European haemodialysis patients? Nephrol Dial Transplant. 2009;24(9):2871-2876.

11. Rodrigues J, Santin F, Barbosa Brito FS, et al. Sensitivity and Specificity of Body Mass Index as a Marker of Obesity in Elderly Patients on Hemodialysis. J. Ren. Nutr. 2016;26(2):65-71.

12. Barbosa-Silva MC. Subjective and objective nutritional assessment methods: what do they really assess? Curr. Opin. Clin. Nutr. Metab. Care. 2008;11(3):248-254.

13. Chamney PW, Wabel P, Moissl UM, et al. A whole-body model to distinguish excess fluid from the hydration of major body tissues. Am J Clin Nutr. 2007;85(1):80-89.

14. Marcelli D, Di Benedetto A, Ciotola A, Grassmann A, Canaud B. Subjective global assessment scores have poor correlation with serum albumin in obese hemodialysis patients by Eric $D$. Erb, Rosa K. Hand, and Alison L. Steiber. J Ren Nutr. 2014;24(6):432-433.

15. Carter M, Morris AT, Zhu F, Zaluska W, Levin NW. Effect of body mass index (BMI) on estimation of extracellular volume (ECV) in hemodialysis (HD) patients using segmental and whole body bioimpedance analysis. Physiol. Meas. 2005;26(2):S93-99.

16. Bosy-Westphal A, Danielzik S, Dorhofer RP, Piccoli A, Muller MJ. Patterns of bioelectrical impedance vector distribution by body mass index and age: implications for bodycomposition analysis. Am. J. Clin. Nutr. 2005;82(1):60-68.

17. Pillon L, Piccoli A, Lowrie EG, Lazarus JM, Chertow GM. Vector length as a proxy for the adequacy of ultrafiltration in hemodialysis. Kidney Int. 2004;66(3):1266-1271.

18. Wabel P, Chamney P, MoissI U, Jirka T. Importance of whole-body bioimpedance spectroscopy for the management of fluid balance. Blood Purif. 2009;27(1):75-80.

19. Zager PG, Nikolic J, Brown RH, et al. "U" curve association of blood pressure and mortality in hemodialysis patients. Medical Directors of Dialysis Clinic, Inc. Kidney Int. 1998;54(2):561569.

20. Andreotti F, Rio T, Lavorgna A, et al. [Body mass index and cardiovascular events: the "obesity paradox"]. Recenti Prog. Med. 2009;100(10):447-450.

21. Oreopoulos A, Padwal R, McAlister FA, et al. Association between obesity and health-related quality of life in patients with coronary artery disease. Int. J. Obes. (Lond.). 2010;34(9):14341441.

22. Zafrir B, Adir Y, Shehadeh W, Shteinberg M, Salman N, Amir O. The association between obesity, mortality and filling pressures in pulmonary hypertension patients; the "obesity paradox". Respir. Med. 2013;107(1):139-146.

23. Stamou SC, Nussbaum M, Stiegel RM, et al. Effect of body mass index on outcomes after cardiac surgery: is there an obesity paradox? Ann. Thorac. Surg. 2011;91(1):42-47. 
24. Badheka AO, Rathod A, Kizilbash MA, et al. Influence of obesity on outcomes in atrial fibrillation: yet another obesity paradox. Am. J. Med. 2010;123(7):646-651.

25. Lavie CJ, Milani RV, Ventura HO. Obesity and the "obesity paradox" in cardiovascular diseases. Clin. Pharmacol. Ther. 2011;90(1):23-25.

26. Andreotti F, Rio T, Lavorgna A. Body fat and cardiovascular risk: understanding the obesity paradox. Eur. Heart J. 2009;30(7):752-754.

27. Goel K, Lopez-Jimenez F, De Schutter A, Coutinho T, Lavie CJ. Obesity paradox in different populations: evidence and controversies. Future Cardiol. 2014;10(1):81-91.

28. Kalantar-Zadeh K. Causes and consequences of the reverse epidemiology of body mass index in dialysis patients. J Ren Nutr. 2005;15(1):142-147.

29. Levy D, Kannel WB. Searching for answers to ethnic disparities in cardiovascular risk. Lancet. 2000;356(9226):266-267.

30. Pupim LB, Kent P, Caglar K, Shyr Y, Hakim RM, Ikizler TA. Improvement in nutritional parameters after initiation of chronic hemodialysis. Am. J. Kidney Dis. 2002;40(1):143-151.

31. Holley JL. The hypothalamic-pituitary axis in men and women with chronic kidney disease. Adv Chronic Kidney Dis. 2004;11(4):337-341.

32. Parker TF, 3rd, Wingard RL, Husni L, Ikizler TA, Parker RA, Hakim RM. Effect of the membrane biocompatibility on nutritional parameters in chronic hemodialysis patients. Kidney Int. 1996;49(2):551-556.

33. Anderstam B, Mamoun AH, Sodersten P, Bergstrom J. Middle-sized molecule fractions isolated from uremic ultrafiltrate and normal urine inhibit ingestive behavior in the rat. $J$. Am. Soc. Nephrol. 1996;7(11):2453-2460.

34. Kopple JD. National kidney foundation K/DOQI clinical practice guidelines for nutrition in chronic renal failure. Am. J. Kidney Dis. 2001;37(1 Suppl 2):S66-70.

35. Vendrely B, Chauveau P, Barthe N, et al. Nutrition in hemodialysis patients previously on a supplemented very low protein diet. Kidney Int. 2003;63(4):1491-1498.

36. Ikizler TA, Pupim LB, Brouillette JR, et al. Hemodialysis stimulates muscle and whole body protein loss and alters substrate oxidation. Am. J. Physiol. Endocrinol. Metab. 2002;282(1):E107-116.

37. Lim VS, Yarasheski KE, Flanigan MJ. The effect of uraemia, acidosis, and dialysis treatment on protein metabolism: a longitudinal leucine kinetic study. Nephrol. Dial. Transplant. 1998;13(7):1723-1730.

38. Ishimura E, Okuno S, Kim M, et al. Increasing body fat mass in the first year of hemodialysis. J. Am. Soc. Nephrol. 2001;12(9):1921-1926.

39. Borah MF, Schoenfeld PY, Gotch FA, Sargent JA, Wolfsen M, Humphreys MH. Nitrogen balance during intermittent dialysis therapy of uremia. Kidney Int. 1978;14(5):491-500.

40. Gutierrez A, Bergstrom J, Alvestrand A. Protein catabolism in sham-hemodialysis: the effect of different membranes. Clin. Nephrol. 1992;38(1):20-29.

41. Gutierrez A, Bergstrom J, Alvestrand A. Hemodialysis-associated protein catabolism with and without glucose in the dialysis fluid. Kidney Int. 1994;46(3):814-822.

42. Lim VS, Bier DM, Flanigan MJ, Sum-Ping ST. The effect of hemodialysis on protein metabolism. A leucine kinetic study. J. Clin. Invest. 1993;91(6):2429-2436.

43. Mitch WE, Maroni BJ. Nutritional considerations and the indications for dialysis. Am. J. Kidney Dis. 1998;31(1):185-189.

44. Borrego Utiel FJ, Segura Torres P, Perez del Barrio MP, et al. How do disorders related to hospitalisation influence haemodialysis patients' nutrition? Nefrologia. 2011;31(4):471-483.

45. Chan KE, Lazarus JM, Wingard RL, Hakim RM. Association between repeat hospitalization and early intervention in dialysis patients following hospital discharge. Kidney Int. 2009;76(3):331-341.

46. Ikizler TA, Greene JH, Yenicesu M, Schulman G, Wingard RL, Hakim RM. Nitrogen balance in hospitalized chronic hemodialysis patients. Kidney Int. Suppl. 1996;57:S53-56. 
47. Borrego Utiel FJ, Segura Torres P, Perez Del Barrio MP, et al. [Loss of weight in hemodialysis patients after hospitalization is related with length of stay and degree of inflammation]. Nefrologia. 2010;30(5):557-566.

48. Bradburn Y, Booth J, Gokal R, et al. A review of food provision to a renal ward and the proposed appointment of feeding assistants. J. Ren. Nutr. 1999;9(4):198-201.

49. Steiber AL, Weatherspoon LJ, Handu D. Clinical and dietary indicators associated with uremic status in hospitalized dialysis patients. J. Ren. Nutr. 2002;12(1):49-54.

50. Monk DN, Plank LD, Franch-Arcas G, Finn PJ, Streat SJ, Hill GL. Sequential changes in the metabolic response in critically injured patients during the first 25 days after blunt trauma. Ann. Surg. 1996;223(4):395-405.

51. Carrero JJ, Chmielewski M, Axelsson J, et al. Muscle atrophy, inflammation and clinical outcome in incident and prevalent dialysis patients. Clin. Nutr. 2008;27(4):557-564.

52. Roubenoff R. Catabolism of aging: is it an inflammatory process? Curr. Opin. Clin. Nutr. Metab. Care. 2003;6(3):295-299.

53. Goodman MN. Interleukin-6 induces skeletal muscle protein breakdown in rats. Proc. Soc. Exp. Biol. Med. 1994;205(2):182-185.

54. Kaizu Y, Ohkawa S, Odamaki M, et al. Association between inflammatory mediators and muscle mass in long-term hemodialysis patients. Am. J. Kidney Dis. 2003;42(2):295-302.

55. Castaneda-Sceppa C, Sarnak MJ, Wang X, et al. Role of adipose tissue in determining muscle mass in patients with chronic kidney disease. J. Ren. Nutr. 2007;17(5):314-322.

56. Sato $\mathrm{H}$, Tsubosa $\mathrm{Y}$, Kawano T. Correlation between the pretherapeutic neutrophil to lymphocyte ratio and the pathologic response to neoadjuvant chemotherapy in patients with advanced esophageal cancer. World J. Surg. 2012;36(3):617-622.

57. Keizman $D$, Ish-Shalom $M$, Huang $P$, et al. The association of pre-treatment neutrophil to lymphocyte ratio with response rate, progression free survival and overall survival of patients treated with sunitinib for metastatic renal cell carcinoma. Eur. J. Cancer. 2012;48(2):202-208.

58. Uthamalingam S, Patvardhan EA, Subramanian S, et al. Utility of the neutrophil to lymphocyte ratio in predicting long-term outcomes in acute decompensated heart failure. Am. J. Cardiol. 2011;107(3):433-438.

59. Mitch WE. Malnutrition is an unusual cause of decreased muscle mass in chronic kidney disease. J. Ren. Nutr. 2007;17(1):66-69.

60. Nair V, Niederman MS, Masani N, Fishbane S. Hyponatremia in community-acquired pneumonia. Am. J. Nephrol. 2007;27(2):184-190.

61. Waikar SS, Mount DB, Curhan GC. Mortality after hospitalization with mild, moderate, and severe hyponatremia. Am. J. Med. 2009;122(9):857-865.

62. Sato N, Gheorghiade M, Kajimoto K, et al. Hyponatremia and in-hospital mortality in patients admitted for heart failure (from the ATTEND registry). Am. J. Cardiol. 2013;111(7):10191025.

63. Kim WR, Biggins SW, Kremers WK, et al. Hyponatremia and mortality among patients on the liver-transplant waiting list. N. Engl. J. Med. 2008;359(10):1018-1026.

64. Milo-Cotter O, Cotter G, Weatherley BD, et al. Hyponatraemia in acute heart failure is a marker of increased mortality but not when associated with hyperglycaemia. Eur. J. Heart Fail. 2008;10(2):196-200.

65. Moritz ML, Ayus JC. The pathophysiology and treatment of hyponatraemic encephalopathy: an update. Nephrol. Dial. Transplant. 2003;18(12):2486-2491.

66. Kovesdy CP, Lott EH, Lu JL, et al. Hyponatremia, hypernatremia, and mortality in patients with chronic kidney disease with and without congestive heart failure. Circulation. 2012;125(5):677-684.

67. Guglielminotti J, Pernet P, Maury E, et al. Osmolar gap hyponatremia in critically ill patients: evidence for the sick cell syndrome? Crit. Care Med. 2002;30(5):1051-1055. 
68. Flear CT, Singh CM. Hyponatraemia and sick cells. Br. J. Anaesth. 1973;45(9):976-994.

69. Waikar SS, Curhan GC, Brunelli SM. Mortality associated with low serum sodium concentration in maintenance hemodialysis. Am. J. Med. 2011;124(1):77-84.

70. Hecking M, Karaboyas A, Saran R, et al. Predialysis serum sodium level, dialysate sodium, and mortality in maintenance hemodialysis patients: the Dialysis Outcomes and Practice Patterns Study (DOPPS). Am. J. Kidney Dis. 2012;59(2):238-248.

71. Hecking $M$, Karaboyas A, Saran R, et al. Dialysate sodium concentration and the association with interdialytic weight gain, hospitalization, and mortality. Clin. J. Am. Soc. Nephrol. 2012;7(1):92-100.

72. Mc Causland FR, Brunelli SM, Waikar SS. Dialysate sodium, serum sodium and mortality in maintenance hemodialysis. Nephrol Dial Transplant. 2012;27(4):1613-1618.

73. Nigwekar SU, Wenger J, Thadhani R, Bhan I. Hyponatremia, mineral metabolism, and mortality in incident maintenance hemodialysis patients: a cohort study. Am J Kidney Dis. 2013;62(4):755-762.

74. Renneboog B, Musch W, Vandemergel X, Manto MU, Decaux G. Mild chronic hyponatremia is associated with falls, unsteadiness, and attention deficits. Am. J. Med. 2006;119(1):71 e7178.

75. Lin GM, Li YH, Chu KM, Han CL. Malnutrition and hyponatremia in dialysis patients. Am. J. Med. 2011;124(8):e21; author reply e25.

76. Perez-Garcia R, Martin-Malo A, Fort J, et al. Baseline characteristics of an incident haemodialysis population in Spain: results from ANSWER--a multicentre, prospective, observational cohort study. Nephrol. Dial. Transplant. 2009;24(2):578-588.

77. Scherz N, Labarere J, Mean M, Ibrahim SA, Fine MJ, Aujesky D. Prognostic importance of hyponatremia in patients with acute pulmonary embolism. Am. J. Respir. Crit. Care Med. 2010;182(9):1178-1183.

78. Lin GM, Li YH, Chu KM, Han CL. Hyponatremia may reflect malnutrition in patients with acute pulmonary embolism. Am. J. Respir. Crit. Care Med. 2011;183(6):827; author reply 827-828.

79. Gill G, Leese G. Hyponatraemia: biochemical and clinical perspectives. Postgrad. Med. J. 1998;74(875):516-523.

80. Marcelli D, Wabel P, Wieskotten S, et al. Physical methods for evaluating the nutrition status of hemodialysis patients. J Nephrol. 2015.

81. Marcelli D, Usvyat LA, Kotanko P, et al. Body Composition and Survival in Dialysis Patients: Results from an International Cohort Study. Clin. J. Am. Soc. Nephrol. 2015.

82. Allen $\mathrm{CL}$, Bayraktutan U. Oxidative stress and its role in the pathogenesis of ischaemic stroke. Int J Stroke. 2009;4(6):461-470.

83. Cottone $\mathrm{S}$, Lorito $\mathrm{MC}$, Riccobene R, et al. Oxidative stress, inflammation and cardiovascular disease in chronic renal failure. J Nephrol. 2008;21(2):175-179.

84. Malhotra R, Marcelli D, von Gersdorff G, et al. Relationship of Neutrophil-to-Lymphocyte Ratio and Serum Albumin Levels with C-Reactive Protein in Hemodialysis Patients: Results from 2 International Cohort Studies. Nephron. 2015.

85. Madan VD, Novak E, Rich MW. Impact of change in serum sodium concentration on mortality in patients hospitalized with heart failure and hyponatremia. Circ. Heart Fail. 2011;4(5):637-643.

86. Flear CT, Hilton P. Hyponatraemia and severity and outcome of myocardial infarction. Br. Med. J. 1979;1(6173):1242-1246. 


\section{Chapter 2}

xicas

Is there any survival advantage of obesity in Southern European haemodialysis patients?

Charles Chazot, Jean-Paul Gassia, Attilio Di Benedetto, Salvatore Cesare, Pedro Ponce and Daniele Marcelli 


\begin{abstract}
Background

In the general population, a high body mass index (BMI) is associated with increased cardiovascular disease and all-cause mortality. However, according to US epidemiological evaluation in maintenance haemodialysis (HD) patients, a reverse epidemiology is described and baseline obesity appears paradoxically associated with better survival. The aim of this study is to examine in a Southern European HD population the relationship between survival and BMI at the start ofHD treatment, and how survival is influenced by the bodyweight (BW) variations during the first year of treatment.
\end{abstract}

\title{
Methods
}

A total of 85 dialysis centres located in Portugal, France and Italy and belonging to the FME European dialysis chain were included. The current prospective analysis focuses on incident patients admitted to these centres between 1 January 2000 and 30 September 2005 with $<1$ month of previous followup on RRT. Data were gained from the FME EuCliD database. Patients were classified at baseline in four categories according to the BMI: underweight, normal range, overweight and obese. Also, the patient survival was analysed according to five quintiles of BW changes during the first year ofHDtreatment $<-5.8 \%,-5.8$ to $-1.1 \%,-1.1$ to $1.7 \%$ (reference category), +1.7 to $+5.5 \%$ and $>+5.5 \%$. Survival analysis was adjusted for a set of demographic and comorbids using Kaplan-Meier curves and Cox model. Hazard ratios and their $95 \%$ confidence intervals were calculated with the use of the estimated regression coefficients and their standard errors.

\section{Results}

A total of 5592 patients were analysed $(40.9 \%$ females), and the mean age at admission was $64.4 \pm 16.5$ years. Of them, $27.7 \%$ were diabetic. The mean follow-up was $2.0 \pm 1.6$ years. Almost half of the patients $(46.4 \%)$ were in the normal range of BMI $\left(20-24.9 \mathrm{~kg} / \mathrm{m}^{2}\right)$. When analysed with the Cox model, the categories of baseline BMI (underweight, normal range, overweight and obese) significantly influenced the survival with the respective hazard ratio (HR) and confidence interval at $1.14(0.96-1.35), 1,0.74(0.67-0.9)$ and $0.78(0.56-0.87)$. The strength of the association as well as the shape of the curve remains unchanged after considering age, diabetes and comorbidities. Moreover, when compared to patients for whom BW remained stable during the first year of HD treatment, survival was significantly lower in patients presenting in the lower quintile of BW variation $(<-5.8 \%$ in 1 year) with an HR of 1.6 .

\section{Conclusions}

Despite increased comorbidities, overweight and obese patients on maintenance HD carry a significant lower mortality risk than patients in the normal and lower BMI ranges. This confirms the reverse epidemiology previously reported in US HD patients for these categories of BMI. Also BW variation during the first year of HD treatment is associated with patient survival, highlighting the importance of nutrition in this setting. 


\section{Introduction}

In the general population, being overweight and obese is found to be associated with the increased prevalence of cardiovascular disease and overall causes of mortality ${ }^{1}$. However, in haemodialysis (HD) patients, an unusual relationship between body mass index (BMI) and survival was reported for the first time almost 25 years ago ${ }^{2}$ with increased mortality in patients with low BMI and no increased mortality in overweight and obese HD patients.

More recently, this association was reported in US HD patients, showing an inverse linear relationship between survival and BMI, that is a survival advantage, even in morbidly obese patients ${ }^{3}$. Also, since the Diaphane study, the DOPPS study has reported this type of relationship in a set of US and European patients ${ }^{4}$. This inverse and unexpected correlation is part of the recent concept called reverse epidemiology, reported also for instance with predialysis blood pressure ${ }^{5}$ and that has been thoroughly reviewed ${ }^{6}$. Nevertheless, the inverse relationship between BMI and survival in $\mathrm{HD}$ patients is not universally recognized.

Several studies have failed to find this association in Asian patients like in $\operatorname{Japan}^{7}$ or among Asian American HD patients ${ }^{8,9}$. The first objective of our study was to examine the relationship between BMI and survival in Southern European incident HD patients whereby the case-mix of the dialysis population has changed dramatically since the DIAPHANE study and because the epidemiology of cardiovascular disease and especially coronary artery disease (CAD) is dramatically different between the US and Northern and Southern Europe ${ }^{10}$. The second objective was to evaluate the effect of the bodyweight (BW) variation during the first year of HD treatment on the prognosis of maintenance HD patients. 


\section{Patients and methods}

This prospective study included 76 dialysis centres owned by Fresenius Medical Care (Bad Homburg, Germany) in Italy, Portugal and France (see the Appendix). All incident end-stage renal disease (ESRD) patients, with less than 1-month previous HD treatment in another facility, were included in the study between 1 January 2000 and 30 September 2005. Amputated patients were excluded from analysis in order to avoid miscalculation of BMI. Data were retrieved from the EuCliD (European Clinical Database) database that is updated monthly with patient characteristics including demographics, comorbidities, dialysis prescriptions, ancillary therapies, lab results and outcome. At the start of HD, the patients were categorized into four categories of BMI: $\mathrm{BMI}<20,20-24.99,25-29.99$ and $>30 \mathrm{~kg} / \mathrm{m}^{2}$. The upper two categories corresponded to the WHO standard classification of overweight $\left(25-29.99 \mathrm{~kg} / \mathrm{m}^{2}\right)$ and obese $\left(\geq 30 \mathrm{~kg} / \mathrm{m}^{2}\right)$.

According to the general acceptance and also in order to have meaningful numbers, a $\mathrm{BMI}<20$ was defined as being underweight, and $\mathrm{BMI}=20-24.99$ was considered to be normal weight. The comorbid conditions present in the study were defined according to the International Classification of Diseases, tenth revision code (ICD10): CAD (I20-I25, Z95.1, Z95.5), heart failure (I50-I51, I13-I13.2, I42-I42.2, I42.6142.7, I11.0, I11.9, 197.1, 197.8, 142.9, 143.2), valvular heart disease (Z95.2, Z95.3, Z95.4, Z95.9, I01.1, I05.0, I08.9, I09.1, I09.8, I33.0, I38, I39.8, T82.0, Z48.8, Z95.9, T82.6, I45.2, I45.3, 145.6-147.9, I49.3-149.9, I44.1-144.3, I48, 149.0, I34-I37.9, I39139.4), atherosclerosis disease (170-176.9), cerebrovascular disease (160-169), pulmonary disease (J41-J47.9, J96), depression (F32.1-F33.9, F06.3, F20.4, F25.1, F31.3, F31.9), cancer/neoplastic disease (C0-C97.9, D37-D48.9) and severe liver disease (K70-K77.9). 
Distribution of comorbidities was analysed in each BMI category and according to age (below and above the age of 65). Survival was studied among the different BMI ranges and adjusted for the different comorbidities.

Also, survival from the second year of treatment has been analysed according to the evolution of the BW during the first year of HD treatment.

Patients were split into five quintiles according to this evolution expressed as a percentage normalized to the ideal BW (calculated from the Broca formula: ideal BW $=($ height in $\mathrm{cm}-100)$ for males and ideal $\mathrm{BW}=($ height in $\mathrm{cm}-104)$ for females $\left.{ }^{11}\right)$ : $<-5.8 \%,-5.8$ to $-1.1 \%,-1.1$ to $1.7 \%$ (reference category), +1.7 to $+5.5 \%$ and $>+5.5 \%$.

\section{Statistics}

The mean values and frequencies of the parameters were compared by ANOVA or the chi-square test, as appropriate. Survival functions according to baseline BMI were described using the Kaplan-Meier technique. The log-rank testwas used for univariable comparisons.Cox proportional hazard models were used to compare survival according to baseline BMI adjusting for a set of demographic and comorbids.

All analyses were performed with adjustment for age, gender and for each of the following comorbidity indicators: diabetes, CAD, heart failure, valvular heart disease, atherosclerosis disease, cerebrovascular disease, pulmonary disease, depression, cancer/neoplastic disease and severe liver disease (Table 1). Only age has been introduced as a continuous variable, and all others as categorical variables (for gender: ref. females; for comorbidity indicators: ref. present/absent). Both KaplanMeier curves and Cox model used the same end-point (death), and patients were 
censored when they were changed to peritoneal dialysis therapy, were transferred to another dialysis unit, received a kidney graft or were still on extra-corporeal treatment on the final observation date (30 September 2005). All patient characteristics considered in the study were reported.

When Cox proportional hazard regression was applied, all reported variables were used to obtain the final multivariate model. Estimated relative risks (hazard ratios) and their $95 \%$ confidence intervals $(\mathrm{Cl})$ were calculated with the use of the estimated regression coefficients and their standard errors. The contribution of covariates to explain the dependent variable was assessed by means of a two-tailed Wald test, with $P<0.05$ considered significant. The proportion hazard assumption was checked for each model by inspection of the complementary log minus log plots. To evaluate the impact of the BW changes on mortality, patients surviving more than 1 year were selected. The behaviour of BW during the first year was evaluated, classifying the patients according to decrease or stability and the increase of dry BW. Then, survival analyses were modelled considering the behaviour of BW change during the first year of follow-up as a predictor of subsequent mortality. All statistical analyses were performed using the SPSS software, version 14 (SPSS Inc., Chicago, IL, USA).

\section{Results}

A total of 5592 patients were included in the study during this 57 -month period. The average age was $64.4 \pm 16.5$ years and the mean follow-up $2.0 \pm 1.6$ years. Female gender represented $40.9 \%$ of the whole population. However, in obese patients, the proportion of female gender increased significantly (Table 1). 
Table 1. Patients' characteristics according to the BMI distribution

\begin{tabular}{|c|c|c|c|c|}
\hline & Underweight & Normal range & Overweight & Obese \\
\hline Patient number $(\%)$ & $679(13.9)$ & $2261(46.4)$ & $1367(28.0)$ & $569(11.7)$ \\
\hline Age (years: mean $\pm S D)$ & $65.7 \pm 22.1$ & $63.7 \pm 16.7$ & $65.2 \pm 13.9$ & $62.7 \pm 13.8$ \\
\hline Female $(\%)$ & 46.7 & 36.8 & 39.1 & 56.9 \\
\hline Diabetes (\%) & 14.3 & 24.2 & 30.8 & 43.1 \\
\hline Coronary artery disease $(\%)$ & 10.0 & 11.1 & 13.8 & 13.7 \\
\hline Heart failure $(\%)$ & 13.7 & 13.4 & 14.3 & 17.6 \\
\hline Valvular heart disease (\%) & 6.8 & 6.6 & 7.2 & 6.9 \\
\hline Atherosclerosis disease (\%) & 8.0 & 5.4 & 6.1 & 4.9 \\
\hline Cerebrovascular disease (\%) & 6.6 & 6.8 & 7.0 & 5.8 \\
\hline Pulmonary disease $(\%)$ & 5.0 & 4.0 & 4.2 & 4.6 \\
\hline Depression $(\%)$ & 1.2 & 0.8 & 1.6 & 1.6 \\
\hline Cancer/neoplastic disease (\%) & 8.7 & 6.7 & 5.6 & 7.9 \\
\hline Severe liver disease $(\%)$ & 1.6 & 2.1 & 2.1 & 0.9 \\
\hline
\end{tabular}

The prevalence of diabetes was $27.7 \%$, but the distribution of diabetic patients increased significantly in the overweight and obese BMI category (Table 1). The distribution of BMI among the studied patients is also shown in Table 1. Almost half of the patients $(46.4 \%)$ were in the normal range of BMI $\left(20-24.99 \mathrm{~kg} / \mathrm{m}^{2}\right)$. A BMI $<20$ (underweight category) was present in $13.9 \%$ of the patients. Overweight $(\mathrm{BMI}=$ $\left.25-29.99 \mathrm{~kg} / \mathrm{m}^{2}\right)$ and obese $(\geq 30)$ represented 28 and $11.7 \%$, respectively. The prevalence of CAD was equally distributed in the different BMI ranges in maintenance HD patients over the age of 65 . In younger patients below $65, C A D$ increased in overweight and obese patients compared to normal and underweight patients (Figure 1).

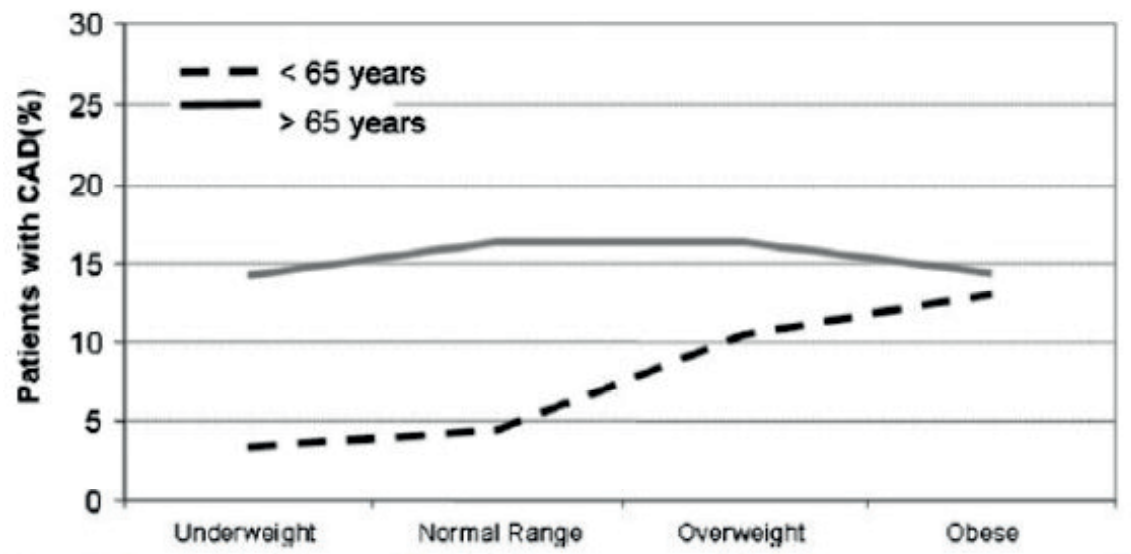

Fig. 1. Coronary artery disease according to BMI in patients below and over 65 years. 
The heart failure prevalence was significantly higher in the obese patients when compared to normal BMI patients, both below and over 65 years of age. The other BMI categories were not significantly different for the prevalence of this comorbidity. The proportion of patients who were transplanted was $6.6 \%$ ranging from $5.2 \%$ in underweight to $7.3 \%$ in the normal range. The proportion of those transferred to peritoneal dialysis was $9.4 \%$ ranging from $8.9 \%$ in overweight to $10.6 \%$ in underweight. The total number of deaths during the follow-up was $1147(23.5 \%)$. The Kaplan-Meier survival curve for the four BMI ranges is displayed in Figure 2.

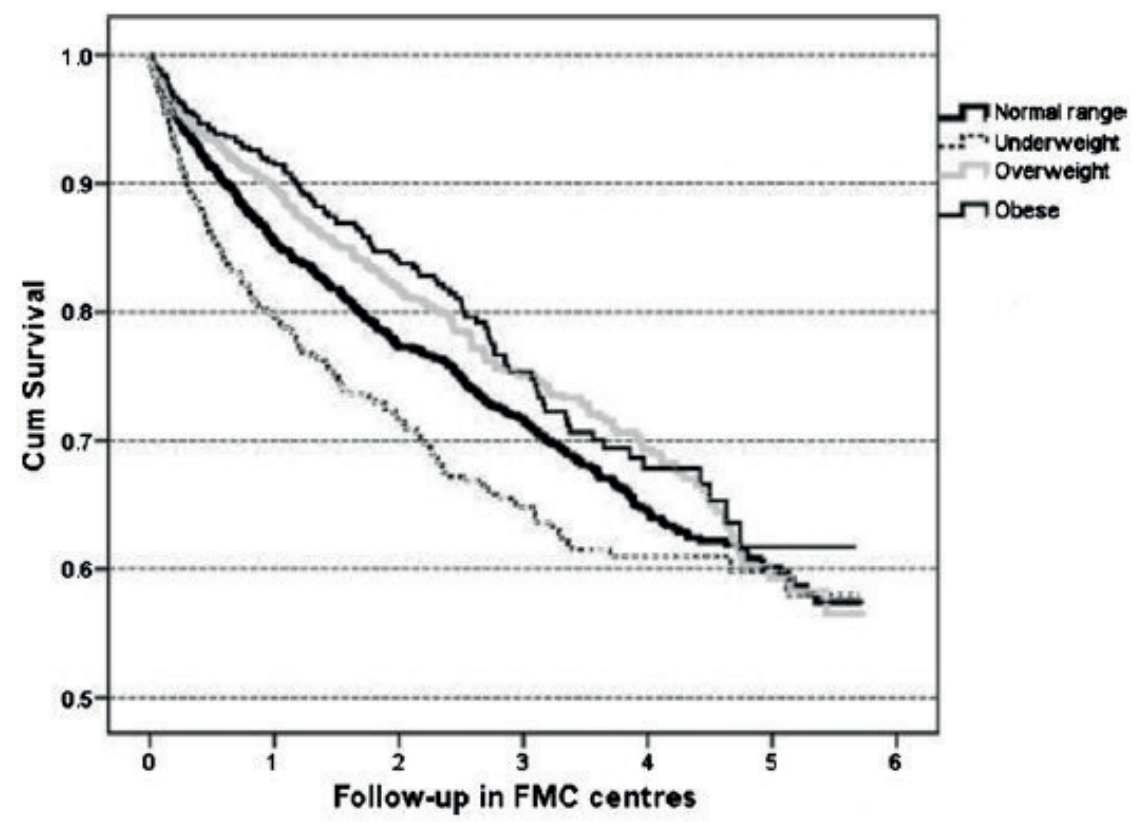

Fig. 2. Kaplan-Meier survival curves according to the BMI categories.

Survival was significantly better for overweight and obese patients compared to that for normal and underweight patients. In Figure 3 and Table 2, the unadjusted and adjusted relative risks of death are displayed for the four BMI categories, with the normal BMI range used as a reference. Overweight and obese patients had an adjusted hazard ratio of $0.78(0.67-0.9)$ and $0.71(0.56-0.87)$, respectively. 
Table 2. Survival and BMI categories; crude and adjusted hazard ratios for the four BMI categories

\begin{tabular}{lllllllll}
\hline & \multicolumn{3}{l}{ Crude hazard ratios } & & \multicolumn{3}{l}{ Adjusted hazard ratios } \\
\cline { 2 - 3 } \cline { 7 - 8 } BMI categories & HR & $95 \% \mathrm{CI}$ & $P$-value & & HR & $95 \% \mathrm{CI}$ & $P$-value \\
\hline Underweight & 1.23 & $1.08-1.49$ & 0.004 & & 1.14 & $0.96-1.35$ & 0.138 \\
Normal & 1 & - & - & & 1 & - & - \\
Overweight & 0.85 & $0.74-0.98$ & 0.026 & & 0.78 & $0.67-0.90$ & 0.001 \\
Obese & 0.79 & $0.65-0.97$ & 0.024 & & 0.71 & $0.56-0.87$ & 0.001 \\
\hline
\end{tabular}

$\mathrm{HR}$, hazard ratio; CI, confidence intervals; BMI, body mass index.

The second part of the study was the report of survival according to the evolution of the BW during the first year of HD treatment. The patients were divided into five categories according to the quintile distribution: $<-5.8 \%,-5.8$ to $-1.1 \%,-1.1$ to $1.7 \%$ (reference category), +1.7 to $+5.5 \%$ and $>+5.5 \%$. Table 3 reports the patient characteristics and the patient outcome of the studied population including the adjusted hazard risks and the corresponding $95 \% \mathrm{Cl}$. Mortality was significantly higher in the lowest quintile, in patients who had a weight loss over $5.8 \%$ during the first year of HD treatment, whereas it was not influenced in other quintiles, in patients with a weight loss lower than $5.8 \%$, or who remained stable or gained weight. 


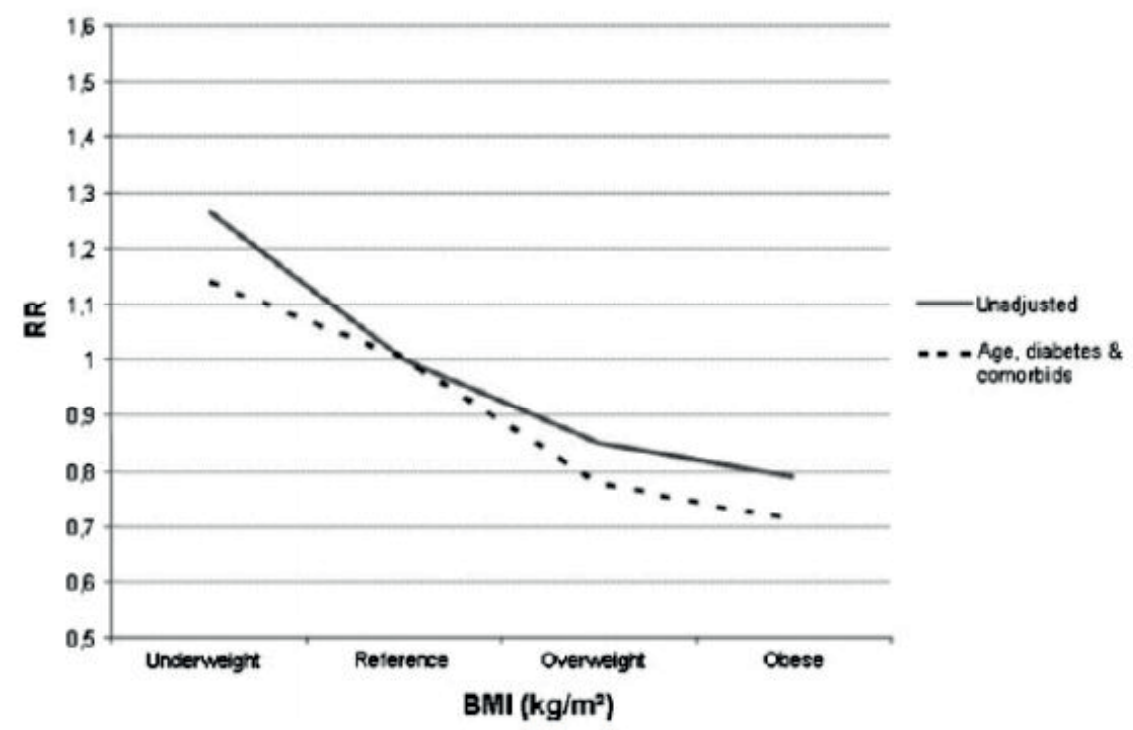

Fig. 3. Relative risk curve according to BMI categories. Adjustment included age, diabetes, CAD, neoplastic disease, cerebrovascular disease, heart failure, liver disease, atherosclerosis and valvular heart disease. For $P$-values, see Table 2.

\section{Discussion}

In this study, we confirm among a large prospective Southern European cohort of incident $\mathrm{HD}$ patients that a high $\mathrm{BMI}$ range in the overweight and obese is associated with better survival than in normal and underweight BMI categories. This unexpected relationship between BMI and survival had been previously suggested in French patients in 1982 by Degoulet et al. ${ }^{2}$ in the DIAPHANE study. It was confirmed later by Fleischmann et al. ${ }^{12}$ using different BW ranges, showing a clear survival advantage in patients with a $\mathrm{BMI}>27 \mathrm{~kg} / \mathrm{m}^{2}$, mostly in African American patients. Our findings in an incident HD patient cohort are close to what has been reported in incident $^{8,13}$ and prevalent US patients ${ }^{3}$. These latter reports used different categories of BMI, from simple (three ranges: $\left.<23.1,23.1-27.8,>27.8 \mathrm{~kg} / \mathrm{m}^{2}\right)^{13}$ to very sophisticated distribution (from $<18$ or 19 to $>37$ to $45 \mathrm{~kg} / \mathrm{m}^{2}$ in 8 to 11 
categories $\left.^{8,14}\right)$. The other studies ${ }^{2,4,13}$ did not analyse specifically the issue of the morbidly obese patients.

Our analysis was not able to confirm the survival advantage in morbidly obese patients, as reported by Kalantar-Zadeh et al. ${ }^{14}$ because the number of patients in this category $\left(\mathrm{BMI}>40 \mathrm{~kg} / \mathrm{m}^{2}\right)$ was too small $(0.7 \%$ of the total patients $)$ and they were pooled with the $30-39.99 \mathrm{~kg} / \mathrm{m}^{2}$ category.

Moreover, we report in the incident patients the distribution of severe comorbidities such as diabetes, CAD and heart failure. Adjustments for these comorbid conditions, absent in the Kalantar-Zadeh study ${ }^{14}$, did not change the paradoxical relationship between BMI and patient survival. It confirms the findings of the DOPPS study ${ }^{4}$ in which obese and overweight patients with high-risk comorbidities were found to have better survival than low and normal BMI patients with the same risk profile.

Studying the mortality among a cohort of Spanish HD patients, Marcen et al. ${ }^{15}$ did not find any difference of BMI between the patients who survived and who died.

However, in this prevalent cohort, the relationship between BMI and survival was not studied independently and was not adjusted for other factors such as age, vintage and comorbidities.

More surprisingly, the Dutch NECOSAD study did not find advantages of a high BMI on the survival of incident female and male HD patients ${ }^{16}$, whereas it reports the expected increased mortality risk in the low range of $\mathrm{BMI}\left(<18.5 \mathrm{~kg} / \mathrm{m}^{2}\right)$. However, this study only included patients between 50 and 65 years of age and used a BMI reference range of $22.5-25 \mathrm{~kg} / \mathrm{m}^{2}$. Even when these criteria are applied to our studied population, it does not change our findings and does not explain the discrepancy between the Dutch and Southern European dialysis patients regarding survival and BMI ranges. The explanation may be related to the difference of 
cardiovascular disease epidemiology between the Netherlands and Southern Europe. As reported by Levy and Kannel ${ }^{10}$, the death rate from CAD in both sex and in the age range 35-74 is much lower in France, Spain and Portugal (three of the four countries involved in the current study) when compared to the Netherlands. A higher prevalence of cardiovascular disease in Dutch obese HD patients may blunt the survival advantage observed in Southern European obese HD patients, especially because young patients, aged between 18 and 50 years, were not included in the Dutch study. The high prevalence of cardiovascular disease in the studied age ranges may have outweighed the benefit of a high BMI.

We have also confirmed that a BW loss $>5.8 \%$ (first quintile) during the first year of HD treatment was associated with significantly increased mortality. The second quintile $(-5.8$ to $-1.1 \%)$ had no significant reduction in survival, whereas KalantarZadeh et al. ${ }^{14}$ reported that each category below $-1 \%$ of BW loss had a significant increase in patient death. In this last study, prevalent patients were analysed whereas our cohort included only incident ones. Previous reports have shown a different evolution of BW in both prevalent and incident cohorts. In the HEMO study ${ }^{17}$, prevalent HD patients displayed a progressive decline of BW all along the 3year follow-up, whereas in patients starting $\mathrm{HD}^{18,19}$, BW initially decreased during the first 2-4 months corresponding to the fluid removal and then increased again because of appetite recovery. Whereas in prevalent patients BW loss is mainly interpreted as progressive malnutrition, in incident patients it is possible that fluid removal for extracellular volume accumulated in the pre-dialysis period may interfere with the interpretation of the BW variation during the first year of treatment. This may explain why only an important BW loss $>5.8 \%$ in incident HD patients is found to have a detrimental effect regarding survival, similar to other nutritional markers such 
as serum albumin and prealbumin whose lowest quartiles were associated with a higher mortality rate in a study by Combe et al. ${ }^{20}$.

Trying to explain this paradoxical association of obesity with better survival among HD patients, Johansen et al. ${ }^{8}$ ruled out from their data the influence of lean body mass and inflammation suggesting that fat itself might be protective in the catabolic condition of HD treatment. For Kwan and Beddhu ${ }^{21}$, the paradox is related to the balance between the deleterious effect of adipose tissue (inflammation, increased associated comorbid conditions, . . .) and the nutritional advantage of adiposity represented by fat tissue in the catabolic situation of HD treatment. Another hypothesis is raised by Sarkar et al. $^{22}$. They have shown that the visceral compartment, also referred to as the high metabolic rate compartment, is inversely related to the BMI and is correlated with the protein catabolic rate, a surrogate of uraemic toxin generation. The interpretation is that patients with low BMI have a relatively higher production of uraemic toxins than high BMI patients, leading to decreased survival by higher or increased dialysis needs. However, this appealing hypothesis cannot be the unique explanation since reverse epidemiology for BMI also exists in other fields, like heart failure for instance ${ }^{23}$. Moreover, it has been recently reported that the reverse epidemiology concept regarding pre-dialysis blood pressure is time dependent ${ }^{24}$ with an increased mortality risk associated with the low blood pressure level in the first 2 years of dialysis treatment followed by an increased risk of mortality associated with high blood pressure from the third year of HD treatment. This time-dependent relationship between BMI and mortality may exist but remains to be confirmed. 
That was not the case in the NECOSAD study in which the 7-year follow-up did not display any change in the relationship of BMI and survival, both in HD patients and normal subjects ${ }^{16}$.

In conclusion, we confirm the reverse epidemiology regarding BMI and survival in incident Southern European HD patients even after adjustments for comorbidities, except in the case of morbid obesity. Also, it is confirmed that loosing weight during the first year of HD treatment is associated with an increased mortality risk. This stresses the pivotal role of nutritional issues in dialysis patients, and strengthens the need for the regular assessment of nutritional markers and nutritional intervention studies.

Acknowledgment. These data have been presented at the XLIII EDTAERA meeting (Glasgow, Scotland, July 2006).

Conflict of interest statement. All authors are employees or consultants of the chain of clinics quoted in the paper.

\section{Appendix}

Participating Centres: France

Centre de Rein Artificiel de Tassin, Centre Hemodialyse du Languedoc Mediterranee, Centre Nephrologique D'Occitanie (CNO), Saint Simon, La Vall'ee, CRAT Montalieu, CRAT Rillieux, CRAT Unite d'Autodialyse (Chateau), Centre d'Autodialyse du Lunel, Centre Hemodialyse du Beziers, C.T.S.I.R., C.H.L.M. Nimes, DIALYTEC, Fondial Fontenay sous Bois, Fondial Vincennes, Fondial Champigny, AERA—Gennevilliers, 
AERA—Pontault Combault, AERA-Villejuif.

Participating Centres: Italy

NephroCare Dialnova, NephroCare Nephros Cassino, NephroCare Centro Dialisi Riviera del Conero, NephroCare Nefrosal, NephroCare Mirabial, NephroCare Malpighi, NephroCare Sodial, NephroCare Emodial Vesuvio, NephroCare SM2, NephroCare Emodial, NephroCare Nephros Venafro, NephroCare Alfadial, NephroCare Dialcenter, NephroCare Cilento Dial Dianoval, NephroCare Kidney, NephroCare Nefrodisal, NephroCare Cilento Dial Olidial, NephroCare Renal Center, NephroCare Nedial, NephroCare Nedial Napoli, NephroCare Cercos, NephroCare Beta Dial, NephroCare Rusdial, NephroCare Omnia Dial, NephroCare Dial Torre, NephroCare Fanus c/o Clinica Ruesch, NephroCare Enne E, NephroCare Fanus Somma Vesuviana, NephroCare Dialten, NephroCare Ruscosa, NephroCare Dialy Center, NephroCare II Nefrologico, NephroCare Centro Diagnostico e Terapeutico delle Malattie Renali.

\section{Participating Centres: Portugal}

Abrandial - Clinica de Doenc, as Renais, FMC_Amadora, Centro Medico Nacional Clinica de Beja, Braga, Cancho, Almada, FMC-NMC Centro Medico Nacional, FMC Entroncamento, FMC Centro de Hemodialise de Evora, Centro de Hemodialise de Fafe, FMC - Clinica Hemodialise de Faro, Egidial, FMC Lumiar, FMC Restelo, FMC - Ponte da Barca, FMC-NMC Centro Medico Nacional Portimao, Ribadial - Clinica de Dialise de Santarem, FMC Setubal, Tavira, FMC Torres Vedras, Hemodial - Vila Franca Xira, Vila Nova de Gaia, Visodial - Centro de Dialise de Viseu, Tagus Dial. 


\section{Reference List}

1. Calle EE, Thun MJ, Petrelli JM, Rodriguez C, Heath CW, Jr. Body-mass index and mortality in a prospective cohort of U.S. adults. N Engl J Med. 1999;341(15):1097-1105.

2. Degoulet $\mathrm{P}$, Legrain $\mathrm{M}$, Reach $\mathrm{I}$, et al. Mortality risk factors in patients treated by chronic hemodialysis. Report of the Diaphane collaborative study. Nephron. 1982;31(2):103-110.

3. Kalantar-Zadeh K. Causes and consequences of the reverse epidemiology of body mass index in dialysis patients. J Ren Nutr. 2005;15(1):142-147.

4. Leavey SF, McCullough K, Hecking E, Goodkin D, Port FK, Young EW. Body mass index and mortality in 'healthier' as compared with 'sicker' haemodialysis patients: results from the Dialysis Outcomes and Practice Patterns Study (DOPPS). Nephrology, dialysis, transplantation : official publication of the European Dialysis and Transplant Association European Renal Association. 2001;16(12):2386-2394.

5. Kalantar-Zadeh K, Block G, Humphreys MH, Kopple JD. Reverse epidemiology of cardiovascular risk factors in maintenance dialysis patients. Kidney Int. 2003;63(3):793-808.

6. Schmidt DS, Salahudeen AK. Obesity-survival paradox-still a controversy? Semin Dial. 2007;20(6):486-492.

7. Kaizu $\mathrm{Y}$, Tsunega $\mathrm{Y}$, Yoneyama $\mathrm{T}$, et al. Overweight as another nutritional risk factor for the long-term survival of non-diabetic hemodialysis patients. Clin Nephrol. 1998;50(1):44-50.

8. Johansen KL, Young B, Kaysen GA, Chertow GM. Association of body size with outcomes among patients beginning dialysis. Am J Clin Nutr. 2004;80(2):324-332.

9. Wong JS, Port FK, Hulbert-Shearon TE, et al. Survival advantage in Asian American end-stage renal disease patients. Kidney Int. 1999;55(6):2515-2523.

10. Levy D, Kannel WB. Searching for answers to ethnic disparities in cardiovascular risk. Lancet. 2000;356(9226):266-267.

11. Locatelli F, Alberti D, Graziani G, Buccianti G, Redaelli B, Giangrande A. Prospective, randomised, multicentre trial of effect of protein restriction on progression of chronic renal insufficiency. Northern Italian Cooperative Study Group. Lancet. 1991;337(8753):1299-1304.

12. Fleischmann E, Teal N, Dudley J, May W, Bower JD, Salahudeen AK. Influence of excess weight on mortality and hospital stay in 1346 hemodialysis patients. Kidney Int. 1999;55(4):1560-1567.

13. Port FK, Ashby VB, Dhingra RK, Roys EC, Wolfe RA. Dialysis dose and body mass index are strongly associated with survival in hemodialysis patients. J Am Soc Nephrol. 2002;13(4):1061-1066.

14. Kalantar-Zadeh K, Kopple JD, Kilpatrick RD, et al. Association of morbid obesity and weight change over time with cardiovascular survival in hemodialysis population. Am J Kidney Dis. 2005;46(3):489-500.

15. Marcen R, Teruel JL, de la Cal MA, Gamez C. The impact of malnutrition in morbidity and mortality in stable haemodialysis patients. Spanish Cooperative Study of Nutrition in Hemodialysis. Nephrology, dialysis, transplantation : official publication of the European Dialysis and Transplant Association - European Renal Association. 1997;12(11):2324-2331.

16. de Mutsert R, Snijder MB, van der Sman-de Beer F, et al. Association between body mass index and mortality is similar in the hemodialysis population and the general population at high age and equal duration of follow-up. J Am Soc Nephrol. 2007;18(3):967-974.

17. Rocco MV, Dwyer JT, Larive B, et al. The effect of dialysis dose and membrane flux on nutritional parameters in hemodialysis patients: results of the HEMO Study. Kidney Int. 2004;65(6):2321-2334.

18. Chazot C, Charra B, Vo Van C, et al. The Janus-faced aspect of 'dry weight'. Nephrology, dialysis, transplantation : official publication of the European Dialysis and Transplant Association - European Renal Association. 1999;14(1):121-124. 
19. Mehrotra R, Berman N, Alistwani A, Kopple JD. Improvement of nutritional status after initiation of maintenance hemodialysis. Am J Kidney Dis. 2002;40(1):133-142.

20. Combe $\mathrm{C}$, Chauveau $\mathrm{P}$, Laville $\mathrm{M}$, et al. Influence of nutritional factors and hemodialysis adequacy on the survival of 1,610 French patients. Am J Kidney Dis. 2001;37(1 Suppl 2):S8188.

21. Kwan BC, Beddhu S. A story half untold: adiposity, adipokines and outcomes in dialysis population. Semin Dial. 2007;20(6):493-497.

22. Sarkar SR, Kuhlmann MK, Kotanko P, et al. Metabolic consequences of body size and body composition in hemodialysis patients. Kidney Int. 2006;70(10):1832-1839.

23. Curtis JP, Selter JG, Wang Y, et al. The obesity paradox: body mass index and outcomes in patients with heart failure. Arch Intern Med. 2005;165(1):55-61.

24. Stidley CA, Hunt WC, Tentori F, et al. Changing relationship of blood pressure with mortality over time among hemodialysis patients. J Am Soc Nephrol. 2006;17(2):513-520. 
$\mathrm{BMI}$ and survival of hemodialysis patients 


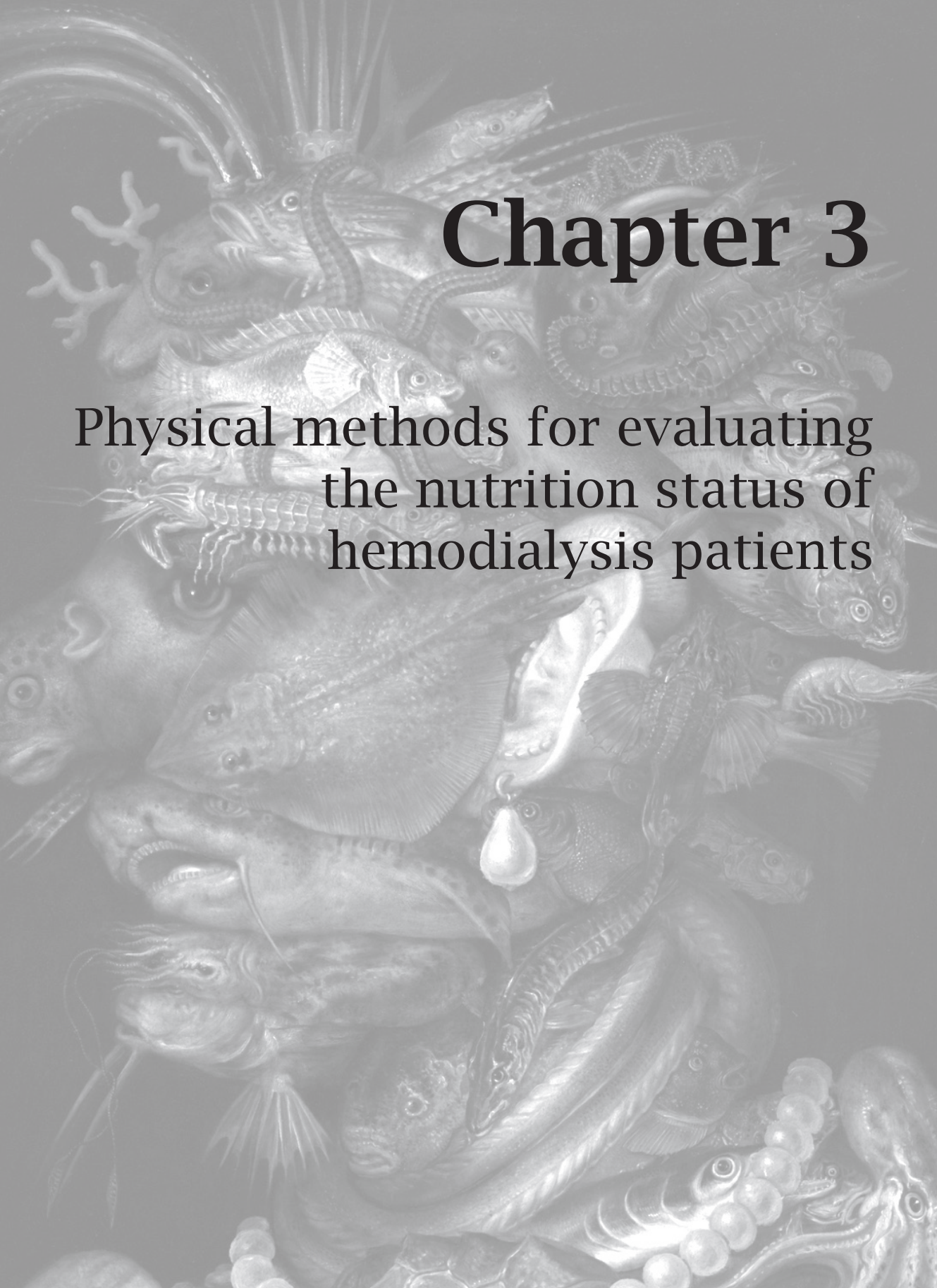

Daniele Marcelli, Peter Wabel, Sebastian Wieskotten, Annalisa Ciotola, Aileen Grassmann, Attilio Di Benedetto, Bernard Canaud

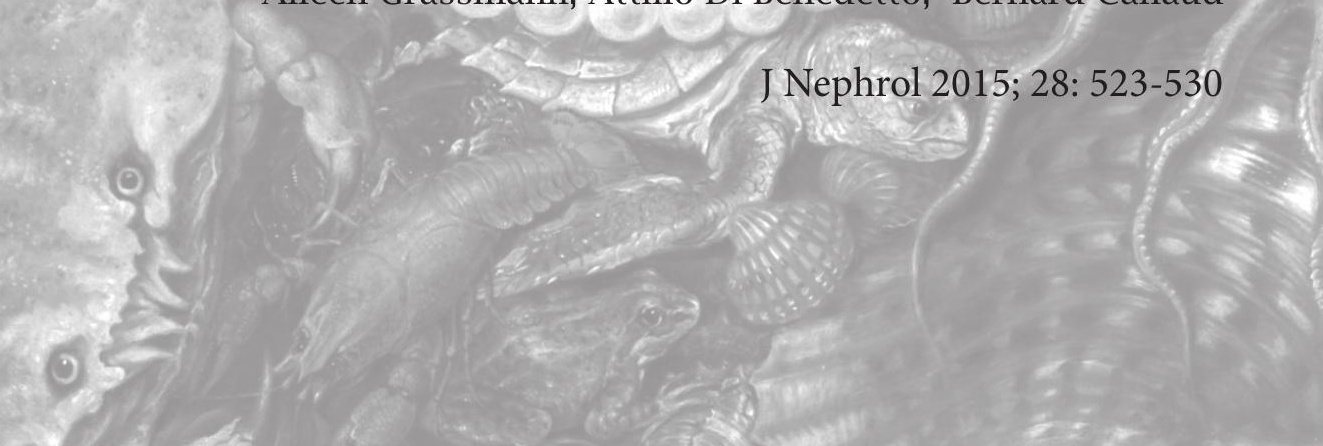




\section{Abstract}

This article aims to provide an overview of the different nutritional markers and the available methodologies for the physical assessment of nutrition status in hemodialysis patients, with special emphasis on early detection of protein energy wasting (PEW).

Nutrition status assessment is made on the basis of anamnesis, physical examination, evaluation of nutrient intake, and on a selection of various screening/diagnostic methodologies. These methodologies can be subjective (e.g. the Subjective Global Assessment score (SGA)) or objective in nature (e.g. bioimpedance analysis). In addition, certain biochemical tests may be employed (e.g. albumin, pre-albumin). The various subjective-based and objective methodologies provide different insights for the assessment of PEW, particularly regarding their propensity to differentiate between the important body composition compartments - fluid overload, fat mass and muscle mass.

This review of currently available methods showed that no single approach and no single marker is able to detect alterations in nutrition status in a timely fashion and to follow such changes over time. The most clinically relevant approach presently appears to be the combination of the SGA method with the bioimpedance spectroscopy technique with physiological model and, additionally, laboratory tests for the detection of micro-nutrient deficiency. 


\section{Introduction}

Multiple metabolic and nutritional derangements are present in $20-50 \%$ of patients with advanced chronic kidney disease (CKD) ${ }^{1}$. A variety of terms have been coined to describe this condition, such as uremic malnutrition ${ }^{2}$, uremic cachexia ${ }^{3}$, protein energy malnutrition ${ }^{4}$, malnutrition-inflammation atherosclerosis syndrome ${ }^{5}$ or malnutrition-inflammation complex syndrome ${ }^{6}$. More recently, the term "malnutrition" has been replaced by "wasting" in recognition that the disorder cannot be corrected by simply increasing dietary nutritional intake. In fact, the deterioration of kidney function is often associated with inflammation, metabolic acidosis, and impaired insulin/insulin-like growth factor functionality, all of which negatively affect protein anabolism even in presence of an adequate nutritional intake. As a consequence, the International Society of Renal Nutrition and Metabolism defined protein-energywasting (PEW) according to the presence of at least three out of the following four characteristics $^{7}$ : (1) Abnormal levels of circulating biomarkers (low serum albumin, pre-albumin, or cholesterol concentrations); (2) Decreased body mass (low or decreased body mass or fat mass, or weight loss with decreased protein and energy intake); (3) Decreased muscle mass; and (4) Abnormal nutritional score. However, even severely reduced muscle mass can be masked by a parallel increase in nonmuscle body weight (even to overweight and obese levels), making a diagnosis of PEW difficult in such cases.

While the nutritional and metabolic derangements observed in advanced CKD cannot be attributed to any one single factor, a common feature is the high rate of protein degradation. Chronic inflammation can be a cause of PEW in CKD patients $^{8,9}$. Chronic inflammation is not only associated with advanced kidney disease itself, but also with the biological response to the dialysis treatment 
(including catheters) and with the presence of comorbid conditions, such as diabetes mellitus, tumors or infections. Another factor that plays a role is the inadequate intake of nutrients, for example due to loss of appetite, dietary restrictions, pillburden, lack of physical activity, the disruptive influence of dialysis scheduling on meal times, and failure to compensate for nutrient losses (e.g. in the dialysate). Lastly, intercurrent events leading to frequent hospitalizations of dialysis patients have been associated with worsening of the patient's nutrition status ${ }^{10}$.

When PEW is present, patient mortality risk and hospitalization rate increase dramatically $^{11}$. In order to hinder, or at least delay, the development of PEW in dialysis patients, the European Best Practice Guidelines recommend a close follow up of patient nutrition status from the initiation of renal replacement therapy ${ }^{12}$.

This article aims to provide an overview of the different nutritional markers and the available methodologies for the physical assessment of nutrition status, with special emphasis on early detection of PEW.

\begin{tabular}{|c|c|}
\hline SGA-Subjective Global Assessment & $\begin{array}{l}\text { The SGA combines weight loss with information about dietary intake and physical examination results, } \\
\text { e.g. comorbidities, gastrointestinal symptoms or signs of muscle loss }\end{array}$ \\
\hline $\begin{array}{l}\text { MIS-Malnutrition Inflammation } \\
\text { Score }\end{array}$ & $\begin{array}{l}\text { The MIS combines the traditional test parameters of the SGA test with additional laboratory information } \\
\text { (e.g. serum albumin or iron binding capacity) }\end{array}$ \\
\hline $\begin{array}{l}\text { MNA-SF-Mini Nutritional } \\
\text { Assessment Short Form }\end{array}$ & $\begin{array}{l}\text { The MNA-SF, which was developed to screen for the risk of malnutrition, includes also information on } \\
\text { psychological problems but does not take any laboratory values into account }\end{array}$ \\
\hline NRS—Nutritional Risk Score & $\begin{array}{l}\text { The NRS was developed for hospitalized patients. It is very similar to the MNA-SF in the tested } \\
\text { parameters }\end{array}$ \\
\hline $\begin{array}{l}\text { MUST—Malnutrition Universal } \\
\text { Screening Tool }\end{array}$ & $\begin{array}{l}\text { The MUST score was developed for multidisciplinary use and was adopted by the British National } \\
\text { Health Service (NHS) to be used in the general population. The test is not adjusted to the specific } \\
\text { population of CKD patients }\end{array}$ \\
\hline $\begin{array}{l}\text { GNRI-Geriatric Nutritional Risk } \\
\text { Index }\end{array}$ & $\begin{array}{l}\text { This index is a mathematical calculation based on patient weight and albumin levels. This test takes the } \\
\text { potential fluid overload of the patients into account }\end{array}$ \\
\hline
\end{tabular}

\section{Available methods for evaluating the nutrition status of hemodialysis patients}

Nutrition status assessment relies on anamnesis, physical examination, evaluation of nutrient intake, and on a selection of various screening/diagnostic methodologies. 


\section{The last can be subjective in character (such as the Subjective Global Assessment score, see Table 1) or objective in nature (for example, employing anthropometric indices, body composition tools or functionality tests, see Table 2).}

Table 2 Objective methods used for nutritional assessment

Anthropometrics
Weight
BMI-body mass index
Mid-arm circumference
Skin fold thickness
Waist-hip ratio
Functional test
Hand-grip strength
Body composition
DEXA-dual X-ray absorptiometry
Four-compartment modelling
BIA-mono-frequency or multifrequency
bioimpedance analysis

BIVA-bioimpedance vector analysis

Bioimpedance spectroscopy without physiological model
Patient weight can be easily measured using a weighing scale

BMI is the weight of the patient normalized to the height squared $\left(\mathrm{BMI}=\right.$ weight height $\left.{ }^{2}\right)$

Measurement of the circumference of the upper mid arm using a measuring tape

Calipers are used to measure skin fold thickness. Several measurements have to be performed at various predefined anthropometric measuring sites of the body, and several measurements have to be averaged

Ratio of the waist to hip circumference measured using a measuring tape

\begin{abstract}
The isometric contraction force of the hand is used to determine the hand grip strength. The measured force can be used to determine the muscle strength of a subject and also allows extrapolation to the muscle mass. Several studies show a correlation between hand-grip strength and survival. With the proper dynamometer, the test is easy to conduct and results are replicable. It does not provide information on fat mass or potential fluid overload [47]
\end{abstract}

The total body of the patient is scanned with two different X-ray intensities, allowing determination of bone mass, fat mass and residual mass

This method combines the bone mineral content (DEXA), total body water (deuterium dilution), weight and body volume/density (air displacement plethysmography) [34]

An alternating current is applied, typically at the wrist and at the ankle of the patient, and the response is measured (resistance at reactance). Mono-frequency bioimpedance devices typically use a frequency of $50 \mathrm{kHz}$. Multifrequency bioimpedance devices typically use 5, 50 and $100 \mathrm{kHz}$. Empirical equations exist to convert measured impedances into fat mass and fat-free mass [48, 49]

BIVA combines the use of a monofrequency bioimpedance device with a graphical analysis. Reactance and impedance are normalized to the height of the patient and plotted against each other, and the vector of normalized resistance and reactance at $50 \mathrm{kHz}$ is drawn. Ellipses are set up, based on a healthy population. The position of the patient vector to the reference ellipses indicates the hydration status and the muscle mass of the patient [50]

Bioimpedance spectroscopy based on the functional principal of monofrequency bioimpedance. Instead of a single (or three) measurement frequencies, a whole sweep of frequencies is applied. A measurement frequency range from 5 to $1000 \mathrm{kHz}$ is covered. At very low frequencies, the current passes nearly exclusively round the cells, while at high frequencies the current passes through the cell membranes. This allows differentiation between extracellular and the intracellular compartments. Based on Cole modelling and the Hanai equations, the extracellular (ECW) and the intracellular water (ICW) can be determined [51-53]. The fat mass and the fatfree mass are estimated using empirical equations [48, 49]

Bioimpedance spectroscopy with physiological model uses the bioimpedance spectroscopy measurement technique described above. ECW and ICW are calculated using the Hanai and Cole model. Additionally, a sophisticated physiological model is applied that allows separation of the fluid overload from the muscle mass. The physiological model is based on normohydrated tissue properties and has been validated in various studies [21]
Bioimpedance spectroscopy with physiological model
In addition, certain biochemical tests may be employed, for example measurements

of serum albumin, pre-albumin, creatinine index, and protein catabolic rate. Table 3

provides an overview of which PEW relevant factors are included in the different 
Table 3 Comparison of different scores with subjective components for the assessment of protein energy wasting (PEW)

\begin{tabular}{lllllll}
\hline Test/parameter & SGA & MIS & MNA-SF & NRS & MUST & GNRI \\
\hline Weight loss & $\mathrm{X}$ & $\mathrm{X}$ & $\mathrm{X}$ & $\mathrm{X}$ & $\mathrm{X}$ & $\mathrm{X}$ \\
Dietary intake & $\mathrm{X}$ & $\mathrm{X}$ & $\mathrm{X}$ & $\mathrm{X}$ & - & - \\
Gastrointestinal symptoms & $\mathrm{X}$ & $\mathrm{X}$ & - & - & - & - \\
Comorbidity & $\mathrm{X}$ & $\mathrm{X}$ & $\mathrm{X}$ & $\mathrm{X}$ & - & - \\
Functional capacity & $\mathrm{X}$ & $\mathrm{X}$ & $\mathrm{X}$ & $\mathrm{X}$ & $\mathrm{X}$ & - \\
Signs of muscle/fat loss or edema & $\mathrm{X}$ & $\mathrm{X}$ & - & - & - & - \\
Psychological problems & - & - & $\mathrm{X}$ & - & - & - \\
Laboratory value (e.g. serum albumin) & - & $\mathrm{X}$ & - & - & - & $\mathrm{X}$ \\
\hline
\end{tabular}

SGA subjective global assessment, $M I S$ Malnutrition Inflammation Score, MNA-SF Mini Nutritional Assessment Short Form, NRS Nutritional Risk Score, MUST Malnutrition Universal Screening Tool, GNRI Geriatric Nutritional Risk Index

The ability to objectively identify reduced muscle mass is clearly critical for the diagnosis of PEW. Today, several methodologies are available targeting detection of changes in body composition and especially reductions in muscle mass (Table 2). These include anthropometric approaches, evaluation of creatinine generation ${ }^{13}$, dual-energy X-ray absorptiometry ${ }^{14}$ bioimpedance-based evaluations of body composition $^{14,15}$, and other methodologies less likely to be used in routine clinical practice (e.g. nuclear magnetic resonance, computerized tomography, total body nitrogen, and total body potassium $)^{16}$. In addition, an indirect assessment of muscle mass can be performed via muscle strength, i.e. by using hand-grip test, or via subjective evaluation of the daily routine activities, as reported in specific questions of the SF-36 questionnaire ${ }^{17}$.

\section{Special requirements for early identification of PEW}

A main target of nutrition status assessment is the detection of early warning indicators for PEW, especially as such may offer opportunities for timely interventions with the potential to stop ongoing cachectic processes. For the assessment of nutrition status it is essential to perform a precise and specific compartment evaluation, identifying fat mass, muscle mass and potential fluid 
overload separately. This compartmental approach is important as the therapeutic approaches to addressing impairments can be very different from compartment to compartment. For example, CKD patients can accumulate significant amounts of fat mass $^{18}$, but at the same time suffer from depletion in the muscle mass ${ }^{19,20}$, e.g. in protein energy malnutrition. Therefore, it is essential to assess fat and muscle mass independently. It is equally necessary to assess fluid overload independent from muscle mass and adipose mass: muscle is $72 \%$ water $^{21}$ and for every $1 \mathrm{~kg}$ of muscle mass a patient catabolizes $720 \mathrm{ml}$ of fluid will be released. In the case of a patient with CKD 5, this fluid will accumulate in the body. The weight of the patient will decrease slightly, but at the same time muscle mass is replaced by fluid volume. Various technical methods exist that can assess the different composition properties of the human body. Table 4 compares the different objective methods regarding their propensity for differentiation between the different body composition compartments fluid overload, fat mass and muscle mass.

\section{Which methods provide the best information?}

Methods for nutrition assessment are applied as diagnostic, prognostic and/or response-tracking tools. Which method is most suitable for which application is a matter of controversy since malnutrition is a continuum triggered by an imbalance between intake and requirements for energy, protein and other nutrients. In addition, these requirements also depend on the actual health status of the individual (i.e. healthy vs. chronically ill). Another important question to address is what exactly the different methods assess, and if they are actually capable of timely identification of PEW. Here it is important to separate between tools that are used for screening (like SGA) and methods that can be used for long-term follow-up of a patient (e.g. 
bioimpedance spectroscopy based on physiological models). Consequently, different methods can be used in different stages of malnutrition, taking into consideration that detectable alterations in body composition occur rather late in the development of PEW.

\begin{tabular}{|c|c|c|c|c|c|c|}
\hline Class & Objective method & $\begin{array}{l}\text { Fluid } \\
\text { over-load }\end{array}$ & Muscle & Fat & $\begin{array}{l}\text { Muscle }+ \text { fluid } \\
\text { together }\end{array}$ & $\begin{array}{l}\text { Fat }+ \text { muscle }+ \\
\text { fluid together }\end{array}$ \\
\hline \multirow[t]{5}{*}{ Anthro-pometrics } & Weight & - & - & - & - & $\mathrm{X}$ \\
\hline & BMI (body mass index) & - & - & - & - & $\mathrm{X}$ \\
\hline & Mid-arm circumference & - & - & - & - & $\mathrm{x}$ \\
\hline & Skin fold thickness & - & - & $\mathrm{x}$ & - & - \\
\hline & Waist-hip ratio & - & - & $\mathrm{X}$ (visceral) & - & - \\
\hline Functional test & Hand-grip strength & - & $\mathrm{x}$ & - & - & - \\
\hline \multirow[t]{6}{*}{ Body compo-sition } & DEXA (dual X-ray absorptiometry) & - & - & $\mathrm{X}$ & $\mathrm{x}$ & - \\
\hline & Four-compartment modeling & - & - & $\mathrm{X}$ & - & - \\
\hline & $\begin{array}{l}\text { Monofrequency BIA_phase angle } \\
50 \mathrm{kHz} \text {. Multifrequency BIA }\end{array}$ & - & - & $\mathrm{X}$ & $\mathrm{X}$ & - \\
\hline & $\begin{array}{l}\text { BIVA-bioimpedance vector } \\
\text { analysis }\end{array}$ & - & - & $\mathrm{X}$ & $\mathrm{X}$ & - \\
\hline & $\begin{array}{l}\text { Bioimpedance spectroscopy without } \\
\text { physiological model }\end{array}$ & - & - & $\begin{array}{l}X \text { (indicator for } \\
\text { nutrition status) }\end{array}$ & $\begin{array}{l}X \text { (indicator for } \\
\text { hydration status) }\end{array}$ & - \\
\hline & $\begin{array}{l}\text { Bioimpedance spectroscopy with } \\
\text { physiological model }\end{array}$ & $\mathrm{x}$ & $\mathrm{x}$ & $\mathrm{x}$ & - & - \\
\hline
\end{tabular}

The first fundamental classification of methods used to assess nutritional status categorizes these as being either subjective or objective in character. Table 3 provides an overview of the different malnutrition parameters tested by six recognized partially subjective methods. The subjective Global Assessment (SGA), the Malnutrition Inflammation Score (MIS) and the Mini Nutritional Assessment Short Form (MNA-SF) score cover a wider range of parameters than the Nutritional Risk Score (NRS), the Malnutrition Universal Screening Tool (MUST) and the Geriatric Nutritional Risk Index (GNRI). The SGA score is globally recognized as a validated tool for the cross-sectional assessment/screening for risk of PEW and also facilitates comparison of different populations ${ }^{22}$. In terms of nutritional dimensions, the SGA score offers the highest coverage. On the negative side, it requires clinical expertise for reliable application and is not sufficiently sensitive for longitudinal patient follow 
up, as subtle changes in nutrition status would not be detectable ${ }^{23}$. GNRI is the most restrictive method, assessing only weight loss and laboratory values. These tests are not set up to reflect the special conditions of CKD patients. In addition to the methods listed in Table 3, many other partially subjective tests exist, but the decision to use a particular tool has to be considered carefully since many of them have not been validated ${ }^{24}$.

Objective methods with high clinical applicability are essential for the diagnosis of PEW. As previously mentioned, a reliable diagnosis requires differentiation between the three main body composition compartments: fat mass, lean mass and fluid overload. Table 4 provides an overview of the ability of different objective methods to make such a differentiation. The advantages of the various methods depend on the exact kind of information they can provide, their ease of use, their respective costs and the respective clinical applicability.

From the anthropometric methods, neither weight, nor BMI nor mid-arm circumferences are able to differentiate between the different compartments (muscle mass, fat mass and fluid overload). Furthermore, the results can be affected by deviations in fluid balance in patients with $\mathrm{CKD}^{25}$. Consequently, large muscle mass and large fat mass will be interpreted in the same way when using these methods. Body fat accumulates to around $33 \%$ in subcutaneous tissue, to about $10 \%$ in intramuscular depots of males ( $4 \%$ in females), and to around $12 \%$ in visceral thoracic and abdominal fat depots in males ( $8 \%$ in females). Subcutaneous fat can be assessed by precision calipers, measuring the skin fold thickness. With skin fold thickness it is possible to get quite a good approximation for the fat mass but the results are highly clinician and device dependent, do not assess muscle mass and are affected by fluid overload and edema ${ }^{25}$. Consequently, the accuracy of the 
results is quite low, even more so in obese people. Experienced clinicians usually need to make three consecutive measurements and average the results. In addition, skin fold thickness represents the subcutaneous fat that differs by location in the body with a distribution that is gender specific ${ }^{25}$. Waist-hip ratio gives a good indicator for the amount of visceral fat, and is therefore a better marker for obesity and for the fat mass than weight or the BMI. However, in general, anthropometric measures are considered vulnerable to errors and are not recommended for diagnosing sarcopenia ${ }^{26}$. Finally, according to Vagianos et $\mathrm{al}^{27}$, one should consider that subjects who appear well-nourished according to anthropometric measures can actually be malnourished because of a deficiency in multiple micronutrients (e.g. iron, vitamin B6, vitamin D). This was shown in a study of patients with inflammatory bowel disease, but cannot be ruled out in CKD patients.

The value of functional methodology for nutritional or PEW assessment is still under discussion. Muscle strength has been shown to be positively associated with muscle mass and, possibly, negatively associated with inflammation ${ }^{28,29}$. However, a recent systematic review ${ }^{30}$ concluded that the protocol for hand-grip test is not standardized and that diagnostic criteria are still missing. Nevertheless, functional tests are generally considered a reliable indicator of short-term changes in nutrition status and surrogate of physical activity ${ }^{31}$.

Dual X-ray absorptiometry (DEXA) provides precise assessment of the fat mass and is sometimes regarded as the "gold standard" for the fat mass assessment ${ }^{32}$. DEXA was able to detect significant increases in fat mass and significant decreases in lean body mass during the first year on hemodialysis treatment ${ }^{33}$. Pitfalls of this method are its complexity and cost, thereby limiting its clinical practicability, especially in the measurement of obese patients. In addition, this method cannot provide diagnostic 
separation of muscle mass and fluid overload. The best method for assessing fat mass in patients with an impaired fluid status is the four-compartment model, which takes into account the bone mineral mass measured with DEXA, the total water content of the body assessed with Deuterium dilution, the weight of the patients, and the density assessed with air displacement plethysmography ${ }^{34}$. This method can be regarded as a further development of the DEXA assessment of fat mass in patients with an impaired renal function, but is very complex in its application.

Bioimpedance analysis (BIA) methods, on the other hand, are comparatively inexpensive and easily applicable. In addition, they can be repeated frequently due to their non-invasive nature, i.e. patients are not exposed to additional health risks such as radiation. There are several different types of bioimpedance methods available today, and the results may vary depending on which type is applied. The simple mono-frequency or multifrequency bioimpedance analysis (BIA) methods are limited in their validity for CKD patients. This is especially because the empirical equations used here to convert measured impedances into clinically meaningful information were developed for healthy subjects, and the results cannot be extrapolated to a CKD population with markedly impaired hydration status. As a consequence, simple mono-frequency or multifrequency BIA cannot distinguish muscle mass from the fluid overload. However, by measuring the phase angle (i.e. the angular transformation of the ratio between reactance and resistance), one can anticipate the change in biochemical nutritional parameters ${ }^{35}$. Accordingly, by using single frequency BIA it was possible to unveil the risk of malnutrition also in apparently healthy overweight and obese patients on hemodialysis ${ }^{36}$, including also those on the waiting list for kidney transplantation ${ }^{37}$. The Bioimpedance Vector Analysis (BIVA) is a more advanced methodology. However, this also does not 
provide absolute values of the various body composition compartments, and the results are always relative to the respective healthy reference population. It also cannot separate fat and fluid compartments. Bioimpedance spectroscopy without a physiological model provides a precise assessment of the extracellular and total body water. The extra- and intracellular compartments are distinguished already on measurement by using a frequency sweep from $3-5 \mathrm{kHz}$ up to $1000 \mathrm{kHz}$. The body composition (fat free mass and fat mass) is then calculated using empirical equations and the resistance and reactance values of the $50 \mathrm{kHz}$ frequency measurement ${ }^{38}$. These equations are identical to the equations used in the mono and multifrequency bioimpedance methods and are not valid in CKD patients. Furthermore, the important fluid overload compartment cannot be determined.

The Bioimpedance Spectroscopy method with physiological model is the only method available today that is able to distinguish between the 3 different body compartments. The well-validated physiological model ${ }^{39}$ facilitates separation of the body into the three essential compartments, lean body mass, adipose tissue mass, and fluid overload. Therefore, the Bioimpedance Spectroscopy method with physiological model is the only clinically practical method that allows the diagnostic separation necessary for the diagnosis of PEW. Ratios of intracellular water or extracellular water to body weight, assessed with bioimpedance spectroscopy were found to be good markers of nutrition status in a Portuguese study of $75 \mathrm{HD}$ patients ${ }^{40}$. Using the same method, Rosenberger et $\mathrm{al}^{41}$ recently showed that lean tissue index levels in hemodialysis patients below the $10^{\text {th }}$ percentile of an age and gender matched distribution in the normal population are associated with a significant $66 \%$ higher relative risk for mortality. Applying the same type of BIA, Broers et $\mathrm{al}^{42}$ were able to detect a seasonal pattern to body composition and 
hydration state, thereby potentially facilitating longitudinal evaluation of nutritional status.

\section{The additional value of laboratory tests}

Despite our focus on physical measurements for nutritional assessment, laboratory measurements relevant to nutritional assessment should also be mentioned here. These are mainly albumin, pre-albumin, creatinine index and protein catabolic rate. Micro-nutrients are sometimes also measured in CKD patient laboratory tests (e.g. serum iron, vitamin D), but will not be discussed here. Serum albumin is not only a marker of visceral proteins, but also of overhydration and inflammation ${ }^{43,44}$. Therefore it is not the best indicator to assess nutrition status and, according to Fuhrman ${ }^{45}$, may be a more appropriate indicator for disease severity. Pre-albumin (transthyretin) is believed to be a better nutritional indicator than albumin, with higher sensitivity because of its shorter half-life (2.5 days $)^{46}$. However, this may have limitations similar to albumin, and is not a standard laboratory parameter that is checked in CKD and dialysis patients. In patients with healthy metabolic status, creatinine generation is an indicator of muscle mass. In CKD patients, serum creatinine reflects muscle mass but is affected by renal function. For patients on dialysis, serum levels then also depend on dialysis dose $(\mathrm{Kt} / \mathrm{V})$ due to the small molecular weight and removal of creatinine during treatment. Canaud et $\mathrm{al}^{13}$ developed a simplified formula to derive creatinine generation in dialysis patients from a combination of serum creatinine levels, $\mathrm{Kt} / \mathrm{V}$ and anthropometric measures. However, this inexpensive indicator, even if potentially useful for monitoring the lean body mass of patients on dialysis, has its limitations in the high prevalence of 
protein-energy wasting, the interference of dietary meat intake and the associated catabolic status. Finally, protein catabolic rate $(\mathrm{nPCR})$ is considered a surrogate marker for dietary protein intake. In stable CKD patients this is estimated from the nitrogen balance (24-hour urine collection), whereas in patients on hemodialysis it is mainly derived from $\mathrm{Kt} / \mathrm{V}$. Again, it can be considered a reliable nutritional indicator only under stable metabolic conditions.

\section{Summary}

This review of currently available methods to assess nutrition status showed that no single approach and no single marker is able to detect alterations in nutrition status in a timely fashion and to follow such changes over time. This is especially the case for patients with CKD and for patients on dialysis where issues of fluid overload may affect the results. Overall, the ideal nutrition assessment tool has to be specific, reliable, inexpensive, non-invasive and easy to use. Considering the intrinsic limitations of all nutritional markers, we support the multi-perspective approach with a combination of measures and a stepwise procedure:

1. A subjective clinical assessment, relying on validated SGA for screening and early detection of malnutrition; and

2. An assessment of the body composition by bioimpedance spectroscopy with the physiological model for quantifying and ensuring follow up of patients at risk of malnutrition, or patients with already established PEW, also in order to verify medium to long term improvement after the initiation of a nutritional therapy.

3. Use of available laboratory parameters, such as albumin or CRP for inflammation. 
Special focus should be placed on patients at higher risk of PEW, such as diabetics, patients after failed kidney transplantation, and patients transferred from previous peritoneal dialysis treatment. A major advantage of bioimpedance spectroscopy with physiological model in CKD patients is the fact that it is the only method that is able to detect fluid overload. This method should be used on a routine basis not only in all CKD 5 but also already in the CKD 3 and 4 stages. Hand-grip tests may be very useful for early detection and even for short-term evaluation of a corrective therapy, but the current lack of standardization remains problematic.

In summary, the most clinically relevant approach to assessing nutrition status in hemodialysis patients presently appears to be the combination of the SGA method with the bioimpedance spectroscopy technique with physiological model and, additionally, laboratory tests for the detection of micro-nutrient deficiency, specifically in a very early phase of malnutrition.

\section{Reference List}

1. Ikizler TA. Nutrition, inflammation and chronic kidney disease. Curr Opin Nephrol Hypertens. 2008;17(2):162-167.

2. Pupim LB, Caglar K, Hakim RM, Shyr Y, Ikizler TA. Uremic malnutrition is a predictor of death independent of inflammatory status. Kidney Int. 2004;66(5):2054-2060.

3. Mak RH, Cheung W. Energy homeostasis and cachexia in chronic kidney disease. Pediatr Nephrol. 2006;21(12):1807-1814.

4. Lindholm B, Heimburger $O$, Stenvinkel P. What are the causes of protein-energy malnutrition in chronic renal insufficiency? Am J Kidney Dis. 2002;39(2):422-425.

5. Pecoits-Filho R, Lindholm B, Stenvinkel P. The malnutrition, inflammation, and atherosclerosis (MIA) syndrome -- the heart of the matter. Nephrology, dialysis, transplantation : official publication of the European Dialysis and Transplant Association European Renal Association. 2002;17 Suppl 11:28-31.

6. Kalantar-Zadeh K, Ikizler TA, Block G, Avram MM, Kopple JD. Malnutrition-inflammation complex syndrome in dialysis patients: causes and consequences. Am J Kidney Dis. 2003;42(5):864-881.

7. Fouque D, Kalantar-Zadeh K, Kopple J, et al. A proposed nomenclature and diagnostic criteria for protein-energy wasting in acute and chronic kidney disease. Kidney Int. 2008;73(4):391398.

8. Kimmel PL, Phillips TM, Simmens SJ, et al. Immunologic function and survival in hemodialysis patients. Kidney Int. 1998;54(1):236-244. 
9. Zimmermann J, Herrlinger S, Pruy A, Metzger T, Wanner C. Inflammation enhances cardiovascular risk and mortality in hemodialysis patients. Kidney Int. 1999;55(2):648-658.

10. Borrego Utiel FJ, Segura Torres P, Perez del Barrio MP, et al. How do disorders related to hospitalisation influence haemodialysis patients' nutrition? Nefrologia. 2011;31(4):471-483.

11. Ikizler TA, Wingard RL, Harvell J, Shyr Y, Hakim RM. Association of morbidity with markers of nutrition and inflammation in chronic hemodialysis patients: a prospective study. Kidney Int. 1999;55(5):1945-1951.

12. Fouque D, Vennegoor $\mathrm{M}$, ter Wee $\mathrm{P}$, et al. EBPG guideline on nutrition. Nephrology, dialysis, transplantation : official publication of the European Dialysis and Transplant Association European Renal Association. 2007;22 Suppl 2:ii45-87.

13. Canaud B, Granger Vallee A, Molinari N, et al. Creatinine index as a surrogate of lean body mass derived from urea $\mathrm{Kt} / \mathrm{V}$, pre-dialysis serum levels and anthropometric characteristics of haemodialysis patients. PLoS One. 2014;9(3):e93286.

14. Donadio C, Halim AB, Caprio F, Grassi G, Khedr B, Mazzantini M. Single- and multi-frequency bioelectrical impedance analyses to analyse body composition in maintenance haemodialysis patients: comparison with dual-energy $\mathrm{x}$-ray absorptiometry. Physiol Meas. 2008;29(6):S517-524.

15. Wieskotten $S$, Heinke $S$, Wabel $P$, et al. Bioimpedance-based identification of malnutrition using fuzzy logic. Physiol Meas. 2008;29(5):639-654.

16. Cohn SH, Vaswani AN, Yasumura S, Yuen K, Ellis KJ. Assessment of cellular mass and lean body mass by noninvasive nuclear techniques. J Lab Clin Med. 1985;105(3):305-311.

17. Gomez-Besteiro MI, Santiago-Perez MI, Alonso-Hernandez A, Valdes-Canedo F, RebolloAlvarez $\mathrm{P}$. Validity and reliability of the SF-36 questionnaire in patients on the waiting list for a kidney transplant and transplant patients. Am J Nephrol. 2004;24(3):346-351.

18. Pupim LB, Kent P, Caglar K, Shyr Y, Hakim RM, Ikizler TA. Improvement in nutritional parameters after initiation of chronic hemodialysis. Am J Kidney Dis. 2002;40(1):143-151.

19. Johansen KL, Kaysen GA, Young BS, Hung AM, da Silva M, Chertow GM. Longitudinal study of nutritional status, body composition, and physical function in hemodialysis patients. Am J Clin Nutr. 2003;77(4):842-846.

20. Raffaitin $C$, Lasseur $C$, Chauveau $P$, et al. Nutritional status in patients with diabetes and chronic kidney disease: a prospective study. Am J Clin Nutr. 2007;85(1):96-101.

21. Chamney PW, Wabel P, Moissl UM, et al. A whole-body model to distinguish excess fluid from the hydration of major body tissues. Am J Clin Nutr. 2007;85(1):80-89.

22. Barbosa-Silva MC. Subjective and objective nutritional assessment methods: what do they really assess? Curr Opin Clin Nutr Metab Care. 2008;11(3):248-254.

23. Meireles MS, Wazlawik E, Bastos JL, Garcia MF. Comparison between nutritional risk tools and parameters derived from bioelectrical impedance analysis with subjective global assessment. J Acad Nutr Diet. 2012;112(10):1543-1549.

24. Green SM, Watson R. Nutritional screening and assessment tools for older adults: literature review. J Adv Nurs. 2006;54(4):477-490.

25. Mathew S, Abraham G, Vijayan M, et al. Body composition monitoring and nutrition in maintenance hemodialysis and CAPD patients--a multicenter longitudinal study. Ren Fail. 2015;37(1):66-72.

26. Cruz-Jentoft AJ, Baeyens JP, Bauer JM, et al. Sarcopenia: European consensus on definition and diagnosis: Report of the European Working Group on Sarcopenia in Older People. Age Ageing. 2010;39(4):412-423.

27. Vagianos K, Bector S, McConnell J, Bernstein CN. Nutrition assessment of patients with inflammatory bowel disease. JPEN J Parenter Enteral Nutr. 2007;31(4):311-319.

28. Pham NV, Cox-Reijven PL, Wodzig WK, Greve JW, Soeters PB. SGA and measures for muscle mass and strength in surgical Vietnamese patients. Nutrition. 2007;23(4):283-291. 
29. Nascimento MM, Qureshi AR, Stenvinkel $P$, et al. Malnutrition and inflammation are associated with impaired pulmonary function in patients with chronic kidney disease. Nephrology, dialysis, transplantation : official publication of the European Dialysis and Transplant Association - European Renal Association. 2004;19(7):1823-1828.

30. Leal VO, Mafra D, Fouque D, Anjos LA. Use of handgrip strength in the assessment of the muscle function of chronic kidney disease patients on dialysis: a systematic review. Nephrology, dialysis, transplantation : official publication of the European Dialysis and Transplant Association - European Renal Association. 2011;26(4):1354-1360.

31. Schlussel MM, dos Anjos LA, de Vasconcellos MT, Kac G. Reference values of handgrip dynamometry of healthy adults: a population-based study. Clin Nutr. 2008;27(4):601-607.

32. Stenver DI, Gotfredsen A, Hilsted J, Nielsen B. Body composition in hemodialysis patients measured by dual-energy X-ray absorptiometry. Am J Nephrol. 1995;15(2):105-110.

33. Ishimura $\mathrm{E}$, Okuno S, Kim M, et al. Increasing body fat mass in the first year of hemodialysis. $J$ Am Soc Nephrol. 2001;12(9):1921-1926.

34. Fuller NJ, Jebb SA, Laskey MA, Coward WA, Elia M. Four-component model for the assessment of body composition in humans: comparison with alternative methods, and evaluation of the density and hydration of fat-free mass. Clin Sci (Lond). 1992;82(6):687-693.

35. Maggiore Q, Nigrelli S, Ciccarelli C, Grimaldi C, Rossi GA, Michelassi C. Nutritional and prognostic correlates of bioimpedance indexes in hemodialysis patients. Kidney Int. 1996;50(6):2103-2108.

36. Guida B, De Nicola L, Pecoraro P, et al. Abnormalities of bioimpedance measures in overweight and obese hemodialyzed patients. Int J Obes Relat Metab Disord. 2001;25(2):265-272.

37. Guida B, Trio R, Nastasi A, et al. Body composition and cardiovascular risk factors in pretransplant hemodialysis patients. Clin Nutr. 2004;23(3):363-372.

38. Presta E, Segal KR, Gutin B, Harrison GG, Van Itallie TB. Comparison in man of total body electrical conductivity and lean body mass derived from body density: validation of a new body composition method. Metabolism. 1983;32(5):524-527.

39. Wabel P, Chamney P, Moissl U, Jirka T. Importance of whole-body bioimpedance spectroscopy for the management of fluid balance. Blood Purif. 2009;27(1):75-80.

40. Garagarza C, Joao-Matias P, Sousa-Guerreiro C, et al. Nutritional status and overhydration: can bioimpedance spectroscopy be useful in haemodialysis patients? Nefrologia. 2013;33(5):667-674.

41. Rosenberger J, Kissova V, Majernikova M, Straussova Z, Boldizsar J. Body composition monitor assessing malnutrition in the hemodialysis population independently predicts mortality. J Ren Nutr. 2014;24(3):172-176.

42. Broers NJ, Usvyat LA, Marcelli D, et al. Season affects body composition and estimation of fluid overload in haemodialysis patients: variations in body composition; a survey from the European MONDO database. Nephrology, dialysis, transplantation : official publication of the European Dialysis and Transplant Association - European Renal Association. 2015;30(4):676681.

43. Marcelli D, Di Benedetto A, Ciotola A, Grassmann A, Canaud B. Subjective global assessment scores have poor correlation with serum albumin in obese hemodialysis patients by Eric $D$. Erb, Rosa K. Hand, and Alison L. Steiber. J Ren Nutr. 2014;24(6):432-433.

44. Friedman AN, Fadem SZ. Reassessment of albumin as a nutritional marker in kidney disease. J Am Soc Nephrol. 2010;21(2):223-230.

45. Fuhrman MP. The albumin-nutrition connection: separating myth from fact. Nutrition. 2002;18(2):199-200.

46. Spiekerman AM. Nutritional assessment (protein nutriture). Anal Chem. 1995;67(12):429R436R. 
Physical methods for evaluating the nutritional status of hemodialysis patients 


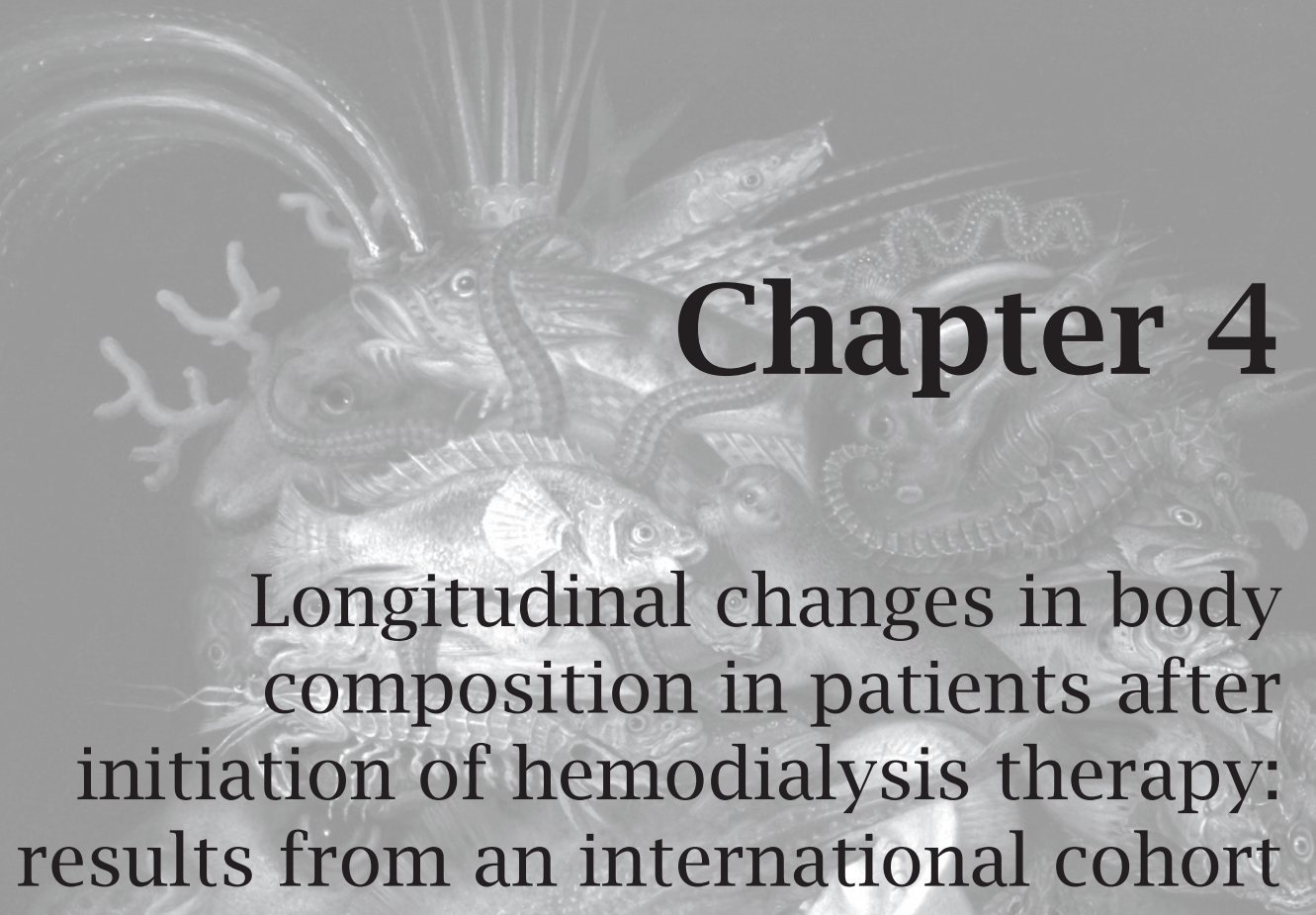

Daniele Marcelli, Katharina Brand, Pedro Ponce, Andrzej Milkowski, Cristina Marelli, Ercan Ok, Jose-Ignacio Merello Godino, Konstantin Gurevich, Tomas Jirka, Jaroslav Rosenberger, Attilio Di Benedetto, Erzsebet Ladanyi, Aileen Grassmann, Laura Scatizzi, Inga Bayh, Jeroen Kooman and Bernard Canaud

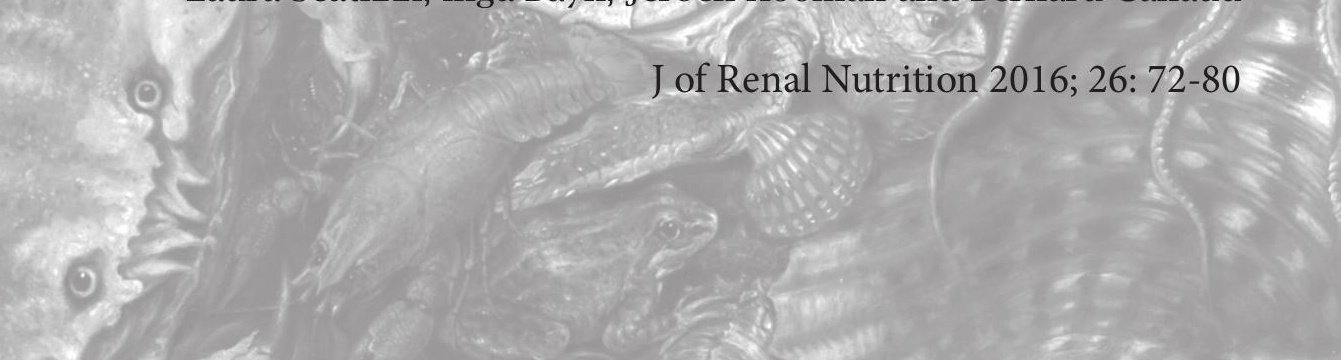


Abstract

\section{Objective}

In patients with advanced kidney disease, metabolic and nutritional derangements induced by uremia interact and reinforce each other in a deleterious vicious circle. Literature addressing the effect of dialysis initiation on changes in body composition (BC) is limited and contradictory. Aim of this study was to evaluate changes in $\mathrm{BC}$ in a large international cohort of incident hemodialysis patients.

\section{Methods}

8227 incident adult ESRD patients with BC evaluation within the initial first 6 months of baseline, defined as 6 months after RRT initiation, were considered. Body composition, including fat tissue index $(\mathrm{FTI})$ and lean tissue index (LTI), were evaluated by Body Composition Monitor ${ }^{\circledR}$ (BCM, Fresenius Medical Care, Bad Homburg, Germany). Exclusion criteria at baseline were lack of a BCM measurement before or after baseline, BMI $<18.5 \mathrm{~kg} / \mathrm{m}^{2}$, presence of metastatic solid tumors, treatment with a catheter, and prescription of less or more than 3 treatments per week. Maximum follow-up was 2 years. Descriptive analysis was performed comparing current values with the baseline in each time interval (delta analysis). Linear mixed models considering the correlation structure of the repeated measurements were used to evaluate factors associated with different trends in FTI and LTI.

\section{Results}

BMI increased about $0.6 \mathrm{~kg} / \mathrm{m}^{2}$ over 24 months from baseline. This was associated with increase in FTI of about $0.95 \mathrm{~kg} / \mathrm{m}^{2}$ and a decrease in LTI of about $0.4 \mathrm{~kg} / \mathrm{m}^{2}$. Female gender, diabetic status and low baseline FTI were associated with a significant greater increase of FTI. Age $>67$ years, diabetes, male gender, high baseline LTI and low baseline FTI were associated with a significantly greater decrease of LTI.

\section{Conclusions}

With the transition to hemodialysis, ESRD patients presented with distinctive changes in BC. These were mainly associated with gender, older age, presence of diabetes, low baseline FTI and high baseline LTI. BMI increases did not fully represent the changes in body composition. 


\section{Introduction}

The prevalence of protein-energy wasting is very high in dialysis patients ${ }^{1}$ because of the synergic contribution of decreased protein and/or energy intake, chronic inflammation, physical inactivity, concurrent acute or chronic conditions or illness, and catabolism induced by hemodialysis process. ${ }^{2}$ On the basis of the repetitive and prolonged nature of these processes, a deterioration of the nutritional status should be concurrent, and longitudinal studies should capture their close association.

However, the initiation of hemodialysis might also improve nutritional state, e.g. by improving appetite due to the partial reversal of the uremic state and correction of metabolic acidosis. Pupim et $\mathrm{al}^{3}$ in 2002 showed that the initiation of hemodialysis was associated with significant improvement of most nutritional markers, including albumin, prealbumin, dietary protein intake derived from nitrogen appearance rate (nPCR), and body composition such as fat mass $(1.29 \pm 2.20 \mathrm{~kg})$. Vendrely et $\mathrm{al}^{4}$, in a study evaluating the fat and lean body mass development during the first year on hemodialysis in 15 patients previously treated with supplemented very low protein diet and 15 patients on less restricted diet, found a significant increase in fat mass (12.6 $\pm 18.7 \%$ and $16.6 \pm 16.1 \%$, respectively). Lean mass remained stable overall in the two groups of patients. On the other hand, other studies showed that lean body mass significantly decreased after 24 months. $^{3,5}$ The increase in albumin and creatinine levels during the first 6 months of hemodialysis also reported by Goldwasser et $\mathrm{al}^{6}$ can be explained by the decline of renal function and the progressive retention of proteins and creatinine. A study by Raffaitin et $\mathrm{al}^{7}$ on a group of 10 diabetic patients starting dialysis and monitored by means of DXA confirmed a significant decrease in lean tissue mass and serum albumin over a period of two years. 
A more recent study from Mathew et $\mathrm{al}^{8}$, evaluating 41 prevalent hemodialysis or peritoneal dialysis patients surviving 24 months after their baseline anthropometric evaluation, showed a significant increase in triceps and biceps skin fold thicknesses and mid-arm circumference. Finally, Kalantar-Zadeh et al ${ }^{9}$ evaluated the body fat in 535 prevalent hemodialysis patients by near infrared interactance. After 6 months they found that the 411 patients still on follow-up were stratified as follows: $27.5 \%$ with significant fat loss and $29.9 \%$ with significant fat gain. Similarly, Johansen et $\mathrm{al}^{10}$, evaluating 54 prevalent hemodialysis patients with 4 measurements of fat mass and lean mass by DEXA over a year, did not find any significant trend.

In summary, the number of studies evaluating changes in nutritional parameters after the initiation of dialysis is limited and largely based on longitudinal studies in prevalent patients, often with contradictory results. This observational study in a large cohort of incident hemodialysis patients regularly monitored with bioimpedance spectroscopy aims to assess changes in body composition in the initial phase of renal replacement therapy.

\section{Methods}

The study population was extracted from a database of 49,846 patients on hemodialysis treatment in 417 NephroCare centres throughout 21 countries in Europe, Latin America and South Africa between January 1, 2007 and January 1, 2014. Patients were included if they were no longer than 6 months on RRT before admission to the unit (incident patients only) and if they underwent evaluation of body composition using the Body Composition Monitor $\left(\mathrm{BCM}^{\circledR}\right.$, Fresenius Medical Care, Germany). Baseline was defined as six months after hemodialysis initiation. 
Baseline values were defined as the mean of all measurements in the last 5 months before baseline (baseline period, Figure 1). Patients were followed for a maximum of 2 years. Patients without at least one BCM-measurement before and after baseline (defined as 6 months after RRT initiation) were excluded. In order to focus on a homogenous well-treated hemodialysis population and to avoid including patients already having a poor outcome at study start, patients were also excluded who were malnourished $\left(\mathrm{BMI}<18.5 \mathrm{~kg} / \mathrm{m}^{2}\right)$, had metastatic solid tumors, were receiving less or more than 3 treatments per week, or were treated with a catheter at baseline.

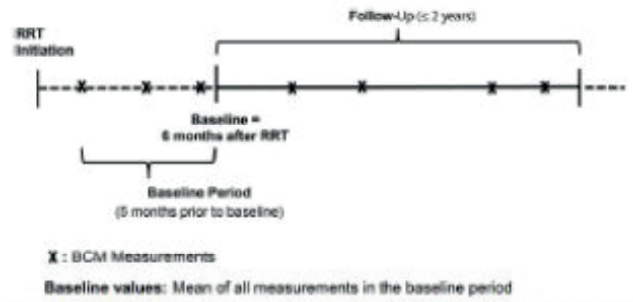

Figure 1. Study design. Hypothetical BCM measurement times are indicated with " $\mathrm{x}$ " as Body Composition Monitor (BCM) measurements were not done at strictly regular intervals. Body composition measurement was conducted with the BCM (FMC, Bad Homburg, Germany). RRT, renal replacement therapy.

Anonymized patient data were accessed through the European Clinical Database (EuCliD), which has been described elsewhere. ${ }^{11,12}$ All patients consented that their data may be used for scientific research in anonymized form.

Lean Tissue Index ( $\mathrm{LTI})$ and Fat Tissue Index $(\mathrm{FTI})$ were calculated as the ratio of the respective tissue masses divided by the height in meters squared. The definition of the age- and gender-dependent reference groups of LTI and FTI, respectively, was based on an evaluation of 1000 healthy individuals: "normal" LTI and FTI were defined as levels between the $10^{\text {th }}$ and $90^{\text {th }}$ percentile of the normal LTI or FTI 
distribution, respectively, whereas "low" is defined as under the $10^{\text {th }}$ percentile and "high" as above the $90^{\text {th }}$ percentile of the respective normal distributions. ${ }^{13}$

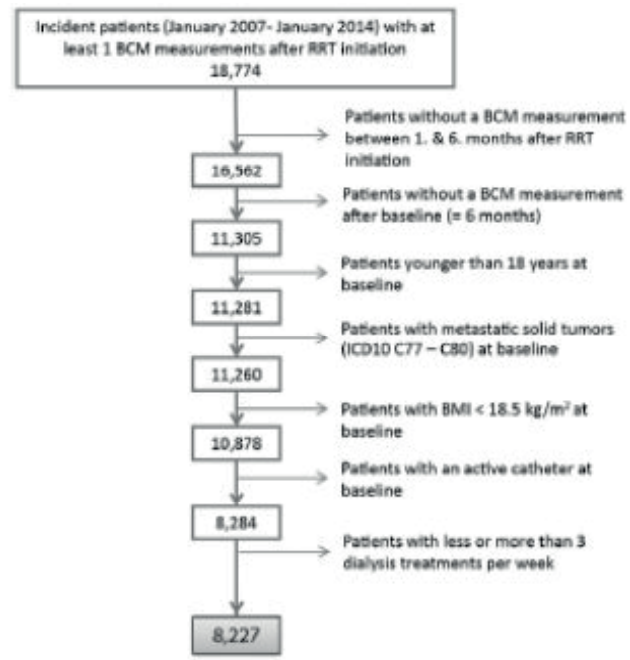

Figure 2. Patient selection. Body composition measurement was conducted with the Body Composition Monitor (BCM: FMC, Bad Homburg, Germany). BMI, body mass index: ICD, International Classification of Diseases; RRT, renal replacement therapy.

Lean tissue index and fat tissue index were evaluated at intervals defined according to the network policy using the $\mathrm{BCM}^{\circledR}$ (FMC, Bad Homburg, Germany), which is based on multifrequency bioimpedance spectroscopy at 50 different frequencies ranging between 5 and $1000 \mathrm{kHz}$. $\mathrm{BCM}^{\circledR}$ measures overhydration, total body water (TBW in L), extracellular water (ECW in L), intracellular water (ICW in L), fat tissue mass (FTM in $\mathrm{Kg}$ ), lean tissue mass (LTM in $\mathrm{Kg}$ ) and body cell mass. BCM has been validated against the following gold standard reference methods: bromide dilution for ECW, total body potassium for ICW, deuterium dilution for TBW, dual X-ray absorptiometry for LTM, four compartment modelling, air displacement plethysmography, under water weighing for adipose tissue mass, magnet resonance 
Body composition changes in incident dialysis patients

tomography for body cell mass and an expert clinical assessment for overhydration. $^{14}$

\section{Statistical analysis}

The outcomes body mass index (BMI), lean tissue index (LTI) and fat tissue index (FTI) were analysed to evaluate the nutrition status of the patients. Descriptive analysis was performed comparing current values for each patient with their baseline values for each 1-month interval (Delta-analysis). In cases without a measurement in the interval, the value of the previous interval was used (last observation carried forward).

To analyse differences between certain patient groups in the development of BMI, LTI and FTI, linear mixed models were used. We applied an autoregressive process of first order as covariance structure to consider the specific structure of the repeated measurements in irregular time intervals. For each outcome (BMI, LTI and FTI) a separate mixed model with an adjustment for the three cardiovascular comorbidities chronic ischemic heart disease (ICD10 code I25), heart failure (ICD10 code I50) and peripheral arterial diseases (PAD) (ICD 10 codes I70-179) were fitted. In each model the time (in days) was included as covariate. In addition, the factors gender, age (in tertiles: 18-56; 57-66; $\geq 67$ ), diabetes, LTI- and FTI-reference groups (“Low”, "Normal", "High") were included as main effects and as interactions with time. The main effects show average differences in the body composition between certain subgroups. Interaction terms between the factors and the time are used to identify if the changes in BMI, FTI and LTI differ in these subgroups over time during the 2 years of follow-up. 
All covariates were categorical and therefore were included in the model as dummyvariables. The corresponding reference categories are reported in the tables in the Results section. Because of the high number of covariates, Akaike information criterion (AIC) was used to select covariates. AIC model selection balances between the goodness of fit and the complexity of the model and can therefore result in exclusion of some covariates that have a low impact on the outcome. The analysis was conducted with the statistical software SAS, version 9.4.

\section{Results}

Patient selection is shown in Figure 2. After the selection process 8227 patients out of the original 49,846 patients were recruited. Baseline characteristics are displayed in Table 1. During the baseline period patients had a median of 4 (interquartile range (IQR): 2-5) BCM measurements. On average, patients had a median of 7 (IQR: 3-14) BCM measurements after baseline, the last of which was in mean 319 days after baseline. Figure 3 shows the means of the delta analyses. In two years of follow-up, the BMI increased by $\sim 0.6 \mathrm{~kg} / \mathrm{m}^{2}$ (or $2.2 \%$ ). This change was mainly the result of an increase of $0.95 \mathrm{~kg} / \mathrm{m}^{2}(7.4 \%)$ in FTI and a decrease of $0.4 \mathrm{~kg} / \mathrm{m}^{2}(3.1 \%)$ in LTI. These changes in BMI, FTI and LTI were significant for all intervals $(p<0.001$, paired t-tests). 
Table 1. Patient Characteristics at Baseline

\begin{tabular}{|c|c|}
\hline List of Variables & \\
\hline \multicolumn{2}{|l|}{ General characteristics } \\
\hline \multicolumn{2}{|l|}{ Area $(\mathrm{N})$} \\
\hline West Europe & 2,459 \\
\hline East Europe & 4,922 \\
\hline Latin America and South Africa & 846 \\
\hline Age (y; mean $\pm S D)$ & $61.46 \pm 14.65$ \\
\hline \multicolumn{2}{|l|}{ Age groups (\%) } \\
\hline$\geq 18-<57 y$ & 33.27 \\
\hline$\geq 57-<67 y$ & 27.15 \\
\hline$\geq 67 y$ & 39.58 \\
\hline Gender (female, \%) & 36.38 \\
\hline \multicolumn{2}{|l|}{ Body composition } \\
\hline Dialysis post weight $(\mathrm{kg}$; mean $\pm \mathrm{SD}$ ) & $71.93 \pm 15.05$ \\
\hline $\begin{array}{l}\text { BMI: body mass index } \\
\left(\mathrm{kg} / \mathrm{m}^{2} ; \text { mean } \pm \mathrm{SD}\right)\end{array}$ & $26.78 \pm 5.15$ \\
\hline $\begin{array}{l}\text { LTI: lean tissue index } \\
\quad\left(\mathrm{kg} / \mathrm{m}^{2} ; \text { mean } \pm \mathrm{SD}\right)\end{array}$ & $13.10 \pm 2.84$ \\
\hline \multicolumn{2}{|l|}{ LTI-reference groups (\%) } \\
\hline Low LT & 42.68 \\
\hline Normal LT & 54.30 \\
\hline High LTI & 3.03 \\
\hline $\mathrm{FTl}$ : fat tissue index $\left(\mathrm{kg} / \mathrm{m}^{2}\right.$; mean $\left.\pm \mathrm{SD}\right)$ & $12.76 \pm 6.01$ \\
\hline \multicolumn{2}{|l|}{ FTI-reference groups (\%) } \\
\hline Low FTI & 7.80 \\
\hline Normal FT & 72.14 \\
\hline High FTI & 3.03 \\
\hline $\begin{array}{l}\text { Pre-dialysis overhydration } \\
\text { (L: mean } \pm \mathrm{SD} \text { ) }\end{array}$ & $2.02 \pm 1.74$ \\
\hline $\begin{array}{l}\text { Post-dialysis overtydration } \\
\text { (L; mean } \pm \text { SD) }\end{array}$ & $-0.18 \pm 1.94$ \\
\hline \multicolumn{2}{|l|}{ Comorbidities } \\
\hline \multicolumn{2}{|l|}{ Charlson Comorbidity Index (\%) } \\
\hline 2 & 46.36 \\
\hline 3 & 15.24 \\
\hline 4 & 21.16 \\
\hline$\geq 5$ & 17.24 \\
\hline Diabetes (\%) & 32.88 \\
\hline Chronic ischemic heart disease (\%) & 13.57 \\
\hline Heart failure (\%) & 8.12 \\
\hline Arrhythmia (\%) & 8.64 \\
\hline Peripheral artery disease (\%) & 13.68 \\
\hline Stroke $(\%)$ & 8.21 \\
\hline Cirrhosis (\%) & 0.82 \\
\hline Malignancies (\%) & 6.70 \\
\hline Respiratory diseases (\%) & 6.32 \\
\hline \multicolumn{2}{|l|}{ Laboratory values } \\
\hline Albumin (g/dL; mean $\pm \mathrm{SD})$ & $3.81 \pm 0.41$ \\
\hline CRP (mg/L; median; interquartile range) & $6.0(2.47-14.45)$ \\
\hline Hemoglobin ( $g / d \mathrm{dL} ;$ mean $\pm \mathrm{SD})$ & $10.90 \pm 1.24$ \\
\hline Creatinine pre $(\mathrm{mg} / \mathrm{dl}$; mean $\pm \mathrm{SD}$ ) & $7.10 \pm 3.99$ \\
\hline Phosphate $(\mathrm{mg} / \mathrm{dL}$; mean $\pm \mathrm{SD})$ & $4.81 \pm 1.23$ \\
\hline Total cholesterol (mg/dL; mean $\pm S D$ ) & $174.34 \pm 44.07$ \\
\hline Equilibrated $\mathrm{Kt} / \mathrm{N}$ (mean $\pm \mathrm{SD})$ & $1.36 \pm 0.30$ \\
\hline
\end{tabular}

CRP, C-reactive protein; SD, standard deviation.

Details of patient numbers per country and of countries per geographical region: West Europe - France (211), Italy (271), Portugal $(1,216)$, Spain (742), and the United Kingdom (19); East Europe = Bosnia (219), Croatia (4), Czech Republic (421), Estonia (8), Hungary (241), Poland (931), Romania (1,129), Russia (727), Serbia (90), Slovakia (319), Slovenia (64), Sweden (4), and Turkey (765); Latin America and South Africa = Chile (33), Colombia (797), and South Africa (16). 
The results of the linear mixed models for the outcomes BMI, FTI and LTI are shown in Tables 2-4. All covariates are listed with the appropriate reference categories and the estimations for the specified groups, the standard errors and the p-values. The results for the time-interactions are highlighted in the following, these being most relevant to the study aim.

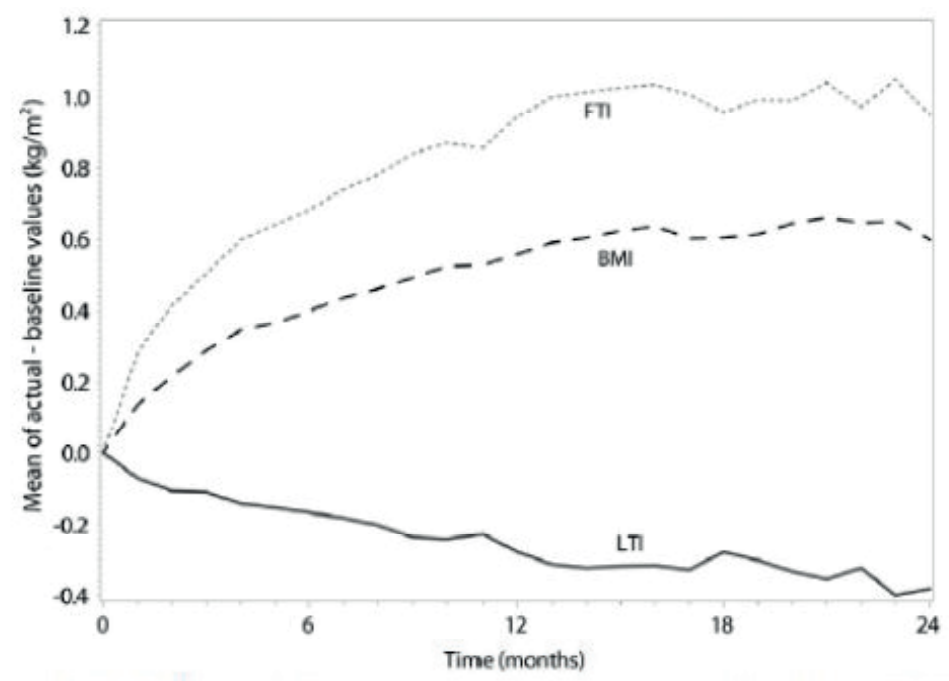

Figure 3. Delta analysis comparing current values of BMI, $\mathrm{LTI}$, and FTI with baseline values. BMI, body mass index; FTI, fat tissue index; LTI, lean tissue index.

Results for BMI:

After AIC selection the model for BMI no longer contained periphery artery disease, heart failure and the interaction term of diabetes and time (Table 2). Diabetes did not significantly affect the development of BMI. BMI increased more for females than for males, more for patients $<57$ years than for patients $\geq 67$ years, and more for patients with normal LTI and normal FTI than for patients with high LTI and FTI at baseline. The model results can also be summarized as follows: 


$$
\begin{aligned}
& B M I(\text { time })=25.78+0.0028 * \text { time }+\left\{\begin{array}{lr}
-0.27-0.001 * \text { time male } \\
0 \quad \text { female }
\end{array}\right. \\
& +\left\{\begin{array}{lc}
0.22-0.0009 * \text { time } & \geq 67 \text { years } \\
1.02-0.0004 * \text { time } & {[57 ; 67) \text { years }} \\
0 & <57 \text { years }
\end{array}+ \begin{cases}0.86 & \text { no diabetes } \\
0 & \text { niabetes }\end{cases} \right. \\
& +\left\{\begin{array}{l}
0.35 \text { ischemic heart disease } \\
0 \text { no ischemic heart disease }
\end{array}+\left\{\begin{array}{l}
-2.06+0.0002 * \text { time low LTI } \\
2.76-0.0015 * \text { time high LTI } \\
0 \quad \text { normal LTI }
\end{array}\right.\right.
\end{aligned}
$$

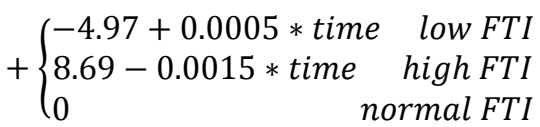

Example: female, between 57 and 66 years old, no diabetes, no ischemic heart disease, with low LTI and high FTI:

$$
\begin{aligned}
\text { BMI }(\text { time })= & 25.78+0.0028 * \text { time }+1.02-0.0004 * \text { time }-2.06+0.0002 * \text { time } \\
& +8.69-0.0015 * \text { time }=33.43+0.0011 * \text { time }
\end{aligned}
$$

After 2 years of follow-up: $B M I(730)=33.43+0.0011 * 730=34.23$

\section{Results for FTI:}

After AIC selection heart failure and the interaction term between age and time were no longer in the model. In this model age did not appear to affect FTI development as the interaction term between age and time was not significant (Table 3). FTI increased more for females than for males, more for diabetics than for non-diabetics, more for patients with normal versus low baseline LTI, and more for patients with low baseline FTI. The increase of FTI over the time was smallest for patients with high FTI at baseline. The corresponding formula is: 


$$
\begin{aligned}
& F T I(\text { time })=11.53+0.003 * \text { time }+\left\{\begin{array}{lr}
-3.29-0.001 * \text { time male } \\
0 \quad \text { female }
\end{array}\right. \\
& +\left\{\begin{array}{cc}
2.44 & \geq 67 \text { years } \\
1.99 & {[57 ; 67) \text { years }} \\
0 & <57 \text { years }
\end{array}+ \begin{cases}0.72+0.0009 * \text { time diabetes } \\
0 & \text { no diabetes }\end{cases} \right. \\
& +\left\{\begin{array}{l}
0.25 \text { ischemic heart disease } \\
0 \text { no ischemic heart disease }
\end{array}+ \begin{cases}0.15 & P A D \\
0 & \text { no } P A D\end{cases} \right. \\
& +\left\{\begin{array} { l } 
{ 0 . 8 8 - 0 . 0 0 0 6 * \text { time } \quad \text { low LTI } } \\
{ - 0 . 5 0 + 0 . 0 0 0 1 * \text { time } \quad \text { high LTI } } \\
{ 0 \quad \text { normal LTI } }
\end{array} \left\{\begin{array}{rr}
-5.80+0.001 * \text { time } \quad \text { low FTI } \\
9.24-0.002 * \text { time } & \text { high FTI } \\
0 \quad \text { normal FTI }
\end{array}\right.\right.
\end{aligned}
$$

Example: female, between 57 and 66 years old, no diabetes, no ischemic heart disease, without PAD, with low LTI and high FTI:

$$
\begin{aligned}
F T I(\text { time })= & 11.53+0.003 * \text { time }+1.99+0.88-0.0006 * \text { time }+9.24-0.002 \\
& * \text { time }=24.36+0.0013 * \text { time }
\end{aligned}
$$

After 2 years of follow-up: $F T I(730)=23.54+0.0004 * 730=23.83$

\section{Results for LTI:}

The same covariates were considered for the outcome LTI. After AIC selection the model no longer contained chronic ischemic heart disease (Table 4). LTI decreased more for males than for females, more for patients $\geq 67$ years than patients $<57$ years, more for diabetics, and more for patients with high LTI or low FTI at baseline. The smallest decrease in LTZ was observed for patients with low LTI or high FTI at baseline. The model results can also be summarized as follows: 


$$
\begin{aligned}
& \operatorname{LTI}(\text { time })=13.91-0.0002 * \text { time }+\left\{\begin{array}{l}
2.83-0.0002 * \text { time male } \\
0 \quad \text { female }
\end{array}\right. \\
& +\left\{\begin{array}{lr}
-2.69-0.0003 * \text { time } & \geq 67 \text { years } \\
-1.22-0.0002 * \text { time } & {[57 ; 67) \text { years }} \\
0 & <57 \text { years }
\end{array}\right. \\
& +\left\{\begin{array}{l}
-0.16-0.0007 * \text { time diabetes } \\
0 \quad \text { no diabetes }
\end{array}+\left\{\begin{array}{cc}
-0.11 & \text { heart failure } \\
0 & \text { no heart failure }
\end{array}\right.\right. \\
& +\left\{\begin{array}{rr}
-0.28 & P A D \\
0 & \text { no } P A D
\end{array}+\left\{\begin{array}{lr}
-2.98+0.0008 * \text { time } & \text { low LTI } \\
3.18-0.0019 * \text { time } & \text { high LTI } \\
0 & \text { normal LTI }
\end{array}\right.\right. \\
& +\left\{\begin{array}{lr}
0.61-0.0006 * \text { time } & \text { low FTI } \\
-0.32+0.0003 * \text { time } & \text { high FTI } \\
0 \quad \text { normal FTI }
\end{array}\right.
\end{aligned}
$$

Example: female, between 57 and 66 years old, no diabetes, without heart failure, without PAD, with low LTI and high FTI:

$$
\begin{aligned}
\operatorname{LTI}(\text { time })= & 13.91-0.0002 * \text { time }-1.22-0.0002 * \text { time }-0.11-2.98+0.0008 \\
& * \text { time }-0.32+0.0003 * \text { time }=9.28+0.0007 * \text { time }
\end{aligned}
$$

After 2 years of follow-up: $\operatorname{LTI}(730)=9.28+0.0007 * 730=9.79$

\section{Discussion}

This study, based on a large international cohort of incident hemodialysis patients, reports a mean BMI increase of $\sim 0.6 \mathrm{~kg} / \mathrm{m}^{2}$ over 24 months from baseline. Patient nutritional status was monitored by bioimpedance spectroscopy and revealed that changes in BMI were associated with an increase of $0.95 \mathrm{~kg} / \mathrm{m}^{2}$ in $\mathrm{FTI}$ and a decrease of $0.40 \mathrm{~kg} / \mathrm{m}^{2}$ in LTI. These latter results confirm trends reported by previous small-sized studies, ${ }^{3,4,7}$ albeit the increase in fat body mass reported by 
Pupim et $\mathrm{al}^{3}$ during the first year on hemodialysis was not associated with significant changes in weight and in body mass index. This is the opposite of what was reported by Mathew et $\mathrm{al}^{8}$, but it should be stressed that anthropometry measurements are not only operator dependent but also subject to artifacts from fluid accumulation. Therefore, it cannot be excluded that previous results can be distorted by the hydration status, especially considering that also DEXA cannot provide diagnostic separation of muscle mass and fluid overload. In the current study, the increase of fat and the decrease in lean body mass was associated with an increased BMI already after 1 year (Figure 3). This observation supports the theory ${ }^{3}$ that fat mass may increase quickly during the first year of hemodialysis and continue to increase slowly thereafter for approximately 7 years.

Table 2. Estimations of the Mixed Model for the Outcome BMI

\begin{tabular}{|c|c|c|c|c|}
\hline Variable & Reference Group & Estimate & Standard Error & $P$ Value \\
\hline Intercept & & 25.7846 & 0.0938 & $<.001$ \\
\hline Time (d) & & 0.0028 & 0.0003 & $<.001$ \\
\hline Gender: male & Female & -0.2657 & 0.0815 & .001 \\
\hline Age: $(57 ; 67)$ & Age $<57$ & 1.0163 & 0.1001 & $<.001$ \\
\hline Age: $\geq 67$ & Age $<57$ & 0.2179 & 0.0918 & .018 \\
\hline Diabetes: yes & No & 0.8555 & 0.0696 & $<.001$ \\
\hline LTI-ref: low & Normal & -2.0646 & 0.0821 & $<.001$ \\
\hline LTI-ref: high & Normal & 2.7639 & 0.2308 & $<.001$ \\
\hline FTI-ref: low & Normal & -4.9664 & 0.1488 & $<.001$ \\
\hline FTI-ref: high & Normal & 8.6878 & 0.0995 & $<.001$ \\
\hline Ischemic heart disease: yes & No & 0.3452 & 0.0927 & $<.001$ \\
\hline Time $\times$ gender: male & Female & -0.0013 & 0.0002 & $<.001$ \\
\hline Time $\times$ age: $(57 ; 67)$ & Age $<57$ & -0.0004 & 0.0003 & .167 \\
\hline Time $\times$ age: $\geq 67$ & Age $<57$ & -0.0009 & 0.0003 & .001 \\
\hline Time $\times$ LTI-ref: Low & Normal & 0.0002 & 0.0003 & .519 \\
\hline Time $\times$ LTI-ref: High & Normal & -0.0015 & 0.0007 & .031 \\
\hline Time $\times$ FTI-ref: Low & Normal & 0.0005 & 0.0005 & .288 \\
\hline Time $\times$ FTI-ref: High & Normal & -0.0015 & 0.0003 & $<.001$ \\
\hline
\end{tabular}

BMI, body mass index; FTI, fat tissue index; LTI, lean tissue index.

The result of the time interactions are highlighted in bold.

An additional analysis was conducted to analyze if changes in the nutritional parameters differ in different regions (West Europe (reference category), East Europe and Latin America \& South Africa). Here, geographical area was included in the linear mixed models as main effect as well as interaction with the time. Significantly higher increases in BMI $\left(0.0008 \mathrm{~kg} / \mathrm{m}^{2}\right.$ per day; $\mathrm{p}$-value $\left.=0.002\right)$ and FTI 
$\left(0.0011 \mathrm{~kg} / \mathrm{m}^{2}\right.$ per day; $p$-value $\left.<0.001\right)$ were found for patients from East Europe compared to patients from West Europe. All other comparisons between the areas regarding the development of BMI, LTI and FTI were not significant.

Regarding the development of fat mass (Table 3), FTI increase was significantly lower for males compared to females, while the presence of diabetes was associated with a significantly higher increase of FTI over time. In agreement with the study of Pupim et $\mathrm{al}^{3}$, patients with the lowest baseline FTI showed the highest increase over time. In addition, patients with high baseline LTI showed the greater increase of fat tissue.

Table 3. Estimations of the Linear Mixed Model for the Outcome LTI

\begin{tabular}{|c|c|c|c|c|}
\hline Variable & Reference Group & Estimate & Standard Error & $P$ Value \\
\hline Intercept & & 13.9088 & 0.0419 & $<.001$ \\
\hline Time (d) & & 0.0002 & 0.0001 & .114 \\
\hline Gender: male & Female & 2.8320 & 0.0362 & $<.001$ \\
\hline Age: $(57 ; 67)$ & Age $<57$ & -1.2249 & 0.0446 & $<.001$ \\
\hline Age: $\geq 67$ & Age $<57$ & -2.6932 & 0.0409 & $<.001$ \\
\hline Diabetes: yes & No & -0.1644 & 0.0378 & $<.001$ \\
\hline LTI-ref: low & Normal & -2.9756 & 0.0366 & $<.001$ \\
\hline LTI-ref: high & Normal & 3.1785 & 0.1033 & $<.001$ \\
\hline FTI-ref: low & Normal & 0.6126 & 0.0668 & $<.001$ \\
\hline FTl-ref: high & Normal & -0.3244 & 0.0443 & $<.001$ \\
\hline Heart failure: yes & No & -0.1139 & 0.0424 & .007 \\
\hline PAD: yes & No & -0.2830 & 0.0336 & $<.001$ \\
\hline Time $\times$ gender: male & Female & -0.0002 & 0.0001 & .046 \\
\hline Time $\times$ age: $(57 ; 67)$ & Age $<57$ & -0.0002 & 0.0002 & .277 \\
\hline Time $\times$ age $: \geq 67$ & Age $<57$ & -0.0003 & 0.0001 & .017 \\
\hline Time $\times$ diabetes: yes & No & -0.0007 & 0.0001 & $<.001$ \\
\hline Time $\times$ LTI-ref: low & Normal & 0.0008 & 0.0001 & $<.001$ \\
\hline Time $\times$ LTI-ref: high & Normal & -0.0019 & 0.0003 & $<.001$ \\
\hline Time $\times$ FTI-ref: low & Normal & -0.0006 & 0.0002 & .007 \\
\hline Time $\times$ FTI-ref: high & Normal & 0.0003 & 0.0002 & .034 \\
\hline
\end{tabular}

$\mathrm{FTI}$, fat tissue index; LTI, lean tissue index; PAD, peripheral artery disease.

The result of the time interactions are highlighted in bold.

Regarding the loss of lean mass (Table 4), LTI decreased more in elderly patients (age $\geq 67$ years) and males than in younger patients and females. It is known from previous studies assessing total body potassium in normal subjects that lean body mass peaks in the third and fourth decade of life, followed by a steady decline with advancing age. ${ }^{15,}{ }^{16} \mathrm{~A}$ more recent study $^{17}$ in older adults based on hydrodensitometry evaluations showed a $2 \%$ decrease in fat-free mass per decade 
in men but not in women, whereas fat mass increased similarly in both genders ( $7.5 \%$ per decade). It is known that the uremic state is associated with several endocrine abnormalities including the axis hypothalamus-pituitary gland-gonads regulation, growth hormone and insulin growth factor regulation, and hormone receptor interaction. ${ }^{18}$ The consequent hormonal derangement is known as uremic hypogonadism ${ }^{18}$, possibly affects the accelerated loss of muscle mass in men. ${ }^{17,19}$

Table 4. Estimations of the Linear Mixed Model for the Outcome FTI

\begin{tabular}{|c|c|c|c|c|}
\hline Variable & Reference Group & Estimate & Standard Error & $P$ Value \\
\hline Intercept & & 11.5251 & 0.0896 & $<.001$ \\
\hline Time (d) & & 0.0030 & 0.0003 & $<.001$ \\
\hline Gender: male & Female & -3.2891 & 0.0835 & $<.001$ \\
\hline Age: $(57 ; 67)$ & Age $<57$ & 1.9908 & 0.0776 & $<.001$ \\
\hline Age: $\geq 67$ & Age $<57$ & 2.4403 & 0.0718 & $<.001$ \\
\hline Diabetes: yes & No & 0.7201 & 0.0865 & $<.001$ \\
\hline LTI-ref: low & Normal & 0.8755 & 0.0841 & $<.001$ \\
\hline LTI-ref: high & Normal & -0.5028 & 0.2367 & .034 \\
\hline FTI-ref: low & Normal & -5.8035 & 0.1528 & $<.001$ \\
\hline FTI-ref: high & Normal & 9.2372 & 0.1022 & $<.001$ \\
\hline Ischemic heart disease: yes & No & 0.2506 & 0.0887 & .005 \\
\hline PAD: yes & No & 0.1486 & 0.0879 & .091 \\
\hline Time $\times$ gender: male & Female & -0.0011 & 0.0003 & $<.001$ \\
\hline Time $\times$ diabetes: yes & No & 0.0009 & 0.0003 & .001 \\
\hline Time $\times$ LTI-ref: low & Normal & -0.0006 & 0.0003 & .020 \\
\hline Time $\times$ LTI-ref: high & Normal & 0.0001 & 0.0008 & .938 \\
\hline Time $\times$ FTI-ref: Low & Normal & 0.0013 & 0.0005 & .009 \\
\hline Time $\times$ FTI-ref: High & Normal & -0.0020 & 0.0003 & $<.001$ \\
\hline
\end{tabular}

FTI, fat tissue index; LTI, lean tissue index; PAD, peripheral artery disease.

The result of the time interactions are highlighted in bold.

In our study diabetes was also significantly associated with a greater decrease in lean tissue index, confirming previous reports for older adults with type 2 diabetes not on renal replacement treatment. ${ }^{5,20}$ Loss of lean tissue was higher in patients with lower baseline $\mathrm{FTI}$ and higher baseline LTI. One can speculate that if the energy reserve of fat is low, lean tissue (muscle mass essentially) catabolism is then facilitated. On the other hand, when the level of muscle mass is already low, the option to have further loss is quite limited.

Inflammation and metabolic acidosis cause wasting of muscle mass through a ubiquitin-mediated process. ${ }^{21}$ Patients treated with a catheter six months after initiation of renal replacement therapy were excluded from the study to ensure a 
homogenous well-treated population, ruling out catheter as an inflammatory source. Recovery of visceral proteins (specifically albumin) after inflammatory events occurs fairly quickly, but regeneration of lost somatic proteins, specifically muscle, is less well assured. Although inflammation occurs in episodes in hemodialysis patients ${ }^{22}$, patients who have evidence of inflammation at one point in time are more likely to experience inflammation later. In an additional analysis we also considered the presence of a microinflammatory process by means of a C-reactive protein higher than $10 \mathrm{mg} / \mathrm{dL}$, but we did not find any significant association, possibly due to the paucity of data points (data not shown).

Non-CKD patients with other chronic diseases (e.g. breast cancer) frequently gain weight after diagnosis that is accompanied by either no change in lean tissue or with a loss of lean tissue. This pattern is defined as sarcopenic obesity and, like the pattern in dialysis patients, is associated with a long history of corticosteroid use, hypopituitarism, hypogonadism and prolonged physical inactivity. ${ }^{23,24}$

This study has limitations inherent in any observation study, particularly that causality cannot be assumed. It is well known that physical exercise facilitates development of muscle and may blunt the negative impact of inflammation on muscle, but a surrogate, such as muscle strength, was not evaluated in this study. Also no direct comparison with a healthy population matched for age and gender was done. However, our previous study reported that as much as $47 \%$ of almost 38,000 prevalent hemodialysis patients studied had LTI lower than the $10^{\text {th }}$ percentile of an age and gender-matched healthy population. ${ }^{25}$ Diet changes may also affect the course of LTI and FTI changes, but the network does not prescribe diets nor were there adequate nPNA data available to facilitate investigation of this aspect. Another limitation was our assumption that the decrease in LTI was due to loss of 
muscle mass. However, it is also possible that LTI loss may be affected by loss of bone, organ or connective tissue mass. Unfortunately, reliable data for residual renal function and for eGFR at time of initiation were not available. However, as baseline was defined at 6 months after initiation of renal replacement therapy, residual renal function can be assumed to be negligible. Strengths of the study lie in the prospective collection of data, the homogenous practice in all clinics, the reliability and frequency of body composition measurements, the large international cohort of incident patients and the statistical methodology applied versus previous studies. The level of homogeneity of hemodialysis practice in these clinics was high due to the clinics belonging to the same network and thus sharing a common set of medical and process targets, standard operating procedures and identical hemodialysis equipment/disposables. This was verified by a quality control tool that detects deviations and benchmarks outcome. ${ }^{26}$

After admission to hemodialysis, patients generally experience an improvement in appetite and general well-being. ${ }^{27}$ This study reports an increase in weight in incident hemodialysis patients during two years of follow-up that is mainly the result of a significant increase in FTI. This was accompanied by a parallel, albeit of small magnitude, decrease in LTI. A recent retrospective study of 37,345 prevalent hemodialysis patients addressing the association between body composition and survival found mortality was lowest with both LTI and FTI in the 10th-90th percentile (reference group) and significantly higher at the lower LTI and FTI extreme. ${ }^{25}$ Interestingly, the results of our longitudinal study support the hypothesis generated in that cross-sectional study ${ }^{25}$ of a possible protective effect of high FTI in patients with low LTI. Since malnutrition, LTI and FTI are recognized important predictors of outcome in hemodialysis patients, incident patients should be closely monitored from 
the initiation of dialysis. Bio-impedance spectroscopy offers clinicians a convenient method to assess both fluid status and body composition changes. The findings of this study deserve further investigation including aspects of physical exercise and muscle strength to address body composition changes in incident dialysis patients in a more comprehensive manner.

\section{Practical Application}

In the months after start of dialysis therapy, body mass index increased, fat tissue index increased, and lean tissue index decreased in this cohort of 8,227 incident hemodialysis patients. Some patient characteristics were associated with higher risk for having/developing malnutrition. The magnitude of the problem supports regular monitoring of all kidney disease patients in terms of body composition, at least from time of admission to dialysis. 
References

1. Dumler F, Kilates C. Body composition analysis by bioelectrical impedance in chronic maintenance dialysis patients: comparisons to the National Health and Nutrition Examination Survey III. J Ren Nutr. 2003;13(2):166-172.

2. Kopple JD. Pathophysiology of protein-energy wasting in chronic renal failure. J Nutr. 1999;129(1)(suppl):S247-251.

3. Pupim LB, Kent P, Caglar K, Shyr Y, Hakim RM, Ikizler TA. Improvement in nutritional parameters after initiation of chronic hemodialysis. Am J Kidney Dis. 2002;40(1):143-151.

4. Vendrely B, Chauveau P, Barthe N, et al. Nutrition in hemodialysis patients previously on a supplemented very low protein diet. Kidney Int. 2003;63(4):1491-1498.

5. Broers NJ, Cuijpers AC, van der Sande FM, Leunissen KM, Kooman JP. The first year on haemodialysis: a critical transition. Clin Kidney J. 2015;8(3):271-277.

6. Goldwasser P, Kaldas Al, Barth RH. Rise in serum albumin and creatinine in the first half year on hemodialysis. Kidney Int. 1999;56(6):2260-2268.

7. Raffaitin C, Lasseur $C$, Chauveau $P$, et al. Nutritional status in patients with diabetes and chronic kidney disease: a prospective study. Am J Clin Nutr. 2007;85(1):96-101.

8. Mathew S, Abraham G, Vijayan M, et al. Body composition monitoring and nutrition in maintenance hemodialysis and CAPD patients--a multicenter longitudinal study. Ren Fail. 2015;37(1):66-72.

9. Kalantar-Zadeh K, Kuwae N, Wu DY, et al. Associations of body fat and its changes over time with quality of life and prospective mortality in hemodialysis patients. Am J Clin Nutr. 2006;83(2):202-210.

10. Johansen KL, Kaysen GA, Young BS, Hung AM, da Silva M, Chertow GM. Longitudinal study of nutritional status, body composition, and physical function in hemodialysis patients. Am J Clin Nutr. 2003;77(4):842-846.

11. Marcelli D, Kirchgessner J, Amato C, et al. EuCliD (European Clinical Database): a database comparing different realities. J Nephrol. 2001;14(4)(suppl):S94-S100.

12. Marcelli $D$, Moscardo $\mathrm{V}$, Steil $\mathrm{H}$, et al. Data management and quality assurance for dialysis network. Contrib Nephrol. 2002(137):293-299.

13. Moissl U, Wieskotten S, Chamney P, Wabel P. Reference ranges for human body composition and fluid overload. J Am Soc Nephrol. 2009;20:469A.

14. Wabel P, Chamney P, Moissl U, Jirka T. Importance of whole-body bioimpedance spectroscopy for the management of fluid balance. Blood Purif. 2009;27(1):75-80.

15. Allen TH, Anderson EC, Langham WH. Total body potassium and gross body composition in relation to age. J Gerontol. 1960;15:348-357.

16. Pierson RN, Jr., Lin DH, Phillips RA. Total-body potassium in health: effects of age, sex, height, and fat. Am J Physiol. 1974;226(1):206-212.

17. Hughes VA, Frontera WR, Roubenoff R, Evans WJ, Singh MA. Longitudinal changes in body composition in older men and women: role of body weight change and physical activity. Am J Clin Nutr. 2002;76(2):473-481.

18. Holley JL. The hypothalamic-pituitary axis in men and women with chronic kidney disease. Adv Chronic Kidney Dis. 2004;11(4):337-341.

19. Wang HL, Ding TT, Lu S, et al. Muscle mass loss and intermuscular lipid accumulation were associated with insulin resistance in patients receiving hemodialysis. Chin Med J (Engl). 2013;126(24):4612-4617.

20. Koster A, Schaap LA. The effect of type 2 diabetes on body composition of older adults. Clin Geriatr Med. 2015;31(1):41-49, vii-viii.

21. Reid MB, Li YP. Tumor necrosis factor-alpha and muscle wasting: a cellular perspective. Respir Res. 2001;2(5):269-272. 
22. Kaysen GA, Dubin JA, Muller HG, Rosales LM, Levin NW. The acute-phase response varies with time and predicts serum albumin levels in hemodialysis patients. The HEMO Study Group. Kidney Int. 2000;58(1):346-352.

23. Heber D, Ingles S, Ashley JM, Maxwell MH, Lyons RF, Elashoff RM. Clinical detection of sarcopenic obesity by bioelectrical impedance analysis. Am J Clin Nutr. 1996;64(3)(suppl):S472-S477. 24. Guo SS, Zeller C, Chumlea WC, Siervogel RM. Aging, body composition, and lifestyle: the Fels Longitudinal Study. Am J Clin Nutr. 1999;70(3):405-411.

25. Marcelli D, Usvyat LA, Kotanko $P$, et al. Body Composition and Survival in Dialysis Patients: Results from an International Cohort Study [published online ahead of print April 21 2015]. Clin J Am Soc Nephrol. 2015. http://www.ncbi.nlm.nih.gov/pubmed/ 25901091. Accessed June 18, 2015.

26. Stopper A, Raddatz A, Grassmann A, et al. Delivering quality of care while managing the interests of all stakeholders. Blood Purif. 2011;32(4):323-330.

27. Henrich WL. Principles and Practice of Dialysis: Lippincott Williams \& Wilkins; 2004. 
Body composition changes in incident dialysis patients 


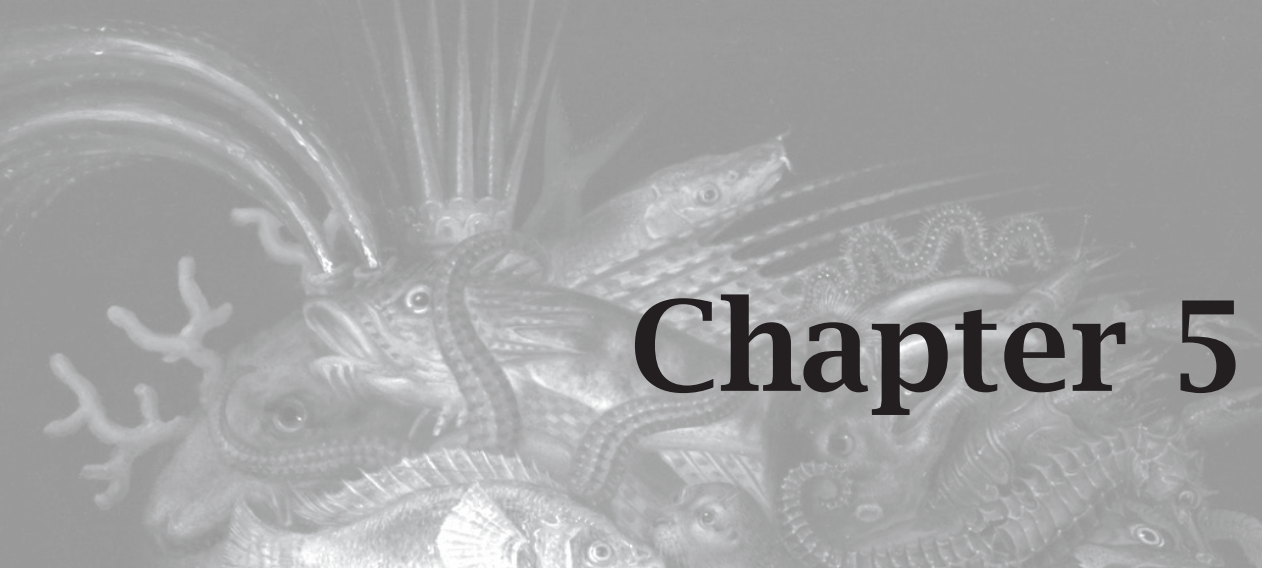

Analysis of creatinine and albumin change dynamics during the first two years on extracorporeal (2) dialysis therapy

Daniele Marcelli, Katharina Brand, Fatih Kircelli, Jose-Ignacio Merello, Pedro Ponce, Tomas Jirka, Jaroslav Rosenberger, Kostantin Gurevich, Cristina Marelli, Goran Imamovic, Attilio Di Benedetto, Aileen Grassmann, Laura Scatizzi, Inga Bayh, Bernard Canaud.

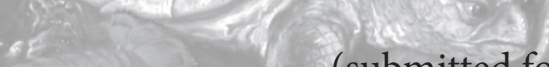




\section{Abstract}

\section{Background}

Dialysis patients are affected by protein energy wasting already early in renal replacement therapy. Serum albumin and creatinine levels are predictors of both nutritional status and of mortality risk in hemodialysis (HD) patients. We examined changes in these nutritional indicators in the 2 years following the first 3 months of HD.

\section{Methods}

The study population comprised HD patients treated in 27 countries between 2007 and 2014. Albumin and creatinine values in 1-month intervals were compared with their baseline values. Differences in the development between patient groups were analyzed using linear mixed models with the correlation structure of an autoregressive process of first order.

\section{Results}

Of the 3860 patients, 295 died during follow-up. In one and two years of follow-up, albumin increased respectively by $4 \%$ and $4 \%$, while creatinine increased by $12 \%$ and $18 \%$. Compared to reference categories, albumin was significantly lower for females, older patients, patients with liver disease and patients with low lean tissue index (LTI) or low fat tissue index (FTI) at baseline. Creatinine was significantly higher for males, for patients with high LTI at baseline and for patients with malignancies, but was significantly lower for older patients, patients with congestive heart failure, peripheral vascular or cerebrovascular disease and diabetes, and patients with low LTI or low and high FTI at baseline. Regarding the development of over time, higher post-dialysis fluid overload at baseline was associated with a greater increase of both albumin and creatinine.

\section{Conclusion}

Serum albumin and creatinine levels improved in patients treated with a good dialysis protocol. The presence of post-dialysis fluid overload and certain comorbidities at baseline, such as vascular disease, liver disease and diabetes, can modify the positive trends. 


\section{Introduction}

Multiple metabolic and nutritional derangements negatively affect the nutritional status of patients with advanced chronic kidney disease (CKD) as their kidney function deteriorates. Additionally, starting renal replacement therapy has a major impact on patients' nutritional status due to the following negative aspects: interference with regular meals, dietary restrictions imposed by clinician, loss of amino-acids and nutrients and dialysis-associated increased catabolic rate. These negative effects can only be partially counter-balanced by the increase in appetite and improvement in wellbeing resulting from uremia correction. Therefore, it is not surprising that many patients are affected by protein energy wasting (PEW) already in the initial phase of the renal replacement therapy. According to the International Society of Renal Nutrition and Metabolism ${ }^{1}$ this syndrome is defined by the presence of at least three of the following four characteristics: 1) abnormal levels of circulating biomarkers (low serum albumin, pre-albumin, or cholesterol concentrations); 2) decreased body mass (low or decreased body mass or fat mass, or weight loss with decreased protein and energy intake); 3) decreased muscle mass; and 4) abnormal nutritional score. Low serum albumin is an important biochemical indicator of PEW and it is part of the routine labs in the follow-up of dialysis patients. In addition, this visceral protein is an acute-phase protein, decreasing during inflammatory episodes, and accordingly is an important predictor of the risk of mortality as established by many studies ${ }^{2,3}$. Serum creatinine is also regularly monitored in many units, often once a month. It is dialyzable and in patients on maintenance hemodialysis its clearance is relatively constant across dialysis prescription. Creatinine generation is, however, proportional to dietary meat intake and mainly to somatic protein mass, with higher levels in those patients whose superior nutritional status sustains an 
increased musculature. Finally, creatinine, similarly to albumin, has been found to be a strong predictor of mortality risk. ${ }^{4}$ Therefore, studies evaluating the development of the level of albumin and creatinine in the initial phase of dialysis should be considered in order to better use the information normally available from the routine continuous assessment. Strangely enough, few studies could be retrieved, ${ }^{4-11}$ and probably the recently published Comprehensive Dialysis study ${ }^{9}$ is the more exhaustive of these, showing an increased level of serum albumin in the initial months on dialysis. Another study from Goldwasser et al ${ }^{10}$ showed a $12-13 \%$ increase of serum albumin and creatinine during the first half year of hemodialysis in a stable cohort. The slope of serum albumin versus time predicted survival, but it was not as predictive as the absolute albumin concentration. In fact, the progressive decline in urinary excretion of proteins and creatinine was correlated with their increases in the serum levels. However, extracellular fluid overload may play an important role, being one of the factors affecting the concentration of albumin.

Therefore, having available a large population of incident patients admitted to hemodialysis, we sought to examine the changes in laboratory nutritional indicators such as albumin (visceral protein) and creatinine (somatic proteins) in the 2 years following the first 3 months of hemodialysis, in a phase when residual renal function is not expected to have major significant role. 


\section{Subjects and Methods}

The study population was extracted from a database of 69,316 patients on hemodialysis treatment in 605 NephroCare centres throughout 27 countries in Europe, Latin America and South Africa between January 1, 2007 and January 1, 2014. Patients were included if they were no longer than 3 months on RRT (incident patients only). Baseline values were defined as the mean of all measurements in the last 2 months before baseline (baseline period, Figure 1). Patients were followed for a maximum of 2 years after baseline. Patients with no albumin or with no creatinine measurement during the baseline period were excluded. Typically the bromocresol green method for albumin measurement was applied. In cases where the bromocresol purple method was used, results were converted to bromocresol green by adding $0.55 \mathrm{~g} / \mathrm{dL}^{12}{ }^{12}$ Patients with no Lean Tissue Index (LTI) or with no Fat Tissue Index $(\mathrm{FTI})$ measurement during this period were also excluded. LTI and FTI were calculated as the ratio of the respective tissue masses divided by the height in meters squared. The definition of the age- and gender-dependent reference groups of LTI and FTI, respectively, was based on an evaluation of 1000 healthy individuals: "normal" LTI and FTI is defined as levels between the $10^{\text {th }}$ and $90^{\text {th }}$ percentile of the normal LTI or FTI distribution, respectively, whereas "low" is defined as under the $10^{\text {th }}$ percentile and "high" as above the $90^{\text {th }}$ percentile of the respective normal distributions. $^{13}$ 


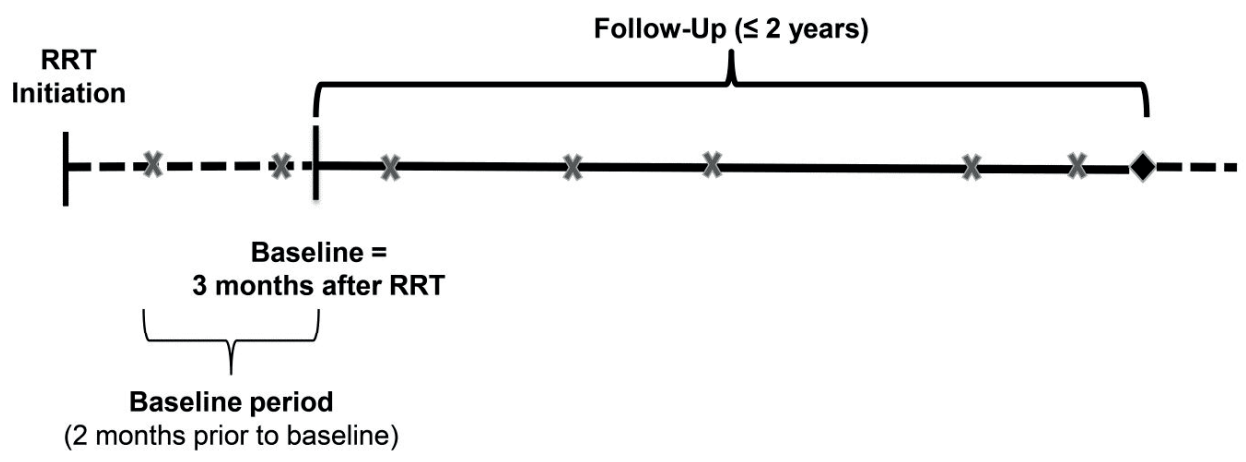

X: Laboratory tests

Baseline values: Mean of measurements in Baseline period

Figure 1. Study design with hypothetical measurement times. RRT: Renal replacement therapy

In order to ensure a homogenous, well-treated study population, patients younger than 18 years, with metastatic solid tumors, with a BMI lower $18.5 \mathrm{~kg} / \mathrm{m}^{2}$, receiving less or more than 3 treatments per week, or treated with a catheter at baseline were also excluded. Catheter patients were also excluded as it has been reported that central venous catheters are associated with a higher level of inflammation than fistula, as defined by $C$ reactive proteins levels in incident hemodialysis patients ${ }^{14,15}$ with consequent significantly lower serum albumin concentration. ${ }^{9}$ Anonymized patient data were accessed through the European Clinical Database (EuCliD), which has been described elsewhere. ${ }^{16,17}$ All patients consented that their data may be used for scientific research in anonymized form.

Lean tissue index and fat tissue index were evaluated at intervals defined according to the network policy using the $\mathrm{BCM}^{\circledR}$ (FMC, Bad Homburg, Germany), which is 
based on multifrequency bioimpedance spectroscopy at 50 different frequencies ranging between 5 and $1000 \mathrm{kHz}$. $\mathrm{BCM}^{\circledR}$ measures fluid overload, total body water (TBW in L), extracellular water (ECW in L), intracellular water (ICW in L), fat tissue mass (FTM in $\mathrm{Kg}$ ), lean tissue mass (LTM in $\mathrm{Kg}$ ) and body cell mass. BCM has been validated against the following gold standard reference methods: bromide dilution for ECW, total body potassium for ICW, deuterium dilution for TBW, dual X-ray absorptiometry for LTM, four compartment modelling, air displacement plethysmography, under water weighing for adipose tissue mass, magnet resonance tomography for body cell mass and an expert clinical assessment for fluid overload. ${ }^{18}$

\section{Statistical analysis}

Albumin and creatinine were analyzed during follow-up time to evaluate the changes in laboratory values after the start of dialysis. To describe the general changes of these two outcomes, a descriptive analysis was performed comparing current values with the baseline value in each 1-month interval (Delta-analysis). The mean delta and the standard error are plotted for each interval of the 2 years of follow-up thereafter. In case of an interval without measurement the value of the interval before was used (last observation carried forward). The Wilcoxon signed rank sum test was used to test the changes in albumin and creatinine in each month-interval compared to baseline. To consider the multiple comparisons, a Bonferoni correction was performed thereafter. $P$ values less than 0.002 were considered to be significant in this case.

To analyze differences in the development of the laboratory values between certain patient groups, linear mixed models ${ }^{19}$ with the correlation structure of an autoregressive process of first $\operatorname{order}^{20}$ were used to consider the specific structure of 
the repeated measurements in irregular time intervals. ${ }^{20}$ For both outcomes a separate mixed models were fitted. In each of them the time (in days) was included as covariate. Main predictors were gender, age $(\geq 18-<56$; $\geq 56-<69$; $\geq 69)$, LTIreference and FTI-reference groups (“Low”, "Normal”, "High”), post-dialysis fluid overload and the comorbidities myocardial infarction, congestive heart failure, vascular disease (peripheral vascular disease or cerebrovascular disease), diabetes with chronic complication, malignancy and liver disease (defined according to the ICD10 coding algorithm, ${ }^{21}$ present (yes/no) at baseline). All these main predictors were included as main effect and as interaction with time. With the main effects general group differences could be analyzed. In addition the interaction terms are used to identify if the changes in albumin and creatinine over follow-up time differ in these subgroups.

With the exception of the continuous variable fluid overload, all covariates are categorical and therefore were included in the model as dummy-variables. The corresponding reference categories are specified in detail in the tables. Because of the high number of covariates, Akaike information criterion (AIC) was used to select covariates. AIC model selection balances between the goodness of fit and the complexity of the model and can therefore result in exclusion of some covariates that have a low impact on the outcome. All analysis was conducted with the statistical software SAS, version 9.4. The SAS procedure MIXED together with the REPEATED statement and SPATIAL POWER correlation structure was used to fit the mixed models.

\section{Results}


Patient selection is shown in Figure 2. After the selection process, 3860 patients out of the original 69,316 patients were included in the study. $97 \%$ of the selected patients were treated with arteriovenous fistula (3\% grafts) and $97 \%$ with high-flux polysulfone dialyzers (Fresenius Medical Care, Germany).

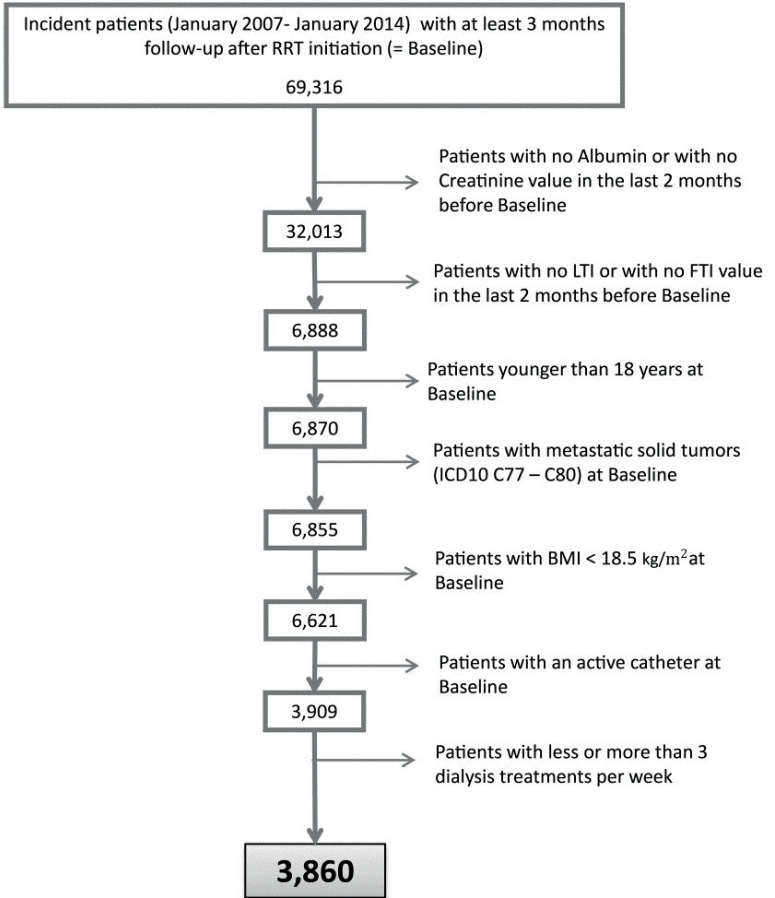

Figure 2. Patient selection. RRT: Renal replacement therapy; LTI: Lean tissue index, FTI: Fat tissue index; BMI= Body mass index

295 patients $(7.6 \%)$ died during follow-up. Baseline characteristics are displayed in Table 1. 
Table 1. Baseline patient characteristics

\begin{tabular}{|c|c|}
\hline General characteristics & \\
\hline Age (years; mean $\pm S D$ ) & $61.03 \pm 14.87$ \\
\hline Age groups (\%) & \\
\hline$[18,56)$ years & 32.23 \\
\hline$[56,69)$ years & 33.65 \\
\hline$\geq 69$ years & 34.12 \\
\hline Gender (female, \%) & 35.75 \\
\hline Body composition & \\
\hline Post-dialysis weight $(\mathrm{Kg} ;$ mean $\pm \mathrm{SD})$ & $72.73 \pm 14.90$ \\
\hline BMI: body mass index $\left(\mathrm{kg} / \mathrm{m}^{2} ;\right.$ mean $\left.\pm \mathrm{SD}\right)$ & $26.74 \pm 5.18$ \\
\hline LTI: lean tissue index $\left(\mathrm{kg} / \mathrm{m}^{2} ;\right.$ mean $\left.\pm \mathrm{SD}\right)$ & $13.06 \pm 2.94$ \\
\hline LTI-reference groups (\%) & \\
\hline Low LTI & 45.10 \\
\hline Normal LTI & 51.79 \\
\hline High LTI & 3.11 \\
\hline FTI: fat tissue index $\left(\mathrm{kg} / \mathrm{m}^{2} ;\right.$ mean $\left.\pm \mathrm{SD}\right)$ & $12.70 \pm 6.16$ \\
\hline FTI reference groups (\%) & \\
\hline Low FTI & 8.45 \\
\hline Normal FTI & 70.85 \\
\hline High FTI & 20.70 \\
\hline Pre-dialysis fluid overload (L; mean $\pm S D)$ & $2.16 \pm 1.96$ \\
\hline Post-dialysis fluid overload (L; mean \pm SD) & $0.16 \pm 2.13$ \\
\hline Comorbidities & \\
\hline Myocardial Infarction (\%) & 3.32 \\
\hline Congestive heart failure (\%) & 10.31 \\
\hline Peripheral vascular disease (\%) & 7.20 \\
\hline Cerebrovascular disease (\%) & 7.07 \\
\hline Dementia (\%) & 0.47 \\
\hline Chronic pulmonary disease (\%) & 5.83 \\
\hline Rheumatic disease (\%) & 0.96 \\
\hline Peptic ulcer disease (\%) & 3.03 \\
\hline Diabetes with chronic complication (\%) & 28.37 \\
\hline Hemiplegia or paraplegia $(\%)$ & 0.10 \\
\hline Malignancy (\%) & 5.36 \\
\hline AIDS/HIV (\%) & 0.05 \\
\hline Mild, moderate or severe liver disease (\%) & 4.84 \\
\hline Laboratory values & \\
\hline Albumin (g/dL; mean \pm SD) & $3.77 \pm 0.44$ \\
\hline Creatinine (mg/dL; mean \pm SD) & $6.71 \pm 2.26$ \\
\hline CRP ( mg/L; median; interquartile range) & $5.66[2.20-14.10]$ \\
\hline Hemoglobin $(\mathrm{g} / \mathrm{dL} ;$ mean $\pm \mathrm{SD})$ & $10.37 \pm 1.47$ \\
\hline Total cholesterol (mg/dL; mean \pm SD) & $171.87 \pm 43.06$ \\
\hline Phosphate (mg/dL; mean \pm SD) & $4.82 \pm 1.33$ \\
\hline Equilibrated Kt/V (mean \pm SD) & $1.34 \pm 0.33$ \\
\hline
\end{tabular}


During the baseline period patients had a median of 1 (interquartile range (IQR): 1-2) albumin and a median of 2 (IQR: 1-2) creatinine measurements. On average, patients had a median of 4 (IQR: 2-9) albumin and 6 (IQR: 2-13) creatinine measurements after baseline. The last albumin measurement was in mean 289 , the last creatinine value 285 days after baseline. Figure 3 shows the means of the delta analyses. In one and two years of follow-up, albumin increased by $0.15 \mathrm{~g} / \mathrm{dL}$ (or $4 \%$ ) and $0.14 \mathrm{~g} / \mathrm{dL}(4 \%)$, respectively. Creatinine increased by $0.8 \mathrm{~g} / \mathrm{dL}$ (or $12 \%$ ) in one year and by $1.2(18 \%)$ in two years. These changes in albumin as well as in creatinine were significant for all intervals $(p<0.001)$. The results of the linear mixed models for the outcomes albumin and creatinine after AIC variable selection are shown in Tables 2-3. All predictors are listed with the appropriate reference categories and the estimations for the specified groups, the standard errors and the p-values.

Results for albumin:

Albumin is significantly higher for males then for females. In comparison to their reference categories, albumin is significant lower for patients older/equal than 56 , patients with liver disease and patients with low LTI or low FTI at baseline. Higher post-dialysis fluid overload is also associated with lower albumin level at baseline, but regarding the development over the follow up time, higher post-dialysis fluid overload at baseline is associated with a greater increase of albumin. For patients without vascular disease, albumin increased more during follow-up time than for patients with this disease. The model results can also be summarized as follows: 


$$
\begin{aligned}
& \text { Albumin (time) }=3.92+0.00033 * \text { time }+\left\{\begin{array}{cc}
0.10 \text { male } \\
0 & \text { female }
\end{array}+\left\{\begin{array}{cc}
-0.20 & \geq 69 \text { years } \\
-0.09 & {[56 ; 69) \text { years }} \\
0 & <56 \text { years }
\end{array}\right.\right. \\
& +\left\{\begin{array}{ll}
-0.09 & \text { low LTI } \\
0.04 & \text { high LTI } \\
0 & \text { normal LTI }
\end{array}+\left\{\begin{array}{l}
-0.12 \text { low FTI } \\
0.05 \text { high FTI } \\
0 \quad \text { normal FTI }
\end{array}\right.\right. \\
& \left\{\begin{array}{l}
0.04 \text { myocardinal infarction } \\
0 \quad \text { no myocardinal infarction }
\end{array}\right. \\
& + \\
& \left\{\begin{array}{cc}
0.01-0.00017 * \text { time } & \begin{array}{r}
\text { peripheral vascular or cerebrovascular disease } \\
\text { no peripheral vascular or cerebrovascular disease }
\end{array}
\end{array}\right. \\
& +\left\{\begin{array}{cc}
-0.02-0.00008 * \text { time } & \text { diabetes } \\
0 & \text { no diabetes }
\end{array}+\left\{\begin{array}{l}
-0.09 \text { liver disease } \\
0 \text { no liver disease }
\end{array}\right.\right. \\
& +(-0.04+0.00007 * \text { time }) \text { per } 1 \text { liter postdialysis fluid overload }
\end{aligned}
$$

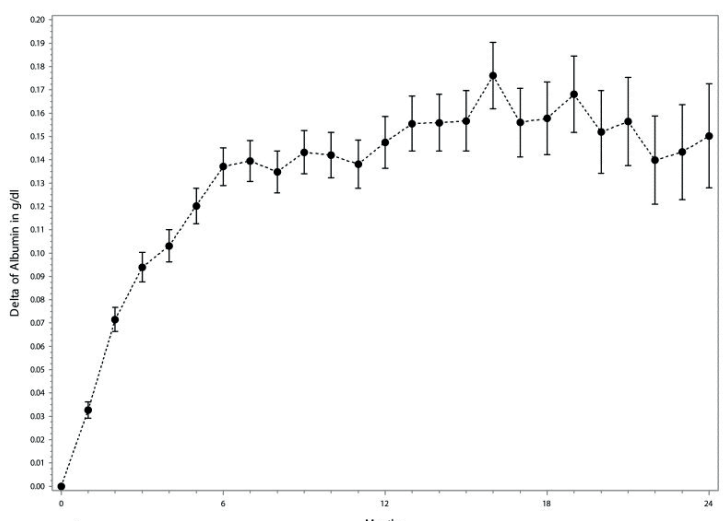

a)

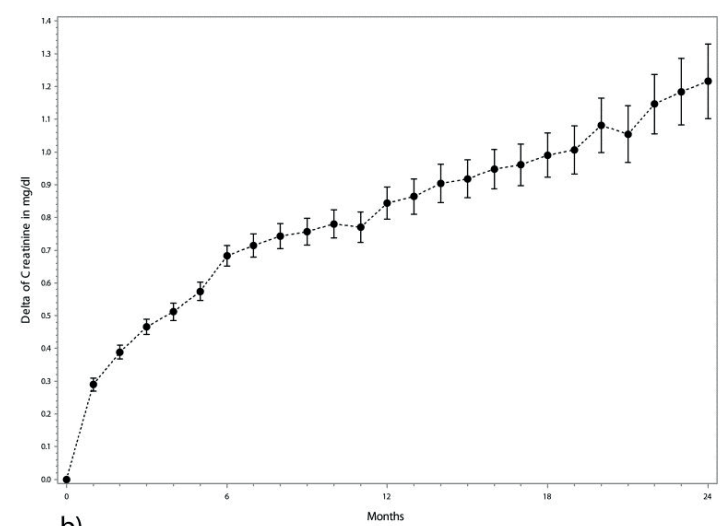

b) 
Figure 3. Delta analysis for outcome albumin (a) and creatinine (b). Means and standard deviations are shown, comparing current values of albumin with baseline values.

\begin{tabular}{|c|c|c|c|c|c|}
\hline Variable & Reference group & category & Estimate & Standard Error & p-value \\
\hline Intercept & & & 3.9171 & 0.01145 & $<0.001$ \\
\hline Time (days) & & & 0.00033 & 0.00003 & $<0.001$ \\
\hline \multicolumn{6}{|c|}{ Baseline predictors } \\
\hline Gender & Female & Male & 0.0966 & 0.00879 & $<0.001$ \\
\hline \multirow{2}{*}{ Age (years) } & \multirow{2}{*}{$<56$} & {$[56 ; 69)$} & -0.0886 & 0.01032 & $<0.001$ \\
\hline & & $\geq 69$ & -0.2038 & 0.01038 & $<0.001$ \\
\hline \multirow{2}{*}{ LTI-reference group } & \multirow{2}{*}{ Normal } & Low & -0.0925 & 0.00884 & $<0.001$ \\
\hline & & High & 0.0357 & 0.02481 & 0.151 \\
\hline \multirow{2}{*}{ FTI-reference group } & \multirow{2}{*}{ Normal } & Low & -0.0796 & 0.01562 & $<0.001$ \\
\hline & & High & -0.0009 & 0.01058 & 0.929 \\
\hline Myocardial Infarction & Absent & Present & 0.0426 & 0.02240 & 0.057 \\
\hline $\begin{array}{l}\text { Peripheral vascular disease or } \\
\text { Cerebrovascular disease }\end{array}$ & Absent & Present & 0.00900 & 0.01720 & 0.601 \\
\hline Diabetes with chronic complication & Absent & Present & -0.0233 & 0.01301 & 0.074 \\
\hline Liver disease & Absent & Present & -0.0879 & 0.01777 & $<0.001$ \\
\hline Post-dialysis fluid overload & & & -0.0410 & 0.00276 & $<0.001$ \\
\hline \multicolumn{6}{|c|}{ Predictors over time } \\
\hline $\begin{array}{l}\text { Time * (Peripheral vascular disease } \\
\text { or Cerebrovascular disease) }\end{array}$ & Absent & Present & -0.00017 & 0.00006 & 0.002 \\
\hline $\begin{array}{l}\text { Time * Diabetes with chronic } \\
\text { complication }\end{array}$ & Absent & Present & -0.00008 & 0.00004 & 0.064 \\
\hline Time* Post-dialysis fluid overload & & & 0.00007 & $9.551 \mathrm{E}-6$ & $<0.001$ \\
\hline
\end{tabular}

Table 2. Estimations of the mixed model for the outcome albumin

To give a better understanding of the model results, the above formula is translated for a concrete but fictive patient with the following attributes: female, aged 56-68 years, with low LTI and high FTI, diabetes, and $1 \mathrm{~L}$ post-dialysis fluid overload:

$\operatorname{Albumin}($ time $)=3.92+0.00033 *$ time $-0.09-0.09+0.05-0.02-0.00008 *$ time

$$
+(-0.04+0.00007 * \text { time }) * 1
$$




$$
=3.73+0.00032 * \text { time }
$$

After two years (730 days) of follow up, the albumin level is increased for this patient example from 3.73 to $3.96 \mathrm{~g} / \mathrm{dL}$.

\begin{tabular}{|c|c|c|c|c|c|}
\hline Variable & Reference group & category & Estimate & Standard Error & p-value \\
\hline Intercept & & & 7.8996 & 0.06047 & $<0.001$ \\
\hline Time (days) & & & 0.001536 & 0.000131 & $<0.001$ \\
\hline \multicolumn{6}{|c|}{ Baseline predictors } \\
\hline Gender & Female & Male & 1.1282 & 0.04639 & $<0.001$ \\
\hline \multirow{2}{*}{ Age (years) } & \multirow{2}{*}{$<56$} & {$[56 ; 69)$} & -1.0934 & 0.05456 & $<0.001$ \\
\hline & & $\geq 69$ & -2.1196 & 0.05551 & $<0.001$ \\
\hline \multirow{2}{*}{ LTI-reference group } & \multirow{2}{*}{ Normal } & Low & -0.4303 & 0.04658 & $<0.001$ \\
\hline & & High & 0.2827 & 0.1318 & 0.032 \\
\hline \multirow{2}{*}{ FTI-reference group } & \multirow{2}{*}{ Normal } & Low & -0.1612 & 0.08188 & 0.049 \\
\hline & & High & -0.1444 & 0.05594 & 0.010 \\
\hline Congestive heart failure & Absent & Present & -0.2933 & 0.07254 & $<0.001$ \\
\hline $\begin{array}{l}\text { Peripheral vascular disease or } \\
\text { Cerebrovascular disease }\end{array}$ & Absent & Present & -0.3362 & 0.09098 & $<0.001$ \\
\hline $\begin{array}{l}\text { Diabetes with chronic } \\
\text { complication }\end{array}$ & Absent & Present & -0.8736 & 0.06843 & $<0.001$ \\
\hline Malignancy & Absent & Present & 0.2644 & 0.09449 & 0.005 \\
\hline Liver disease & Absent & Present & -0.06052 & 0.1368 & 0.658 \\
\hline Post-dialysis fluid overload & & & -0.07915 & 0.01450 & $<0.001$ \\
\hline \multicolumn{6}{|c|}{ Predictors over time } \\
\hline $\begin{array}{l}\text { Time* (Peripheral vascular } \\
\text { disease or Cerebrovascular } \\
\text { disease) }\end{array}$ & Absent & Present & -0.00051 & 0.000295 & 0.081 \\
\hline $\begin{array}{l}\text { Time* Diabetes with chronic } \\
\text { complications }\end{array}$ & Absent & Present & 0.000402 & 0.000230 & 0.081 \\
\hline Time* Liver disease & Absent & Present & -0.00106 & 0.000454 & 0.020 \\
\hline Time*Post-dialysis fluid overload & Absent & Present & 0.000142 & 0.000051 & 0.005 \\
\hline
\end{tabular}

Table 3. Estimations of the mixed model for the outcome creatinine

Results for creatinine: 
In comparison to their reference categories creatinine is significantly higher for males, for patients with high LTI at baseline and for patients with malignancy, whereas creatinine is significant lower for patients older/equal than 56 , patients with congestive heart failure, peripheral vascular or cerebrovascular disease and diabetes and patients with low LTI or low and high FTI at baseline. Higher postdialysis fluid overload is also associated with lower creatinine level at baseline, but regarding the development over the follow up time, higher post-dialysis fluid overload at baseline is associated with a greater increase of creatinine. The increase of creatinine is higher for patients with liver disease than for patients without liver disease. The model results can also be summarized as follows:

Creatinine $($ time $)=7.90+0.00154 *$ time $+\left\{\begin{array}{cc}1.13 \text { male } \\ 0 & \text { female }\end{array}+\left\{\begin{array}{cc}-2.12 & \geq 69 \\ -1.09 & {[56 ; 69)} \\ 0 & <56\end{array}\right.\right.$

$$
+\left\{\begin{array}{cc}
-0.43 \quad \text { low LTI } \\
0.28 \quad \text { high LTI } \\
0 & \text { normal LTI }
\end{array}+\quad\left\{\begin{array}{cc}
-0.16 & \text { low FTI } \\
-0.14 & \text { high FTI } \\
0 & \text { normal FTI }
\end{array}+\right.\right.
$$
$\{-0.29$ congestive heart failure

$\{$ no congestive heart failure $+$ $\left\{\begin{array}{r}-0.34-0.00051 * \text { time peripheral vascular or cerebrovascular disease } \\ 0 \quad \text { no peripheral vascular or cerebrovascular disease }\end{array}\right.$

$$
\begin{aligned}
& +\left\{\begin{array}{c}
-0.87+0.00040 * \text { time diabetes } \\
0 \quad \text { no diabetes }
\end{array}+\left\{\begin{array}{c}
0.26 \text { Malignancy } \\
0 \quad \text { no Malignancy }
\end{array}\right.\right. \\
& +\left\{\begin{array}{c}
-0.06-0.00106 * \text { time liver disease } \\
0 \quad \text { no liver disease }
\end{array}\right. \\
& +(-0.08+0.00014 * \text { time }) \text { per } 1 \text { liter postdialysis fluid overload }
\end{aligned}
$$

To give a better understanding of these model results, the formula is as follows for a concrete but fictive patient with the attributes: female, aged 56-68 years, with low LTI and high $\mathrm{FTI}$, diabetes, $1 \mathrm{~L}$ post-dialysis fluid overload: 
Creatinine $($ time $)=7.90+0.00154 *$ time $-1.09-0.43-0.14-0.87+0.00040 *$ time

$$
\begin{gathered}
+(-0.08+0.00014 * \text { time }) * 1 \\
=5.29+0.00208 * \text { time }
\end{gathered}
$$

After two years (730 days) of follow up, the creatinine level is increased for this patient example from 5.29 to $6.81 \mathrm{~g} / \mathrm{dL}$.

\section{Discussion}

This study showed a significant rate of increase in serum albumin and creatinine during the two years following the first 3 months of dialysis, and examined the relationship of the trends to demographics, body composition and comorbidities. More specifically, evaluating 2 years from baseline to 27 months after initiation of dialysis, a significant increase in serum albumin of $0.15 \pm 0.45 \mathrm{~g} / \mathrm{dL}$ was found using the delta analysis. Of note, the serum albumin increased most significantly in the first 6 months. During the first six months on hemodialysis, Parker et $\mathrm{al}^{11}$ reported a mean increase of $0.3 \mathrm{~g} / \mathrm{dL}$ in serum albumin. Evaluating the first 12 months of RRT in 266 patients on hemodialysis or peritoneal dialysis, Dalrymple et al ${ }^{9}$ reported a significant but lower increase - about $0.08+0.04 \mathrm{~g} / \mathrm{dL}$. This is close to the level observed in our study. Since patients with lower albumin and creatinine are more likely to die earlier, ${ }^{22,23}$ increasing trends can result from a positive selection of patients. However, also comparing paired values of surviving patients at each time point, similarly to what was presented in Figures 1 and 2, Parker et al ${ }^{11}$ were able to confirm the rise in serum albumin levels. During the first months on hemodialysis many factors can play roles and act in opposite directions. For example, in patients with significant proteinuria, the loss of residual renal function will decrease albumin loss. However, in parallel, hemoconcentration (resulting from the achievement of a 
lower hydration status) would increase albumin levels. With the initiation of renal replacement therapy, dietary protein intake is expected to improve, but the loss of amino acids through the dialysis membrane may negatively affect the protein balance. Currently, the almost standard prescription of biocompatible dialysis membranes should avoid significant membrane-associated inflammatory stimulus. After 3 months from the initiation of hemodialysis, because of a policy of strict volume control applied in our dialysis network as evidenced by the low post-dialysis fluid overload $(0.16 \pm 2.13$ liters $)$, residual diuresis is expected to be negligible. ${ }^{24}$ However, in our study the even residual presence of baseline post-dialysis fluid overload was still associated with a significantly higher rate of albumin increase, showing that hemoconcentration may still play an important role. In long-standing hemodialysis patients with negligible renal function, serum albumin has been reported to decline slowly over time. For example, in a group in prevalent, stable patients followed up for 2 years in a study comparing different membranes and dialysis technologies, Locatelli et $\mathrm{al}^{25}$ reported a progressive decline of serum albumin in the range of $0.11-0.22 \mathrm{~g} / \mathrm{dL}$. In our study the presence of peripheral and cerebrovascular disease was not associated with a significantly different albumin value at baseline, but patients with this comorbidity showed a significant negative trend during the 2 year follow-up $(-0.062 \pm 0.022 \mathrm{~g} / \mathrm{dL}$ per year lower than in patients without). The link between vascular disease and plasma proteins has been already reported $^{26}$ and it is associated with inflammation, even if the question whether inflammation is the cause or just a marker of an existing disease is still unresolved. However, inflammation affects plasma proteins composition and specifically albumin levels even more than malnutrition, as already reported by several studies and confirmed by our results, since extremely low levels of albumin are nearly always 
associated with the presence of the acute-phase response. ${ }^{5}$ Unfortunately, due to a very high number of missing values (43\%) C-reactive protein (CRP) could not be included in our main analysis. However, as an exercise, we included CRP $(<10$ $\mathrm{mg} / \mathrm{dL} ; \geq 10 \mathrm{mg} / \mathrm{dL}$ ) as main effect and as interaction with the time (in days) in our mixed models. Patients with $\mathrm{CRP} \geq 10 \mathrm{mg} / \mathrm{dL}$ had significantly lower albumin ($0.1355 \mathrm{mg} / \mathrm{dL}$ difference, $\mathrm{p}$-value $<0.001$ ), but had a significantly higher albumin increase over the follow-up time (by 0.00019 per day, p-value<0.001). No significant effect was found for creatinine, neither for the main effect of CRP nor for the interaction term. Finally, it has to be mentioned that, as already reported by Dalrymple et al, ${ }^{9}$ males had a significantly higher serum albumin than females $(+0.097 \pm 0.009 \mathrm{~g} / \mathrm{dL})$ as well as did patients younger than 56 years in comparison to those of $\geq 56-<69$ and $\geq 69$ years $(+0.089 \pm 0.010 \mathrm{~g} / \mathrm{dL}$ and $+0.204 \pm 0.010 \mathrm{~g} / \mathrm{dL}$, respectively), but no significant difference in rates were detected during the 2-year follow-up.

Diabetes was associated with a borderline lower baseline albumin level ($0.0233+0.0130 \mathrm{~g} / \mathrm{dL}$ difference, $\mathrm{p}=0.074)$ and also during the 2-year follow-up diabetics showed a borderline lower increasing rate $(-0.0292 \pm 0.0146 \mathrm{~g} / \mathrm{dL}$ per year difference, $p=0.064)$. Dalrymple et $a l,{ }^{9}$ probably because of a lower sample size, however reported that diabetes was not statistically associated with a different level of albumin, neither at baseline nor during the follow-up.

In regards to serum creatinine, this study showed a significant increase of $0.84 \pm$ $1.94 \mathrm{mg} / \mathrm{dL}$ in the first year, mainly in the first 6 months of the study follow-up (from the baseline of 3 to 9 months after the initiation of extracorporeal dialysis). Similarly, Culp et $\mathrm{al}^{4}$ showed an initial increase of serum creatinine from the baseline (mean, SE) of $8.56 \pm 3.35$ to $9.52 \pm 3.58$ and to $10.16 \pm 3.55 \mathrm{mg} / \mathrm{dL}$ after 6 and 12 months of 
follow-up, respectively. Their values after 2 and 3 years were not significantly different $\left(10.54 \underline{+3} .39\right.$ and $10.97 \pm 3.58 \mathrm{mg} / \mathrm{dL}$, respectively). Jadoul et $\mathrm{al}^{27}$ reported that, in a series of 15 incident patients on hemodialysis trice a week, serum creatinine after an initial slight increase declined on average by $19.6 \%$ after 5 -years of follow-up; the decline correlated with age. The cause of the increasing creatinine level in incident dialysis patients during the first 6-month of follow-up on dialysis is very likely to be due not only to the increase of protein intake due to an improved appetite, but also the parallel decline in residual renal function, mainly occurring in earlier phases of maintenance hemodialysis. ${ }^{28}$ Patients with liver disease did not show statistically different levels of baseline serum creatinine but a significantly lower rate of increase compared to those without this comorbid condition during the 2-year follow-up. The decline in hepatic functional capacity results in decreased creatine production. In addition, patients with liver disease are known to have less skeletal muscle mass, resulting in diminished creatine storage and lower conversion of creatine to creatinine. ${ }^{29}$ Therefore, the significant lower change rate in the level of serum creatinine during the 2 years of follow-up in patients with liver disease can be considered an expected result. The direct relationship between muscle mass and serum creatinine level was also confirmed by the significant $0.430 \pm 0.047 \mathrm{mg} / \mathrm{dL}$ lower creatinine level in patients with baseline lean tissue index below the $10^{\text {th }}$ percentile in respect of normal $10^{\text {th }}$ to $90^{\text {th }}$ range of the normal population distribution by age and gender. On the other hand, patients with a lean tissue index beyond the $90^{\text {th }}$ percentile showed a significantly higher serum creatinine level in the range of $0.283+0.132 \mathrm{mg} / \mathrm{dL}$. However, despite the fact that lean tissue index has been reported to decline by about $0.4 \mathrm{~kg} / \mathrm{m}^{2}$ during the 2-year follow-up in incident patients from a baseline of 6 month to 30 months, ${ }^{30}$ this did not significantly affect the trend of 
serum creatinine in our study, probably because magnitude was not the most relevant factor.

The presence of diabetes and of vascular diseases were both associated with a significantly lower serum creatinine compared to those patients without these comorbidities $(-0.874+0.068$ and $-0.336 \pm 0.091 \mathrm{mg} / \mathrm{dL}$ differences, respectively). In addition, diabetics showed a borderline higher increase and patients with vascular disease a comparable borderline lower increase during the 2-year follow-up. Creatinine clearance is expected to be very low from 3 to 27 months after the start of extra-corporeal dialysis, probably in the range of 1 to $8 \mathrm{~mL} / \mathrm{min}^{4}$ and without relevant differences between different dialysis modalities. Therefore, higher levels of predialysis creatinine can be found in patients who either receive a lower dialysis dose or whose superior nutritional status sustains an increased musculature. As already mentioned, in the presence of vascular disease and inflammation, the higher risk of malnutrition could already explain the current results. In diabetics, poorer dialysis tolerance with more frequent predialytic symptoms, such as nausea and vomiting, has been reported. ${ }^{31}$ Whether the higher rate of intra-dialysis symptoms actually compromises the dialysis dose in term of small molecules, with consequent higher increase of creatinine, is still open for proof.

Finally, also for creatinine the presence of post-dialysis fluid overload at the 3-month baseline was associated with lower creatinine level and a higher increase during the 2-year follow-up, probably reflecting the correction of dry body weight.

This study has limitations associated with its retrospective and observational nature. The exclusion of catheter patients reduces the generalizability of the findings. Of particular note are the absence of data on residual renal function and the paucity of data on C-reactive protein and serum bicarbonate. The strength of the study lies in 
the broad geographical distribution in Europe, Middle East and Latin America, ensuring a certain generalizability of the results, as well as in the selection of patients on a homogeneous treatment (i.e. all have three times weekly 4-hour dialysis sessions, treatment by fistula or graft, adequate dialysis dose, and strict fluid overload management according to the treatment protocol of the dialysis chain network).

\section{Conclusions}

This study showed that serum albumin and creatinine levels, which belong to the strongest independent predictors of survival in hemodialysis patients, ${ }^{4,32}$ improved in patients treated according to a good dialysis protocol. The presence of fluid overload and certain comorbidities, such as vascular disease, liver disease and maybe diabetes, may modify the trends. Therefore, monitoring of such visceral and somatic proteins remains of high priority in the follow-up of patients on renal replacement therapy, independent of the need for comprehensive and regular assessments of body composition. 
Protein dynamics in the first 2 years of dialysis

\section{Practical Application}

In the two years after the start of dialysis therapy, serum albumin and creatinine levels increased in this cohort of 3,860 incident dialysis patients. The presence of post-dialysis fluid overload and certain comorbidities, such as vascular disease, liver disease and diabetes, modified these positive trends. Given that albumin and creatinine are predictors of both nutritional status and mortality, and that many dialysis patients suffer from protein energy wasting already in the initial phase of the renal replacement therapy, these results show the importance of monitoring such visceral and somatic proteins from the beginning of dialysis therapy. 
References

1. Fouque $D$, Kalantar-Zadeh $K$, Kopple J, et al. A proposed nomenclature and diagnostic criteria for protein-energy wasting in acute and chronic kidney disease. Kidney Int. 2008;73(4):391-398.

2. Iseki K, Miyasato F, Tokuyama K, et al. Low diastolic blood pressure, hypoalbuminemia, and risk of death in a cohort of chronic hemodialysis patients. Kidney Int. 1997;51(4):1212-1217.

3. Komatsu M, Okazaki M, Tsuchiya K, Kawaguchi H, Nitta K. A Low Serum Albumin Level Predicts Cardiovascular Events in Hemodialysis Patients with Preserved Left Ventricular Ejection Fraction. Int J Clin Med. 2015;6:85-95.

4. Culp K, Flanigan $\mathrm{M}$, Lowrie EG, Lew N, Zimmerman B. Modeling mortality risk in hemodialysis patients using laboratory values as time-dependent covariates. Am J Kidney Dis. 1996;28(5):741-746. 5. Kaysen GA, Dubin JA, Muller HG, Rosales LM, Levin NW. The acute-phase response varies with time and predicts serum albumin levels in hemodialysis patients. The HEMO Study Group. Kidney Int. 2000;58(1):346-352.

6. Kaysen GA, Greene T, Daugirdas JT, et al. Longitudinal and cross-sectional effects of C-reactive protein, equilibrated normalized protein catabolic rate, and serum bicarbonate on creatinine and albumin levels in dialysis patients. Am J Kidney Dis. 2003;42(6):1200-1211.

7. Kalantar-Zadeh K, Kilpatrick RD, Kuwae N, et al. Revisiting mortality predictability of serum albumin in the dialysis population: time dependency, longitudinal changes and populationattributable fraction. Nephrol Dial Transplant. 2005;20(9):1880-1888.

8. Rambod M, Kovesdy CP, Bross R, Kopple JD, Kalantar-Zadeh K. Association of serum prealbumin and its changes over time with clinical outcomes and survival in patients receiving hemodialysis. $A m$ J Clin Nutr. 2008;88(6):1485-1494.

9. Dalrymple LS, Johansen KL, Chertow GM, et al. Longitudinal measures of serum albumin and prealbumin concentrations in incident dialysis patients: the comprehensive dialysis study. $J$ Ren Nutr. 2013;23(2):91-97.

10. Goldwasser P, Kaldas Al, Barth RH. Rise in serum albumin and creatinine in the first half year on hemodialysis. Kidney Int. 1999;56(6):2260-2268.

11. Parker TF, 3rd, Wingard RL, Husni L, Ikizler TA, Parker RA, Hakim RM. Effect of the membrane biocompatibility on nutritional parameters in chronic hemodialysis patients. Kidney Int. 1996;49(2):551-556.

12. Clase CM, St Pierre MW, Churchill DN. Conversion between bromcresol green- and bromcresol purple-measured albumin in renal disease. Nephrol Dial Transplant. 2001;16(9):1925-1929.

13. Moiss U, Wieskotten S, Chamney P, Wabel P. Reference ranges for human body composition and fluid overload. J Am Soc Nephrol. 2009;20:469A.

14. Banerjee T, Kim SJ, Astor B, Shafi T, Coresh J, Powe NR. Vascular access type, inflammatory markers, and mortality in incident hemodialysis patients: the Choices for Healthy Outcomes in Caring for End-Stage Renal Disease (CHOICE) Study. Am J Kidney Dis. 2014;64(6):954-961.

15. Goldstein SL, Ikizler TA, Zappitelli M, Silverstein DM, Ayus JC. Non-infected hemodialysis catheters are associated with increased inflammation compared to arteriovenous fistulas. Kidney Int. 2009;76(10):1063-1069.

16. Marcelli D, Kirchgessner J, Amato C, et al. EuCliD (European Clinical Database): a database comparing different realities. J Nephrol. 2001;14 Suppl 4:S94-100.

17. Marcelli D, Moscardo V, Steil H, et al. Data management and quality assurance for dialysis network. Contrib Nephrol. 2002(137):293-299.

18. Wabel P, Chamney P, Moissl U, Jirka T. Importance of whole-body bioimpedance spectroscopy for the management of fluid balance. Blood Purif. 2009;27(1):75-80.

19. Fahrmeir L, Kneib T, Lang S, Marx B. Regression. Models, Methods and Applications. Berlin: Springer; 2013.

20. Verbeke GM, G. Linear Mixed Models for Longitudinal Data. New York, LLC: Springer; 2009. 
21. Quan $\mathrm{H}$, Sundararajan $\mathrm{V}$, Halfon $\mathrm{P}$, et al. Coding algorithms for defining comorbidities in ICD-9CM and ICD-10 administrative data. Med Care. 2005;43(11):1130-1139.

22. Foucan L, Merault H, Velayoudom-Cephise FL, Larifla L, Alecu C, Ducros J. Impact of protein energy wasting status on survival among Afro-Caribbean hemodialysis patients: a 3-year prospective study. Springerplus. 2015;4:452.

23. Usvyat LA, Barth C, Bayh I, et al. Interdialytic weight gain, systolic blood pressure, serum albumin, and C-reactive protein levels change in chronic dialysis patients prior to death. Kidney Int. 2013;84(1):149-157.

24. Gunal Al, Kirciman E, Guler M, Yavuzkir M, Celiker H. Should the preservation of residual renal function cost volume overload and its consequence left ventricular hypertrophy in new hemodialysis patients? Ren Fail. 2004;26(4):405-409.

25. Locatelli F, Mastrangelo F, Redaelli B, et al. Effects of different membranes and dialysis technologies on patient treatment tolerance and nutritional parameters. The Italian Cooperative Dialysis Study Group. Kidney Int. 1996;50(4):1293-1302.

26. Kaysen GA. Inflammation: cause of vascular disease and malnutrition in dialysis patients. Semin Nephrol. 2004;24(5):431-436.

27. Jadoul MB, P, Gerges, B; Jamez, J; Loute, G; Pochet, JM; Quoidbach, A; Stolear, JC; Pirson, Y. Dry body weight evolution on long ter-term HD. J Am Soc Nephrol. 1998;9:212A.

28. Jansen MA, Hart AA, Korevaar JC, et al. Predictors of the rate of decline of residual renal function in incident dialysis patients. Kidney Int. 2002;62(3):1046-1053.

29. MacAulay J, Thompson K, Kiberd BA, Barnes DC, Peltekian KM. Serum creatinine in patients with advanced liver disease is of limited value for identification of moderate renal dysfunction: are the equations for estimating renal function better? Can J Gastroenterol. 2006;20(8):521-526.

30. Marcelli $D$, Brand $K$, Ponce $P$, et al. Longitudinal changes in body composition in patients after initiation of hemodialysis therapy: results from an international cohort. J Ren Nutr. 2015.

31. Brunet $P$, Saingra $Y$, Leonetti $F$, Vacher-Coponat $H$, Ramananarivo $P$, Berland $Y$. Tolerance of haemodialysis: a randomized cross-over trial of 5-h versus 4-h treatment time. Nephrol Dial Transplant. 1996;11 Suppl 8:46-51.

32. Goldwasser P, Feldman J. Association of serum albumin and mortality risk. J Clin Epidemiol. 1997;50(6):693-703. 


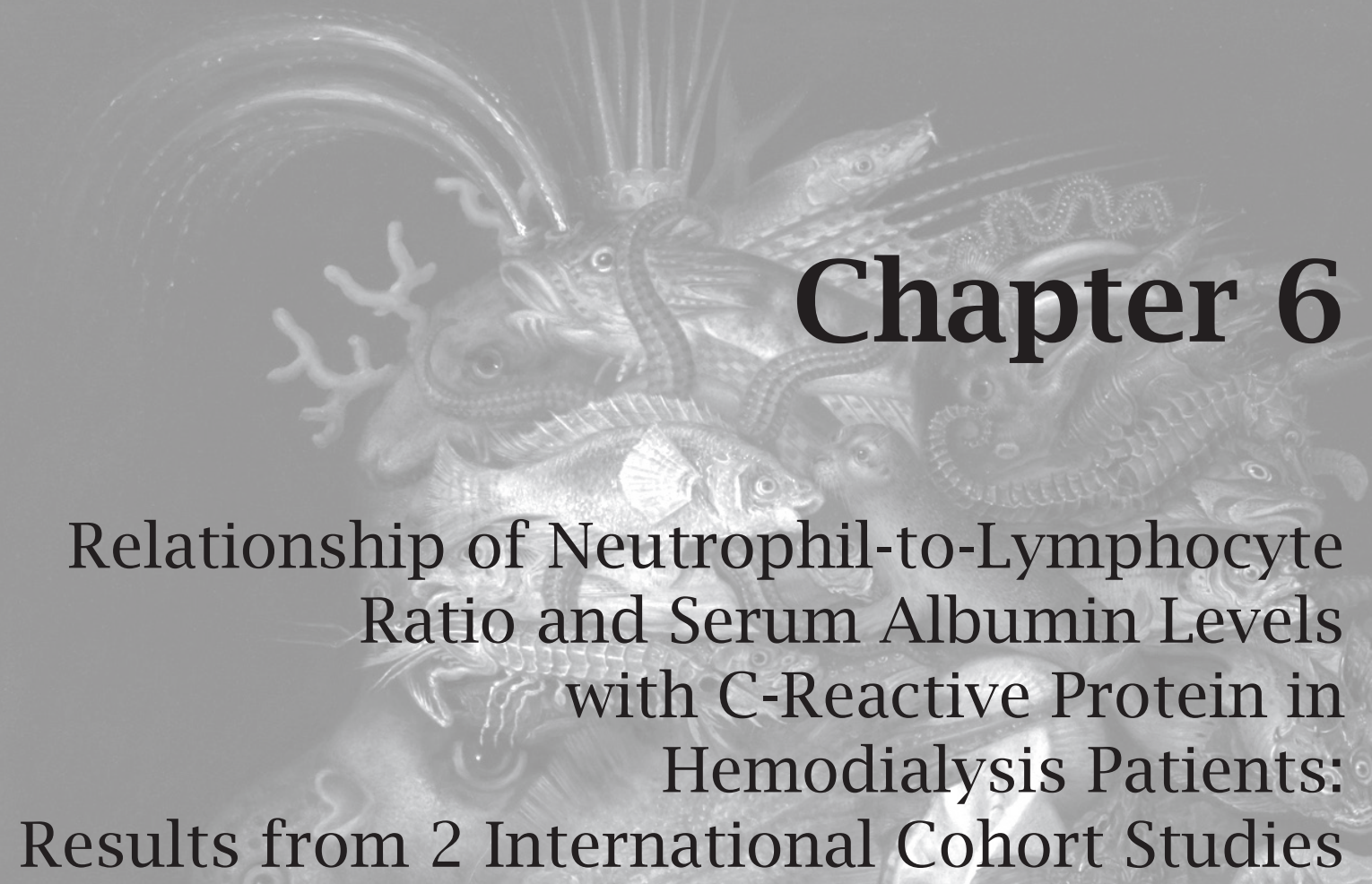

\section{Relationship of Neutrophil-to-Lymphocyte Ratio and Serum Albumin Levels with C-Reactive Protein in Hemodialysis Patients: Results from 2 International Cohort Studies}

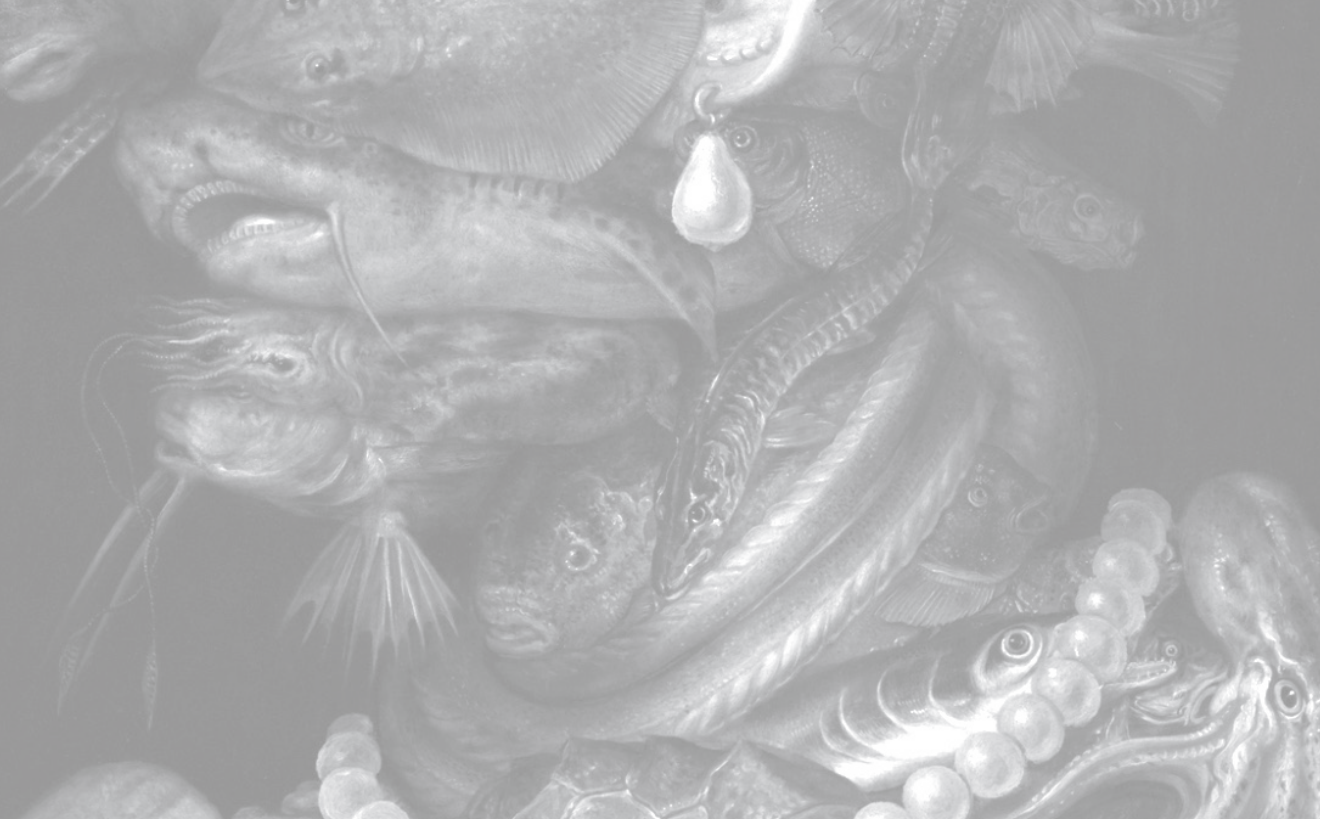

Rakesh Malhotra*, Daniele Marcelli*, Gero von Gersdorff, Aileen Grassmann, Mathias Schaller, Inga Bayh, Laura Scatizzi, Michael Etter, Adrian Guinsburg,Claudia Barth, Cristina Marelli, Paola Carioni, Frank van der Sande, Jeroen P. Kooman, Eric Liu, Ted Toffelmire, Yuedong Wang, Stephan Thijssen,

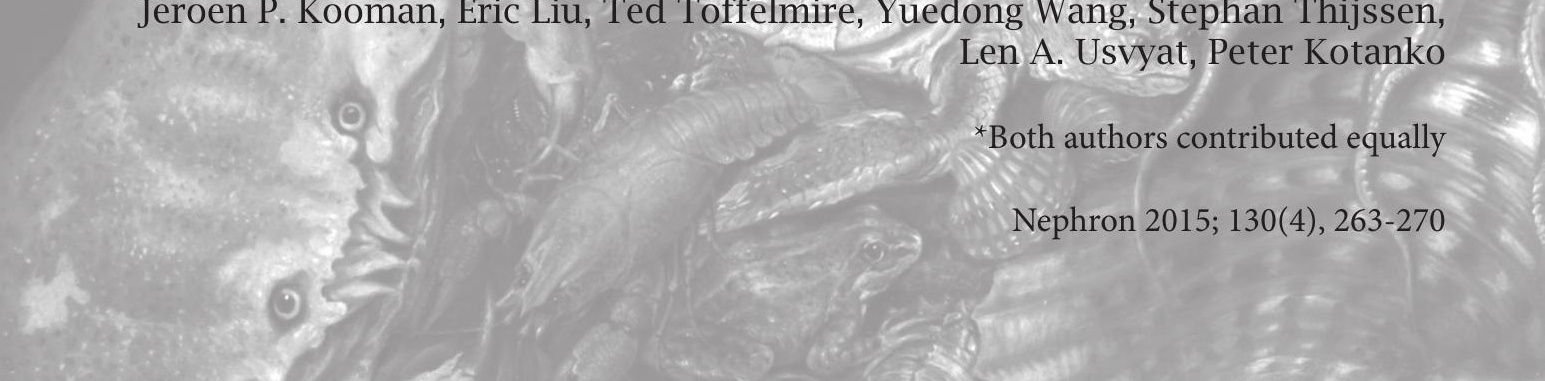




\section{Relationship of NLR and Albumin with CRP in hemodialysis patients}

Abstract

Background/Aim

The neutrophil-to-lymphocyte ratio (NLR), defined as the neutrophil count divided by lymphocyte count, is an inexpensive and readily available parameter, which may serve as a surrogate for inflammation markers, such as C-reactive protein (CRP). The aim of this study was to determine the utility of NLR in the prediction of elevated CRP levels in hemodialysis (HD) patients.

\section{Methods}

We analyzed 43,272 HD patients from 2 distinct cohorts within the Monitoring Dialysis Outcomes research collaboration in whom contemporaneous measurements of neutrophil and lymphocyte counts, serum albumin and CRP levels were available. Logistic regression was used to determine the relationship of trichotomized NLR $(<2.5,2.5-5$ and $>5.0)$ and albumin levels $(<3.1,3.1-4.0$ and $>4.0$ $\mathrm{g} / \mathrm{dl})$ with elevated CRP levels $(>10.0,>20.0$ and $>30.0 \mathrm{mg} / \mathrm{l})$. Congruence of the prediction models was examined by comparing the regression parameters and by cross-validating each regression equation within the other cohort.

\section{Results}

We found that NLR $>5.0$ vs. $<2.5$ (cohort 1: OR 2.3; $p<0.0001$ and cohort 2: OR 2.0; $p<0.0001$ ) was associated with CRP levels $>10.0 \mathrm{mg} / \mathrm{l}$. Stepwise increase in odds ratio for CRP $>10.0 \mathrm{mg} / \mathrm{l}$ was observed with the combination of high NLR and low albumin levels (NLR $>5.0$ and albumin $<3.1)$ (cohort 1: OR 7.6; $p<0.0001$ and cohort 2: OR 11.9; $p<0.0001$ ). Cross-validation of the 2 regression models revealed a predictive accuracy of 0.68 and 0.69 in the respective cohorts.

\section{Conclusion}

This study suggests that NLR could serve as a potential surrogate marker for CRP. Our results may add to diagnostic abilities in settings where CRP is not measured routinely in HD patients. NLR is easy to integrate into daily practice and may be used as a marker of systemic inflammation. 


\section{Introduction}

Cardiovascular events, infections, anemia and malnutrition are well recognized complications in hemodialysis (HD) patients and are associated with increased morbidity and mortality ${ }^{1-5}$. The underlying causes for the development of these complications are complex, multifactorial and poorly understood. Over the past decade, there has been increasing evidence linking oxidative stress and inflammation with multiple disease states including myocardial infarction and stroke $e^{6,7}$. Several studies in the chronic HD patient population have shown elevated levels of circulating inflammatory markers, suggesting susceptibility for both micro and macro vascular complications ${ }^{8,9}$. Various biomarkers including total lymphocyte count, C-reactive protein (CRP), interleukin (IL)-6, IL-18, tumor necrosis factor- $\alpha$ (TNF- $\alpha$ ), pentraxin-3, and proteases such as matrix metalloproteinase- 9 have been proposed to measure systemic inflammation and are associated with increased hospitalization trends and mortality in HD patients ${ }^{10-21}$. CRP, an acute-phase reactant, has emerged as the most widespread inflammatory biomarker for clinical use. CRP is chemically stable and has a relatively long half-life without diurnal variation ${ }^{22,23}$. Recently, neutrophil-to-lymphocyte ratio (NLR) has been increasingly recognized as a marker of systemic inflammation in oncology and cardiology literature, where elevated levels of NLR have been reported to be associated with poor outcomes ${ }^{24-26}$. We have recently shown that elevated NLR may also be linked with poor prognosis in chronic HD patients. However, there is scarcity of clinical studies concerning NLR and its relationship to other inflammatory biomarkers. The aim of our study was to evaluate whether NLR correlated with CRP levels. Furthermore, we aimed at determining whether a combination of inflammatory markers (NLR and albumin levels) improves prediction of CRP levels in chronic HD patients. We suggest that NLR can be a surrogate marker of systemic inflammation and serve as a useful tool to identify subgroups of patients who are at a heightened risk of cardiovascular and non-cardiovascular complications. Additionally, NLR because of its easy availability and cost-efficiency may be used to assist physicians and nephrologists to evaluate nutritional and cardiovascular status and prognostic outcome in HD patients in locations where CRP is not available. 


\section{Material and Methods}

Study Population

This cross-sectional and retrospective study was conducted at the Renal Research Institute, New York, N.Y., USA. Patients included in this study were part of MONDO (Monitoring Dialysis Outcomes). MONDO is a global, multicenter research collaboration that was designed to explore the determinants of patient survival in worldwide HD population, where longitudinal clinical data were collected in 148,772 patients from 27 countries in 5 continents (Asia, Europe, North America, South America and Australia) ${ }^{27}$. The institutional review board committee at each of the participant institutions approved the study independently. Informed consent was

obtained as required in each country. This analysis was restricted to HD patients with available demographic information (age, sex and dialysis vintage) and contemporaneous laboratory parameters (serum albumin, neutrophil count, lymphocyte count and CRP levels). Consequently, the study population comprised a sample of $27,326 \mathrm{HD}$ patients from Fresenius Medical Care (FMC) clinics in 17 European countries (cohort 1) and 15,946 HD patients from Kuratorium fur Heimdialyse $(\mathrm{KfH})$ centers in Germany (cohort 2).

\section{Data Collection and Measurements}

The independent variables of interest were NLR and albumin levels. Total white cell count, neutrophils and lymphocytes counts were determined using an automated blood cell counter. NLR was calculated as a simple ratio between the absolute neutrophil and the absolute lymphocyte counts. The same blood samples were analyzed to measure albumin levels according to local laboratory standards by one of the following methodologies: nephelometry, bromocresol green or bromocresol purple (Sigma-Aldrich, St. Louis, Mo., USA $)^{28,29}$. Bromocresol purple measurements were later converted to the bromocresol green method $^{30}$. The independent variables NLR and albumin levels were trichotomized (NLR $<2.5,2.5-5$ and $>5.0$ and albumin $<3.1,3.1-4.0$ and $>4.0 \mathrm{~g} / \mathrm{dl}$ ) based on practical clinical 
cut-off points described in the literature ${ }^{31,32}$. The primary dependent variable was CRP measured in $\mathrm{mg} / \mathrm{l}$. CRP values were trichotomized at $(>10.0,>20.0$ and $>30.0 \mathrm{mg} / \mathrm{l})$. These cut-offs were selected based on reference ranges for CRP reported in literature ${ }^{33,34}$. We have chosen categorization because it is easier to interpret and also because of its simplicity in reporting results.

\section{Statistical Analysis}

A logistic regression was used to determine the relationship of trichotomized NLR and albumin levels, respectively, with elevated CRP levels $(>10.0,>20.0$ and $>30.0 \mathrm{mg} / \mathrm{l})$ as an outcome variable.

Continuous variables were expressed as the mean (SD) or median and interquartile range (IQR). Categorical variables were expressed as absolute (n) and relative (\%) frequency. Natural log transformation was applied to non-normal distributions. Spearman rank correlation was used to examine the relationship between continuous variables (NLR and CRP). A forward stepwise logistic regression model was developed to determine the relationship between trichotomized $\operatorname{NLR}(<2.5,2.5-5$ and $>5.0)$ and albumin levels $(<3.1,3.1-4.0$ and $>4.0 \mathrm{~g} /$ day $)$, respectively, with elevated CRP levels $(>10.0,>20.0$ and $>30.0 \mathrm{mg} / \mathrm{l})$, adjusting for confounders including age, sex and dialysis vintage. The entry and retention $p$ value thresholds were set at $p<0.05$ and $p<0.1$, respectively.

Statistical analysis was performed using SPSS software version 17.0 (SPSS, Chicago, III., USA) and R (version 2.12.0). A 2-tailed $p$ value $<0.05$ was considered statistically significant. 
Table 1. Characteristics of the patients in cohort $1(n=27,326)$ and cohort $2(\mathrm{n}=15,946)$

\begin{tabular}{|c|c|c|}
\hline Characteristics & Cohort 1 & Cohort 2 \\
\hline Age, years & $63.4 \pm 15.3$ & $63.1 \pm 16.5$ \\
\hline Gender, male, n (\%) & $15,946(60.4)$ & $9,503(59.6)$ \\
\hline \multicolumn{3}{|l|}{ Countries, $\mathrm{n}(\%)$} \\
\hline Germany & - & $15,946(100.0)$ \\
\hline Turkey & $7,159(26.2)$ & - \\
\hline Spain & $6,630(24.3)$ & - \\
\hline Portugal & $5,571(20.4)$ & - \\
\hline Italy & $2,117(7.7)$ & - \\
\hline Hungary & $1,671(6.1)$ & - \\
\hline Romania & $1,254(4.6)$ & - \\
\hline Czech Republic & $975(3.6)$ & - \\
\hline France & $696(2.5)$ & - \\
\hline Russia & $529(1.9)$ & - \\
\hline Serbia & $334(1.2)$ & - \\
\hline United Kingdom & $223(0.8)$ & - \\
\hline Slovakia & $139(0.5)$ & - \\
\hline Slovenia & $28(0.1)$ & - \\
\hline \multicolumn{3}{|l|}{ Blood chemistry } \\
\hline Hemoglobin, g/dl & $11.4 \pm 1.6$ & $11.5 \pm 1.3$ \\
\hline Serum sodium, mg/dl & $138.5 \pm 1.0$ & $138.3 \pm 3.4$ \\
\hline Potassium, mg/dl & $5.1 \pm 0.8$ & $5.1 \pm 0.8$ \\
\hline Creatinine, mg/dl & $7.6 \pm 2.5$ & $7.5 \pm 3.0$ \\
\hline Calcium & $8.9 \pm 0.8$ & $9.1 \pm 0.8$ \\
\hline Phosphorous, mg/dl & $4.7 \pm 1.5$ & $5.4 \pm 1.5$ \\
\hline Total leucocytes, $\times 10^{9} / 1$ & $6.9 \pm 2.5$ & $7.6 \pm 10.5$ \\
\hline Neutrophils, $\times 10^{9} / 1$ & $4.3 \pm 2.1$ & $5.0 \pm 7.1$ \\
\hline Lymphocytes, $\times 10^{9} / 1$ & $1.6 \pm 0.9$ & $1.5 \pm 3.1$ \\
\hline Platelets, $\times 10^{9} / 1$ & $212.9 \pm 75.7$ & $230.1 \pm 79.1$ \\
\hline Albumin, g/dl & $3.9 \pm 0.5$ & $3.8 \pm 0.5$ \\
\hline $\mathrm{CRP}, \mathrm{mg} / \mathrm{l}$ & $6.3(0.10-160)$ & $5.9(0.10-459)$ \\
\hline HD vintage, months & $33.2(11.30-73.67)$ & $13.0(4.0-44.0)$ \\
\hline $\mathrm{Kt} / \mathrm{V}$ & $1.4 \pm 0.3$ & $1.5 \pm 0.5$ \\
\hline Urea reduction ratio & $73.6 \pm 8.0$ & $69.0 \pm 8.9$ \\
\hline
\end{tabular}

Continuous variables are expressed as mean $\pm \mathrm{SD}$ or median (IQR) and categorical variables as frequency $(\mathrm{n})$ and percentage (\%). 
Relationship of NLR and Albumin with CRP in hemodialysis patients

\section{Results}

Baseline characteristics of both cohorts are shown in table 1. In cohort 1, 27,326 patients enrolled with the mean age of 63.5 years (SD 15.2), and 16,251 (60.4\%) were male. Cohort 2 consisted of 15,946 patients with a mean age of 63.1 years (SD 16.5), and 9,503 (59.6\%) were male.

The median dialysis vintages in both cohorts were 33.2 months (IQR 11.3-73.7 months) and 13.0 months (IQR 4.0-44.0 months), respectively. The mean total leukocyte, absolute neutrophil and absolute lymphocyte counts in cohorts 1 and 2 were $6.9 \pm 2.5 \times 10^{9} / /, 4.3 \pm 2.1 \times 10^{9} / /$ and $1.6 \pm 0.9 \times 10^{9} / /$ and $7.6 \pm 10.5 \times 10^{9} / /$, $5.0 \pm 7.1 \times 10^{9} / /$ and $1.5 \pm 3.1 \times 10^{9} /$, respectively (table 1 )

Table 2. Multivariate regression analysis for association between NLR and CRP levels ( $>10 \mathrm{mg} / \mathrm{l})$ in HD patients

\begin{tabular}{|c|c|c|c|c|}
\hline & \multirow[t]{2}{*}{ Coefficient } & \multirow[t]{2}{*}{ OR } & \multicolumn{2}{|c|}{$95 \%$ CI for OR } \\
\hline & & & lower & upper \\
\hline \multicolumn{5}{|l|}{ a Cohort $1(n=27,326)$} \\
\hline Age, years* & 0.015 & 1.015 & 1.014 & 1.017 \\
\hline \multicolumn{5}{|l|}{ Gender } \\
\hline Male* & 0.156 & 1.168 & 1.109 & 1.231 \\
\hline Female & & 1.0 (reference) & & \\
\hline Neutrophils, $\times 10^{9} / 1^{*}$ & 0.105 & 1.111 & 1.068 & 1.155 \\
\hline Total leukocytes, $\times 10^{9} / 1^{*}$ & 0.063 & 1.065 & 1.036 & 1.096 \\
\hline \multicolumn{5}{|l|}{ NLR } \\
\hline$>5.0^{*}$ & 0.826 & 2.284 & 2.046 & 2.549 \\
\hline $2.5-5.0^{*}$ & 0.352 & 1.421 & 1.331 & 1.518 \\
\hline$<2.5$ & & 1.0 (reference) & & \\
\hline \multicolumn{5}{|l|}{ b Cohort $2(n=15,946)$} \\
\hline Age, years* & 0.019 & 1.019 & 1.016 & 1.021 \\
\hline \multicolumn{5}{|l|}{ Gender } \\
\hline Male* & 0.210 & 1.234 & 1.148 & 1.326 \\
\hline Female & & 1.0 (reference) & & \\
\hline Lymphocytes, $\times 10^{9} / 1^{*}$ & -0.322 & 0.725 & 0.664 & 0.790 \\
\hline Total leukocytes, $\times 10^{9} / 1^{*}$ & 0.241 & 1.273 & 1.205 & 1.345 \\
\hline \multicolumn{5}{|l|}{ NLR } \\
\hline$>5.0^{*}$ & 0.714 & 2.042 & 1.746 & 2.389 \\
\hline $2.5-5.0^{*}$ & 0.336 & 1.400 & 1.258 & 1.557 \\
\hline$<2.5$ & & 1.0 (reference) & & \\
\hline
\end{tabular}

A dichotomous datum CRP $(\leq 10.0 />10.0 \mathrm{mg} / \mathrm{l})$ was the dependent variable. ${ }^{*} \mathrm{p}<0.0001$. 
Bivariate correlation analysis showed a significant positive correlation between NLR and CRP in cohort 1 (Spearman rank correlation $\rho=0.23 ; p<0.0001$ ) and negative association between NLR and serum albumin levels in both cohorts $(\rho=-0.18$ and $\rho$ $=-0.27 ; p<0.0001$, respectively). Correlation between NLR and CRP was 0.04 in cohort 2. Stepwise multiple logistic regression analysis for both cohorts showed that high levels of NLR are independently associated with high CRP levels (>10.0 mg/l) (NLR >5.0 vs. $<2.5$; adjusted OR 2.3, 95\% Cl 2.1-2.6; $p<0.0001$ and adjusted OR 2.0, 95\% Cl 1.8-2.4; $p<0.0001$, respectively; table $2 a, b)$. Similarly, low levels of albumin were associated with high CRP levels (albumin $<3.1 \mathrm{vs}$. $>4.0 \mathrm{~g} / \mathrm{dl}$; cohort 1 : adjusted OR 3.39, 95\% Cl 2.99-3.85; $p<0.0001$ and cohort 2: adjusted OR 5.59, 95\% Cl 4.94-6.33; $p<0.0001)$. There was stepwise increase in odds ratio for high CRP (>10.0 mg/l) with stepwise increase in NLR and low albumin levels in both study cohorts (table 3 a, b).

When CRP cut-off values were increased $(>10.0,>20.0$ and $>30.0 \mathrm{mg} / \mathrm{l})$, odds of prediction improved in both the study cohorts (fig. 1).

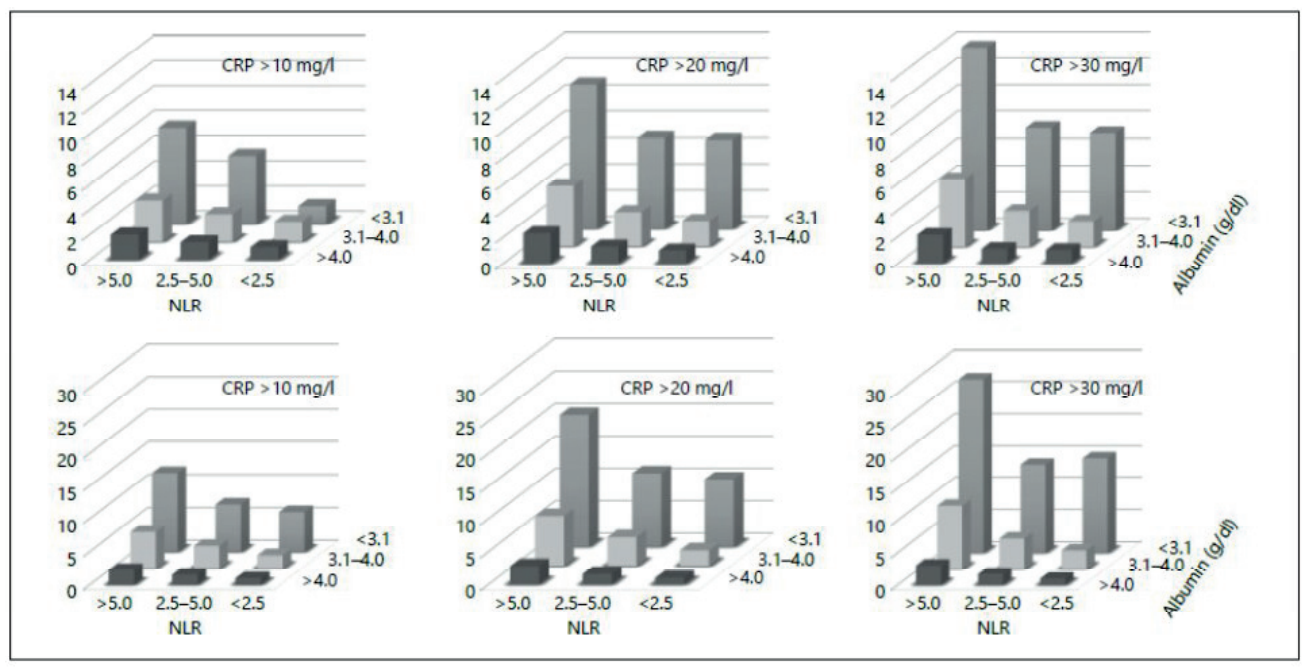

Fig. 1. Relationship between the adjusted odds ratio for CRP $>10.0,>20.0$ and $>30.0 \mathrm{mg} / \mathrm{l}$ and the predictor variables albumin and NLR in cohorts 1 and 2, respectively. 
Cross validation of the 2 regression models for CRP cut-off $>10.0 \mathrm{mg} / \mathrm{l}$ revealed predictive accuracy of $0.68(95 \% \mathrm{Cl} 0.67-0.69)$ for prediction in cohort 2 and 0.69 $(95 \% \mathrm{Cl} 0.68-0.70)$ for prediction in cohort 1 , respectively (fig. 2$)$. The predictive models exhibited a higher and statistically significant diagnostic accuracy with higher CRP cut-off points in both study cohorts (fig. 2).

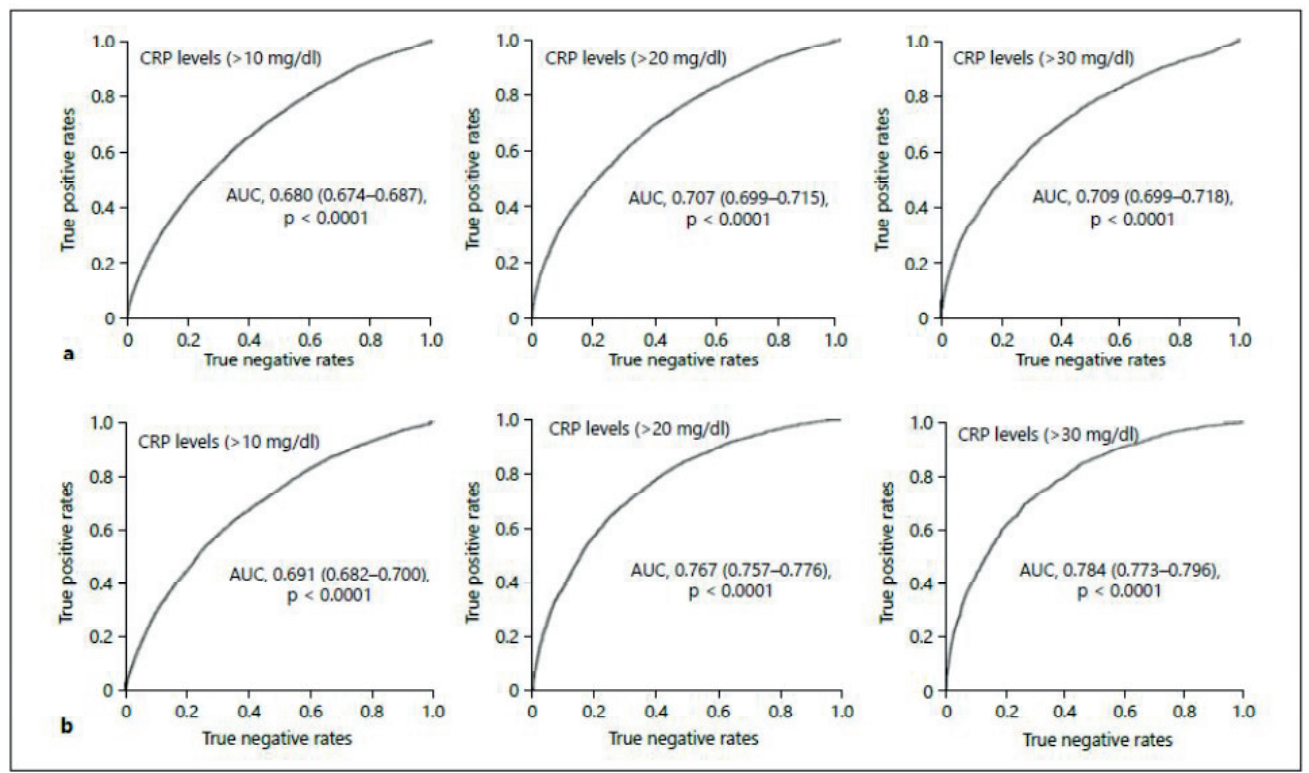

Fig. 2. Cross-validated receiver-operative curves: cohort 1 training models in cohort 2 (a) and cohort 2 training models in cohort 1 (b).

\section{Discussion}

In this study, a statistically significant positive association was found between NLR and CRP levels in the MONDO cohort. This result is not surprising because leukocytes have long been recognized as principal effectors cell in the acute 
Table 3. Multivariate regression analysis for association between combination of NLR and albumin levels and CRP levels $(>10 \mathrm{mg} / \mathrm{l})$ in $\mathrm{HD}$ patients

\begin{tabular}{|c|c|c|c|c|}
\hline & \multirow[t]{2}{*}{ Coefficient } & \multirow[t]{2}{*}{ OR } & \multicolumn{2}{|c|}{$95 \% \mathrm{CI}$ for OR } \\
\hline & & & lower & upper \\
\hline \multicolumn{5}{|l|}{ a Cohort $1(n=27,326)$} \\
\hline Age, years* & 0.012 & 1.012 & 1.010 & 1.013 \\
\hline \multicolumn{5}{|l|}{ Gender } \\
\hline Male* & 0.199 & 1.220 & 1.156 & 1.287 \\
\hline Female & & 1.0 (reference) & & \\
\hline Total leukocytes, $\times 10^{9} / 1^{*}$ & 0.068 & 1.070 & 1.040 & 1.101 \\
\hline Absolute neutrophils, $\times 10^{9} / 1^{*}$ & 0.105 & 1.111 & 1.067 & 1.157 \\
\hline Vintage, months* & 0.001 & 1.001 & 1.000 & 1.001 \\
\hline NLR $>5.0$ and albumin $<3.1^{*}$ & 2.031 & 7.620 & 5.875 & 9.885 \\
\hline NLR $2.5-5.0$ and albumin $<3.1^{*}$ & 1.678 & 5.356 & 4.430 & 6.476 \\
\hline NLR $<2.5$ and albumin $<3.1^{*}$ & 1.399 & 4.052 & 3.282 & 5.003 \\
\hline NLR $>5.0$ and albumin $3.1-4.0^{*}$ & 1.184 & 3.269 & 2.850 & 3.749 \\
\hline NLR $2.5-5.0$ and albumin $3.1-4.0^{*}$ & 0.793 & 2.209 & 2.002 & 2.414 \\
\hline NLR $<2.5$ and albumin $3.1-4.0^{*}$ & 0.469 & 1.598 & 1.470 & 1.737 \\
\hline NLR $>5.0$ and albumin $>4.0^{*}$ & 0.681 & 1.976 & 1.677 & 2.328 \\
\hline NLR $2.5-5.0$ and albumin $>4.0^{*}$ & 0.314 & 1.369 & 1.246 & 1.505 \\
\hline NLR $<2.5$ and albumin $>4.0$ & & 1.0 (reference) & & \\
\hline \multicolumn{5}{|l|}{ b Cohort $2(n=15,946)$} \\
\hline Age, years* & 0.017 & 1.017 & 1.015 & 1.020 \\
\hline \multicolumn{5}{|l|}{ Gender } \\
\hline Male* & 0.311 & 1.365 & 1.268 & 1.469 \\
\hline Female & & 1.0 (reference) & & \\
\hline Total leukocytes, $\times 10^{9} / 1^{*}$ & 0.109 & 1.115 & 1.070 & 1.163 \\
\hline Absolute neutrophils, $\times 10^{9} / 1^{*}$ & 0.087 & 1.091 & 1.032 & 1.154 \\
\hline Vintage, months* & 0.002 & 1.002 & 1.002 & 1.003 \\
\hline NLR $>5.0$ and albumin $<3.1^{*}$ & 2.482 & 11.965 & 9.113 & 15.170 \\
\hline NLR $2.5-5.0$ and albumin $<3.1^{*}$ & 1.966 & 7.145 & 5.747 & 8.884 \\
\hline NLR $<2.5$ and albumin $<3.1^{*}$ & 1.791 & 5.994 & 4.609 & 7.796 \\
\hline NLR $>5.0$ and albumin $3.1-4.0^{*}$ & 1.695 & 5.446 & 4.480 & 6.621 \\
\hline NLR $2.5-5.0$ and albumin $3.1-4.0^{*}$ & 1.214 & 3.366 & 2.861 & 3.961 \\
\hline NLR $<2.5$ and albumin $3.1-4.0^{*}$ & 0.675 & 1.964 & 1.656 & 2.329 \\
\hline NLR $>5.0$ and albumin $>4.0^{*}$ & 0.816 & 2.262 & 1.808 & 2.831 \\
\hline NLR $2.5-5.0$ and albumin $>4.0^{*}$ & 0.428 & 1.534 & 1.285 & 1.831 \\
\hline NLR $<2.5$ and albumin $>4.0$ & & 1.0 (reference) & & \\
\hline
\end{tabular}

A dichotomous datum CRP $(\leq 10.0 />10.0 \mathrm{mg} / \mathrm{l})$ was the dependent variable. ${ }^{*} \mathrm{p}<0.0001$.

Experimental models have shown that inflammatory cells, mainly neutrophils, possibly regulate CRP levels through secretion of pro-inflammatory cytokine TNF- $\alpha$ and IL-6 ${ }^{36}$. In fact, cellular immune response to infection is characterized by the elevation of neutrophil count and decline in lymphocyte count ${ }^{37}$. Recently, Turkmen et al. $^{38}$ have shown positive correlation between NLR and TNF- $\alpha$ in HD patients. In 
this study, serum albumin levels were negatively correlated with both NLR and CRP levels. These findings are consistent with the published literature that albumin behaves as a negative acute phase protein and also support the concept of Malnutrition-Inflammation Complex in HD patients ${ }^{39,40}$.

One of the findings of this study is that high NLR significantly predicts high CRP levels (NLR >5.0 vs. <2.5; cohort 1: OR 3.9, 95\% Cl 3.5-4.2; $p<0.0001$ and cohort 2: OR 3.2, 95\% Cl 3.0-3.6; $p<0.0001)$ in HD patients. A high CRP level was defined as values $>10 \mathrm{mg} / \mathrm{dl}$. This relationship remains materially unchanged even after adjusting for age, gender and dialysis vintage (NLR $>5.0$ vs. $<2.5$; cohort 1 : adjusted OR 2.3, 95\% Cl 2.1-2.6; $\mathrm{p}<0.0001$ and cohort 2: adjusted OR 2.0, 95\% Cl $1.8-2.4 ; p<0.0001$, respectively). Interestingly, in the multivariate regression model, absolute neutrophil and absolute lymphocyte counts separately were not strongly associated with high CRP levels as compared to NLR. There is also evidence about a similar trend in relationship between absolute neutrophil and lymphocyte counts and serum TNF- $\alpha^{37}$. These findings are clinically relevant, suggesting NLR to be a better predictor of CRP than the total number of white cell count.

We also found an additive relationship between albumin and NLR levels in terms of predicting an individual likelihood of high CRP level. As shown in table 3 a, subjects with high NLR and low albumin levels (NLR $>5.0$ and albumin level $<3.1 \mathrm{~g} / \mathrm{dl}$ ) had a 7.6-fold greater odds of having elevated CRP level >10 mg/l (95\% Cl 5.5-9.9) as compared to the 2-fold odds with high NLR alone (95\% Cl 1.7-2.4) and the 3.39-fold odds with low albumin alone $(95 \% \mathrm{Cl} 2.99-3.85)$ in cohort 1 (table 2 a). Similar trends were seen in cohort 2 (tables $2 \mathrm{~b}$ and $3 \mathrm{~b}$ ). In this study, we showed that the regression model derived from NLR and albumin can predict CRP levels in HD 
population with an area under an ROC curve of 0.68 and 0.69 in 2 different cohorts (fig. 2).

We suggest that the use of an NLR as an inflammatory biomarker in HD patients has significant diagnostic benefits. Considering the short half-life of neutrophils, NLR can be used as an effective marker of acute inflammation and reflect the intensity of systemic inflammation. Serial measurements of NLR may be used to identify HD patients at high risk for an adverse outcome and thus help in informed medical decision making. Recent studies have suggested that the epidemiological association of CRP with cardiovascular events is widely exaggerated ${ }^{41-45}$. In fact, other inflammatory markers, including serum albumin and leukocyte count, have shown similar associations with cardiovascular disease risk $^{41-45}$. A systemic approach incorporating NLR with other inflammatory biomarkers and traditional risk factors may improve the diagnostic accuracy of cardiovascular and noncardiovascular risk prediction models. In addition, NLR may also be used as a tool to monitor the effect of anti-inflammatory therapies ${ }^{46}$. Most importantly, NLR is routinely available and easy and inexpensive to measure, and thus could be used as a costeffective surrogate to CRP in dialysis units (approximate CBC with differential cost per sample; Europe: EUR 3.50 and United states: USD 4.25; CRP cost per sample; Europe: EUR 11.66 and United States: USD 7.04); it can also be used in resource limited settings lacking the facility for measuring CRP for therapeutic decision making. An additional consideration is the fact that in most European countries, CPR is measured no more than once a month on a routine basis, limiting its utility to detect inflammation at the right time.

This study has several strengths. This was a multicenter study with a large sample size and wide geographic representation, thus increasing the generalization of the 
results. The study also has limitations. First, it was a cross-sectional analysis because NLR, albumin and CRP levels were considered only once in our study. Second, the majority of the patient population was Caucasian. Also, leukocyte and neutrophil counts are nonspecific and have high false-positive and false-negative rates to predict cardiovascular complications ${ }^{47}$.

In summary, the results of the present study highlight the relationship between NLR, albumin and CRP levels. It is shown that NLR may be a surrogate marker of systemic inflammation in its ability to predict CRP levels. Addition of albumin to NLR substantially improves the prediction of CRP. NLR may not be the best available laboratory-based assay to measure inflammation. However, from a pragmatic standpoint, it can certainly be a useful assay for systemic inflammation in resourcelimited settings. In-depth and epidemiological studies of high standards are further required to establish the potential clinical utility and applicability of NLR. Further studies are also warranted to assess the contributing role of albumin and NLR in predicting other inflammatory biomarkers. Lastly, it will be interesting to study if NLR can provide independent prognostic information over and above that provided by inflammatory biomarkers such as CRP. 
Relationship of NLR and Albumin with CRP in hemodialysis patients

\section{Acknowledgments}

This work was supported by Renal Research Institute, a wholly owned subsidiary of

Fresenius Medical Care North America. Parts of this work were presented at the

ERA-EDTA 2012 conference in Paris, France on May 24-27, 2012.

Reference List

1. de Jager DJ, Grootendorst DC, Jager KJ, et al. Cardiovascular and noncardiovascular mortality among patients starting dialysis. JAMA. 2009;302(16):1782-1789.

2. Robinson BM, Joffe MM, Berns JS, Pisoni RL, Port FK, Feldman HI. Anemia and mortality in hemodialysis patients: accounting for morbidity and treatment variables updated over time. Kidney Int. 2005;68(5):2323-2330.

3. Ishani A, Collins AJ, Herzog CA, Foley RN. Septicemia, access and cardiovascular disease in dialysis patients: the USRDS Wave 2 study. Kidney Int. 2005;68(1):311-318.

4. Fein PA, Mittman N, Gadh R, et al. Malnutrition and inflammation in peritoneal dialysis patients. Kidney Int Suppl. 2003(87):S87-91.

5. Mailloux LU, Bellucci AG, Wilkes BM, et al. Mortality in dialysis patients: analysis of the causes of death. Am J Kidney Dis. 1991;18(3):326-335.

6. Allen $\mathrm{CL}$, Bayraktutan $\mathrm{U}$. Oxidative stress and its role in the pathogenesis of ischaemic stroke. Int J Stroke. 2009;4(6):461-470.

7. Cottone $\mathrm{S}$, Lorito $\mathrm{MC}$, Riccobene $\mathrm{R}$, et al. Oxidative stress, inflammation and cardiovascular disease in chronic renal failure. Journal of nephrology. 2008;21(2):175-179.

8. Shlipak MG, Fried LF, Crump C, et al. Elevations of inflammatory and procoagulant biomarkers in elderly persons with renal insufficiency. Circulation. 2003;107(1):87-92.

9. Filiopoulos V, Hadjiyannakos D, Takouli L, Metaxaki P, Sideris V, Vlassopoulos D. Inflammation and oxidative stress in end-stage renal disease patients treated with hemodialysis or peritoneal dialysis. Int J Artif Organs. 2009;32(12):872-882.

10. Pupim LB, Himmelfarb J, McMonagle E, Shyr Y, Ikizler TA. Influence of initiation of maintenance hemodialysis on biomarkers of inflammation and oxidative stress. Kidney Int. 2004;65(6):2371-2379.

11. Herbelin A, Urena P, Nguyen AT, Zingraff J, Descamps-Latscha B. Elevated circulating levels of interleukin-6 in patients with chronic renal failure. Kidney Int. 1991;39(5):954-960.

12. Samouilidou EC, Grapsa EJ, Kakavas I, Lagouranis A, Agrogiannis B. Oxidative stress markers and C-reactive protein in end-stage renal failure patients on dialysis. Int Urol Nephrol. 2003;35(3):393-397.

13. Kuwae N, Kopple JD, Kalantar-Zadeh K. A low lymphocyte percentage is a predictor of mortality and hospitalization in hemodialysis patients. Clin Nephrol. 2005;63(1):22-34.

14. Streja $\mathrm{E}$, Kovesdy $\mathrm{CP}$, Molnar MZ, et al. Role of nutritional status and inflammation in higher survival of African American and Hispanic hemodialysis patients. Am J Kidney Dis.

2011;57(6):883-893. 
15. Kovesdy CP, George SM, Anderson JE, Kalantar-Zadeh K. Outcome predictability of biomarkers of protein-energy wasting and inflammation in moderate and advanced chronic kidney disease. Am J Clin Nutr. 2009;90(2):407-414.

16. Bazeley J, Bieber B, Li Y, et al. C-reactive protein and prediction of 1-year mortality in prevalent hemodialysis patients. Clinical journal of the American Society of Nephrology : CJASN. 2011;6(10):2452-2461.

17. Lichtenberg S, Korzets A, Zingerman B, et al. An intradialytic increase in serum interleukin-6 levels is associated with an increased mortality in hemodialysis patients. Int J Artif Organs. 2015;38(5):237-243.

18. Chiang CK, Hsu SP, Pai MF, et al. Interleukin-18 is a strong predictor of hospitalization in haemodialysis patients. Nephrology, dialysis, transplantation : official publication of the European Dialysis and Transplant Association - European Renal Association. 2004;19(11):2810-2815.

19. Carlsson AC, Carrero JJ, Stenvinkel P, et al. High levels of soluble tumor necrosis factor receptors 1 and 2 and their association with mortality in patients undergoing hemodialysis. Cardiorenal Med. 2015;5(2):89-95.

20. Suliman ME, Qureshi AR, Carrero JJ, et al. The long pentraxin PTX-3 in prevalent hemodialysis patients: associations with comorbidities and mortality. QJM. 2008;101(5):397-405.

21. Cozzolino M, Biondi ML, Galassi A, Turri O, Brancaccio D, Gallieni M. Matrix metalloproteinase-1 and matrix metalloproteinase-3 gene promoter polymorphisms are associated with mortality in haemodialysis patients. Nephrology, dialysis, transplantation : official publication of the European Dialysis and Transplant Association - European Renal Association. 2009;24(7):2207-2212.

22. Ridker PM, Silvertown JD. Inflammation, C-reactive protein, and atherothrombosis. J Periodontol. 2008;79(8 Suppl):1544-1551.

23. Conen D, Ridker PM. Clinical significance of high-sensitivity C-reactive protein in cardiovascular disease. Biomark Med. 2007;1(2):229-241.

24. Sato H, Tsubosa Y, Kawano T. Correlation between the pretherapeutic neutrophil to lymphocyte ratio and the pathologic response to neoadjuvant chemotherapy in patients with advanced esophageal cancer. World J Surg. 2012;36(3):617-622.

25. Keizman D, Ish-Shalom $M$, Huang $P$, et al. The association of pre-treatment neutrophil to lymphocyte ratio with response rate, progression free survival and overall survival of patients treated with sunitinib for metastatic renal cell carcinoma. Eur J Cancer. 2012;48(2):202-208.

26. Uthamalingam S, Patvardhan EA, Subramanian S, et al. Utility of the neutrophil to lymphocyte ratio in predicting long-term outcomes in acute decompensated heart failure. Am J Cardiol. 2011;107(3):433-438.

27. Usvyat LA, Haviv YS, Etter M, et al. The MONitoring Dialysis Outcomes (MONDO) initiative. Blood Purif. 2013;35(1-3):37-48.

28. Doumas BT, Watson WA, Biggs HG. Albumin standards and the measurement of serum albumin with bromcresol green. Clin Chim Acta. 1971;31(1):87-96.

29. Pinnell $A E$, Northam BE. New automated dye-binding method for serum albumin determination with bromcresol purple. Clin Chem. 1978;24(1):80-86.

30. Clase CM, St Pierre MW, Churchill DN. Conversion between bromcresol green- and bromcresol purple-measured albumin in renal disease. Nephrology, dialysis, transplantation : official publication of the European Dialysis and Transplant Association - European Renal Association. 2001;16(9):1925-1929.

31. Azab B, Camacho-Rivera M, Taioli E. Average values and racial differences of neutrophil lymphocyte ratio among a nationally representative sample of United States subjects. PLoS One. 2014;9(11):e112361. 
32. Kaysen GA, Dubin JA, Muller HG, Mitch WE, Rosales LM, Levin NW. Relationships among inflammation nutrition and physiologic mechanisms establishing albumin levels in hemodialysis patients. Kidney Int. 2002;61(6):2240-2249.

33. Workgroup KD. K/DOQI clinical practice guidelines for cardiovascular disease in dialysis patients. Am J Kidney Dis. 2005;45(4 Suppl 3):S1-153.

34. Kelley-Hedgepeth A, Lloyd-Jones DM, Colvin A, et al. Ethnic differences in C-reactive protein concentrations. Clin Chem. 2008;54(6):1027-1037.

35. Sunderkotter C, Mosser D, Ridley A, Sorg C, Roth J. Meeting report: molecular mechanisms of inflammation: how leukocytes come, see and seize. Eur J Cell Biol. 2003;82(7):379-383.

36. Mortensen RF. C-reactive protein, inflammation, and innate immunity. Immunol Res. 2001;24(2):163-176.

37. Jilma B, Blann A, Pernerstorfer $\mathrm{T}$, et al. Regulation of adhesion molecules during human endotoxemia. No acute effects of aspirin. Am J Respir Crit Care Med. 1999;159(3):857-863.

38. Turkmen K, Tonbul HZ, Toker A, et al. The relationship between oxidative stress, inflammation, and atherosclerosis in renal transplant and end-stage renal disease patients. Ren Fail. 2012;34(10):1229-1237.

39. Don BR, Kaysen G. Serum albumin: relationship to inflammation and nutrition. Semin Dial. 2004;17(6):432-437.

40. Tsirpanlis $G$, Bagos $P$, loannou D, et al. Serum albumin: a late-reacting negative acute-phase protein in clinically evident inflammation in dialysis patients. Nephrology, dialysis, transplantation : official publication of the European Dialysis and Transplant Association European Renal Association. 2005;20(3):658-659; author reply 659-660.

41. Danesh J, Wheeler JG, Hirschfield GM, et al. C-reactive protein and other circulating markers of inflammation in the prediction of coronary heart disease. $N$ Engl J Med. 2004;350(14):1387-1397.

42. Lowe GD, Pepys MB. C-reactive protein and cardiovascular disease: weighing the evidence. Curr Atheroscler Rep. 2006;8(5):421-428.

43. Collaboration CRPCHDG, Wensley F, Gao P, et al. Association between $C$ reactive protein and coronary heart disease: mendelian randomisation analysis based on individual participant data. BMJ. 2011;342:d548.

44. Emerging Risk Factors C, Kaptoge S, Di Angelantonio E, et al. C-reactive protein concentration and risk of coronary heart disease, stroke, and mortality: an individual participant meta-analysis. Lancet. 2010;375(9709):132-140.

45. Casas JP, Shah T, Hingorani AD, Danesh J, Pepys MB. C-reactive protein and coronary heart disease: a critical review. J Intern Med. 2008;264(4):295-314.

46. Kuo MT, Hu TH, Lu SN, et al. Neutrophil-to-lymphocyte ratio as a predictor of response to peginterferon plus ribavirin therapy for chronic hepatitis C. Dis Markers. 2014;2014:462958.

47. Madjid M, Fatemi O. Components of the complete blood count as risk predictors for coronary heart disease: in-depth review and update. Tex Heart Inst J. 2013;40(1):17-29. 


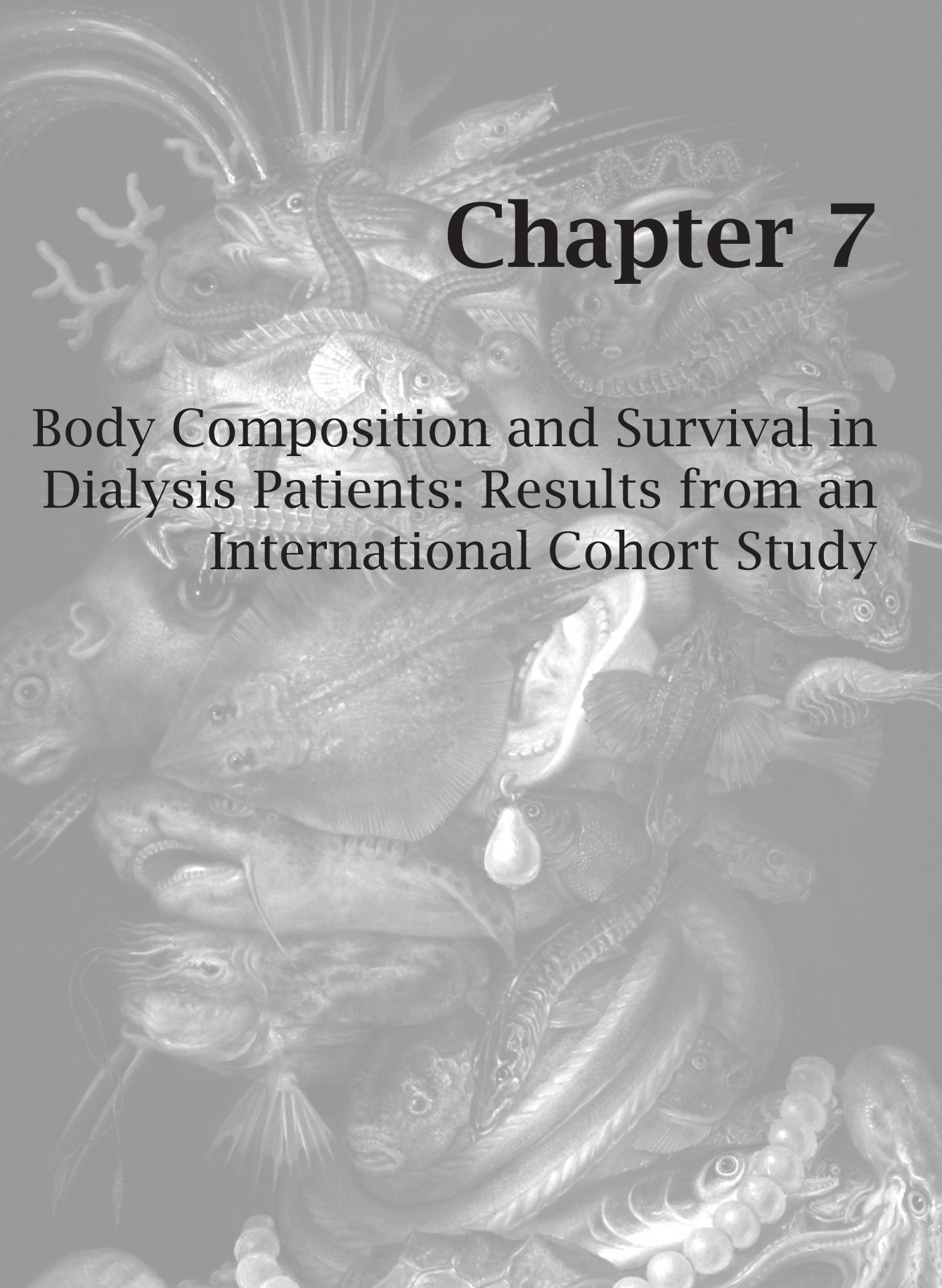

Daniele Marcelli, Len A. Usvyat, Peter Kotanko, Inga Bayh, Bernard Canaud, Michael Etter, Emanuele Gatti, Aileen Grassmann, Yuedong Wang, Cristina Marelli, Laura Scatizzi, Andrea Stopper, Frank M. van der Sande and Jeroen Kooman, on behalf of the MONitoring Dialysis Outcomes (MONDO) Consortium

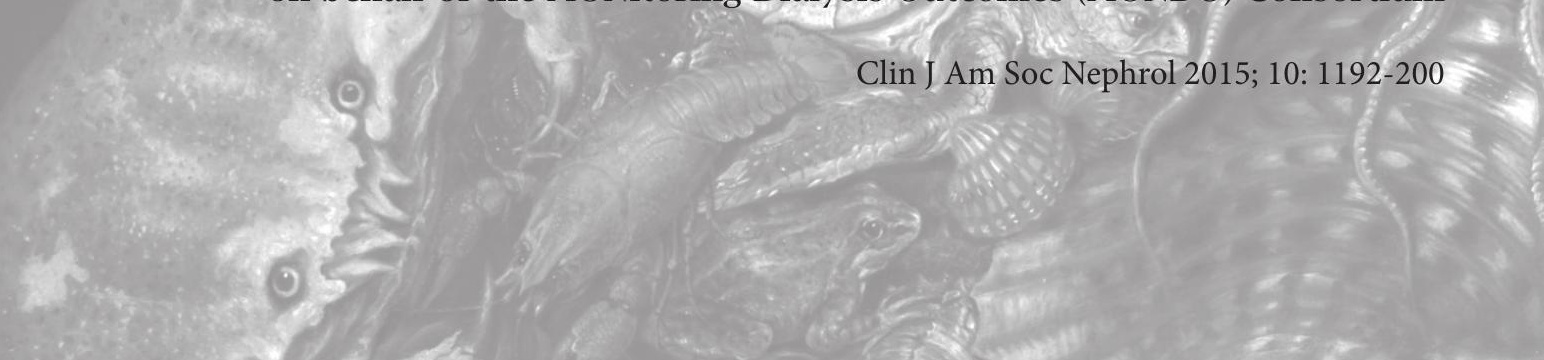




\begin{abstract}
Background and objectives

High body mass index appears protective in hemodialysis patients, but uncertainty prevails regarding which components of body composition, fat or lean body mass, are primarily associated with survival.

\section{Design, setting, participants, \& measurements}

Data between April 2006 and December 2012 were extracted from the Fresenius Medical Care Europe subset of the international MONitoring Dialysis Outcomes initiative. Fresenius Medical Care Europe archives a unique repository of predialysis body composition measurements determined by multifrequency bioimpedance (BCM Body Composition Monitor). The BCM Body Composition Monitor reports lean tissue indices (LTIs) and fat tissue indices (FTls), which are the respective tissue masses normalized to height squared, relative to an age- and sex-matched healthy population. The relationship between LTI and FTI and all-cause mortality was studied by Kaplan-Meier analysis, multivariate Cox regression, and smoothing spline ANOVA logistic regression.
\end{abstract}

\title{
Results
}

In 37,345 hemodialysis patients, median (25th-75th percentile) LTI and FTI were 12.2 (10.3-14.5) and $9.8(6.6-12.4) \mathrm{kg} / \mathrm{m}^{2}$, respectively. Median (25th-75th percentile) follow-up time was 266 (132$379)$ days; $3458(9.2 \%)$ patients died during follow-up. Mortality was lowest with both LTI and FTI in the 10th-90th percentile (reference group) and significantly higher at the lower LTI and FTI extreme (hazard ratio [HR], 3.37; 95\%confidence interval [95\% Cl], 2.94 to $3.87 ; \mathrm{P}<0.001$ ). Survival was best with LTI between 15 and $20 \mathrm{~kg} / \mathrm{m}^{2}$ and FTI between 4 and $15 \mathrm{~kg} / \mathrm{m}^{2}$ (probability of death during follow-up:, $5 \%$ ). When taking the relation between both compartments into account, the interaction was significant $(P=0.01)$. Higher $\mathrm{FTI}$ appeared protective in patients with low $\mathrm{LTI}(\mathrm{HR}, 3.37 ; 95 \% \mathrm{Cl}$, 2.94 to $3.87 ; \mathrm{P}<0.001$ at low $\mathrm{LTI}$-low $\mathrm{FTI}$, decreasing to $\mathrm{HR}, 1.79 ; 95 \% \mathrm{Cl}, 1.47$ to $2.17 ; \mathrm{P}<0.001$ at low LTI-high FTI).

\section{Conclusions}

This large international study indicates best survival in patients with both LTI and FTI in the 10th-90th percentiles of a healthy population. In analyses of body composition, both lean tissue and fat tissue compartments and also their relationship should be considered. 


\section{Introduction}

Contrary to the general population, higher body mass index (BMI) in hemodialysis (HD) patients is associated with better survival ${ }^{1}$. Similar results were found in older adults and in many chronic diseases ${ }^{2-6}$. Numerous HD studies have addressed this phenomenon, with largely inconsistent results. Discrepancy exists even regarding the upper BMI limit for survival advantage, with some studies reporting a positive effect even at BMI values $>35 \mathrm{~kg} / \mathrm{m}^{2}$ and others indicating an upper limit of $25 \mathrm{~kg} / \mathrm{m}^{2}$ 7,8 .

Postulated reasons for improved survival with high BMI include potential benefits of adipose tissue per se, for example as a source of TNF- $\alpha$-soluble receptors and lipoproteins that counteract the effects of TNF- $\alpha$ itself or the inflammatory effects of circulating endotoxins $s^{8-10}$ or as a vital energy source in undernourished patients ${ }^{10}$. In health, aging is associated with loss of muscle mass in the range of $2-4 \mathrm{~kg}$ over 10 years $^{11}$

This physiologic process is believed to precede at a faster rate in patients with ESRD where several catabolic factors accelerate muscle wasting ${ }^{12,13}$. In addition, anabolic pathways are compromised by low testosterone levels ${ }^{14}$ and abnormalities in the insulin growth factor-1 pathways ${ }^{15,16}$. It is therefore not surprising that patients with ESRD develop protein energy wasting (PEW), not because of reduction in fat mass, but because of loss of lean tissue. PEW is present in $18 \%-75 \%$ of patients with $\mathrm{CKD}^{17,18}$

BMI measures do not differentiate between fat and lean body mass so it is challenging to understand quantitatively which components of body composition are related to survival in patients with ESRD: fat tissue mass (FTM), lean tissue mass (LTM), or both. 


\begin{tabular}{|c|c|c|c|c|c|c|c|c|c|c|c|c|c|}
\hline 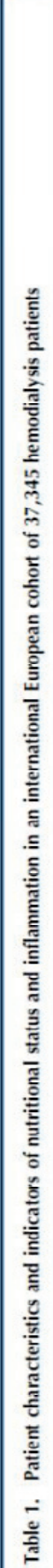 & 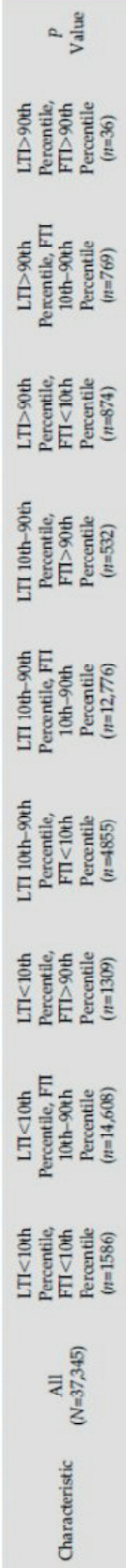 & 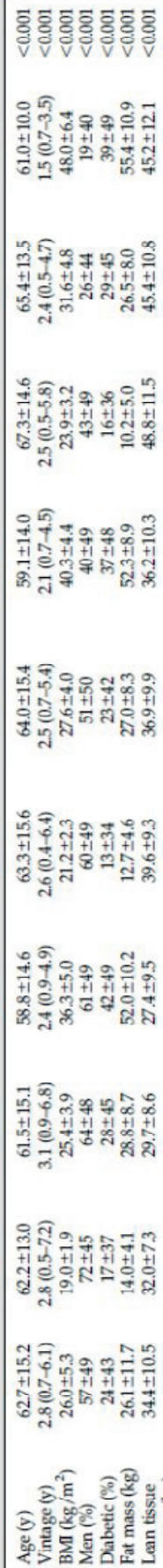 & $\begin{array}{l}\text { 足 } \\
\text { +1 } \\
\text { +1 } \\
\text { ले }\end{array}$ & 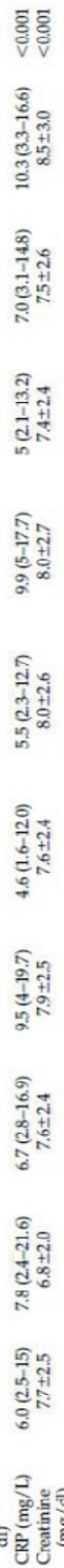 & $\begin{array}{l}0 \\
\stackrel{0}{+} \\
+1 \\
+1 \\
0 \\
0\end{array}$ & 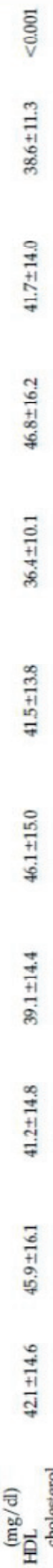 & 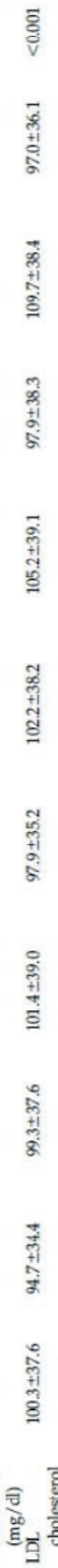 & 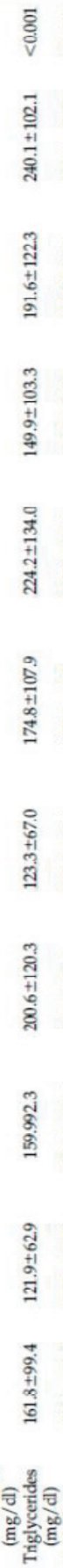 & 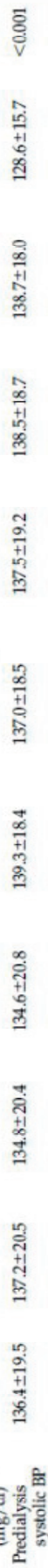 & $\begin{array}{l}\overrightarrow{+} \\
\stackrel{+}{+1} \\
\infty \\
\stackrel{0}{0} \\
\\
\end{array}$ & $\begin{array}{c}0 \\
\frac{0}{4} \\
\frac{1}{3}\end{array}$ & 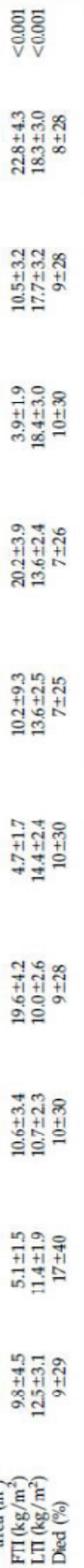 & 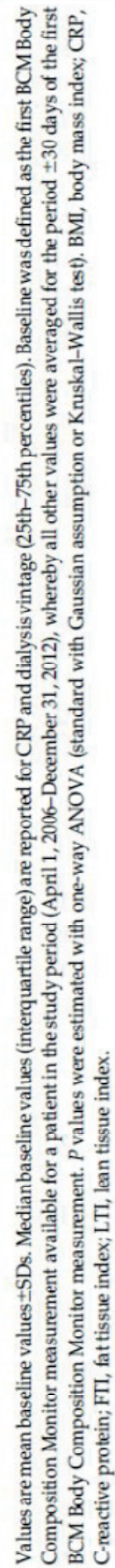 \\
\hline
\end{tabular}


Studies with surrogate markers of FTM and LTM suggest a dominant protective role of LTM over FTM ${ }^{7,17,19,20}$.

However, other studies concluded that survival is dependent more on FTM than LTM $^{10,21}$. Recently, multifrequency bioimpedance spectroscopy (MF-BIS) devices have been introduced to assess body composition in HD patients. MF-BIS directly measures FTM and LTM on a routine basis. In this study, predialysis standard of care body composition assessed by MF-BIS was used to explore the relationship between lean tissue, fat tissue, and survival.

\section{Materials and Methods}

The MONitoring Dialysis Outcomes initiative comprises HD databases from Renal Research Institute clinics in the United States; Fresenius Medical Care (FMC) clinics in Europe, Asia Pacific, and Latin America; $\mathrm{KfH}$ clinics in Germany; and clinics associated with the Imperial College (United Kingdom), Hadassah Medical Center (Israel), and Maastricht University Medical Center (The Netherlands) ${ }^{22}$. Electronic medical records are assembled in a primary database after obtaining informed consent and in accordance with local privacy and data protection regulations.

For this study, data from European FMC clinics were extracted for all patients who had at least one routine measurement using the BCM Body Composition Monitor (FMC, Bad Homburg, Germany) between April 1, 2006, and December 31, $2012^{23}$. In contrast to earlier bioimpedance methodologies, the BCM Body Composition Monitor expresses body composition as a three-compartment model, providing overhydration, lean tissue index ( $\mathrm{LTI})$, and fat tissue index (FTI), whereby $\mathrm{LTI}$ and $\mathrm{FTI}$ are the respective tissue masses normalized to height squared. Also, LTI and FTI percentiles (<10th percentile [low]; 10th-90th percentile [normal]; and >90th 
percentile [high]) relative to an age- and sex-matched healthy population are supplied. The three compartment model of the BCM Body Composition Monitor has been validated against standard reference methods for assessment of fluid status and body composition in dialysis patients, albeit partly against gold standard techniques in healthy controls only ${ }^{24-27}$.

Baseline was defined as the first BCM Body Composition Monitor measurement available for a patient in the study period (April 1, 2006-December 31, 2012). All other values were averaged for the period 630 days of the first BCM Body Composition Monitor measurement. Measurements were performed predialysis.

\begin{tabular}{|c|c|c|c|c|}
\hline \multirow{2}{*}{ LTI $\left(\mathrm{kg} / \mathrm{m}^{2}\right)$} & \multicolumn{3}{|c|}{ FTI $\left(\mathrm{kg} / \mathrm{m}^{2}\right)$} & \\
\hline & $<10$ th Percentile & 10th-90th Percentile & $>90$ th Percentile & \\
\hline$<10$ th percentile & $19.0 \pm 1.9$ & $25.4 \pm 3.9$ & $36.3 \pm 5.0$ & WHO: normal-obese class II \\
\hline 10th-90th percentile & $21.2 \pm 2.3$ & $27.6 \pm 4.0$ & $40.3 \pm 4.4$ & WHO: normal-obese class III \\
\hline \multirow[t]{2}{*}{$>90$ th percentile } & $23.9 \pm 3.2$ & $31.6 \pm 4.8$ & $48.0 \pm 6.4$ & WHO: normal-obese class III \\
\hline & WHO: normal & WHO: overweight-obese class I & WHO: obese class II-III & \\
\hline
\end{tabular}

\section{Statistical Analyses}

Primary outcome was all-cause death. In survival analysis, baseline values of LTI and FTI were entered as categorical variables. Univariate Kaplan-Meier analyses were conducted to explore the association of combinations of LTI and FTI categories and the time between first body composition measurement and death. Survival differences between groups were assessed using the log-rank test. Multivariate Cox proportional-hazard models adjusted for age, sex, and dialysis vintage assessed the association of LTI, FTI, and different FTI/LTI category combinations with mortality. The robustness of the results was tested with sensitivity analyses controlling for $\mathrm{Kt} / \mathrm{V}$ 
and restricted to patients with dialysis vintage $<6$ months. Cox proportional hazards and linearity assumptions were confirmed using diagnostic plots of scaled Schoenfeld and Martingale residuals. Censoring events were transfer to non-FMC clinics, transplantation, or study end on December 31, 2012. To confirm the results, we fitted a smoothing spline ANOVA logistic regression model for the probability of death 1 year later. This treats both LTI and FTI as continuous variables and allows the data to decide the joint effect of LTI and FTI. The same covariates as included in the Cox regression analysis were included in the spline model. In addition, sexspecific spline analyses were also performed to test the observations pertaining to the relationship between $\mathrm{BMI}$ and FTI. The R package gss was used to fit the smoothing spline ANOVA model. A $\mathrm{P}$ value $<0.05$ was considered significant. Analyses were performed with SAS version 9.3 (Cary, NC) and R statistics software system version 3.0.2.

\section{Results}

We analyzed data from 37,345 HD patients ( $57 \%$ men) from 380 clinics in the following 17 European countries: Bosnia and Herzegovina, Czech Republic, France, Hungary, Ireland, Italy, Poland, Portugal, Romania, Russia, Serbia, Slovakia, Slovenia, Spain, Sweden, Turkey, and the United Kingdom. At the time of first body composition measurement, mean patient age was $62.7 \pm 15.2$ years, and mean BMI was $26.0+5.3 \mathrm{~kg} / \mathrm{m}^{2}$. Median (25th-75th percentile) follow-up time was 266 (132379 ) days. Median (25th-75 ${ }^{\text {th }}$ percentile) of LTI and FTI were $12.2(10.3-14.5) \mathrm{kg} / \mathrm{m}^{2}$ and $9.8(6.6-12.4) \mathrm{kg} / \mathrm{m}^{2}$, respectively. Between the first body composition measurement and study end $3458(9.2 \%)$ patients died. 


\begin{tabular}{|c|c|c|c|c|c|c|c|c|}
\hline \multirow{2}{*}{ Model } & \multicolumn{4}{|c|}{ Models Adjusted for Age, Vintage, and Sex } & \multicolumn{4}{|c|}{ Fully Adjusted Models ${ }^{a}$} \\
\hline & HR & $\begin{array}{l}95 \% \\
\text { LCI }\end{array}$ & $\begin{array}{l}95 \% \\
\text { UCI }\end{array}$ & $P$ Value & HR & $\begin{array}{l}95 \% \\
\mathrm{LCI}\end{array}$ & $\begin{array}{l}95 \% \\
\text { UCI }\end{array}$ & $P$ Value \\
\hline \multicolumn{9}{|l|}{ Model 1: LTI without FTI } \\
\hline $\begin{array}{l}\text { Low LTI } \\
\text { Normal LTI (reference) }\end{array}$ & 1.68 & 1.56 & 1.80 & $<0.001$ & 1.53 & 1.40 & 1.66 & $<0.001$ \\
\hline High LTI & 1.20 & 1.01 & 1.41 & 0.03 & 1.02 & 0.84 & 1.24 & 0.85 \\
\hline \multicolumn{9}{|l|}{ Model 2: FTI without LTI } \\
\hline $\begin{array}{l}\text { Low FTI } \\
\text { Normal FTI (reference) }\end{array}$ & 1.34 & 1.24 & 1.45 & $<0.001$ & 1.19 & 1.08 & 1.31 & $<0.001$ \\
\hline High FTI & 1.19 & 1.01 & 1.40 & 0.03 & 1.23 & 1.02 & 1.47 & 0.03 \\
\hline \multicolumn{9}{|l|}{$\begin{array}{l}\text { Model 3: LTI and FTI } \\
\text { combined }\end{array}$} \\
\hline Low LTI, low FTI & 3.37 & 2.94 & 3.87 & $<0.001$ & 2.51 & 2.12 & 2.96 & $<0.001$ \\
\hline Low LTI, normal FTI & 1.81 & 1.67 & 1.97 & $<0.001$ & 1.63 & 1.48 & 1.81 & $<0.001$ \\
\hline Low LTI, high FTI & 1.79 & 1.47 & 2.17 & $<0.001$ & 1.74 & 1.40 & 2.17 & $<0.001$ \\
\hline Normal LTI, low FTI & 1.57 & 1.40 & 1.75 & $<0.001$ & 1.42 & 1.25 & 1.62 & $<0.001$ \\
\hline \multicolumn{9}{|l|}{$\begin{array}{l}\text { Normal LTI, normal FTI } \\
\text { (reference) }\end{array}$} \\
\hline Normal LTI, high FTI & 1.36 & 0.99 & 1.89 & 0.06 & 1.41 & 0.99 & 2.01 & 0.06 \\
\hline High LTI, low FTI & 1.42 & 1.14 & 1.76 & 0.002 & 0.99 & 0.75 & 1.32 & 0.95 \\
\hline High LTI, normal FTI & 1.28 & 1.00 & 1.64 & 0.05 & 1.31 & 1.00 & 1.73 & 0.05 \\
\hline High LTI, high FTI & 1.73 & 0.56 & 5.38 & 0.34 & 1.91 & 0.48 & 7.65 & 0.36 \\
\hline $\begin{array}{l}\text { Outcome was all-cause mortal } \\
\text { spectively. Models were adjust } \\
\text { erence, normal LTI and FTI (10 } \\
\text { confidence interval; } 95 \% \text { UCI; }\end{array}$ & edicto & nce int & low $(<$ & thy popul & $\operatorname{gh}(>c$ & perce & e) LTI & $\begin{array}{l}\text { FTI, re- } \\
\text { ndex; ref- } \\
\text { ower } 95 \%\end{array}$ \\
\hline
\end{tabular}

Table 1 shows key patient characteristics, inflammation markers, and nutritional parameters at baseline and nine distinct body composition categories: (1) low LTI and low FTI; (2) low LTI and normal FTI; (3) low LTI and high FTI; (4) normal LTI and low FTI; (5) normal LTI and normal FTI; (6) normal LTI and high FTI; (7) high LTI and low FTI; (8) high LTI and normal FTI; and (9) high LTI and high FTI. Although 85\% of patients had a normal FTI, almost $50 \%$ had low LTI (Table 1). Reliable data on residual renal function were not available.

Of the six groups with normal or high FTI, BMI values were higher than the cohort average value (i.e., $\left.26.0 \pm 5.3 \mathrm{~kg} / \mathrm{m}^{2}\right)$ in five groups $(41.3 \%$ of the study population). A BMI value slightly lower than the cohort average was observed for the remaining group with normal FTI and low LTI (39.1\% of the study population; BMI, 25.41_3.89 $\mathrm{kg} / \mathrm{m}^{2}$ ). Sex-specific spline analyses of the relationship between BMI and FTI revealed that BMI increases with increasing FTI (Supplemental Figures 1 and 2). Of 
the six groups with normal or high LTI, BMI values were higher than the cohort average in four groups (37.8\% of the study population). Lower than cohort average BMI was observed for the remaining two groups with low $\mathrm{FTI}(15.3 \%$ of the study population). Table 2 provides a summary of the BMI categories as defined by the World Health Organization (WHO) (in 2004) and the LTI and FTI groups analyzed in this study. BMI levels were higher than one would expect given the lean and fat tissue amounts: respectively, $20 \%$ and $47 \%$ of patients had FTI and LTI below the 10th percentile, but they had normal to obese BMI levels.

Univariate Kaplan-Meier analyses indicated a survival benefit for patients with normal LTI and concomitant normal FTI. The worst survival was observed for patients with a combination of low LTI and low FTI. The results of the multivariate Cox proportional-hazard analyses are presented in Table 3. First, we constructed three explanatory models with LTI and FTI as categorical variables and with normal FTI and normal LTI as references. Model 1 included LTI but not FTI; model 2 included FTI but not LTI; and model 3 included combinations of LTI and FTI categories. Model 1 indicated that both low and high LTIs were associated with higher mortality (hazard ratio [HR], 1.68; 95\% confidence interval [95\% Cl], 1.56 to 1.80; $\mathrm{P}<0.001$ and $\mathrm{HR}, 1.20 ; 95 \% \mathrm{Cl}, 1.01$ to $1.41 ; \mathrm{P}=0.03$, respectively). Model 2 indicated that also both low and high FTIs were associated with higher mortality $(\mathrm{HR}$, 1.34; $95 \% \mathrm{Cl}, 1.24$ to $1.45 ; \mathrm{P}<0.001$ and $\mathrm{HR}, 1.19 ; 95 \% \mathrm{Cl}, 1.01$ to $1.40 ; \mathrm{P}=0.03$, respectively). Model 3 indicated the highest HR for the combination of low LTI and low FTI; the lowest HR was for normal LTI and FTI. Sensitivity analyses controlling for $\mathrm{Kt} / \mathrm{V}$ and restricting dialysis vintage confirmed the robustness of these results (data not shown). 


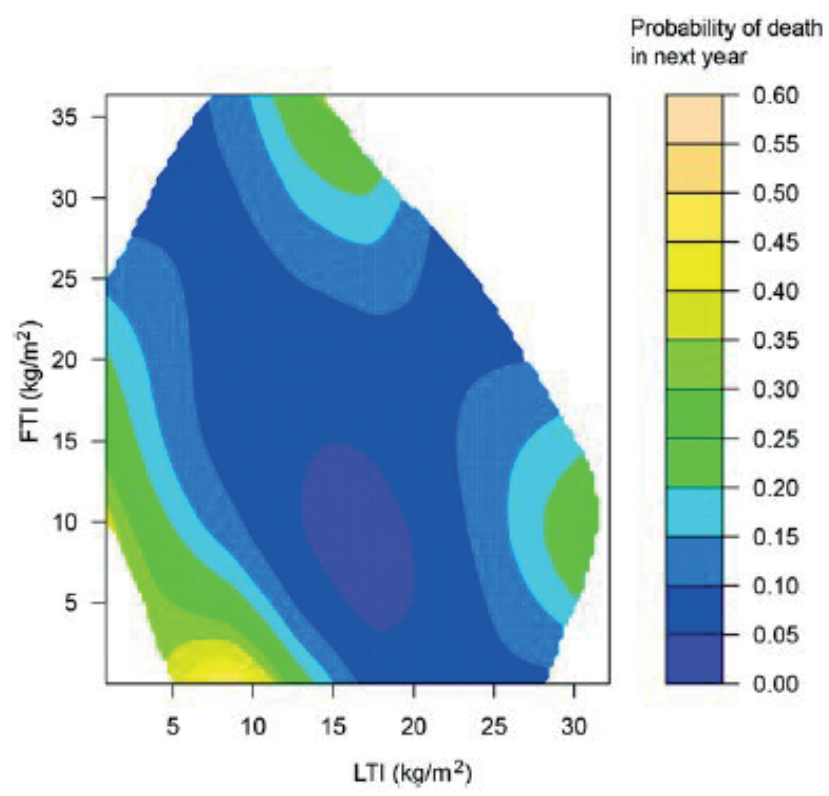

Figure 1. | Risk of death across levels of FTI and LTI. Contour plot of the estimated probability of death in the next year as a joint function of LTI and FTI for female patients with age and body mass index fixed at their median values. Estimates of the joint effects are shown in a region with sufficient data decided by posterior SDs. FTI, fat tissue index; LTI, lean tissue index.

All three explanatory models were only adjusted for age, sex, and vintage to avoid collinearity, but the addition of other potential variables were included in a predictive model (fully adjusted model, Table 3): only the statistical significance at high LTI-low FTI was reduced. Next we conducted a 1-year survival analysis for the joint effect of LTI and FTI as continuous variables. The contour plot of the estimated death probability as a function of LTI and FTI with other covariates fixed on the basis of the smoothing spline ANOVA logistic regression model is shown in Figure 1. The result of FTI and LTI slices through the contour plot at discrete LTI and FTI values $(5,10$, 15,20 , and $25 \mathrm{~kg} / \mathrm{m}^{2}$ ) are displayed in Figures 2 and 3, respectively. The results corroborate the Cox regression results, revealing optimal survival at LTI and FTI in 
the middle ranges. However, although the range $15-20 \mathrm{~kg} / \mathrm{m}^{2}$ appeared optimal for $\mathrm{LTI}$, the optimal range for FTI appeared to be lower $\left(4-15 \mathrm{~kg} / \mathrm{m}^{2}\right)$.
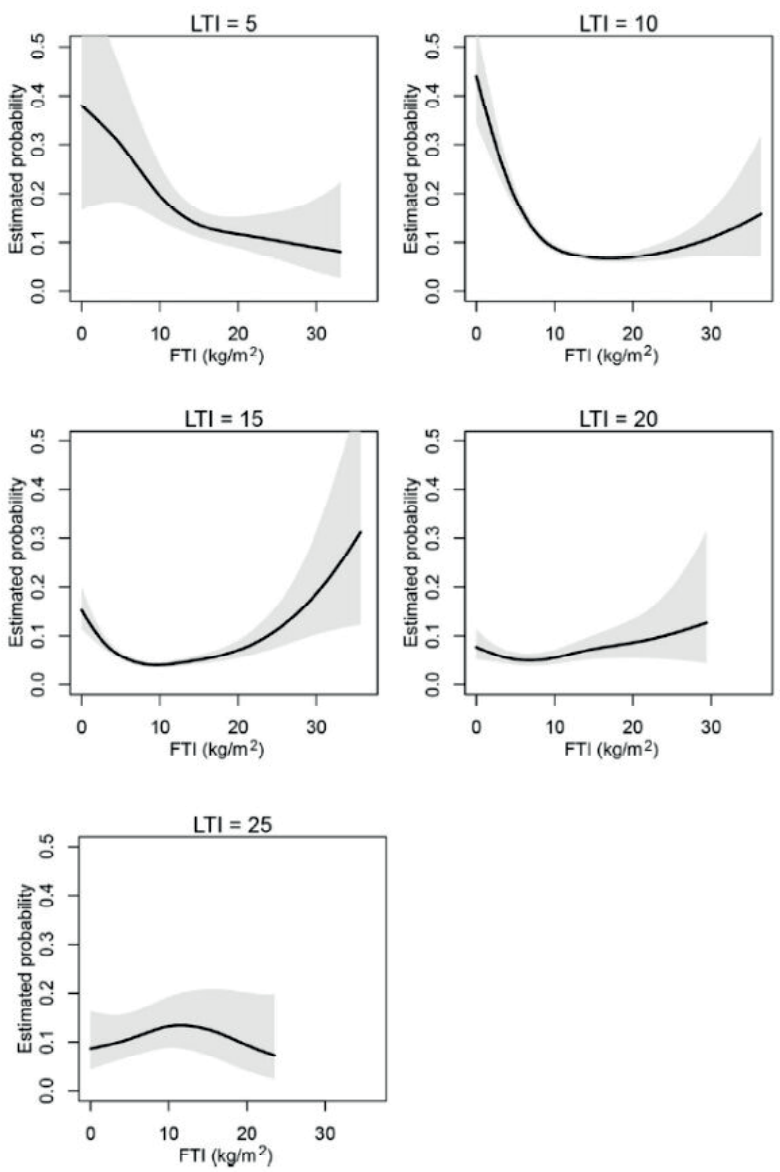

Figure 2. | FTI slices at different LTI ranges. Sections though the contour plot (Figure 1) at five LTI levels. FTI, fat tissue index; LTI, lean tissue index.

\section{Discussion}

In this study of prevalent HD patients, body composition was determined as part of standard of care using a validated multifrequency bioimpedance device. LTI and FTI within the 10th-90th percentile of an age- and sex matched healthy population were associated with best survival, whereas low FTI and low LTI, and especially the combination of both, were associated with higher mortality. The average patient BMI was $26.0 \pm 15.2 \mathrm{~kg} / \mathrm{m}^{2}$, which is overweight for the general population (normal BMI 
defined by WHO: $18.5-24.9 \mathrm{~kg} / \mathrm{m}^{2}$ ). In fact, the BMI distribution was found to approximately parallel the FTI distribution, but starting already at WHO normal status and progressing to overweight and then even obese: irrespective of LTI, patients with low FTI had on average a WHO normal BMI (normal, $18.5-24.9 \mathrm{~kg} / \mathrm{m}^{2}$ ); patients with normal FTI had a high WHO BMI (overweight, 25-29.9 kg/m²); and patients with high FTI were obese according to the WHO classification (30 to $\geq 40 \mathrm{~kg} / \mathrm{m}^{2}$ ) (Table 2). This observation, which was also confirmed by sex-specific analyses, indicates a shift toward higher BMls in this HD population and can explain some previous interpretations of a protective effect of high BMI per se. Furthermore, patients in our study with even a low LTI did not appear to be underweight, but rather to have normal weight or even be obese according to the WHO BMI classification. Therefore, BMls of HD patients are incompletely informative in predicting body composition. This can only be partially explained by the effect of fluid loading on BMI in dialysis patients (e.g., approximately $+0.6 \mathrm{~kg} / \mathrm{m}^{2}$ for an interdialytic weight gain from 75 to 77 $\mathrm{kg}$ in a patient of height $1.75 \mathrm{~m}$ ), but appears to be mainly related to an altered relation between fat and lean tissue in this population. 

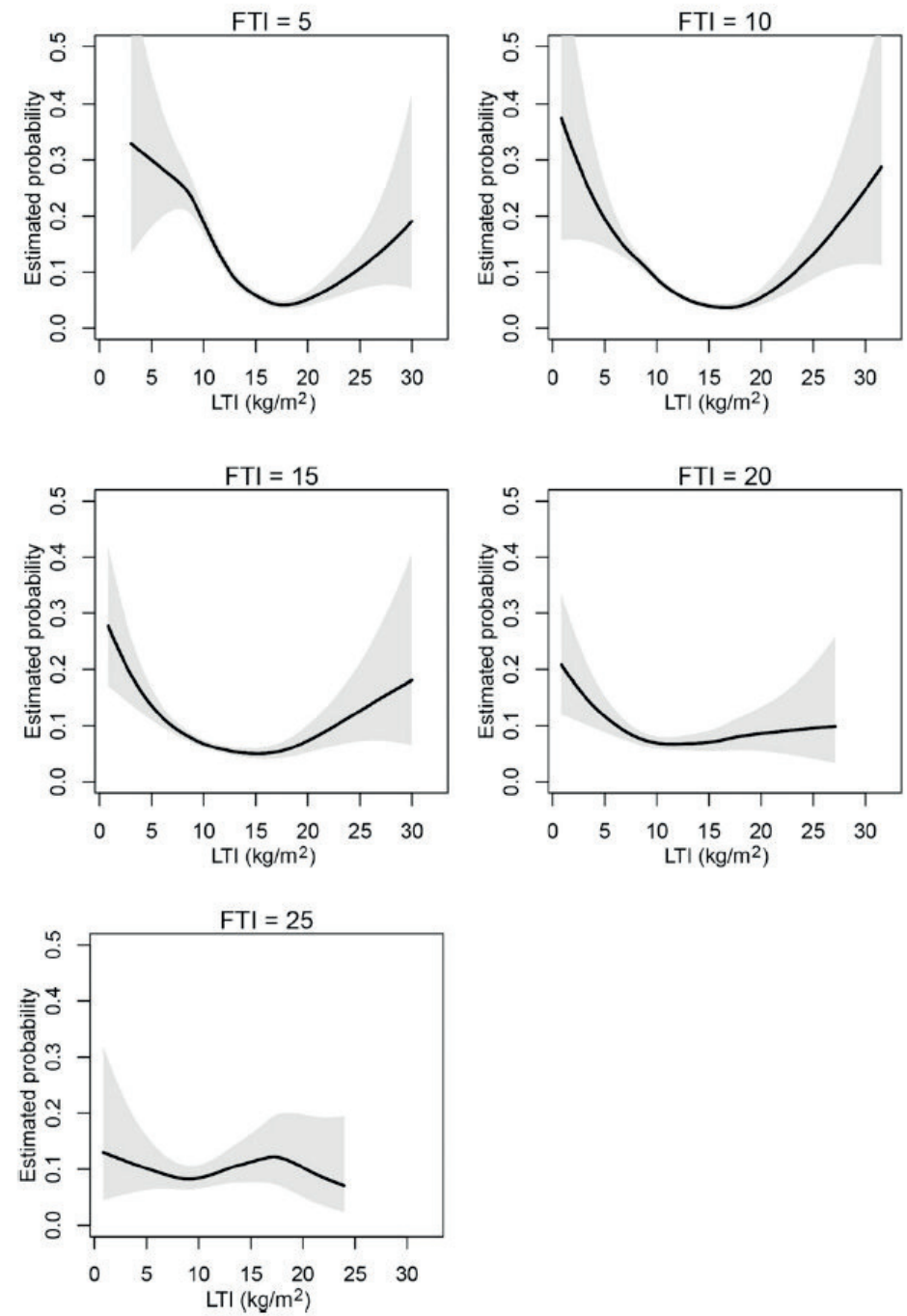

Figure 3. | LTI slices at different FTI ranges. Sections though the contour plot (Figure 1) at five FTI levels. FTI, fat tissue index; LTI, lean tissue index.

These findings add valuable insight to understanding the observation that HD patients with high BMI experience a better survival compared with fellow patients with lower BMI. In essence, our results indicate that body composition, and not just $\mathrm{BMI}$, is related to outcome and that patients with the same BMI but different ratios of lean to fat mass may have different outcomes. The robustness of the result was tested with various models incorporating LTI and FTI as categorical and continuous 
variables and by a sensitivity analysis when $\mathrm{Kt} / \mathrm{V}$ is controlled for or when restricted to patients with dialysis vintage $<6$ months.

Almost half of the patients in our study had LTIs below the 10th percentile of an ageand sex-matched healthy population, whereas only $4.5 \%$ had LTIs above the $90^{\text {th }}$ percentile (Table 1). Low lean body mass is a component of the PEW syndrome, and it is thought to be associated with a parallel decrease in BMI. However, our results show that most patients with low $\mathrm{LTI}$ had normal $\mathrm{FTI}$ and BMI levels ranging between normal and obese. Honda et al. demonstrated that low lean BMI (defined in their study as lean body mass determined by dual energy x-ray absorptiometry and divided by height squared) is not exclusively a characteristic of patients with low $\mathrm{BMI}^{21}$.

In fact, the prevalence of patients with PEW according to the Subjective Global Assessment was $60 \%$ in patients with a $\mathrm{BMl}<20 \mathrm{~kg} / \mathrm{m}^{2}, 39 \%$ in patients in the normal 20-25 $\mathrm{kg} / \mathrm{m}^{2}$ group, and $16 \%$ in patients in the overweight group (BMI 25-29.9 $\mathrm{kg} / \mathrm{m}^{2}$ ). Patients with PEW in the latter group were characterized by a higher fat BMI over lean BMI, a condition labeled obese sarcopenia. On the basis of the current findings, we suggest that the presence of a normal BMI is insufficient to refute diagnose of malnutrition and that $\mathrm{LTI}, \mathrm{FTI}$, and their relation must be taken into account.

Knowledge of predictors of low and high LTI and FTI may help to develop interventional corrective strategies. Inflammatory markers are known to be higher in patients with PEW; therefore, it is not surprising that a low LTI is associated with mortality $^{21}$. This relationship suggests that malnourished (even obese) HD patients have a low LTI because of the catabolic effects of inflammatory mediators. The Creactive protein levels in Table 1 support this. It has also recently been demonstrated 
that an excess of fat mass in obese patients can amplify the oxidative stress and inflammation caused by renal insufficiency ${ }^{28}$. This is in line with the results of our model 2, but not model 3 (whereby the latter may be because of the small numbers of patients in the upper categories). As shown in this study, the relation between LTI and FTI has to be taken into account. In patients with normal LTI, higher FTI was associated with a borderline significant outcome $(\mathrm{P}=0.06)$ compared with normal $\mathrm{FTI}$, and in patients with low LTI it was associated with improved outcome. Fat mass can also serve as an energy reservoir in case of energy depletion, which might provide an explanation for the latter phenomenon because patients with low LTI are likely to be protein-energy wasted. Therefore, there may be a discrepancy between the longterm health risks with increased fat mass and short-term positive effects of higher fat mass in patients with low LTI and protein energy wasting ${ }^{10,29}$.

Interventions aimed to reduce inflammation may translate into a higher LTI. One such intervention would be to reduce catheter use because even subclinical infections can trigger inflammation ${ }^{30}$. Another intervention would be timely and effective treatment of periodontitis, a frequently neglected source of inflammation ${ }^{31}$. Strategies to improve nutritional competence may include oral supplemental nutrition programs.

Strategies to increase creatinine by increasing muscle mass could possibly benefit both $\mathrm{LTI}$ and $\mathrm{FTI}^{32}$. An unexpected finding of this study is the adverse association between high LTI and survival in the simple model, which was only adjusted for age, sex, and vintage. Theoretically, underdialysis might explain this ${ }^{10,29,33,34}$. However, adjustment for $\mathrm{Kt} / \mathrm{V}$ did not materially change the results. Adjustment for age, vintage, sex, geographic region, albumin, hemoglobin, diabetes, and BP in the background predictive models resulted in a loss of statistical significance for high 
LTIs. This could either indicate a problem of multicollinearity in the extended model or a low degree of robustness of the association at high LTI.

This study had certain limitations. The number of patients with high LTI and FTI was small $(n=36)$, which could compromise achievement of statistical significance here. Prevalent HD patients were studied, and the dialysis vintage at the time of first body composition measurement varied between patients. In an attempt to address this we adjusted all Cox models for dialysis vintage. MF-BIS by the BCM Body Composition Monitor was the sole source of body composition assessment. However, this specific methodology has been validated in several studies ${ }^{24-27}$ (although fat mass was validated against gold standard techniques in healthy controls only), and the strong relationship to outcome supports the functional validity of the device and its measurements. Moreover, the BCM Body Composition Monitor is not able to distinguish between appendicular and visceral muscle mass. LTM and adipose tissue mass were normalized to height squared for reporting of LTI and FTI, but other normalizations could better reflect differences in body compositions between races and geographic areas. However, inclusion of geographic area into the model did not change the results substantially. Also, indexing to height squared is common in sarcopenia studies ${ }^{35}$, and use of this facilitates comparison of study results. BCM Body Composition Monitor measurements were performed for clinical reasons, and supervising clinicians could use these for interventions (not blinded). However, we do not believe that this should be considered a confounder because all clinicians followed a common policy (i.e., to target relative overhydration to be $\leq 15 \%$ ); therefore, an individual effect may be overruled. Strengths of this research lie in its multinational and diverse study population. The fact that this is the largest study on this subject conducted so far improves generalizability of the findings. Moreover, the 
BCM Body Composition Monitor is used on a routine basis, which reduces the chances of bias by indication.

In conclusion, this large multinational study demonstrated that LTM and FTM, as determined by whole-body MF-BIS, are important predictors of survival in chronic HD patients. Both low LTI and $\mathrm{FTI}$, but especially the combination of both, are associated with poorer survival. Although BMI values for HD patients are generally higher than those for the general population, many patients with apparently overweight BMI levels have LTI levels below the 10th percentile of healthy controls. These results suggest that routine assessment of body composition by bioimpedance adds to the clinical care of HD patients. Trials of interventions to maintain lean body mass and fat mass in middle ranges are warranted to further explore the relationship between body composition and survival.

\section{Acknowledgments}

J.K. and F.M.vdS. received an unrestricted research grant from FMC EMEA and the Renal Research Institute.

\section{Disclosures}

D.M., L.A.U., I.B., B.C., M.E., E.G., A.G., C.M., L.S., and A.S. are employees of Fresenius Medical Care and may hold stock in the company. P.K. holds stock in Fresenius Medical Care. 
1. Chazot C, Gassia JP, Di Benedetto A, Cesare S, Ponce P, Marcelli D. Is there any survival advantage of obesity in Southern European haemodialysis patients? Nephrology, dialysis, transplantation : official publication of the European Dialysis and Transplant Association European Renal Association. 2009;24(9):2871-2876.

2. Chao FC, Efron $B$, Wolf $P$. The possible prognostic usefulness of assessing serum proteins and cholesterol in malignancy. Cancer. 1975;35(4):1223-1229.

3. Yeh S, Wu SY, Levine DM, et al. Quality of life and stimulation of weight gain after treatment with megestrol acetate: correlation between cytokine levels and nutritional status, appetite in geriatric patients with wasting syndrome. J Nutr Health Aging. 2000;4(4):246-251.

4. Malvy E, Thiebaut R, Marimoutou C, Dabis F, Groupe d'Epidemiologie Clinique du Sida en A. Weight loss and body mass index as predictors of HIV disease progression to AIDS in adults. Aquitaine cohort, France, 1985-1997. J Am Coll Nutr. 2001;20(6):609-615.

5. Kenchaiah S, Pocock SJ, Wang D, et al. Body mass index and prognosis in patients with chronic heart failure: insights from the Candesartan in Heart failure: Assessment of Reduction in Mortality and morbidity (CHARM) program. Circulation. 2007;116(6):627-636.

6. Bouchard C. BMI, fat mass, abdominal adiposity and visceral fat: where is the 'beef'? Int J Obes (Lond). 2007;31(10):1552-1553.

7. Beddhu S, Pappas LM, Ramkumar N, Samore M. Effects of body size and body composition on survival in hemodialysis patients. J Am Soc Nephrol. 2003;14(9):2366-2372.

8. Kalantar-Zadeh K, Abbott KC, Salahudeen AK, Kilpatrick RD, Horwich TB. Survival advantages of obesity in dialysis patients. Am J Clin Nutr. 2005;81(3):543-554.

9. Hakim RM, Lowrie E. Obesity and mortality in ESRD: is it good to be fat? Kidney Int. 1999;55(4):1580-1581.

10. Ikizler TA. Resolved: being fat is good for dialysis patients: the Godzilla effect: pro. J Am Soc Nephrol. 2008;19(6):1059-1062.

11. Roubenoff R, Hughes VA. Sarcopenia: current concepts. J Gerontol A Biol Sci Med Sci. 2000;55(12):M716-724.

12. Carrero JJ, Chmielewski M, Axelsson J, et al. Muscle atrophy, inflammation and clinical outcome in incident and prevalent dialysis patients. Clin Nutr. 2008;27(4):557-564.

13. Kooman JP, Broers NJ, Usvyat L, et al. Out of control: accelerated aging in uremia. Nephrology, dialysis, transplantation : official publication of the European Dialysis and Transplant Association - European Renal Association. 2013;28(1):48-54.

14. Carrero JJ, Qureshi AR, Nakashima A, et al. Prevalence and clinical implications of testosterone deficiency in men with end-stage renal disease. Nephrology, dialysis, transplantation : official publication of the European Dialysis and Transplant Association European Renal Association. 2011;26(1):184-190.

15. Bailey JL, Zheng B, Hu Z, Price SR, Mitch WE. Chronic kidney disease causes defects in signaling through the insulin receptor substrate/phosphatidylinositol 3-kinase/Akt pathway: implications for muscle atrophy. J Am Soc Nephrol. 2006;17(5):1388-1394.

16. Johansen KL, Dalrymple LS, Delgado C, et al. Association between body composition and frailty among prevalent hemodialysis patients: a US Renal Data System special study. J Am Soc Nephrol. 2014;25(2):381-389.

17. Kalantar-Zadeh K, Ikizler TA, Block G, Avram MM, Kopple JD. Malnutrition-inflammation complex syndrome in dialysis patients: causes and consequences. Am J Kidney Dis. 2003;42(5):864-881.

18. Qureshi AR, Alvestrand A, Danielsson A, et al. Factors predicting malnutrition in hemodialysis patients: a cross-sectional study. Kidney Int. 1998;53(3):773-782.

19. Moreau-Gaudry X, Guebre-Egziabher F, Jean G, et al. Serum creatinine improves body mass index survival prediction in hemodialysis patients: a 1-year prospective cohort analysis from the ARNOS study. J Ren Nutr. 2011;21(5):369-375. 
20. Desmeules S, Levesque R, Jaussent I, Leray-Moragues H, Chalabi L, Canaud B. Creatinine index and lean body mass are excellent predictors of long-term survival in haemodiafiltration patients. Nephrology, dialysis, transplantation : official publication of the European Dialysis and Transplant Association - European Renal Association. 2004;19(5):1182-1189.

21. Honda H, Qureshi AR, Axelsson J, et al. Obese sarcopenia in patients with end-stage renal disease is associated with inflammation and increased mortality. Am J Clin Nutr. 2007;86(3):633-638.

22. Usvyat LA, Haviv YS, Etter M, et al. The MONitoring Dialysis Outcomes (MONDO) initiative. Blood Purif. 2013;35(1-3):37-48.

23. Marcelli D, Kirchgessner J, Amato C, et al. EuCliD (European Clinical Database): a database comparing different realities. Journal of nephrology. 2001;14 Suppl 4:S94-100.

24. Chamney PW, Wabel P, MoissI UM, et al. A whole-body model to distinguish excess fluid from the hydration of major body tissues. Am J Clin Nutr. 2007;85(1):80-89.

25. MoissI UM, Wabel P, Chamney PW, et al. Body fluid volume determination via body composition spectroscopy in health and disease. Physiol Meas. 2006;27(9):921-933.

26. Passauer J, Petrov H, Schleser A, Leicht J, Pucalka K. Evaluation of clinical dry weight assessment in haemodialysis patients using bioimpedance spectroscopy: a cross-sectional study. Nephrology, dialysis, transplantation : official publication of the European Dialysis and Transplant Association - European Renal Association. 2010;25(2):545-551.

27. Broers NJ, Martens RJ, Cornelis T, et al. Body composition in dialysis patients: a functional assessment of bioimpedance using different prediction models. J Ren Nutr. 2015;25(2):121128.

28. Ramos LF, Shintani A, Ikizler TA, Himmelfarb J. Oxidative stress and inflammation are associated with adiposity in moderate to severe CKD. J Am Soc Nephrol. 2008;19(3):593-599.

29. Stenvinkel P, Lindholm B. Resolved: being fat is good for dialysis patients: the Godzilla effect: con. J Am Soc Nephrol. 2008;19(6):1062-1064.

30. Dittmer ID, Sharp D, McNulty CA, Williams AJ, Banks RA. A prospective study of central venous hemodialysis catheter colonization and peripheral bacteremia. Clin Nephrol. 1999;51(1):34-39.

31. Jofre R, Rodriguez-Benitez P, Lopez-Gomez JM, Perez-Garcia R. Inflammatory syndrome in patients on hemodialysis. J Am Soc Nephrol. 2006;17(12 Suppl 3):S274-280.

32. Mihaescu A, Avram C, Bob F, Gaita D, Schiller O, Schiller A. Benefits of exercise training during hemodialysis sessions: a prospective cohort study. Nephron Clin Pract. 2013;124(12):72-78.

33. Kotanko $P$, Thijssen S, Kitzler T, et al. Size matters: body composition and outcomes in maintenance hemodialysis patients. Blood Purif. 2007;25(1):27-30.

34. Sridharan S, Vilar E, Berdeprado J, Farrington K. Energy metabolism, body composition, and urea generation rate in hemodialysis patients. Hemodial Int. 2013;17(4):502-509.

35. Cruz-Jentoft AJ, Baeyens JP, Bauer JM, et al. Sarcopenia: European consensus on definition and diagnosis: Report of the European Working Group on Sarcopenia in Older People. Age Ageing. 2010;39(4):412-423. 
Body composition and survival on dialysis 


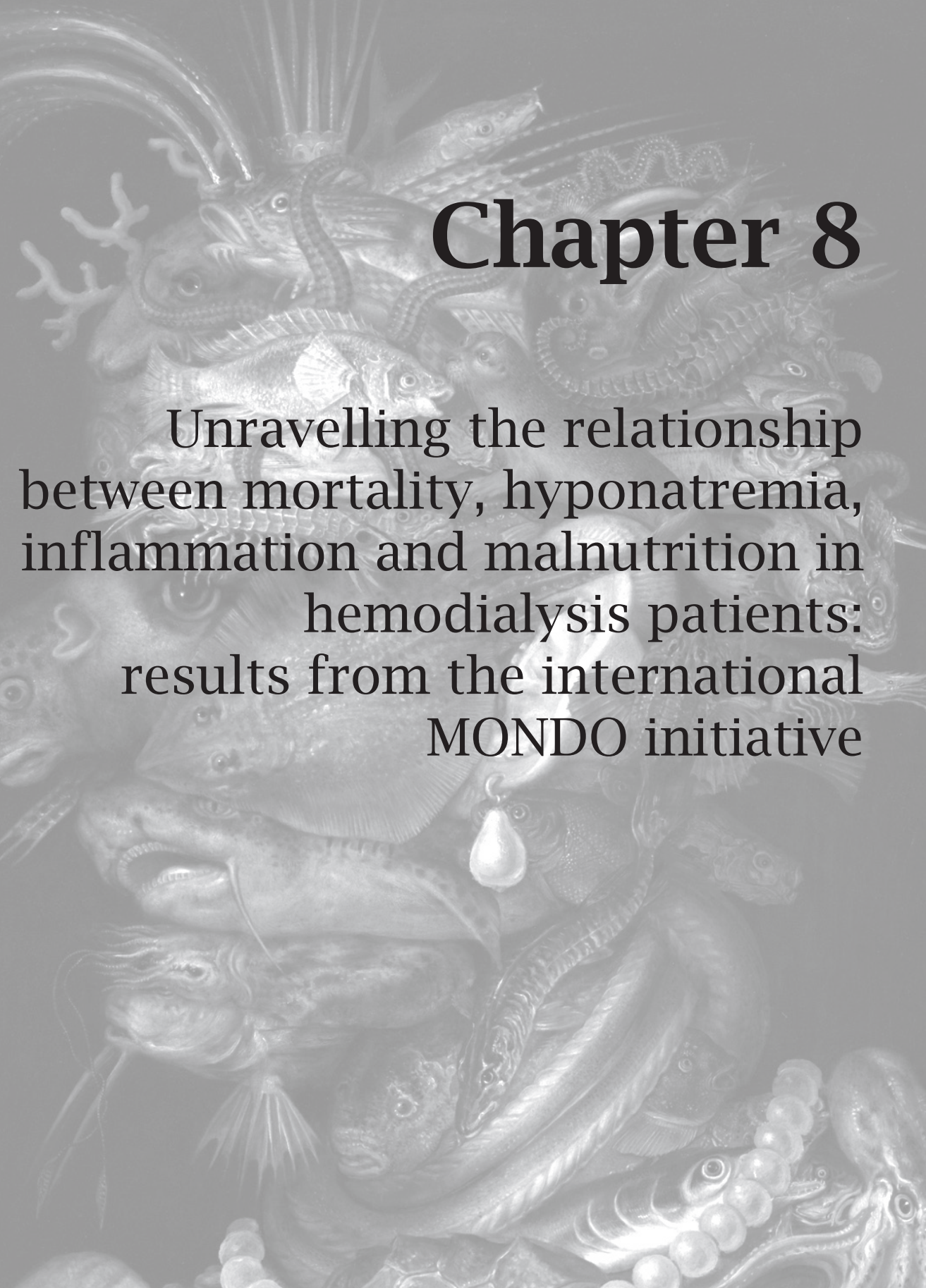

Marijke JE Dekker*, Daniele Marcelli*, Bernard Canaud, Constantijn JAM Konings, Karel M Leunissen, Nathan W Levin, Paola Carioni, Vaibhav Maheshwari, Jochen G Raimann, Frank M van der Sande, Len A Usvyat, Peter Kotanko, Jeroen P Kooman for the MONDO initiative 
mortality, hyponatremia, inflammation and malnutrition in hemodialysis patients

\begin{abstract}
Background:

Hyponatremia is a risk factor for mortality in hemodialysis patients. It is not well known to which extent the comorbidities, malnutrition, fluid status imbalance and inflammation are related to hyponatremia and affect outcomes.
\end{abstract}

\title{
Methods:
}

We studied 8883 patients from the European subset of the international MONitoring Dialysis Outcomes initiative. Nutritional and fluid statuses were assessed by bioimpedance spectroscopy. Fluid depletion was defined as overhydration $\leq-1.1 \mathrm{~L}$ and fluid overload as overhydration $>+1.1 \mathrm{~L}$, respectively. Malnutrition was defined as a lean tissue index below the $10^{\text {th }}$ percentile of age- and gender-matched healthy controls. Hyponatremia and inflammation were defined as serum sodium levels $<135 \mathrm{mEq} / \mathrm{L}$ and C-reactive protein levels $>6.0 \mathrm{mg} / \mathrm{L}$, respectively. We used logistic regression to test for predictors of hyponatremia and Cox proportional hazards analysis to assess the association with all-cause mortality.

\section{Results:}

Hyponatremia was predicted by the presence of malnutrition (odds ratio (OR) 1.50 (95\% Cl 1.31-1.71), inflammation (OR $1.41(95 \% \mathrm{Cl} 1.24-1.61))$, and moderate fluid overload $((>+1.1 \mathrm{~L}$ to $+2.5 \mathrm{~L}) \mathrm{OR} 0.86$ (95\% Cl 0.76 0.65-0.89)), but neither severe fluid overload (> +2.5L) nor fluid depletion (OR 1.31 (95\% $\mathrm{Cl}$ 0.90-1.91)). Malnutrition, inflammation, fluid overload, fluid depletion and hyponatremia (hazard ratio $1.73(95 \% \mathrm{Cl} 1.48-2.02))$ were independent predictors for all-cause mortality.

\section{Conclusion:}

In hemodialysis patients hyponatremia is associated with malnutrition, inflammation and mild fluid overload. Hyponatremia maintained predictive for all-cause mortality after adjustment for malnutrition, inflammation and fluid status abnormalities. The presence of hyponatremia may assist in identifying hemodialysis patients at increased risk of death. 
mortality, hyponatremia, inflammation and malnutrition in hemodialysis patients

\section{Introduction}

Hyponatremia has recently emerged as a risk factor for mortality in chronic hemodialysis $(\mathrm{HD})$ patients $^{1-3}$. The association between hyponatremia and mortality is not limited to HD patients, but has also been observed in patients with other acute and chronic diseases, such as congestive heart failure, pulmonary embolism and myocardial infarction ${ }^{4-6}$. It has been suggested that hyponatremia is associated with a "frail phenotype", given its association with low body mass index (BMI) and biochemical markers of malnutrition ${ }^{1,2,7}$. A relationship between hyponatremia and malnutrition has also been observed in other diseases ${ }^{6,8}$. Hyponatremia may also be associated with abnormalities in fluid status, both with regard to fluid overload, as well as fluid depletion ${ }^{7,9}$, or with inflammation, possibly as a reflection of the so called "sick cell syndrome"9-11. However, the determinants of hyponatremia in HD patients have not been comprehensively addressed, partly because of absence of routine measurements of C-reactive protein (CRP) as marker of inflammation and objective indicators of body composition and fluid state in previous studies. The paucity of research has complicated the interpretation of the relative importance of confounding mechanisms when exploring the relation between hyponatremia and outcomes ${ }^{1,8}$. Our study aimed to address that knowledge gap and explore the relationship between hyponatremia, nutrition, inflammation and fluid status. We drew on data from dialysis facilities where body composition and laboratory markers of inflammation are assessed routinely as part of standard of care. The primary goal was to determine predictors of hyponatremia, including biomarkers of inflammation, fluid status and malnutrition. The secondary goal was to assess the association between hyponatremia and mortality with appropriate adjustments for malnutrition, fluid status and inflammation. 
mortality, hyponatremia, inflammation and malnutrition in hemodialysis patients

\section{Subjects}

This retrospective observational study was performed in a European subset of the international MONitoring Dialysis Outcomes (MONDO) initiative ${ }^{12,13}$.

At the time of analysis, MONDO consisted of hemodialysis databases from Renal Research Institute clinics in the US, Fresenius Medical Care clinics in Canada, Europe, Asia Pacific and Latin America, Kuratorium für Dialyse und Nierentransplantation clinics in Germany, Imperial College in United Kingdom, Hadassah Medical Center in Israel and Maastricht University Medical Center in The Netherlands.

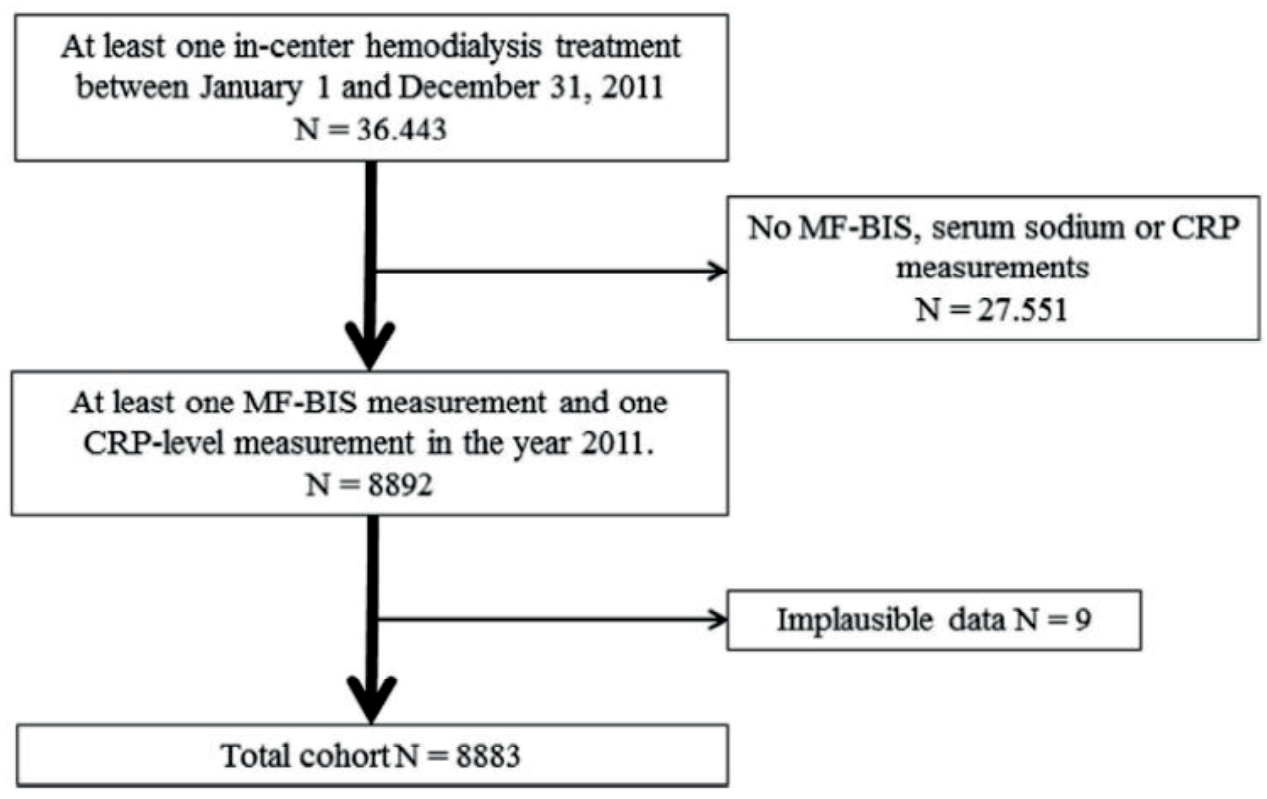

Figure 1: Study flow chart

For this research we only included dialysis facilities in which body composition and CRP were determined simultaneously as part of routine care. We considered the 
mortality, hyponatremia, inflammation and malnutrition in hemodialysis patients

routine assessments essential to prevent bias by indication. The final analysis included patients from 380 clinics in 17 European countries, namely: Bosnia and Herzegovina, Czech Republic, France, Hungary, Ireland, Italy, Poland, Portugal, Romania, Russia, Serbia, Slovakia, Slovenia, Spain, Sweden, Turkey and the United Kingdom. Countries were stratified into four regions (Northern, Eastern, Southern and Western Europe), based on the United Nations geographic scheme ${ }^{14}$. Analyses were adjusted for these regions because of possible differences in practice patterns. Patients with at least one routine body composition measurement, one CRP and serum sodium measurement during the baseline year January 1 to December 31 , 2011 were included (Figure 1). The latest body composition measurement in 2011 served as the start date of a 12 months follow up period (Figure 2).

\section{Last MF-BIS measurement of 2011}

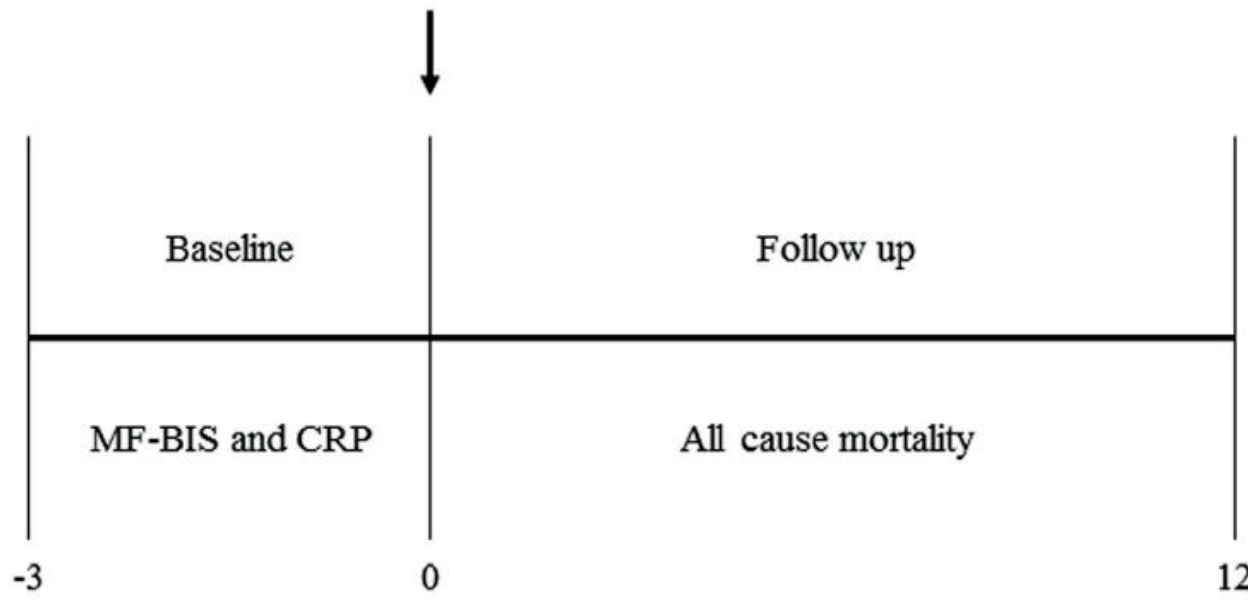

Figure 2: Study design. All patients of the European subset of the MONDO initiative database with at least one whole body multifrequency bioimpedance spectroscopy (MF-BIS) and C-reactive protein (CRP) measurement in 2011 were included. Baseline was defined as the 3 months preceding the last bioimpedance measurement in 2011, plus the day of that respective MF-BIS measurement. Baseline was followed by a 12 monhts period, during which outcomes were noted. 
mortality, hyponatremia, inflammation and malnutrition in hemodialysis patients

Averages of clinical and laboratory data collected in the 3 months prior to the body composition measurement were used for subsequent logistic regression and Cox proportional hazard analyses. Patients consented to the use of their data in anonymized form for research in epidemiological studies; absence of that consent was the sole exclusion criterion. The MONDO database includes information on all patients treated in the respective provider network with the data directly extracted from the electronic health record systems. Every individual provider has its own procedures for data cleaning before data end up in the respective provider system. The MONDO database contains only de-identified data. Research conducted by MONDO complies with the Declaration of Helsinki. MONDO partner organizations are responsible for the primary collection and safeguarding of patient data in accordance with all applicable local data protection laws and privacy protection regulations. They also ensure full compliance with laws and regulations regarding the secondary use of data in the context of MONDO. For data collection and analysis, local ethical, compliance, and legal standards are followed ${ }^{12,13}$. The New England Institutional Review Board (IRB) has reviewed the claim of exemption for the study and has determined that this research activity is exempt from IRB review.

\section{Methods}

Determination and definition of fluid status and body composition

We used the body composition monitor (BCM; Fresenius Medical Care, Bad Homburg, Germany) to assess body composition and fluid status. The BCM is a whole body multifrequency bioimpedance spectroscopy (MF-BIS) device that has been validated against gold standard techniques in $\mathrm{HD}$ patients ${ }^{15-17}$. The $\mathrm{BCM}$ 
mortality, hyponatremia, inflammation and malnutrition in hemodialysis patients

reports overhydration $(\mathrm{OH})$ as a separate compartment in reference to normohydration. We defined normohydration as pre-dialysis $\mathrm{OH}$ in a range of -1.1 to $+1.1 \mathrm{~L}$ around normohydration. These thresholds were chosen according the hydration reference plots provided by the manufacturer, based on the reference values for normohydration as derived from the $10^{\text {th }}$ and $90^{\text {th }}$ percentiles in the healthy population ${ }^{18}$. Fluid depletion was defined as pre-dialysis $\mathrm{OH} \leq-1.1 \mathrm{~L}$, moderate fluid overload as pre-dialysis $\mathrm{OH}>+1.1 \mathrm{~L}$ to $+2.5 \mathrm{~L}$ and severe fluid overload as predialysis $\mathrm{OH}>+2.5 \mathrm{~L}$ to $+5.0 \mathrm{~L}$. Definitions of the fluid overload groups were chosen according to literature ${ }^{19}$. We accounted for differences in body-phenotype by adjusting for body surface area (BSA), calculated by the Du Bois Formula, BSA $\left(\mathrm{m}^{2}\right)$ $=0.007184 \times(\text { pre-dialysis weight }(\mathrm{kg}))^{0.425} \times(\text { patient height }(\mathrm{cm}))^{0.72520}$.

Malnutrition was defined as a lean tissue index (LTI) below $10^{\text {th }}$ percentile of age and gender matched healthy controls. BCM reports the LTI, which is lean tissue mass normalized to the height in meters squared, and also age- and gender-matched LTI percentiles. Fat tissue index (FTI), also assessed by $\mathrm{BCM}$, was included as an additional independent parameter in the Cox regression model. LTI was chosen as the prime nutritional parameter because derangements in lean tissue mass are expected to have larger effects on sodium distribution as compared to changes in fat mass.

\section{Definition of hyponatremia and inflammation}

In agreement with the literature ${ }^{2,21}$, hyponatremia was defined as a pre-dialysis serum sodium level below $135 \mathrm{mEq} / \mathrm{L}$. Serum sodium was measured using standard indirect ionometry. Inflammation was defined as CRP levels $>6.0 \mathrm{mg} / \mathrm{L}^{22-24}$. Serum glucose levels were not routinely available at the time of sodium measurements. 
mortality, hyponatremia, inflammation and malnutrition in hemodialysis patients

\section{Statistical analysis}

Continuous variables are reported as mean \pm standard deviation (SD), or median and $25^{\text {th }}-75^{\text {th }}$ percentile depending on their distributions. Logistic regression models with adjustment for age, gender, dialysate sodium, dialysis vintage, access (arteriovenous versus catheter access), region, body surface area (BSA) diabetes mellitus and congestive heart failure, were used to analyse predictors of hyponatremia. Cox proportional hazards models with adjustment for inflammation, malnutrition, fluid status abnormalities, age, gender, dialysate sodium concentration, dialysis vintage, diabetes mellitus, congestive heart failure, cerebrovascular disease, peripheral vascular disease and presence of a malignancy, were developed to assess the association between hyponatremia and mortality. We constructed both a basic Cox model, including only LTI as a parameter of nutrition, and an extended Cox model including also systolic blood pressure, normalized protein catabolic rate (nPCR) and serum albumin levels. We report point estimates and 95\% confidence intervals $(\mathrm{Cl})$ of the odds ratios $(\mathrm{OR})$ and hazard ratios $(\mathrm{HR})$. Censoring events were transfer to another dialysis facility, kidney transplantation, recovery of renal function, modality change, or the end of study on December 31, 2012. Differences between patients with and without hyponatremia were analysed by independent samples Student ttest, Mann-Wittney $U$ Test or Pearson chi square analyses, as appropriate. Computations were performed with SAS version 9.3 (Cary, NC, USA) and R statistics software system version 3.0.2.

\section{Results}


mortality, hyponatremia, inflammation and malnutrition in hemodialysis patients

\section{Prevalence and predictors of hyponatremia}

We included 8883 patients, their demographic characteristics, body composition and dialysis treatment characteristics are shown in Table 1.

\begin{tabular}{|c|c|c|c|c|c|c|c|}
\hline Variable & $\begin{array}{c}\text { Total cohort } \\
\% \text { of total }\end{array}$ & & $\begin{array}{l}\text { Serum sodium } \\
\% \text { of total }\end{array}$ & $<135 \mathrm{mEq} / \mathrm{l}$ & $\begin{array}{l}\text { Serum sodium } \\
\% \text { of total }\end{array}$ & $\geqslant 135 \mathrm{mEq} / \mathrm{l}$ & $P$ \\
\hline Number of patients & 100 & & 12.7 & & 87.3 & & NA \\
\hline Age (years) (mean (s.d.)) & $63(14.8)$ & & $64(14.8)$ & & $63(14.7)$ & & \\
\hline Male gender & 57.2 & & 55 & & 57.6 & & 0.11 \\
\hline \multicolumn{8}{|l|}{ Comorbidities } \\
\hline Diabetes mellitus (yes) & 18.6 & & 29.5 & & 17 & & $<0.001$ \\
\hline Cerebrovascular disease (yes) & 2.2 & & 2.7 & & 2.2 & & 0.31 \\
\hline Congestive heart failure (yes) & 0.9 & & 0.5 & & 0.9 & & 0.19 \\
\hline Peripheral vascular disease (yes) & 0.8 & & 0.8 & & 0.9 & & 0.85 \\
\hline Malignancy (yes) & 3.5 & & 3.1 & & 3.6 & & 0.43 \\
\hline \multicolumn{8}{|l|}{ Region } \\
\hline Northern Europe & 0.2 & & 0.7 & & 0.2 & & $<0.001$ \\
\hline Eastern Europe & 3.7 & & 2.9 & & 2.9 & & $<0.001$ \\
\hline Western Europe & 46.7 & & 42.9 & & 47.2 & & $<0.001$ \\
\hline \multirow[t]{2}{*}{ Southern Europe } & 49.4 & & 53.5 & & 48.7 & & $<0.001$ \\
\hline & Mean/median & s.d./IQ-range & Mean/median & s.d./IQ-range & Mean/median & s.d./IQ-range & \\
\hline \multicolumn{8}{|l|}{ Body composition } \\
\hline Pre-dialysis fluid status (I) & 1.66 & 0.78 to 2.62 & 1.62 & 0.69 to 2.70 & 1.66 & 0.79 to 2.62 & 0.37 \\
\hline Normohydration weight (kg) & 70.79 & 16.05 & 68.38 & 15.73 & 71.14 & 16.07 & $<0.001$ \\
\hline Fat tissue index $\left(\mathrm{kg} / \mathrm{m}^{2}\right)$ & 9.78 & 4.42 & 9.91 & 4.61 & 9.76 & 4.39 & 0.31 \\
\hline Lean tissue index $\left(\mathrm{kg} / \mathrm{m}^{2}\right)$ & 12.55 & 2.97 & 11.85 & 2.87 & 12.66 & 2.97 & $<0.001$ \\
\hline Body surface area $\left(\mathrm{m}^{2}\right)$ & 1.79 & 0.21 & 1.76 & 0.2 & 1.8 & 0.21 & $<0.001$ \\
\hline Body mass index $\left(\mathrm{kg} / \mathrm{m}^{2}\right)$ & 25.96 & 5.23 & 25.35 & 5.42 & 26.05 & 5.2 & $<0.001$ \\
\hline \multicolumn{8}{|l|}{ Clinical characteristics } \\
\hline Dialysis vintage (years) & 3.6 & 1.63 to 6.94 & 3.47 & 1.41 to 6.85 & 3.62 & 1.66 to 6.96 & 0.08 \\
\hline Pre-dialysis systolic BP (mmHg) & 139.1 & 19.88 & 139 & 21.32 & 139 & 19.66 & 0.6 \\
\hline Pre-dialysis weight $(\mathrm{kg})$ & 72.69 & 16.01 & 70.25 & 15.66 & 73.04 & 16.03 & $<0.001$ \\
\hline Inter-dialytic weight gain (kg) & 2.1 & 0.84 & 2.23 & 0.84 & 2.08 & 0.84 & $<0.001$ \\
\hline Ultrafiltration volume (I) & 2.09 & 0.83 & 2.22 & 0.83 & 2.07 & 0.83 & $<0.001$ \\
\hline Dialysate sodium (mEq/l) & 139 & 1.85 & 138 & 2.06 & 139 & 1.81 & $<0.001$ \\
\hline Sodium gradient (mEq/l) & 0.54 & -1.67 to +2.67 & 5.33 & 3.67 to 7.00 & 0.00 & -2.0 to +2.0 & $<0.001$ \\
\hline Serum sodium $(\mathrm{mEq} / \mathrm{l})$ & 138 & 136 to 140 & 133 & 132 to 134 & 139 & 137 to 140 & NA \\
\hline Albumin ( $\mathrm{g} / \mathrm{dl})$ & 3.85 & 0.39 & 3.7 & 0.43 & 3.87 & 0.38 & $<0.001$ \\
\hline C-reactive protein $(\mathrm{mg} / \mathrm{l})$ & 5.7 & 2.40 to 13.0 & 7 & 3.0 to 18.6 & 5.43 & 2.33 to 12.4 & $<0.001$ \\
\hline Creatinine $(\mathrm{mg} / \mathrm{dl})$ & 7.95 & 2.27 & 7.48 & 2.32 & 8.02 & 2.25 & $<0.001$ \\
\hline nPCR ( $\mathrm{g} / \mathrm{kg}$ per day) & 1.07 & 0.13 & 1.06 & 0.13 & 1.07 & 0.13 & 0.04 \\
\hline
\end{tabular}

Patients' median age was 63 years, $57.2 \%$ males, and median dialysis vintage was 3.6 years. Median serum sodium was $138 \mathrm{mEq} / \mathrm{l}(136-140)$, and 1129 (12.7\%) patients were hyponatremic. Significant predictors for hyponatremia were malnutrition $(\mathrm{OR}=1.49(95 \% \mathrm{Cl}=1.30-1.70))$ and inflammation $(\mathrm{OR}=1.44(95 \% \mathrm{Cl}=1.26-$ 1.64)). Fluid overload, moderate $(>+1.1 \mathrm{I}$ to $+2.5 \mathrm{I}(\mathrm{OR}=0.73(95 \% \mathrm{Cl}=0.62-0.85)))$ 
mortality, hyponatremia, inflammation and malnutrition in hemodialysis patients

and severe $(>+2.5 \mathrm{I}$ to $5.0 \mathrm{I}(\mathrm{OR}=0.79(95 \% \mathrm{Cl}=0.65-0.94))$, was associated with a protective effect, whereas fluid depletion $(\mathrm{OR}=1.34(95 \% \mathrm{Cl}=0.92-1.96))$ was not predictive for hyponatremia (Table 2). Diabetes was more prevalent in hyponatremic patients (29.5\% vs 17.0\%; Po0.001). CRP levels were higher in hyponatremic patients (7.0 vs 5.43 mg/l; Po0.001; Table 1). Mean dialysate sodium was $139 \mathrm{mmol} / \mathrm{l}$ (s.d. 1.81) in the 'normal' group and $138 \mathrm{mmol} / \mathrm{l}$ (s.d. 2.06) in the hyponatremia group. The sodium gradient (calculated as dialysate sodium minus plasma sodium level) was higher in the hyponatremia group (median $5.33 \mathrm{mmol} / \mathrm{l}$ (3.67-7.0 (25th75th percentile))), compared with the group without hyponatremia (median 0.00 $\mathrm{mmol} / \mathrm{l}(-2.00$ to $+2.00(25$ th -75 th percentile $)))$.

\section{Table 2. Predictors of hyponatremia}

\begin{tabular}{lllll}
\hline & \multicolumn{4}{c}{$95 \% \mathrm{Cl}$} \\
\cline { 2 - 5 } & OR & Lower & Upper \\
\hline Inflammation (CRP $>6.0 \mathrm{mg} / \mathrm{l})$ & 1.44 & 1.26 & 1.64 \\
Malnutrition (LTI < 10th percentile) & 1.49 & 1.30 & 1.70 \\
Fluid status pre-dialysis < -1.11 & 1.34 & 0.92 & 1.96 \\
Fluid status pre-dialysis +1.1 to +2.5 I & 0.73 & 0.62 & 0.85 \\
Fluid status pre-dialysis +2.5 to +5.0 I & 0.79 & 0.65 & 0.94 \\
\hline Logistic regression model adjusted for age, gender, dialysis & vintage, \\
dialysate sodium, body mass index, region, catheter access and the \\
presence of the comorbidities diabetes mellitus and congestive heart \\
failure. Abbreviations: Cl, confidence interval; CRP, C-reactive protein; LTI, \\
lean tissue index; OR, odds ratio.
\end{tabular}

Hyponatremia and mortality

In multivariate analysis, hyponatremia, malnutrition, inflammation, moderate and severe fluid overload and fluid depletion were associated with mortality (Table 3). 
mortality, hyponatremia, inflammation and malnutrition in hemodialysis patients

\begin{tabular}{|c|c|c|c|c|c|}
\hline Predictor & Definition & $H R$ & \multicolumn{2}{|c|}{$95 \% \mathrm{Cl}$} & P-value \\
\hline Hyponatremia & Serum sodium < $135 \mathrm{mEq} / \mathrm{l}$ & 1.70 & 1.46 & 1.99 & $<0.001$ \\
\hline Malnutrition & Lean tissue index $<10$ th percentile & 1.41 & 1.24 & 1.60 & $<0.001$ \\
\hline Inflammation & Serum $C R P>6.0 \mathrm{mg} / \mathrm{l}$ & 2.13 & 1.86 & 2.44 & $<0.001$ \\
\hline Fluid depletion & Pre-dialysis fluid status $\leqslant-1.11$ & 2.00 & 1.31 & 3.05 & 0.001 \\
\hline Moderate fluid overload & Pre-dialysis fluid status $>+1.1$ to +2.5 I & 1.60 & 1.34 & 1.91 & $<0.001$ \\
\hline Severe fluid overload & Pre-dialysis fluid status $>+2.5$ to +5.0 l & 2.53 & 2.10 & 3.05 & $<0.001$ \\
\hline
\end{tabular}

The extended model yielded materially identical results with respect (Table 4) to

hyponatremia $(\mathrm{HR}=1.65(95 \% \mathrm{Cl}=1.40-1.95))$, malnutrition $(\mathrm{HR}=1.49(95 \% \mathrm{Cl}=$ 1.23-1.81)), inflammation $(\mathrm{HR}=1.87(95 \% \mathrm{Cl}=1.62-2.16))$, and the various fluid status groups, fluid depletion $\leq-1.1 \mathrm{I}(\mathrm{HR}=1.86(95 \% \mathrm{Cl}=1.20-2.91))$, moderate fluid overload $(>+1.1$ to $+2.5 \mathrm{l} ; \mathrm{HR}=1.65(95 \% \mathrm{Cl}=1.36-2.00))$ and severe fluid overload (>+2.5 to +5.0 l; $\mathrm{HR}=2.44(95 \% \mathrm{Cl}=1.99-3.00)$; Supplementary Material).

\begin{tabular}{|c|c|c|c|c|c|}
\hline Predictor & Definition & $H R$ & \multicolumn{2}{|c|}{$95 \% \mathrm{Cl}$} & P-value \\
\hline Hyponatremia & Serum sodium $<135 \mathrm{mEq} / \mathrm{l}$ & 1.65 & 1.40 & 1.95 & $<0.001$ \\
\hline Malnutrition & $\mathrm{LTI}<10$ th percentile & 1.49 & 1.23 & 1.81 & $<0.001$ \\
\hline Inflammation & Serum CRP $>6.0 \mathrm{mg} / \mathrm{l}$ & 1.87 & 1.62 & 2.16 & $<0.001$ \\
\hline Fat Tissue Index $/ \mathrm{m}^{2}$ ) & & 0.95 & 0.91 & 0.99 & 0.05 \\
\hline $\mathrm{nPCR}$ (g per kg per day) & & 0.71 & 0.40 & 1.26 & 0.25 \\
\hline Albumin $(\mathrm{g} / \mathrm{dl})$ & & 0.35 & 0.30 & 0.41 & $<0.001$ \\
\hline Moderate fluid overload & Pre-dialysis $>+1.1$ to +2.5 l & 1.65 & 1.36 & 2.00 & $<0.001$ \\
\hline Severe fluid overload & Pre-dialysis $>+2.5$ to +5.01 & 2.44 & 1.99 & 3.00 & $<0.001$ \\
\hline Fluid depletion & Pre-dialysis $\leq-1.1 \mathrm{I}$ & 1.86 & 1.20 & 2.91 & 0.006 \\
\hline Pre dialysis systolic blood pressure $(\mathrm{mmHg})$ & & 1 & 0.99 & 1 & 0.18 \\
\hline Age (years) & & 1.04 & 1.04 & 1.05 & $<0.001$ \\
\hline Gender & Male & 0.97 & 0.83 & 1.14 & 0.67 \\
\hline Dialysis vintage (years) & & 1 & 0.98 & 1.02 & 0.94 \\
\hline Dialysate sodium $(\mathrm{mEq} / \mathrm{l})$ & & 0.99 & 0.95 & 1.03 & 0.64 \\
\hline Diabetes mellitus & Present & 1.18 & 1 & 1.39 & 0.06 \\
\hline Catheter as vascular access & Yes & 1.35 & 1.16 & 1.58 & $<0.001$ \\
\hline
\end{tabular}

\section{Discussion}

This study resulted in two main insights. First, we found a robust association between hyponatremia, malnutrition and inflammation. Second, hyponatremia remained a 
mortality, hyponatremia, inflammation and malnutrition in hemodialysis patients

significant predictor of death in Cox models with adjustment for malnutrition, inflammation and deranged fluid status.

Our study adds to the literature by including objective indices of body composition, malnutrition and fluid status determined in a large multinational dialysis patient cohort. In contrast, previous studies employed primarily biochemical nutritional markers ${ }^{1,2}$. We defined malnutrition as LTI below the $10^{\text {th }}$ percentile of age and gender matched healthy subjects, reflecting more protein energy wasting ${ }^{25}$. In a previous study, low LTI assessed by bioimpedance, was highly predictive of mortality $^{26}$. The LTI measured by the BCM is not influenced by fluid overload, which is expressed as a separate compartment in a 3-compartment model ${ }^{15,16}$. Although various means allow the diagnosis of malnutrition in dialysis patients ${ }^{27}$, we prefer LTI as a standardized and objective indicator of somatic phenotype, as the main nutritional marker. However we used several statistical models to assess the association between hyponatremia, malnutrition and mortality. In the basic model, we deliberately did not include other parameters of malnutrition because of potential co linearity with either CRP or LTI. However, the extended model which included these parameters, namely, albumin, FTI and nPCR, showed materially identical results.

The pathophysiology of the relation between malnutrition and hyponatremia is being quite intensively discussed ${ }^{1,2,7}$. Insufficient intake of sodium or excess of free water intake in anuric patient, but also the derangements in body composition itself, could contribute to this phenomenon. Flear et al. observed differences in the relation between muscle water and serum sodium in seven patients suffering from a variety of diseases ${ }^{28}$. They observed a higher sodium-to-water ratio, suggesting an abnormal electrolyte distribution, although the relation to serum sodium was not analysed ${ }^{28}$. In addition, catabolism of organic phosphates in the intracellular compartment (IC) could 
mortality, hyponatremia, inflammation and malnutrition in hemodialysis patients

result in the excretion of inorganic phosphate and potassium into the extracellular compartment (EC), accompanied by a concomitant water shift from the IC to the $E C^{29}$. An increased water shift from the IC to the EC could also be explained by defective cell membrane integrity, allowing movement of intracellular solutes to extracellular water compartment. Both mechanisms have been described in the "sickcell syndrome", a rather controversial condition ${ }^{30}$.

Inflammation was associated with hyponatremia independent from the presence or absence of malnutrition. Data are limited regarding the relation between inflammation and serum sodium in dialysis patients. Hecking et al. observed an inverse relation between white blood cell count and serum sodium levels in their cohort ${ }^{2}$. Interestingly, hyponatremia was associated with infection-related mortality in HD patients, and is frequently associated with other inflammatory diseases ${ }^{3}$. It has been suggested that either hyponatremia per se, or by mucosal barrier breakdown through cellular edema, could stimulate inflammation ${ }^{3}$. Also, non-osmotic storage of sodium may induce the synthesis of interleukin-17 by CD4+ T-helper cells, which may contribute to chronic systemic inflammation ${ }^{31}$.

Another potential cause of hyponatremia, explored in the present study, is sodium dilution due to fluid overload. In congestive heart failure dilutional hyponatremia frequently occurs, which is related to an increased release of copeptin, vasopressin and impaired renal free water excretion ${ }^{4,9,32}$. Whereas this mechanism is absent in anuric HD patients, dipsogenic factors such as angiotensin II, could contribute to increased thirst ${ }^{33,34}$; of note, an inverse relation between interdialytic weight gain and pre-dialysis sodium has been observed ${ }^{1,2}$. In the present study we found moderate fluid overload (pre-dialysis $\mathrm{OH}>+1.1 \mathrm{~L}$ to $+2.5 \mathrm{~L}$ ) to be associated with a decreased change on hyponatremia. Although we suggest that this might be due to the isotonic 
mortality, hyponatremia, inflammation and malnutrition in hemodialysis patients

increase in body fluid with a good appetite, we acknowledge that this hypothesis is still conjectural. Dialysate sodium levels were slightly lower in patients with hyponatremia as compared to patients with normal serum sodium levels. However, the sodium gradient (difference between dialysate and serum sodium) was higher in the hyponatremic patients, with likely higher diffusive sodium gains in hyponatremic patients $^{35}$. From the present database, it cannot be concluded whether the lower dialysate sodium is a cause or consequence (e.g. due to individualization of the dialysate) of lower pre-dialytic serum sodium levels. However, large cohort studies did not observe a significant correlation between both variables in large cohort studies $^{36,37}$. Possibly, higher dialysate-serum sodium gradients may lead to increased water intake in the inter-dialytic period, in order to compensate for the diffusive sodium gain and plasma tonicity during dialysis, leading to increased inter-dialytic weight gain without a change in serum sodium ${ }^{38}$. Additional factors, most notably diabetes, were associated with hyponatremia, corroborating previous studies ${ }^{39}$. Unfortunately, we do not have availability of serum glucose and $\mathrm{HbA} 1 \mathrm{C}$ measurements on a routine basis in the present database.

Despite its strong association with malnutrition and inflammation, hyponatremia remained an independent risk factor for mortality after adjustment for nutritional status, inflammation and fluid overload. This finding corroborates previous studies employing biochemical parameters or BMI as nutrition markers ${ }^{1,2}$. Our study expands on these reports by providing detailed measures of body composition, and CRP levels. Since all these results are observational, we cannot address the question whether hyponatremia per se is causally related to mortality, or whether this observation is due to residual confounding ${ }^{40,41}$. 
mortality, hyponatremia, inflammation and malnutrition in hemodialysis patients

We recognize that our study has limitation beyond its observational nature. First, bioimpedance and laboratory studies were not always done concurrently. Therefore we used time averaged values over a short baseline period to mitigate this problem. We able to use data of $25 \%$ of the entire cohort, due to the fact that both bioimpedance measurements, serum sodium and CRP measurements had to be performed within these predefined limits. Although bioimpedance measurements are used on a routine basis in the cohort, we cannot exclude some selection bias in our study due to the fact that measurements might also have been performed on an additional clinical indication. Second, one could argue that thresholds e.g. for sodium and CRP are arbitrary. However, we deliberately chose clinically useful cut-off limits to improve clarity and to relate to literature $e^{2,21-24,42}$. Third, while serum sodium levels are strongly influenced by hyperglycemia ${ }^{43}$, concurrent measurements of glucose and sodium were not routinely available. To alleviate that shortcoming, we adjusted for the presence of diabetes, which - not unexpectedly - turned out to be a risk factor for hyponatremia and to be associated with outcome ${ }^{39}$. Forth, we lack reliable data on residual renal function, a potential determinant of pre-dialytic serum sodium ${ }^{2}$. In conclusion, malnutrition and inflammation, and moderate pre-dialysis fluid overload, but not severe fluid overload nor fluid depletion, were associated with hyponatremia in a large multinational HD patients cohort. Importantly, even after adjustment for these parameters, hyponatremia remained a significant predictor of mortality. Whether hyponatremia and outcome are causally related or a mere reflection of residual confounding cannot be concluded from this study. However, next to markers of inflammation, malnutrition and fluid status, serum sodium appears to be an important clinical parameter relevant for the care of HD patients. 
mortality, hyponatremia, inflammation and malnutrition in hemodialysis patients

\section{Authors' contribution to the manuscript:}

DM, JK, LU: conceived the idea; LU: performed the statistical analyses; MD, DM, JK: wrote the paper. MD: had primary responsibility for final content; $B C, P C, C K, K L, N L$, JR, FvdS, PK: revised the manuscript. All authors critically revised the manuscript for intellectual content and approved the final version of the manuscript. 
mortality, hyponatremia, inflammation and malnutrition in hemodialysis patients

\section{Conflicts of interest:}

DM, BC, PC and LU are employees of Fresenius Medical Care and may hold stock in the company. PK and NL hold stock in Fresenius Medical Care. MD, CK, KL, JR, FvdS, JK have no conflict of interest.

\section{References:}

1. Waikar SS, Curhan GC, Brunelli SM. Mortality associated with low serum sodium concentration in maintenance hemodialysis. Am J Med. 2011;124(1):77-84.

2. Hecking $M$, Karaboyas $A$, Saran $R$, et al. Predialysis serum sodium level, dialysate sodium, and mortality in maintenance hemodialysis patients: the Dialysis Outcomes and Practice Patterns Study (DOPPS). Am J Kidney Dis. 2012;59(2):238-248.

3. Mandai $S$, Kuwahara $M$, Kasagi $Y$, et al. Lower serum sodium level predicts higher risk of infection-related hospitalization in maintenance hemodialysis patients: an observational cohort study. BMC Nephrol. 2013;14:276.

4. Madan VD, Novak E, Rich MW. Impact of change in serum sodium concentration on mortality in patients hospitalized with heart failure and hyponatremia. Circ Heart Fail. 2011;4(5):637643.

5. Flear CT, Hilton P. Hyponatraemia and severity and outcome of myocardial infarction. Br Med J. 1979;1(6173):1242-1246.

6. Scherz N, Labarere J, Mean M, Ibrahim SA, Fine MJ, Aujesky D. Prognostic importance of hyponatremia in patients with acute pulmonary embolism. Am J Respir Crit Care Med. 2010;182(9):1178-1183.

7. Lin GM, Li YH, Chu KM, Han CL. Malnutrition and hyponatremia in dialysis patients. Am J Med. 2011;124(8):e21; author reply e25.

8. Lin GM, Li YH, Chu KM, Han CL. Hyponatremia may reflect malnutrition in patients with acute pulmonary embolism. Am J Respir Crit Care Med. 2011;183(6):827; author reply 827-828.

9. Gill G, Leese G. Hyponatraemia: biochemical and clinical perspectives. Postgrad Med J. 1998;74(875):516-523.

10. Guglielminotti J, Pernet P, Maury E, et al. Osmolar gap hyponatremia in critically ill patients: evidence for the sick cell syndrome? Crit Care Med. 2002;30(5):1051-1055.

11. Flear CT, Singh CM. Hyponatraemia and sick cells. Br J Anaesth. 1973;45(9):976-994.

12. von Gersdorff GD, Usvyat $L$, Marcelli $D$, et al. Monitoring dialysis outcomes across the world-the MONDO Global Database Consortium. Blood Purif. 2013;36(3-4):165-172.

13. Usvyat LA, Haviv YS, Etter M, et al. The MONitoring Dialysis Outcomes (MONDO) initiative. Blood Purif. 2013;35(1-3):37-48.

14. http://unstats.un.org/unsd/methods/m49/m49regin.htm\#europe.

15. Moissl UM, Wabel P, Chamney PW, et al. Body fluid volume determination via body composition spectroscopy in health and disease. Physiol Meas. 2006;27(9):921-933.

16. Chamney PW, Wabel P, Moissl UM, et al. A whole-body model to distinguish excess fluid from the hydration of major body tissues. Am J Clin Nutr. 2007;85(1):80-89.

17. Wabel P, Chamney P, Moissl U, Jirka T. Importance of whole-body bioimpedance spectroscopy for the management of fluid balance. Blood Purif. 2009;27(1):75-80. 
mortality, hyponatremia, inflammation and malnutrition in hemodialysis patients

18. Wabel P, Moissl U, Chamney P, et al. Towards improved cardiovascular management: the necessity of combining blood pressure and fluid overload. Nephrology, dialysis, transplantation : official publication of the European Dialysis and Transplant Association European Renal Association. 2008;23(9):2965-2971.

19. Wizemann V, Wabel $\mathrm{P}$, Chamney $\mathrm{P}$, et al. The mortality risk of overhydration in haemodialysis patients. Nephrology, dialysis, transplantation : official publication of the European Dialysis and Transplant Association - European Renal Association. 2009;24(5):1574-1579.

20. Du Bois D, Du Bois EF. A formula to estimate the approximate surface area if height and weight be known. 1916. Nutrition. 1989;5(5):303-311; discussion 312-303.

21. Nigwekar SU, Wenger J, Thadhani R, Bhan I. Hyponatremia, mineral metabolism, and mortality in incident maintenance hemodialysis patients: a cohort study. American journal of kidney diseases : the official journal of the National Kidney Foundation. 2013;62(4):755-762.

22. Herzig KA, Purdie DM, Chang W, et al. Is C-reactive protein a useful predictor of outcome in peritoneal dialysis patients? J Am Soc Nephrol. 2001;12(4):814-821.

23. Menon $\mathrm{V}$, Wang $\mathrm{X}$, Greene $\mathrm{T}$, et al. Relationship between C-reactive protein, albumin, and cardiovascular disease in patients with chronic kidney disease. Am J Kidney Dis. 2003;42(1):44-52.

24. Ortega O, Rodriguez I, Gallar P, et al. Significance of high C-reactive protein levels in predialysis patients. Nephrology, dialysis, transplantation : official publication of the European Dialysis and Transplant Association - European Renal Association. 2002;17(6):1105-1109.

25. Fouque D, Kalantar-Zadeh K, Kopple J, et al. A proposed nomenclature and diagnostic criteria for protein-energy wasting in acute and chronic kidney disease. Kidney Int. 2008;73(4):391398.

26. Marcelli D, Usvyat, L., Marelli, C., Etter, M., Kooman, J.,Grassmann, A.,Scatizzi, L., Bayh, I., Kotanko, P., Canaud, B. Relationship between Body Composition Evaluated by Whole Body Bioimpedance and Survival in Hemodialysis Patients. . Journal of the American Society of Nephrology. 2013;24(26A).

27. Kuhlmann MK, Levin NW. How common is malnutrition in ESRD? New approaches to diagnosis of malnutrition. Blood Purif. 2008;26(1):49-53.

28. Flear CT, Florence I, Williams JA. Water, sodium, potassium, and chloride content of skeletal muscle in fit and ill subjucts. J Clin Pathol. 1968;21(5):555-563.

29. Cherney DZ, Zevallos G, Oreopoulos D, Halperin ML. A physiological analysis of hyponatremia: implications for patients on peritoneal dialysis. Perit Dial Int. 2001;21(1):7-13.

30. Gill GV, Osypiw JC, Shearer E, English PJ, Watson ID. Critical illness with hyponatraemia and impaired cell membrane integrity--the "sick cell syndrome" revisited. Clin Biochem. 2005;38(11):1045-1048.

31. Kleinewietfeld $M$, Manzel A, Titze J, et al. Sodium chloride drives autoimmune disease by the induction of pathogenic TH17 cells. Nature. 2013;496(7446):518-522.

32. Miller WL, Grill DE, Struck J, Jaffe AS. Association of hyponatremia and elevated copeptin with death and need for transplantation in ambulatory patients with chronic heart failure. Am J Cardiol. 2013;111(6):880-885.

33. Graziani G, Badalamenti S, Del Bo A, et al. Abnormal hemodynamics and elevated angiotensin II plasma levels in polydipsic patients on regular hemodialysis treatment. Kidney Int. 1993;44(1):107-114.

34. Yamamoto $T$, Shimizu $M$, Morioka $M$, Kitano $M$, Wakabayashi $H$, Aizawa N. Role of angiotensin $\mathrm{II}$ in the pathogenesis of hyperdipsia in chronic renal failure. JAMA. 1986;256(5):604-608.

35. Moret $\mathrm{K}$, Hassell $\mathrm{D}$, Kooman JP, et al. Ionic mass balance and blood volume preservation during a high, standard, and individualized dialysate sodium concentration. Nephrology, dialysis, transplantation : official publication of the European Dialysis and Transplant Association - European Renal Association. 2002;17(8):1463-1469. 
mortality, hyponatremia, inflammation and malnutrition in hemodialysis patients

36. Mc Causland FR, Brunelli SM, Waikar SS. Dialysate sodium, serum sodium and mortality in maintenance hemodialysis. Nephrology, dialysis, transplantation : official publication of the European Dialysis and Transplant Association - European Renal Association. 2012;27(4):16131618.

37. Hecking M, Karaboyas A, Saran R, et al. Dialysate sodium concentration and the association with interdialytic weight gain, hospitalization, and mortality. Clinical journal of the American Society of Nephrology : CJASN. 2012;7(1):92-100.

38. Munoz Mendoza J, Arramreddy R, Schiller B. Dialysate Sodium: Choosing the Optimal Hemodialysis Bath. Am J Kidney Dis. 2015;66(4):710-720.

39. Sahin OZ, Asci G, Kircelli F, et al. The impact of low serum sodium level on mortality depends on glycemic control. Eur J Clin Invest. 2012;42(5):534-540.

40. Chawla A, Sterns RH, Nigwekar SU, Cappuccio JD. Mortality and serum sodium: do patients die from or with hyponatremia? Clinical journal of the American Society of Nephrology : CJASN. 2011;6(5):960-965.

41. Hoorn EJ, Zietse R. Hyponatremia and mortality: how innocent is the bystander? Clinical journal of the American Society of Nephrology: CJASN. 2011;6(5):951-953.

42. Stenvinkel $P$, Heimburger $O$, Lindholm B, Kaysen GA, Bergstrom J. Are there two types of malnutrition in chronic renal failure? Evidence for relationships between malnutrition, inflammation and atherosclerosis (MIA syndrome). Nephrology, dialysis, transplantation : official publication of the European Dialysis and Transplant Association - European Renal Association. 2000;15(7):953-960.

43. Penne EL, Thijssen S, Raimann JG, Levin NW, Kotanko P. Correction of serum sodium for glucose concentration in hemodialysis patients with poor glucose control. Diabetes Care. 2010;33(7):e91. 
mortality, hyponatremia, inflammation and malnutrition in hemodialysis patients 


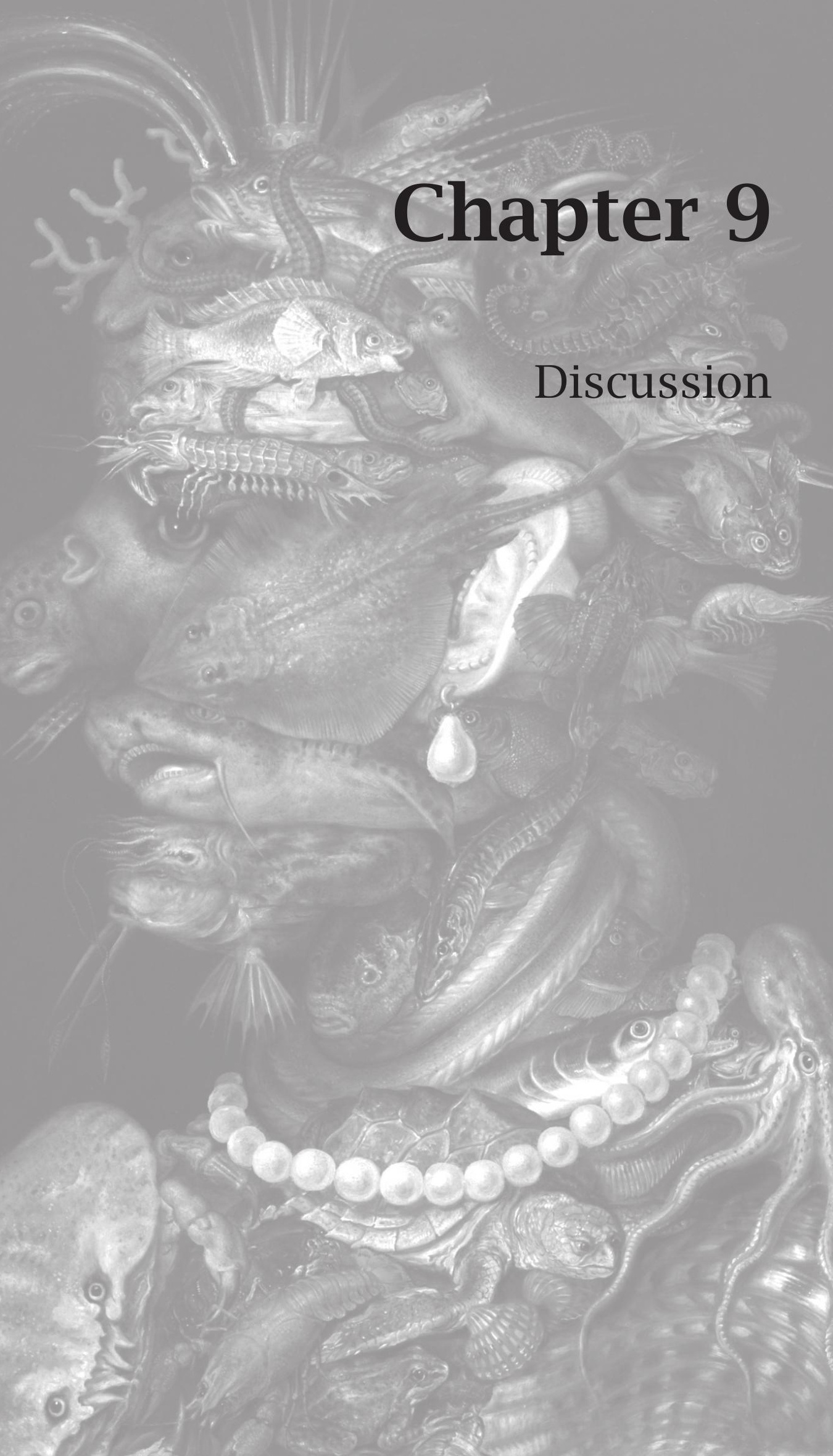




\section{General discussion}

The first aim of this thesis was to clarify the reason for the improved survival in obese end-stage renal disease (ESRD) patients, which is different from the general population where obesity is a cardiovascular risk factor. Since obesity is defined by the ratio of body weight to height squared, it is also important to differentiate its components. Therefore, the relation between fat mass, lean tissue mass and outcome was investigated.

The second aim was to assess the dynamics of nutritional parameters, including body composition, following the start of dialysis treatment. This is of importance as dialysis treatment may have both beneficial and adverse effects on nutritional state, whereas the available data on this subject are both limited as well as controversial.

Abnormalities in nutritional state have various correlates in ESRD patients. Whereas the relation with inflammation is well established, hyponatremia appears to be an emerging risk factor for mortality which is both associated with inflammation and nutritional abnormalities. However, there are limited data on this relation in ESRD patients. Therefore, the third and last aim dealt with the relationship between nutritional status with inflammation and hyponatremia.

As reported in chapter 2, higher body mass index in the range of overweight and obesity was associated with better survival in a large prospective Southern European cohort of patients on hemodialysis $(\mathrm{HD})^{2}$. This paradoxical association of obesity and even morbid obesity with improved outcome was confirmed by several studies not only in patients with ESRD but also in patients with other chronic diseases ${ }^{3,4}$, including chronic heart failure ${ }^{5}$. However, the categorization of patients according to nutritional status as defined by body mass index (BMI) is a strong limitation of this 
large mass of medical research. In fact, as deeply discussed in chapter 2 , this index

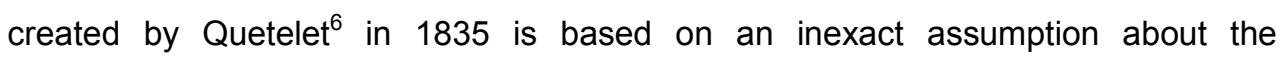
distribution of body mass between muscle and fat. BMI has the tendency to overestimate adiposity in those with more lean body mass, e.g. athletes, and to underestimate excess adiposity on those with less lean body mass. The risk of such a misclassification is particularly high in the intermediate level between 20 and 30 $\mathrm{kg} / \mathrm{m}^{2}$, which is associated with a wide range of body fat percentages ${ }^{7}$. In addition, as recently highlighted by Carrero et $\mathrm{al}^{8}$, BMI does not capture the aging changes in body composition, the gender-variation in body shape, and the difference between central and peripheral fat accumulation. Finally, BMI is falsely increased by fluid overload, which is very important in patients on dialysis. Therefore, the conclusion of chapter $\mathbf{3}$ was that considering the intrinsic limitations of all nutritional markers, a multi-perspective approach with a combination of measures and a stepwise procedure is recommended ${ }^{9}$. The first step for the purpose for screening and early detection of malnutrition is to use subjective clinical assessment, relying on validated subjective global assessment $(\mathrm{SGA})^{10}$. The second is the assessment of the body composition by bioimpedance spectroscopy with the physiological model for quantifying and ensuring follow-up of patients at risk of malnutrition or for monitoring patients with already established protein-energy wasting, as discussed in chapter 4 and 7 . The third step is to deal with the use of routine laboratory parameters, such as albumin or CRP for monitoring inflammation level, as discussed in chapters $\mathbf{5}$ and $\mathbf{6}$.

The verification of a medium to long term improvement of patients with compromised nutritional status after the initiation of a proper nutritional therapy or other important interventions, such as the start of dialysis treatment, would be a major benefit. In fact, as shown in chapter 2 patients losing more than $5.8 \%$ of the initial body weight 
are those with the higher risk of death. It is likely that this subgroup is composed of patients whose loss in lean tissue is not balanced by an increase in fat tissue, as pointed out in chapter 4 . This subgroup should be the main target of a nutritional therapy but, as discussed, results cannot be judged only on the basis of a proportion of recovery in body weight.

In bioimpedance spectroscopy with physiological model technique, the extra- and intra-cellular water compartments are calculated using the Hanai and Cole model $^{11,12}$. Additionally, using the physiological model based on normohydrated tissue properties ${ }^{13}$, it is possible to distinguish fluid overload from muscle mass. The importance of estimating a proxy to muscle mass has been recently recommended by the ESPEN consensus statement ${ }^{14}$, advocating the general use of body composition measurements in all health care settings, i.e. in primary care, in nursing homes, and home elderly care. Recently, the National Health and Nutrition Examination Survey $(\text { NHANES })^{15}$, reported results on the association between sarcopenia (defined as appendicular skeletal muscle mass index $<5.45 \mathrm{~kg} / \mathrm{m}^{2}$ in women and $<7.26 \mathrm{~kg} / \mathrm{m}^{2}$ in men) and chronic kidney disease (CKD) stages of 11643 subjects who underwent dual-energy X-ray absorptiometry (DXA) evaluation. The main result was an almost linear association between the increasing proportions of patients with sarcopenia with more advanced stages of CKD.

Therefore, loss of muscle mass is commonly observed among CKD and dialysis patients, but since muscle mass normally declines with age with gender specific trajectories, a consensus criteria has to be developed in order to properly classify patients ${ }^{17}$. In the absence of such diagnostic criteria, in chapter 7 patients with lean tissue index ( $\mathrm{LTI}$; lean tissue mass $/$ height $\left.^{2}\right)$ and fat tissue index $(\mathrm{FTI}$; fat tissue mass/height ${ }^{2}$ ) measured using bioimpedance were compared with the distribution in 
age and sex-matched healthy controls. Patients with LTI or FTI values below the $10^{\text {th }}$ percentile were considered as low LTI or FTI patients, respectively. Similarly, those patients with $\mathrm{LTI}$ or $\mathrm{FTI}$ values over the $90^{\text {th }}$ percentile of the distribution in age and sex-matched healthy controls were considered high LTI or FTI patients, respectively. In summary, chapter 7 showed that LTI and FTI within the 10th-90th percentile of an age- and sex matched healthy population were associated with the best survival, whereas low $\mathrm{FTI}$ and low LTI, and especially the combination of both, were associated with higher mortality ${ }^{18}$. Skeletal muscle accounts for about $40 \%$ of body weight and $50 \%$ of the body protein $^{19}$ and is the major protein physiological reserve of the body, used when renal function declines. Muscle mass decreases when protein or amino acids are needed because, contrary to fats, excess proteins are not stored, and protein balance is physiologically based on sufficient protein intake. In cases of inadequate protein intake, the priority will be on the maintenance of critical metabolic functions, even sacrificing muscle mass. Therefore, a low level of muscle mass may indicate that the protein reserves are already exhausted and that these critical functions cannot be ensured anymore, explaining the reported association between low LTI and mortality ${ }^{20}$. Regarding the fat tissue, fat it is the largest energy reserve in mammals. Adipose tissue is involved in fatty acid metabolism, with a store of triacylglycerol that can be hydrolyzed in a regulated way to directly release fatty acids into the circulation for delivery to other tissues ${ }^{21}$. The presence of a fat tissue energy reserve can prevent an additional catabolic stress to the muscle, from the quantitative point of view the second tissue involved in the metabolism of fatty acid ${ }^{21}$. However, the protective effect of normal and even high FTI appears to be somehow contradictory since the pro-inflammatory properties of fat, mainly visceral, have been demonstrated in the general population. Finally, it has to be stressed that fat may be 
associated with greater secretion of anti-inflammatory cytokines than proinflammatory molecules in dialysis patients ${ }^{22,23}$.

The start of dialysis treatment is a major transition in the life of a patients of ESRD. Starting dialysis treatment can have both beneficial as well as adverse effect on nutritional state. longitudinal studies, should capture this close association. Chapter 4 showed that, following the transition to HD, ESRD patients presented with distinctive changes in body composition, namely with a decrease of $0.40 \mathrm{~kg} / \mathrm{m}^{2}$ of lean tissue index $(\mathrm{LTI})$ and a parallel increase of $0.95 \mathrm{~kg} / \mathrm{m}^{2}$ of fat tissue index $(\mathrm{FTI})^{24}$. These were mainly associated with gender, older age, presence of diabetes, low baseline FTI, and high baseline LTI. As expected, BMI increases of about 0.60 $\mathrm{kg} / \mathrm{m}^{2}$ did not fully represent the changes in body composition.

Albumin is a marker of visceral protein, inflammation and overhydration ${ }^{25}$. Low albumin levels not only mean low oncotic pressure, with water shift between the intravascular and interstitial space, but may also be associated with increased blood viscosity $^{26}$ and hypercoagulable states ${ }^{27}$. Finally, reduced albumin binding capacity for drugs and endogenous ligands is a characteristic of $C K D^{28}$. The association with negative outcome in patients having low albumin levels is well known. However, since low albumin levels can be the result of different processes, it is not clear if the outcome is causally related or if albumin is just an indicator of events associated with increased mortality. Creatinine generation is proportional to dietary meat intake and mainly to somatic protein mass, with higher levels in those patients whose superior nutritional status sustains an increased musculature. Finally, creatinine, similarly to albumin, has been found to be a strong predictor of mortality risk. ${ }^{29}$ The study reported in chapter 5 evaluated the development of the level of albumin and creatinine in the initial phase of dialysis, with the aim to maximize the benefit of 
laboratory measurements normally available from the routine continuous assessment. Evaluating 2 years from baseline to 27 months after initiation of dialysis, a significant increase in serum albumin of $0.15 \pm 0.45 \mathrm{~g} / \mathrm{dL}$ was found using delta analysis. Of note, the serum albumin increased most significantly in the first 6 months. During the first months on HD many factors can play roles and act in opposite directions. For example, in patients with significant proteinuria, the loss of residual renal function (RRF) will decrease albumin loss. In fact, after 3 months from the initiation of $\mathrm{HD}$, because of a policy of strict volume control applied in the dialysis network as evidenced by the low post-dialysis fluid overload $(0.16 \pm 2.13$ liters), residual diuresis is expected to be negligible ${ }^{30}$. In parallel, hemoconcentration (resulting from the achievement of a lower hydration status) would increase albumin levels. Finally, with the initiation of renal replacement therapy (RRT), dietary protein intake is expected to improve while the loss of amino acids through the dialysis membrane may negatively affect the protein balance. It has to be stressed that patients with C-reactive protein $(\mathrm{CRP}) \geq 10 \mathrm{mg} / \mathrm{dL}$ had significantly lower albumin ($0.1355 \mathrm{mg} / \mathrm{dL}$ difference, $\mathrm{p}$-value $<0.001$ ), but had a significantly higher albumin increase over the follow-up time (by $0.07 \mathrm{mg} / \mathrm{dL}$ per year, $\mathrm{p}$-value<0.001). No significant effect was found for creatinine, neither for the main effect of CRP nor for the interaction term. The conflicting trends of lean body mass and albumin following the initiation of dialysis deserve further comments. It is clear that serum albumin cannot be considered the best marker to verify nutritional status because it is not only a marker of visceral protein but also of inflammation and overhydration ${ }^{25}$. Gama Axelsson et $\mathrm{al}^{31}$ clearly demonstrated that serum albumin is a weak predictor of nutritional status as defined by SGA scores, with association between serum 
albumin and other markers of nutritional status such as handgrip strength and lean body mass being even weaker.

The relationship between inflammation and albumin as a biochemical marker for malnutrition was more deeply discussed in chapter 6. CRP is clinically the most popular inflammatory marker routinely used. It is an acute phase reactant, chemically stable and with a relatively long half-life without diurnal variation. However, neutrophil-to-lymphocyte ratio (NLR) is becoming increasingly more recognized as a marker of systemic inflammation in oncology and in cardiology ${ }^{32,33}$, and finally also in CKD patients ${ }^{34}$. Oxidative stress and inflammation are both known to inhibit albumin synthesis $^{35,36}$, and they are often present in dialysis patients ${ }^{37,38}$. In the study reported in chapter 6, serum albumin levels were negatively correlated with both NLR and $\mathrm{CRP}^{39}$. These findings are consistent with the hypothesis that albumin behaves as a negative acute phase protein and also support the concept of malnutrition-inflammation complex in patients on dialysis ${ }^{40}$.

An emerging risk factor in dialysis patients is the presence of hyponatremia (defined as a serum sodium below $135 \mathrm{mmol} / \mathrm{l})$. Waikar et al reported an association of low predialysis serum sodium concentration with an increased risk of death ${ }^{41}$. In principle this observation is not surprising since hyponatremia is very often associated with several medical conditions, including congestive heart failure ${ }^{42}$ and cirrhosis $^{43}$. In patients with congestive heart failure and cirrhosis, hyponatremia partially derives from high arginine vasopressin levels, which are directly correlated with the severity of heart failure and liver disease. In these conditions, hyponatremia is mediated by the non-osmotic release of arginine vasopressin and a reduced free water clearance by the kidney, which in turn may reflect the severity of the underlying disease process through mechanisms such as reduced glomerular filtration rate and 
activation of the sympathetic nervous system. However, a relationship between hyponatremia and malnutrition was already observed in other diseases ${ }^{44}$. Waikar et $\mathrm{al}^{41}$ excluded the possibility that the analysis may be confused by cachexia and malnutrition because of adjustment with measures of dietary intake. This conclusion was discussed by Lin et $\mathrm{al}^{45}$, who noted that patients with hyponatremia in the first quartile of the distribution of baseline predialysis serum sodium concentration had the lowest estimated dry body mass index and creatinine level. This reflects a malnutrition status and was associated with a higher death rate in a maintenance dialysis population. In line with Lin's opinion, results reported in chapter 8 confirm a robust association between hyponatremia, malnutrition and inflammation. An additional association was found with moderate fluid overload, but not with severe fluid overload or fluid depletion. Similarly to the findings of Waikar et $\mathrm{al}^{41}$, it was found that hyponatremia remained a significant predictor of mortality even after adjustment for these parameters.

In conclusion, with this thesis the importance of disease-related malnutrition ${ }^{14}$ - or more precisely protein-energy wasting - regarding the outcome of dialysis patients has been confirmed. Moreover, the paradoxical association between obesity and improved outcome has been explored in more detail using more detailed assessment of body composition in large international cohorts of dialysis patients.

Protein energy wasting is very frequent and develops over time after admission to RRT. Several factors are associated with malnutrition, including inflammation and hyponatremia. However, whether they are causally related or not cannot be definitely concluded by this study. Regarding future research, a move from body weight, normalized or not for squared height, to body composition ${ }^{1}$ would surely open new promising fields. In fact, the availability of a simple, inexpensive and easily 
repeatable technique able to estimate lean and fat body mass means that a powerful surrogate outcome is available to test all new therapeutical options in the management of chronic diseases. For example, it is possible to make comparisons not only between different dialysis modalities but also between intensities of treatment (standard vs. frequent or long HD). 


\section{Reference List}

1. Carrero JJ, Wanner C. Clinical Monitoring of Protein-Energy Wasting in Chronic Kidney Disease: Moving From Body Size to Body Composition. J. Ren. Nutr. 2016;26(2):63-64.

2. Chazot C, Gassia JP, Di Benedetto A, Cesare S, Ponce P, Marcelli D. Is there any survival advantage of obesity in Southern European haemodialysis patients? Nephrology, dialysis, transplantation : official publication of the European Dialysis and Transplant Association European Renal Association. 2009;24(9):2871-2876.

3. Yeh S, Wu SY, Levine DM, et al. Quality of life and stimulation of weight gain after treatment with megestrol acetate: correlation between cytokine levels and nutritional status, appetite in geriatric patients with wasting syndrome. J. Nutr. Health Aging. 2000;4(4):246-251.

4. Malvy E, Thiebaut R, Marimoutou C, Dabis F, Groupe d'Epidemiologie Clinique du Sida en A. Weight loss and body mass index as predictors of HIV disease progression to AIDS in adults. Aquitaine cohort, France, 1985-1997. J. Am. Coll. Nutr. 2001;20(6):609-615.

5. Kenchaiah S, Pocock SJ, Wang D, et al. Body mass index and prognosis in patients with chronic heart failure: insights from the Candesartan in Heart failure: Assessment of Reduction in Mortality and morbidity (CHARM) program. Circulation. 2007;116(6):627-636.

6. Quetelet A. Anthropométrie ou mesure des différentes facultés de l'homme. Brüssel 1870.

7. Romero-Corral A, Somers VK, Sierra-Johnson J, et al. Accuracy of body mass index in diagnosing obesity in the adult general population. Int. J. Obes. (Lond.). 2008;32(6):959-966.

8. Carrero JJ, Avesani CM. Pros and cons of body mass index as a nutritional and risk assessment tool in dialysis patients. Semin Dial. 2015;28(1):48-58.

9. Marcelli D, Wabel P, Wieskotten S, et al. Physical methods for evaluating the nutrition status of hemodialysis patients. Journal of nephrology. 2015.

10. Barbosa-Silva MC. Subjective and objective nutritional assessment methods: what do they really assess? Curr. Opin. Clin. Nutr. Metab. Care. 2008;11(3):248-254.

11. Cole K, Cole RH. Dispersion and absorption in dielectrics. I. Alternating current characteristics. . J. Chem. Phys.;9:341-351.

12. Hanai T. Theory of the dielectric dispersion due to the interfacial polarization and its application to emulsions. Kolloid-Zeitschrift 1960;171:23-31.

13. Carter M, Morris AT, Zhu F, Zaluska W, Levin NW. Effect of body mass index (BMI) on estimation of extracellular volume (ECV) in hemodialysis (HD) patients using segmental and whole body bioimpedance analysis. Physiol. Meas. 2005;26(2):S93-99.

14. Cederholm T, Bosaeus I, Barazzoni R, et al. Diagnostic criteria for malnutrition - An ESPEN Consensus Statement. Clin. Nutr. 2015;34(3):335-340.

15. Sharma D, Hawkins M, Abramowitz MK. Association of sarcopenia with eGFR and misclassification of obesity in adults with CKD in the United States. Clin. J. Am. Soc. Nephrol. 2014;9(12):2079-2088.

16. Fouque D, Kalantar-Zadeh K, Kopple J, et al. A proposed nomenclature and diagnostic criteria for protein-energy wasting in acute and chronic kidney disease. Kidney Int. 2008;73(4):391398.

17. Stenvinkel P, Carrero JJ, von Walden F, Ikizler TA, Nader GA. Muscle wasting in end-stage renal disease promulgates premature death: established, emerging and potential novel treatment strategies. Nephrol. Dial. Transplant. 2015.

18. Marcelli D, Usvyat LA, Kotanko P, et al. Body Composition and Survival in Dialysis Patients: Results from an International Cohort Study. Clin. J. Am. Soc. Nephrol. 2015.

19. Griffiths RD. Muscle mass, survival, and the elderly ICU patient. Nutrition. 1996;12(6):456458. 
20. Bonanni A, Mannucci I, Verzola D, et al. Protein-energy wasting and mortality in chronic kidney disease. Int. J. Environ. Res. Public Health. 2011;8(5):1631-1654.

21. Frayn KN, Arner P, Yki-Jarvinen H. Fatty acid metabolism in adipose tissue, muscle and liver in health and disease. Essays Biochem. 2006;42:89-103.

22. Shoji T, Shinohara K, Hatsuda S, et al. Altered relationship between body fat and plasma adiponectin in end-stage renal disease. Metabolism. 2005;54(3):330-334.

23. Stenvinkel P, Gillespie IA, Tunks J, et al. Inflammation Modifies the Paradoxical Association between Body Mass Index and Mortality in Hemodialysis Patients. J. Am. Soc. Nephrol. 2015.

24. Marcelli D, Brand K, Ponce P, et al. Longitudinal Changes in Body Composition in Patients After Initiation of Hemodialysis Therapy: Results From an International Cohort. J. Ren. Nutr. 2015.

25. Marcelli D, Di Benedetto A, Ciotola A, Grassmann A, Canaud B. Subjective global assessment scores have poor correlation with serum albumin in obese hemodialysis patients by Eric $D$. Erb, Rosa K. Hand, and Alison L. Steiber. J Ren Nutr. 2014;24(6):432-433.

26. Joles JA, Willekes-Koolschijn N, Koomans HA. Hypoalbuminemia causes high blood viscosity by increasing red cell lysophosphatidylcholine. Kidney Int. 1997;52(3):761-770.

27. Kario K, Matsuo T, Kobayashi H. Heparin cofactor II deficiency in the elderly: comparison with antithrombin III. Thromb. Res. 1992;66(5):489-498.

28. Emerson TE, Jr. Unique features of albumin: a brief review. Crit. Care Med. 1989;17(7):690694.

29. Culp K, Flanigan M, Lowrie EG, Lew N, Zimmerman B. Modeling mortality risk in hemodialysis patients using laboratory values as time-dependent covariates. Am. J. Kidney Dis. 1996;28(5):741-746.

30. Gunal Al, Kirciman E, Guler M, Yavuzkir M, Celiker H. Should the preservation of residual renal function cost volume overload and its consequence left ventricular hypertrophy in new hemodialysis patients? Ren. Fail. 2004;26(4):405-409.

31. Gama-Axelsson T, Heimburger O, Stenvinkel P, Barany P, Lindholm B, Qureshi AR. Serum albumin as predictor of nutritional status in patients with ESRD. Clin. J. Am. Soc. Nephrol. 2012;7(9):1446-1453.

32. Sato H, Tsubosa Y, Kawano T. Correlation between the pretherapeutic neutrophil to lymphocyte ratio and the pathologic response to neoadjuvant chemotherapy in patients with advanced esophageal cancer. World J. Surg. 2012;36(3):617-622.

33. Uthamalingam S, Patvardhan EA, Subramanian S, et al. Utility of the neutrophil to lymphocyte ratio in predicting long-term outcomes in acute decompensated heart failure. Am. J. Cardiol. 2011;107(3):433-438.

34. Thijssen S, Wystrychowski G, Usvyat L, Kotanko P, Levin NW. Determinants of serum albumin concentration analyzed in a large cohort of patients on maintenance hemodialysis. J. Ren. Nutr. 2007;17(1):70-74.

35. Buck M, Zhang L, Halasz NA, Hunter T, Chojkier M. Nuclear export of phosphorylated C/EBPbeta mediates the inhibition of albumin expression by TNF-alpha. EMBO J. 2001;20(23):6712-6723.

36. Prinsen $\mathrm{BH}$, Rabelink TJ, Beutler JJ, et al. Increased albumin and fibrinogen synthesis rate in patients with chronic renal failure. Kidney Int. 2003;64(4):1495-1504.

37. Martin-Mateo MC, Sanchez-Portugal M, Iglesias S, de Paula A, Bustamante J. Oxidative stress in chronic renal failure. Ren. Fail. 1999;21(2):155-167.

38. Stam F, van Guldener C, Schalkwijk CG, ter Wee PM, Donker AJ, Stehouwer CD. Impaired renal function is associated with markers of endothelial dysfunction and increased inflammatory activity. Nephrol. Dial. Transplant. 2003;18(5):892-898.

39. Malhotra R, Marcelli D, von Gersdorff G, et al. Relationship of Neutrophil-to-Lymphocyte Ratio and Serum Albumin Levels with C-Reactive Protein in Hemodialysis Patients: Results from 2 International Cohort Studies. Nephron. 2015. 


\section{Discussion}

40. Don BR, Kaysen G. Serum albumin: relationship to inflammation and nutrition. Semin Dial. 2004;17(6):432-437.

41. Waikar SS, Curhan GC, Brunelli SM. Mortality associated with low serum sodium concentration in maintenance hemodialysis. Am. J. Med. 2011;124(1):77-84.

42. Milo-Cotter $\mathrm{O}$, Cotter $\mathrm{G}$, Weatherley BD, et al. Hyponatraemia in acute heart failure is a marker of increased mortality but not when associated with hyperglycaemia. Eur. J. Heart Fail. 2008;10(2):196-200.

43. Kim WR, Biggins SW, Kremers WK, et al. Hyponatremia and mortality among patients on the liver-transplant waiting list. N. Engl. J. Med. 2008;359(10):1018-1026.

44. Lin GM, Li YH, Chu KM, Han CL. Hyponatremia may reflect malnutrition in patients with acute pulmonary embolism. Am. J. Respir. Crit. Care Med. 2011;183(6):827; author reply 827-828.

45. Lin GM, Li YH, Chu KM, Han CL. Malnutrition and hyponatremia in dialysis patients. Am. J. Med. 2011;124(8):e21; author reply e25. 


\section{Discussion}




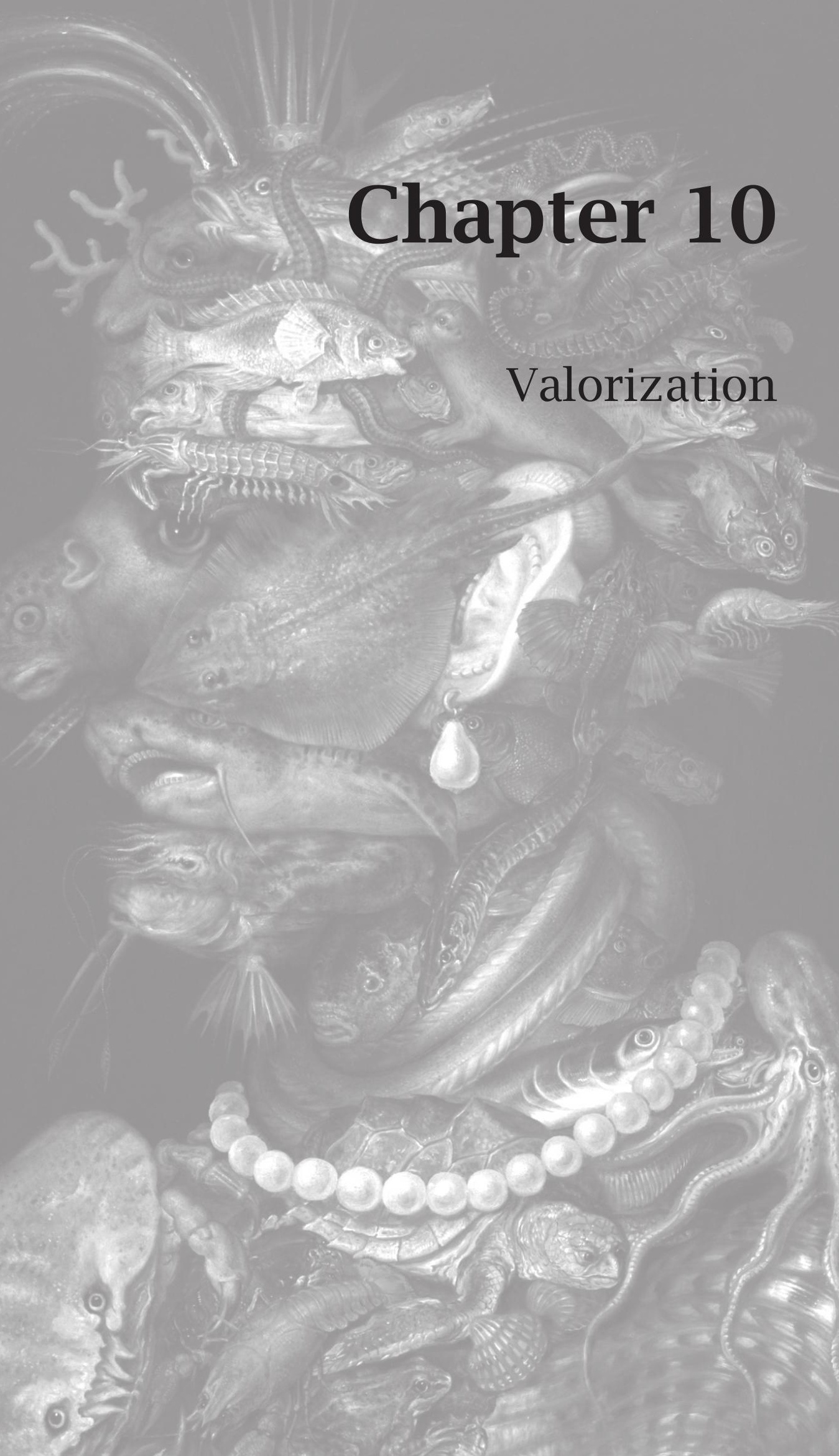




\section{Valorization}

The collection of manuscripts included in this thesis highlights the high prevalence of protein-energy wasting in patients on hemodialysis and its relationship with mortality. Additionally, the dynamics of the development of malnutrition during the first 30 months on dialysis treatment were clarified. Therefore, the problem of malnutrition is clear and it is likely to be at least partially responsible for the high risk of clinical complications during the follow-up, associated with a significant component of the total cost burden of the disease due to hospitalization costs.

However, in front of a clear need to improve the nutritional therapy of patients on hemodialysis, as recently stressed by Hand et $\mathrm{al}^{1}$, in US a dietician has to follow about 150 patients and the focus is mainly on mineral and bone disorder. Dieticians spend more checking phosphate intake and compliance to phosphate binders. It is not the aim of this chapter to judge the importance of this specific complication, but the evidence that today in US the yearly pharmaceutical budget spent for mineral and bone disorder is about 30 -fold higher than that of parenteral nutrition is impressive $^{2}$. In absence of clear data, the general opinion is that the US situation is common with many other countries.

Protein-energy wasting should be prevented, or at least detected and also followedup after start of renal replacement therapy in a very early phase according to a judicious choice of methods discussed in this thesis, in combination with a serious nutrient intake assessment and consequent dietary advice. However, it is well known that the change of the nutritional habits is one of the hardest tasks, and requires competence, dedication and time of experience dieticians, nephrologists and dialysis 
nurses. Patients have to be strictly followed-up, educated on the benefit of maintaining proper dietary standards. It is a matter of fact that patients starting dialysis after a pre-dialysis phase on low protein diet do not present major nutritional problems and are likely more compliant to dietary advices ${ }^{3}$. Patient empowerment is clearly a strong tool in the hands of nephrologists to improve the outcome of patients on dialysis, and it is expected to be very cost-effective. However, it is clear that the very limited resources in term of available dieticians will not allow an efficient realization of this strategy. But whereas in US and other countries (e.g. France, Portugal, UK) the discussion is on the limited number of renal dieticians available, at least they are mandatory members of the team taking care of dialysis patients. In other countries their presence is even considered as optional and close collaboration between dialysis and dietetic staffs remains essential to handle this challenge. Web based educational tools may become in future effective approaches, but the current generation of patients will hardly benefit.

The uncover of a progressive protein-energy wasting disease should also trigger the search for hidden foci of infection/inflammation, facilitating the earlier reclaim.

Since nutritional therapy is so important in the follow-up of renal patients before and after the initiation of renal replacement therapy, it should be an important component of the education of nephrologists, so improving the communication with renal dieticians. Quality indicators related to the regular and frequent performance of nutritional assessment and of the obtained results in term of corrected nutritional habits should be part of the follow-up of dialysis patients. Likely, this should be the next logic development as the system of reimbursement for the treatment of dialysis patients is moving to total capitation ${ }^{4}$, in future including also cost of hospitalization. If it is true that nutritional secondary prevention is cost effective in avoiding or 
delaying certain complications requiring expensive hospitalizations, providers of dialysis care will quickly move to implement a strong nutritional follow-up and therapy in their treatment protocols.

In conclusion, the research manuscripts included in this thesis supports a change in the management of patients on dialysis, with more focus on the nutritional aspects and the implementation of therapeutical measures able to prevent or correct in early phase protein-energy wasting. More research is required to define which therapy is more effective, and appropriately designed randomized clinical trials are urgently needed.

\section{References}

1 Hand RK, Steiber A, Burrowes J. Renal dietitians lack time and resources to follow the NKF KDOQI guidelines for frequency and method of diet assessment: results of a survey. J Ren Nutr 2013; 23 : 445-9.

2 Ikizler TA, Franch HA, Kalantar-Zadeh K, Ter Wee PM, et al. Time to revisit the role of renal dietitian in the dialysis unit. J Ren Nutr 2014;24:58-60.

3 Vendrely B, Chauveau P, Barthe N, et al. Nutrition in hemodialysis patients previously on a supplemented very low protein diet. Kidney Int. 2003;63:1491-1498.

4 Ponce P, Marcelli D, Guerreiro A, Grassmann A, Gonçalves C, Scatizzi L, Bayh I, Stopper A, Da Silva R. Converting to a capitation system for dialysis payment--the Portuguese experience. Blood Purif. 2012;34(3-4):313-24. 


\section{Acknowledgement/Dankwoord}

This thesis is the result of collaborations with many people who have highly influenced and helped me since the first days of my medical career at the Nephrological Division of the 'Alessandro Manzoni' Hospital in my birth town Lecco (Italy), under the guidance of Prof. Francesco Locatelli. This thesis was compiled after 30 years of work in the field of chronic diseases, and during this time in various positions within the clinical ward, in the dialysis industry and in governance of a network of dialysis units. In each I had to face and solve many problems of different nature. The common denominator of my continuous research activity was the always the patient, permanently in focus of all that I did. Two years ago, during a brainstorming in New York dedicated to a difficult question (see chapter 8), Prof. Dr. Jeroen P. Kooman approached me with the surprising suggestion to consolidate my research in the form of a $\mathrm{PhD}$ in Maastricht. Initially, considering my age, I was a bit skeptical, but then I realized that it could be the way to somehow round off my professional academic qualifications. Additionally, at that time I was focusing on the topic nutrition, which was coincidentally also my first research topic in the early days of my medical career.

My deepest gratitude goes to my advisors and mentors from the Maastricht University Medical Center, Prof. Dr. Jeroen P. Kooman and Dr. Frank M. van der Sande. They have been key persons in making this thesis possible and guiding me through the dissertation process. On multiple occasions they worked very late hours or during weekends, most certainly giving up their personal time with their families and friends. Also, their guidance with the completion of the main manuscripts included in this thesis was of primary importance as well as in creating a thesis 
which covers the complex and fundamental unsolved problem of nutritional aspects in chronic kidney disease. Actually, working deeper and deeper on this topic, it gradually became clear that this is the common unifying issue of chronic diseases, and is not just confined to the field of renal disease. I am grateful beyond words to them for what they have done and the dedication they put into their work. I am also obliged to Prof. K. M. Leunissen, who agreed to accept me into this PhD program. I am honoured and grateful for all he has done.

I have to express my deepest and most sincere appreciation to Prof. Dr. Francesco Locatelli. He was my first mentor, teaching me the fundamentals of scientific investigation. Many years ago he incited a change in my career path by stimulating me to consider all problems have a logical solution and not to be afraid of the difficulties along the way. Based in a hospital of a town in the deep northern province of Italy he was able to become an important Key Opinion Leader and finally the president of the ERA-EDTA society, one of the most prestigious international scientific societies in the field of nephrology. His impressive example was certainly very inspirational for me in facing many problems of life.

There are many other people I have to mention. Prof. Alessandra Marinoni, Director in the Medical Statistical School in the historical University of Pavia. During her 3 year course I was formally trained in the principles of scientific research. Prof. Ferruccio Conte, Dr. Aurelio Limido, Dr. Donatella Spotti from the Lombardy Renal Registry. With them I learned to appreciate the spirit of team work in research, building an everlasting friendship. Also Prof. Friedrich Port, Director of the US Renal Registry (USRDS) in Ann Arbor - under his guidance I made a significant step in my professional life, moving from the regional to the international scope. Dr. Giancarlo Orlandini guided me in another significant step of my professional career, supporting 
the change from the public hospital ward to the Headquarters of a private biomedical device company. I have to mention also Dr. Peter Kotanko, Director of the prestigious Renal Research Center in New York. Together we founded the international collaborative project MONDO, today probably the largest dialysis database worldwide. Finally, last but not least, I have to express my gratitude to Prof. Bernard Canaud, by definition the expert of the most innovative extracorporeal dialysis treatment and Prof. Claudia Barth, my current mentor. Their continuous challenging during my scientific publication activity was of extreme value in enhancing the quality of my work.

I would also like to express my gratitude to the people with whom I worked most closely in recent years. A special mention is dedicated to Dr. Laura Scatizzi, precious coworker of 20 years, Dr. Aileen Grassmann, who is able to manage and finalize all kinds of scientific projects, Ms. Gerdi Klinkner for her very precious support in addressing almost impossible projects, and the statisticians Inga Bayh and Katharina Brand for support in all the more complex statistical requests.

Professionally, there are many others to whom I would like to express my gratitude, including the medical directors who supported me in developing clinical governance of the European dialysis network of Fresenius Medical Care: Dr, Jose-Ignacio Merello, Dr. Pedro Ponce, Dr. Attilio Di Benedetto, Dr. Tomas Jirka, to mention just a few.

Finally, I have to emphasize that my entire professional career was supported by my family. First in this context I would like to name my wife Dr. Giovanna Colombo, who shared with me the challenging decision to move to Germany in 1999. Second the 
Acknowledgement

children Tommaso D. Marcelli and Martino J. Marcelli, currently University students in Frankfurt am Main and in Zürich, who had to grow up with a forever-student father. 
Acknowledgement 


\section{Curriculum Vitae}

30 years' diverse leadership experiences in Nephrology (University of Modena Certification) with significant accomplishments in organizing dialysis care process (i.e. see publications $63,67,83,115$ ) derived from 10 year experience in the nephrological ward and in the kidney transplantation outpatient follow-up (Hospital Manzoni, Lecco, Prof. Locatelli) and 20 years in medical device companies vertically integrated with dialysis service (Fresenius Medical Care, Bad Homburg, Germany and B. Braun Avitum, Melsungen, Germany).

The key points of my curriculum in renal care were related to scientific research, healthcare organization managements, dialysis medical device and renal pharmaceuticals.

In the research field, I started my career as technician in the chemical lab in CRTN, the research division of ENEL, at that time the monopolist Electric Energy producer in Italy, with involvement in a project funded by the European Economic Community (EEC) aimed at evaluating an innovative efficient multi-flash process in producing pure water from sea water. After medical graduation and the degree in Medical Statistics (University of Pavia) I remained in the research field publishing several papers in the field of progression of chronic renal failure and in dialysis (outcome and cardiovascular complication of ESRD diabetic and non-diabetic patients), being involved in the design, analysis and finalization of manuscripts on randomized clinical trials. However, large part of the research activity was conducted as epidemiological research, using existing databases (Lombardy Dialysis Registry, US Renal Data System) and an ad-hoc renal Database (EuCliD, European Clinical 
Database), developed according to my input. As result 141 publications in peerreview journals have been accomplished, in the field of: Medical device validation and application, Epidemiology, Healthcare management, Health economics, Nephrology, Cardiology, Nutrition and Hypertension. My Hirsch index is 29 (Google scholar). I also served several scientific journals as reviewer (Nephrology Dialysis Transplantation, J of Nephrology, British Medical Journal, Int J Artificial Organs, etc).

In the field of dialysis medical device, I was involved in the design of the study proving the superiority of high-flux membranes (ref. 14, 23), in epidemiological analysis supporting the evidence of the superior outcome of convective therapies (ref. 35,109 ) and in the validation of components of the dialysis equipment: blood temperature monitor (ref. 38), on-line clearance measurement (ref. 52), tool for the maximization of convective dose in online HDF (ref. 113, 125).

In the pharmaceutical environment I cooperated with different Pharma companies (Ciba-Geigy, Glaxo, Amgen, Sigma-Tau) in generating research protocols, analysing data from clinical trials, organizing and managing steering committees and finalizing manuscripts aimed to evaluate the impact of different therapies on outcome (i.e. ref 79).

Clinical governance and in general healthcare management is one of the topic I was mainly involved, being also MBA certified on International Hospital and Healthcare Management (Frankfurt school of Finance and Management). More in details, I was Responsible for Clinical Governance of the NephroCare Dialysis Clinics Network in Europe, Middle East and Africa for more than 500 dialysis clinics located in 23 countries (about 50,000 patient), leading a team of professionals in the field of dialysis, nursing, data analysis, clinical risk management and working within a matrix 
organization with the Country Medical and Nursing Directors of all related countries (additional 46 people). The activity required the implementation of Practice Medical Guidelines, the development of standards operating procedures (SOPs), the provision of GCP ("Good Clinical Practice") trainings, and the preparation of internal and external audits. Additionally, with my contribution a Crisis response organization for the same geographical area was founded.

In healthcare policy, I was a member of the Dialysis Registry commission of the Regional Healthcare Authority of Lombardy (Italy), and then I followed up the reimbursement issues of different National Healthcare Authorities, initially focusing on premium price for innovative therapies (i.e. see publication on HTA evaluation 89 and on cost-effectiveness 126 and 139) and then on new reimbursement policies (from bundled reimbursement to full capitation, see publication 93).

As physician, I still have strong motivations to play a role not only in the scientific world but also on educational activities for the population. For this reason from 2012 to 2016 I cooperated with the Journal "Corriere d'Italia", published in Germany for the Italian Community $(30,000$ copies per issue). Every month a patient-empowerment like articles on different relevant topics for elderly people was published.

\section{LIST OF PUBLICATIONS}

(1) Locatelli F, Di Filippo S, Ponti R, La M, V, Citterio A, Marcelli D et al. Changes in dialysate composition related to new dialysis techniques. Contrib Nephrol 1990;77:106-14.

(2) Locatelli F, Marai P, Tentori F, Marcelli D. Per salvare la funzione renale. Doctor 1991 January 12;9(18):20-9.

(3) Fabrizi F, Di Filippo S, Erba G, Bacchini G, Marcelli D, Pontoriero G et al. Hepatitis C virus infection and hepatic function in chronic hemodialysis patients. Nephron 1992;61(1):119.

(4) Fabrizi F, Marai P, Di Filippo S, Marcelli D, Erba G, Pontoriero G et al. Hepatitis C virus infection in kidney graft recipients (letter). Nephrol Dial Transplant 1992;7(3):274. 
(5) Locatelli F, Alberti D, Graziani G, Buccianti G, Redaelli B, Giangrande A et al. Factors affecting chronic renal failure progression: results from a multicentre trial. The Northern Italian Cooperative Study Group. Miner Electrolyte Metab 1992;18(2-5):295-302.

(6) Alberti D, Locatelli F, Graziani G, Buccianti G, Redaelli B, Giangrande A et al. Hypertension and chronic renal insufficiency: the experience of the Northern Italian Cooperative Study Group. Am J Kidney Dis 1993 May;21(5 Suppl 2):124-30.

(7) Locatelli F, Marcelli D, Tentori F, Bigi MC, Marai P. Controlled trials on low-protein diet: effects on chronic renal insufficiency progression. Ren Fail 1993;15(3):407-13.

(8) Locatelli F, Tentori F, Marcelli D, Bigi MC, Marai P. [Diet therapy in preventing the progression of chronic renal insufficiency]. Ann Ital Med Int 1993 July;8(3):179-84.

(9) Fabrizi F, Marcelli D, Bacchini G, Guarnori I, Erba G, Locatelli F. Antibodies to hepatitis C virus (HCV) in chronic renal failure (CRF) patients on conservative therapy: prevalence, risk factors and relationship to liver disease. Nephrol Dial Transplant 1994;9(7):780-4.

(10) Locatelli F, Mastrangelo F, Redaelli B, Ronco C, Marcelli D, Orlandini G. Effetto di differenti membrane e tecniche dialitiche sulla tolleranza al trattamento ed i parametri nutrizionali dei pazienti emodializzati. Razionale e protocollo di studio. In: Locatelli F, Mastrangelo F, Redaelli B, Ronco C, Marcelli D, Orlandini G et al., editors. Evolution in dialysis '94.Milano: Springer-Verlag; 1994. p. 25-39.

(11) Comelli M, Marcelli D, Locatelli F, Mastrangelo F, Redaelli B, Ronco C, Orlandini G. Effetto di differenti membrane e tecniche dialitiche sulla tolleranza al trattamento ed i parametri nutrizionali dei pazienti emodializzati. Analisi statistica. In: Locatelli F, Mastrangelo F, Redaelli B, Ronco C, Marcelli D, Orlandini G et al., editors. Evolution in dialysis '94.Milano: Springer-Verlag; 1994. p. 40-45.

(12) Mastrangelo F, Locatelli F, Redaelli B, Ronco C, Marcelli D, Orlandini G. Effetto di differenti membrane e tecniche dialitiche sulla tolleranza al trattamento ed i parametri nutrizionali dei pazienti emodializzati. Razionale e metodologia per lo studio dello stato nutrizionale. In: Locatelli F, Mastrangelo F, Redaelli B, Ronco C, Marcelli D, Orlandini G et al., editors. Evolution in dialysis '94.Milano: Springer-Verlag; 1994. p. 46-51.

(13) Locatelli F, Marcelli D, Marai P. Low protein Diet may postpone the start of dialysis without affecting early progression of chronic renal insufficiency. J Nephrol 1994;7:36-42.

(14) Locatelli F, Mastrangelo F, Redaelli B, Ronco C, Marcelli D, Orlandini G. The effect of different membranes and dialysis technologies on the treatment tolerance and nutritional parameteres of hemodialysis patients. Design of a prospective randomised multicentre trial. J Nephrol 1994;7:1.

(15) Locatelli F, Marcelli D, Alberti D, Graziani G, Buccianti G, Redaelli B et al. Hypertension as a factor in chronic renal insufficiency progression. High Blood Pressure 1994;3:175-84.

(16) Locatelli F, Marcelli D, Marai P. Proteinarme Diät kann den Dialysebeginn hinauszögern, ohne die frühe Progression der chronischen Niereninsuffizienz zu berühren. Dialyse-Journal 1994;48:27-33.

(17) Locatelli F, Marcelli D, Conte F, Limido A, Lonati F, Malberti F et al. 1983 to 1992: report on regular dialysis and transplantation in Lombardy. Am J Kidney Dis 1995 January;25(1):196-205.

(18) Marcelli D, Spotti D, Conte F, Limido A, Lonati F, Malberti F et al. Prognosis of diabetic patients on dialysis: analysis of Lombardy Registry data. Nephrol Dial Transplant 1995 October;10(10):1895-900.

(19) Marcelli D, Locatelli F, Alberti D, Graziani G, Buccianti G, Redaelli B et al. Hypertension as a factor in chronic renal insufficiency progression in polycystic kidney disease. The Northern Italian Cooperative Study Group. Nephrol Dial Transplant 1995;10 Suppl 6:15-7. 
(20) Fabrizi F, Di FS, Marcelli D, Guarnori I, Raffaele L, Crepaldi M et al. Recombinant hepatitis B vaccine use in chronic hemodialysis patients. Long-term evaluation and cost-effectiveness analysis. Nephron 1996;72(4):536-43.

(21) Fabrizi F, Lunghi G, Marai P, Marcelli D, Guarnori I, Raffaele L et al. Virological and histological features of hepatitis C virus (HCV) infection in kidney transplant recipients. Nephrol Dial Transplant 1996 January;11(1):15964.

(22) Locatelli F, Marcelli D, Comelli M, Alberti D, Graziani G, Buccianti G et al. Proteinuria and blood pressure as causal components of progression to end-stage renal failure. Northern Italian Cooperative Study Group. Nephrol Dial Transplant 1996 March;11(3):461-7.

(23) Locatelli F, Mastrangelo F, Redaelli B, Ronco C, Marcelli D, La Greca G et al. Effects of different membranes and dialysis technologies on patient treatment tolerance and nutritional parameters. The Italian Cooperative Dialysis Study Group. Kidney Int 1996 October;50(4):1293-302.

(24) Malberti F, Corradi B, Cosci P, Calliada F, Marcelli D, Imbasciati E. Long-term effects of intravenous calcitriol therapy on the control of secondary hyperparathyroidism. Am J Kidney Dis 1996 November;28(5):704-12.

(25) Marcelli D, Spotti D, Conte F, Tagliaferro A, Limido A, Lonati F et al. Survival of diabetic patients on peritoneal dialysis or hemodialysis. Perit Dial Int 1996;16 Suppl 1:S283-S287.

(26) Marcelli D, Stannard D, Conte F, Held PJ, Locatelli F, Port FK. ESRD patient mortality with adjustment for comorbid conditions in Lombardy (Italy) versus the United States. Kidney Int 1996 September;50(3):1013-8.

(27) Locatelli F, Marai P, Marcelli D, Bigi C. La terapia conservativa dell'insufficienza renale cronica dell'anziano. In rene dell'anziano, Masson; 1996: 69-76.

(28) Bacchini G, Fabrizi F, Pontoriero G, Marcelli D, Di Filippo S, Locatelli F. 'Pulse oral' versus intravenous calcitriol therapy in chronic hemodialysis patients. A prospective and randomized study. Nephron 1997;77(3):267-72.

(29) Locatelli F, Manzoni C, Marcelli D. Treatment of hypertension in chronic renal insufficiency. J Nephrol 1997 July;10(4):220-3.

(30) Locatelli F, Manzoni C, Marcelli D. Factors affecting progression of renal insufficiency. Miner Electrolyte Metab 1997;23(3-6):301-5.

(31) Locatelli F, Marcelli D, Conte F. Dialysis patient outcomes in Europe vs the USA. Why do Europeans live longer? Nephrol Dial Transplant 1997 September;12(9):1816-9.

(32) Malberti F, Conte F, Limido A, Marcelli D, Spotti D, Lonati F et al. Ten years experience of renal replacement treatment in the elderly. Geriatr Nephrol Urol 1997;7(1):1-10.

(33) Marcelli D, Port FK, Conte F, Locatelli F, Held PJ. International comparison of survival for peritoneal dialysis and hemodialysis patients: a review. Nieren un Hochdruckkrankeiten 1997;26 (suppl. 1):S60-S65.

(34) Locatelli F, Conte F, Marcelli D. The impact of haematocrit levels and erythropoietin treatment on overall and cardiovascular mortality and morbidity--the experience of the Lombardy Dialysis Registry. Nephrol Dial Transplant 1998 July;13(7):1642-4.

(35) Locatelli F, Marcelli D, Conte F, Limido A, Malberti F, Spotti D. Comparison of mortality in ESRD patients on convective and diffusive extracorporeal treatments. The Registro Lombardo Dialisi E Trapianto. Kidney Int 1999 January;55(1):286-93.

(36) Ronco C, Marcelli D. Opinions regarding outcome differences in European and US haemodialysis patients. Nephrol Dial Transplant 1999 November;14(11):2616-20. 
(37) Ronco C, Marcelli D. Are better outcome in hemodialysis in Europe explained by superior ESRD care? Seminars in Dialysis 1999;(12):345-8.

(38) Gauly A, Maggiore Q, Marcelli D, Orlandini G, Krämer M, Roy T. Der Bluttentemperaturmonitor in der klinischen Anwendung. In: Vienken J, Roy T, editors. Symbiose von Medizin und Technik: Dialyse und Extrakorporealer Blutkreislauf.Berlin: Pabst Science Publisher; 2000. p. 57-64.

(39) Locatelli F, Marcelli D, Conte F, Del VL, Limido A, Malberti F et al. Patient selection affects end-stage renal disease outcome comparisons. Kidney Int 2000;(57 (suppl 74)):S94-S99.

(40) Locatelli F, Marcelli D, Conte F, D'Amico M, Del Vecchio L, Limido A et al. Cardiovascular disease in chronic renal failure: the challenge continues. Registro Lombardo Dialisi e Trapianto. Nephrol Dial Transplant 2000;15 Suppl 5:69-80.

(41) Ritz E, Bianchi G, London GM, Marcelli D, Massy ZA, Parfrey PS et al. Clinical algorithms on cardiovascular risk factors in renal patients. Nephrol Dial Transplant 2000;15(Suppl 5):123-54.

(42) Charra B, VoVan C, Marcelli D, Ruffet M, Jean G, Hurot JM et al. Diabetes mellitus in Tassin, France: remarkable transformation in incidence and outcome of ESRD in diabetes. Adv Ren Replace Ther 2001 January;8(1):42-56.

(43) Locatelli F, Marcelli D, Conte F, D'Amico M, Del Vecchio L, Limido A et al. Cardiovascular disease in chronic renal failure: the challenge continues. In: Passlick-Deetjen J, Ritz E, editors. Management of the renal patients: Experts' recommendations and clinical algorithms on cardiovascular risk factors.Berlin: Pabst; 2001. p. 35-58.

(44) Locatelli F, Rutkowski B, Andrulli S, Enia G, Gellert R, Kramar R et al. Gdansk bio-statistic and epidemiology course. Nephrol Dial Transplant 2001 August;16(8):1559-61.

(45) Locatelli F, Marcelli D, Conte F, D'Amico M, Del VL, Limido A et al. Survival and development of cardiovascular disease by modality of treatment in patients with end-stage renal disease. J Am Soc Nephrol 2001 November;12(11):2411-7.

(46) Malberti F, Marcelli D, Conte F, Limido A, Spotti D, Locatelli F. Parathyroidectomy in patients on renal replacement therapy: an epidemiologic study. J Am Soc Nephrol 2001 June;12(6):1242-8.

(47) Marcelli D, Kirchgessner J, Amato C, Steil H, Mitteregger A, Moscardo V et al. EuCliD (European Clinical database): un database che confronta realta differenti. In: D'Amico G, Bazzi C, Colasanti G, editors. Attualita Nefrologiche \& Dialitiche 2000. Wichtig; 2001. p. 157-68.

(48) Marcelli D, Kirchgessner J, Amato C, Steil H, Mitteregger A, Moscardo V et al. EuCliD (European Clinical Database): a database comparing different realities. J Nephrol 2001 November;14 Suppl 4:S94-100.

(49) Ravani P, Marcelli D, Pecchini P, Malberti F. Early failure rates of arterovenous fistulas for hemodialysis: evaluation of six-year activity. J Vasc Access 2001 October;2(4):154-60.

(50) Ritz E, Bianchi G, London GM, Marcelli D, Massy ZA, Parfrey PS et al. Clinical algorithms on cardiovascular risk factors in renal patients. In: Passlick-Deetjen J, Ritz E, editors. Management of the renal patients: Experts' recommendations and clinical algorithms on cardiovascular risk factors.Berlin: Pabst; 2001. p. 153-88.

(51) Aviles B, Coronel F, Perez-Garcia R, Marcelli D, Orlandini G, Ayala JA et al. [Anemia management in haemodialysis. EuCliD database in Spain]. Nefrologia 2002;22(6):555-63.

(52) Goldau R, Kuhlmann U, Samadi N, Gross M, Graf T, Orlandini G et al. Ionic dialysance measurement is urea distribution volume dependent: a new approach to better results. Artif Organs 2002 April;26(4):321-32.

(53) Marcelli D, Moscardo V, Steil H, Day M, Kirchgessner J, Mitteregger A et al. Data management and quality assurance for dialysis network. Contrib Nephrol 2002;(137):293-9. 
(54) Merello Godino JI, Rentero R, Orlandini G, Marcelli D, Ronco C. Results from EuCliD (European Clinical Dialysis Database): impact of shifting treatment modality. Int J Artif Organs 2002 November;25(11):1049-60.

(55) Ravani P, Marcelli D, Malberti F. Vascular access surgery managed by renal physicians: the choice of native arteriovenous fistulas for hemodialysis. Am J Kidney Dis 2002 December;40(6):1264-76.

(56) Ravani P, Marcelli D, Malberti F. Access surgery and the role of nephrologist (letter). Am J Kidney Dis 2003;(41):1126.

(57) Steil H, Marcelli D, Gatti E. Tecnologia informatica in Nefrologia. In: Locatelli F, editor. Vademecum della Nefrologia. Hippocrates Edizioni Scientifiche; 2003. p. 212-48.

(58) Ravani P, Brunori G, Mandolfo S, Cancarini G, Imbasciati E, Marcelli D et al. Cardiovascular comorbidity and late referral impact arteriovenous fistula survival: a prospective multicenter study. J Am Soc Nephrol 2004 January;15(1):204-9.

(59) Steil H, Amato C, Carioni C, Kirchgessner J, Marcelli D, Mitteregger A et al. EuCliD--a medical registry. Methods Inf Med 2004;43(1):83-8.

(60) Di Benedetto A, Marcelli D, D'Andrea A, Cice G, D'Isa S, Cappabianca F et al. Risk factors and underlying cardiovascular diseases in incident ESRD patients. J Nephrol 2005 September;18(5):592-8.

(61) Garrancho JM, Kirchgessner J, Arranz M, Klinkner G, Rentero R, Ayala JA et al. Haemoglobin level and vascular access survival in haemodialysis patients. Nephrol Dial Transplant 2005 November;20(11):2453-7.

(62) Garrancho JM, Kirchgessner J, Arranz M, Ayala JA, Marcelli D. Notes on angiotensin inhibition and vascular access survival: time for randomized controlled trials. Nephrol Dial Transplant 2006;21(3):824.

(63) Kirchgessner J, Perera-Chang M, Klinkner G, Soley I, Marcelli D, Arkossy O et al. Satisfaction with care in peritoneal dialysis patients. Kidney Int 2006 October;70(7):1325-31.

(64) Tetta C, David S, Marcelli D, Cogliati P, Formica M, Inguaggiato P et al. Clinical effects of online dialysate and infusion fluids. Hemodial Int 2006 January;10 Suppl 1:S60-S66.

(65) Di Benedetto A, Basci A, Cesare S, Marcelli D, Ponce P, Richards N. Increased use of catheters as vascular access: is it justified by patients' clinical conditions? J Vasc Access 2007 January;8(1):21-7.

(66) Richards N, Ayala JA, Cesare S, Chazot C, Di BA, Gassia JP et al. Assessment of quality guidelines implementation using a continuous quality improvement programme. Blood Purif 2007;25(3):221-8.

(67) Stopper A, Amato C, Gioberge S, Giordana G, Marcelli D, Gatti E. Managing complexity at dialysis service centers across Europe. Blood Purif 2007;25(1):77-89.

(68) Cice G, Di Benedetto A, D'Andrea A, D'Isa S, De GP, Marcelli D et al. Heart rate as independent prognostic factor for mortality in normotensive hemodialysed patients. J Nephrol 2008 September;21(5):704-12.

(69) Di Benedetto A, Richards N, Marcelli D, Basci A, Cesare S, Ponce P et al. Is it necessary to check outcomes to improve quality of care? The example of anemia management. J Nephrol 2008 March;21 Suppl 13:S146-S152.

(70) Marcelli D, Richards N, Amato C. The modern haemodialysis factory: Must quality improvement trump personalized care? (letter) Nephrol Dial Transplant 2008 July;23(7):2433-4.

(71) Richards N, Harris K, Whitfield M, O'Donoghue D, Lewis R, Mansell M et al. The impact of population-based identification of chronic kidney disease using estimated glomerular filtration rate (eGFR) reporting. Nephrol Dial Transplant 2008 February;23(2):556-61. 
(72) Richards N, Harris K, Whitfield M, O'Donoghue D, Lewis R, Mansell M et al. Primary care-based disease management of chronic kidney disease (CKD), based on estimated glomerular filtration rate (eGFR) reporting, improves patient outcomes. Nephrol Dial Transplant 2008 February;23(2):549-55.

(73) Chazot C, Gassia JP, Di Benedetto A, Cesare S, Ponce P, Marcelli D. Is there any survival advantage of obesity in Southern European haemodialysis patients? Nephrol Dial Transplant 2009 September;24(9):2871-6.

(74) Imbasciati E, Tincani A, Gregorini G, Doria A, Moroni G, Cabiddu G et al. Pregnancy in women with pre-existing lupus nephritis: predictors of fetal and maternal outcome. Nephrol Dial Transplant 2009 February;24(2):519-25.

(75) Marcelli D, Marelli C, Richards N. Influenza A(H1N1)v pandemic in the dialysis population: first wave results from an international survey. Nephrol Dial Transplant 2009 December;24(12):3566-72.

(76) Marcelli D, Parisotto MT, Soley I, Bedenbender-Stoll E, Scatizzi L, Boccato C et al. [Risk management in healthcare organizations: the example of NephroCare]. G Ital Nefrol 2009 November;26(6):719-28.

(77) Wizemann V, Wabel P, Chamney P, Zaluska W, Moissl U, Rode C et al. The mortality risk of overhydration in haemodialysis patients. Nephrol Dial Transplant 2009 May;24(5):1574-9.

(78) Chazot C, Gassia JP, Di Benedetto A., Cesare S, Ponce P, Marcelli D. Is there any survival advantage of obesity in southern European haemodialysis patients? (letter) Nephrol Dial Transplant 2010;25(1):319.

(79) Cice G, Di Benedetto A, D'Isa S, D'Andrea A, Marcelli D, Gatti E et al. Effects of telmisartan added to Angiotensinconverting enzyme inhibitors on mortality and morbidity in hemodialysis patients with chronic heart failure a double-blind, placebo-controlled trial. J Am Coll Cardiol 2010 November 16;56(21):1701-8.

(80) de Francisco AL, Kim J, Anker SD, Belozeroff V, Canaud B, Chazot C et al. An Epidemiological Study of Hemodialysis Patients Based on the European Fresenius Medical Care Hemodialysis Network: Results of the ARO Study. Nephron Clin Pract 2010 December 10;118(2):c143-c154.

(81) Di Benedetto A, Marcelli D, Cerino F, Giordana G. [The value of early referral in the management of chronic kidney disease: NephroCare's eight years of interaction with general practitioners.]. G Ital Nefrol 2010 November;27(S52):17-22.

(82) Marcelli D, Marelli C, Richards N. Influenza a(H1N1)v pandemic in the dialysis population: first wave results from an international survey (letter). Nephrol Dial Transplant 2010 January 25;(25):1362.

(83) Di Benedetto A, Pelliccia F, Moretti M, D'Orsi W, Storace F, Scatizzi L et al. What causes an improved safety climate in the staff of a dialysis unit? Report of an evaluation in a large network. J Nephrol 2011;24(5):604-12.

(84) Floege J, Kim J, Ireland E, Chazot C, Drueke T, de Francisco A et al. Serum iPTH, calcium and phosphate, and the risk of mortality in a European haemodialysis population. Nephrol Dial Transplant 2011 December 10;26:1948-55.

(85) Gauly A, Parisotto MT, Skinder A, Schoder V, Furlan A, Schuh E, Marcelli D. Vascular access cannulation in Hemodialysis patients - A survey of current practice and its relation to dialysis dose. J Vasc Access 2011;12(4):358-64

(86) Stopper A, Raddatz A, Grassmann A, Stuard S, Menzer M, Possnien G et al. Delivering Quality of Care while Managing the Interests of all Stakeholders. Blood Purif 2011;32(4):333-40.

(87) Stopper A, Scatizzi L, Klinkner G, Boccato C, Grassmann A, Marcelli D. Adopting on-line hemodiafiltration as standard therapy in EMEA NephroCare centers. Contrib Nephrol. 2011;175:152-62.

(88) Canaud B, Grassmann A, Marelli C, Koehler K, Marcelli D. Response to: "What can the dialysis physician learn from kinetic modelling beyond kt/Vurea? (letter) Nephrol Dial Transplant 2012 (published on line: http://ndt.oxfordjournals.org/content/27/11/4021.full/reply\#ndt el 147). 
(89) Del Vecchio L, Giordana G, Pedrini L, Marcelli D, Sisti N. Elements for economic evaluation on Hemofiltration (olHDF) versus standard haemodialysis to treat patients with end-stage renal disease (ESRD). Italian Journal of Public Health $9[4$ (suppl. 1)], S1-S51. 2012.

(90) Titapiccolo Jl, Ferrario M, Barbieri C, Marcelli D, Mari F, Cerutti S, Signorini MG, Smyth P, Cardiovascular shortterm outcome in hemodialysis patients: a machine learning approach. GNB 2012; 1 -2.

(91) Martin Guerriero JD, Marcelli D, Soria-Olivas E, Mari F, Martinez-Martinez JM, Soley I et al. Self-organising maps: a new way to screen the level of satisfaction of dialysis patients. Expert Systems with application 2012 August;39:8793-8.

(92) Perez-Garcia R, Palomares-Sancho I, Merello Godino JI, Aljama P, Bustamante-Bustamante J, Luno J et al. Estudio epidemiológico de 7316 pacientes en hemodiálisis tratados en las clínicas Fresenius Medical Care de España, con los datos obtenidos mediante la base de datos EuCliD ${ }^{\circledR}$ : resultados de los años 2009-2010. Nefrologia 2012;32(6):743-53.

(93) Ponce P, Marcelli D, Guerreiro A, Grassmann A, Gonçalves C, Scatizzi L et al. Converting to a Capitation System for Dialysis Payment - The Portuguese Experience. Blood Purif 2012 December 1;34:313-24.

(94) Titapiccolo J, Ferrario M, Barbieri C, Marcelli D, Mari F, Gatti E et al. Predictive modeling of cardiovascular complications in incident hemodialysis patients. 2012 p. 3943-6.

(95) Usvyat L, Sheppard P, Marcelli D, Guinsburg A, Etter M, Kotanko P. The MONDO initiative. Dialysis Times 2012 January 1;19(1):1-2.

(96) Canaud B, Tetta C, Marcelli D, Giordana G, Stuard S, Koehler K et al. Implementation and management of strategies to set and to achieve clinical targets. In: Suzuki H, editor. Hemodialysis. InTech; 2013. p. 439-53.

(97) Esposito P, Di Benedetto A, Tinelli C, De Silvestri A, Rampino T, Marcelli D et al. Clinical Audit improves control of hypertension in Haemodialysis patients. Int J Artif Organs 2013; 36: 305-313.

(98) Imamovic G, Marcelli D, Bayh I, Hrvacevic R, kapun S, Grassmann A et al. Survival of patients on high-volume online Hemodiafiltration compared to low-volume hemodiafiltration and high-flux hemodialysis. Int Urol Nephrol 2014; 46: 1191-200.

(99) Marcelli D, Grassmann A, Ponce P. Accomplishement of integrated management for renal replacement therapy in Portugal (letter). Hemodial Int 2014; 18: 215.

(100) Marcelli D, Grassmann A, Ponce P. Changes in dialysis treatment modalities during institution of flat rate reimbursement and quality assurance program (letter). Kidney Int 2013; 84: 1051.

(101) Parisotto MT, Schoder VU, Miriunis C, Grassmann A, Scatizzi L, Kaufmann P, Stopper A, Marcelli D. Does cannulation technique impact arteriovenous fistula and graft survival? Kidney Int 2014: 86: 790-97.

(102) Praga M, Merello JI, Palomares-Sancho I, Bayh I, Marcelli D, Aljama P et al. Type of vascular access and survival among very elderly hemodialysis patients. Nephron Clin Pract 2013; 124: 47-53.

(103) Usvyat L, Barth C, Bayh I, Etter M, von Gersdorff G, Grassmann A et al. Interdialytic weight gain, systolic blood pressure, serum albumin and C-reactive protein levels change in chronic dialysis patients prior to death. Kidney Int 2013; 84: 149-57.

(104) Usvyat L, Barth C, von Gersdorff G, Haviv Y, Etter M, Kooman J et al. The Monitoring Dialysis Outcome (MONDO) Initiative. Blood Purif 2013; 35:37-48.

(105) von Gersdorff G, Guinsburg A, Grassmann A, Barth C, Marelli C, Marcelli D et al. Monitoring Dialysis Outcomes Across The World - the MONDO global database consortium. Blood Purif 2013; 36: 165-172. 
(106) Esposito P, Di Benedetto A., Rampino T, Marcelli D, Dal Canton A. Management of mineral metabolism in haemodialysis patients: need for new strategies. Eur J Clin Nutrition 2014; 68: 859-60.

(107) Castellano S, Palomares I, Molina M et al. Clinical, analytical and bioimpedance characteristics of persistently overhydrated haemodialysis patients. Nefrologia 2014; 34: 716-723.

(108) Marcelli D, Di Benedetto A., Ciotola A, Grassmann A, Canaud B. Subjective Global Assessment scores have poor correlation with serum albumin in obese hemodialysis patients (Letter). J Ren Nutr 2014; 24: 432-3.

(109) Canaud B, Bayh I., Marcelli D, Ponce P, Merello Godino J.I, Gurevich K, Ladanyi E, Imamovic G, Grassmann A, Scatizzi L, Gatti E. Improved survival of incident patients with high-volume haemodiafiltration: a propensitymatched cohort study with inverse probability of censoring weighting. Nephron 2015; 129:179-188.

(110) Broers N, Usvyat L, Marcelli D et al. Season affect body composition and estimation of fluid overload in hemodialysis patients: variations in body composition; a survey from the European Mondo database. Nephrol Dial Transplant 2015; 30: 676-81.

(111) Ponce P, Marcelli D, Scholz C et al. Does the extracorporeal Blood Flow affect Survival of the Arteriovenous Vascular Access? Nephron Clin Pract 2015; 19: 314-22.

(112) Calice-Silva V, Russein R, Yousi D et al. Association between global population health indicators and dialysis variables in the monitoring dialysis outcome (MONDO) registry. Blood Purif 2015; 39: 125-136.

(113) Marcelli D, Scholz C, Ponce P, Sousa T, Kopperschmidt P, Grassmann A, Pinto B, Canaud, B. High-volume postdilution haemodiafiltration is a feasible option in routine clinical practice. Artif Organs 2015; 39: 142-9.

(114) Richards N, Hassan M, Saleh AK, Dastoor H, Bernieh B, Abouchacra S, Al Jabri O, Fleishmann A, Richards M, Marcelli D. Epidemiology and referral patterns of patients with chronic kidney disease in the Emirate of Abu Dhabi. Saudi J of kidney Diseases and Transplantion 2015; 26: 1028-34.

(115) Marcelli D, Matos A, Sousa F et al. Implementation of a quality and safety checklist for haemodialysis sessions. Clin Kidney J 2015; 8: 265-70.

(116) Floege J, Gillespie IA, Kronenberg F, Anker SD, Gioni I, Richards S, Pisoni RL, Robinson BM, Marcelli D, Froissart M, Eckardt K. Development and validation of a predictive mortality risk score from a European hemodialysis cohort. Kidney Int 2015; 87: 996-1008.

(117) Chazot C, Pham J, Kirchgessner J, Vo-Van C, Lorriaux C, Hurot J, Zaoui E, Grassman A, Jean G, Marcelli D. Effect of membrane permeability on cardiovascular risk factors and beta2M plasma levels in patients on long hemodialysis: a randomized cross-over trial. Nephron 2015; 129: 269-75.

(118) Gillespie,I.A.; Macdougall,I.C.; Richards,S.; Jones,V.; Marcelli,D.; Froissart,M.; Eckardt,K.U. Factors precipitating erythropoiesis-stimulating agent responsiveness in a European haemodialysis cohort: case-crossover study. Pharmacoepidemiol.Drug Saf 2015; 24: 414-26.

(119) Marcelli D, Wabel P, Wieskotten S, Ciotola A, Grassmann A, Di Benedetto A, Canaud B. Physical methods for evaluating the nutritional status of hemodialysis patients. J Nephrol 2015; 28: 523-30.

(120) Eckardt KU, Gillespie IA, Kronenberg F, Richards S, Stenvinkel P, Anker SD, Wheeler DC, de Francisco AL, Marcelli D, Froissart M, Floege J. High Cardiovascular Event Rates within the first Weeks of Starting Hemodialysis. Kidney Int 2015; 88(5): 1117-1125.

(121) Marcelli D, Usvyat L, Kotanko P, Bayh I, Canaud B, Etter M, Gatti E, Grassmann A, Wang Y, Marelli C, Scatizzi L, Stopper A, van der Sande FM, Kooman J. Body composition and survival in dialysis patients: Results from an international cohort study. Clin J Am Soc Nephrol 2015; 10: 1192-200. 
(122) Canaud B, Barbieri C, Marcelli D, Bellocchio F, Bowry S, Mari F, Amato C, Gatti E. Optimal Convection Volume Finding for Improving Patient Outcome in an International Incident Dialysis Cohort Treated with Online Hemodiafiltration. Kidney Int 2015; 88(5): 1108-1116.

(123) Canaud B, Scatizzi L, Grassmann A, Marcelli D. Haemofiltration: present time technical, clinical and financial issues. Port J Nephrol Hypert 2015; 29: (Epub ahead of print).

(124) Guinsburg AM, Usvyat LA, Etter M, Xu X, Thijssen S, Marcelli D, Canaud B, Marelli C, Barth C, Wang Y, van der Sande FM, Kotanko $P$ and Kooman JP. Seasonal variations in mortality and clinical indicators in international hemodialysis populations from the MONDO registry. BMC Nephrology 2015; 16: 139.

(125) Marcelli D, Kopperschmidt P, Bayh I, Jirka T, Merello JI, Ponce P, Ladanyi E, Di Benedetto A, Dovc-Dimec R, Rosenberger J, Stuard S, Scholz C, Grassmann A, Canaud B. Modifiable factors associated with achievement of high-volume post-dilution hemodiafiltration: results from an international study. Int J Artif Organs 2015; 38: 24450.

(126) Lévesque R, Marcelli D, Cardinal H, Caron ML, Grooteman MPC, Bots ML, Blankestijn PJ, Nubé MJ, Grassmann A, Canaud B, Gandjour A. Cost-effectiveness analysis of high-efficiency hemodiafiltration vs. low-flux hemodialysis based on the Canadian arm of the CONTRAST study. Applied Health Economics and Health Policy 2015; 13: 64759.

(127) Malhotra R, Marcelli D, von Gersdorff G, Grassmann A, Schaller M, Bayh I, Scatizzi L, Etter M, Guinsburg A, Barth C, Marelli C, Carioni C, van der Sande F, Kooman JP, Liu E, Toffelmire T, Wang Y, Thijssen S, Usvyat LA, Kotanko P. Relationshiop od neuthrophil-to- lymphocyte ratio and serum albumin levels with C-reactive protein in hemodialysis patients: results from 2 international cohort studies. Nephron 2015; 130(4), 263-270.

(128) Majernikova M, Rosenberger J, Prihodova L, Marcelli D, Nagyova I, Roland R, Groothoff JW, van Dijk JP. Anemia has a negative impact on self-rated health in kidney transplant recipients with well-functioning grafts: findings from an 8-year follow-up study. Qual. Life Res. 2016; 25(1): 183-192.

(129) Raimann J, Canaud B, Etter M, Kooman J, Levin N, Marcelli D, Marelli C, Power A, Duncan N, van der Sande F, Thijssen S, Xu X, Usvyat N, Wang Y, Kotanko P. Relationship between pre hemodialysis serum sodium concentration and blood pressure: results from a retrospective analysis from the international Monitoring Dialysis Outcomes (MONDO) initiative. J Human Hypertens 2016; 30: 442-8.

(130) Stevinkel P, Gillespie IA, Tunks J, Addison J, Kronenberg F, Drueke TB, Marcelli D, Schenthaner G, Eckardt KU, Floege J, Froissart M, Anker SD. Inflammation Modifies the Paradoxical Association between Body Mass Index and Mortality in Hemodialysis Patients. JASN 2016; 27: 1479-86.

(131) de Francisco ALM, Gillespie IA, Gioni I, Floege J, Kroenenberg F, Marcelli D, Wheeler DC, Froissart M, Drueke TB. Anti-parathyroid treatment effectiveness and persistence in incident hemodialysis patients with secondary hyperparathyroidism. Nefrologia 2016; 36: 164-175.

(132) Marcelli D, Brand K, Ponce P, Milkowski A, Marelli C, Ok E, Merello Godino JI, Gurevich K, Jirka T, Rosenberger J, Di BenedettoA, Ladanyi E, Grassmann A, Scatizzi L, Bayh I, Kooman J, Canaud B. Longitudinal changes in body composition in patients after initiation of hemodialysis therapy: results from an international cohort. J Ren Nutr 2016; 26: 72-80.

(133) Pérez-García R, Palomares I, Merello JI, Ramos R, Maduell F, Molina M, Aljama P, Marcelli D. Hiponatremia, mortalidad y hemodiálisis: una asociación no explicada. Nefrologia 2016; 36: 42-50.

(134) Dekker M, Marcelli D, Canaud B, Konings K, Leunissen K, Levin N, Carioni P, Maheshwari V, Raimann J, van der Sande F, Usvyat L, Kotanko P, and Kooman J. Unravelling the relationship between mortality, hyponatremia, inflammation and malnutrition in hemodialysis patients: results from the international MONDO initiative. Eur J Clin Nutr. 2016; 70: 779-84. 
(135) Ferris M, Gibson K, Plattner B, Gipson D, Kotanko P, Marcelli D, Marelli C, Etter M, Gersdorff G, Xu X, Kooman J, Xiao $Q$, Sande F, Power A, Picoits-Filho R, Sylvestre L, Westreich $K$ and Usvyat $L$ on behalf of the MONDO Consortium. Longitudinal Hemodialysis Outcomes in a Global Sample of Children and Young Adult Hemodialysis Patients: The PICCOLO MONDO Initiative. Clin Kidney J 2016; 9: 295-302.

(136) Marcelli D, Bayh I, Merello JI, Ponce P, Heaton A, Kircelli F, Chazot C, Di Benedetto A, Marelli C, Ladanyi E, Kroczak M, Stuard S, Grassmann A, Scatizzi L, Brand K, Canaud B. Dynamics of ESA Resistance Index in incident hemodiafiltration and high-flux hemodialysis patients. Kidney Int 2016; 90: 192-202.

(137) Anker SD, Gillespie IA, Eckardt KU, Kronenberg F, Richards S, Drueke TB, Stenvinkel P, Pisoni RL, Robinson BM, Marcelli D, Froissart M, Floege J. Development and validation of cardiovascular risk scores for haemodialysis patients. Int J Cardiology 2016; 216: 68-77.

(138) Asci G, Marcelli D, Celtik A, Grassmann A, Gunestepe K, Yaprak M, Tamer AF, Turan MN, Sever MS, Ok E. Comparison of Turkish and US haemodialysis patient mortality rates: an observational cohort study. Clin Kidney J 2016; 9: 476-80.

(139) Ramponi F, Ronco C, Mason G, Rettore E, Marcelli D, Martino F, Neri M, Martin-Malo A, Canaud B, Locatelli F. Cost-effectiveness analysis of online hemodiafiltration versus high-flux hemodialysis. J of ClinicoEconomics and Outcome Research 2016; (accepted for publication).

(140) Garzotto F, Ostermann M, Martin-Langerwerf D, Sánchez-Sánchez M, Teng J, Robert R, Marinho A, HerreraGutierrez ME, Mao HJ, Benavente D, Kipnis E, Lorenzin A, Marcelli D, Tetta C, Ronco C and the DoReMIFA study group. The dose response multicentre investigation on fluid assessment (DoReMIFA) in critically ill patients. Critical Care 2016; 20:196-209.

(141) Parisotto MT, Pelliccia F, Grassmann A, Marcelli D. Elements of dialysis nursing practice associated with successful cannulation: Results o fan international survey. J Vasc Access 2016; (Accepted for publication). 
